DANIELLA CARDOSO BUZZI

\begin{abstract}
APLICAÇÃO DA ELETRODIÁLISE NO TRATAMENTO DA DRENAGEM ÁCIDA DE MINAS VISANDO A RECUPERAÇÃO DE ÁCIDO SULFÚRICO
\end{abstract}


DANIELLA CARDOSO BUZZI

\section{APLICAÇÃO DA ELETRODIÁLISE NO TRATAMENTO DA DRENAGEM ÁCIDA DE MINAS VISANDO A RECUPERAÇÃO DE ÁCIDO SULFÚRICO}

Tese apresentada à Escola Politécnica da Universidade de São Paulo para obtenção do título de Doutor em Engenharia

São Paulo 
DANIELLA CARDOSO BUZZI

\section{APLICAÇÃO DA ELETRODIÁLISE NO TRATAMENTO DA DRENAGEM ÁCIDA DE MINAS VISANDO A RECUPERAÇÃO DE ÁCIDO SULFÚRICO}

Tese apresentada à Escola Politécnica da Universidade de São Paulo para obtenção do título de Doutor em Engenharia

Área de Concentração:

Engenharia Metalúrgica e de Materiais

Orientador: Professor Titular Jorge Alberto Soares Tenório

São Paulo 
Este exemplar foi revisado e alterado em relação à versão original, sob responsabilidade única do autor e com a anuência de seu orientador.

São Paulo, de dezembro de 2012.

Assinatura do autor

Assinatura do orientador

FICHA CATALOGRÁFICA

Buzzi, Daniella Cardoso

Aplicação da eletrodiálise no tratamento da drenagem ácida de minas visando a recuperação de ácido sulfúrico/ D.C. Buzzi. ed.rev. -- São Paulo, 2012.

$137 \mathrm{p}$.

Tese (Doutorado) - Escola Politécnica da Universidade de São Paulo. Departamento de Engenharia Metalúrgica e de Materiais.

1. Eletrodiálise 2. Carvão mineral 3. Drenagem em minas 4. Tratamento de águas residuárias 5 . Ácido sulfúrico I. Universidade de São Paulo. Escola Politécnica. Departamento de Engenharia Metalúrgica e de Materiais II. t. 
Àqueles que sonharam comigo o sonho de ser doutora, pai e mãe, essa vitória é nossa! 


\section{AGRADECIMENTOS}

Agradeço a todos que de forma direta ou indireta contribuíram para a realização deste trabalho e antecipadamente peço desculpas aos que foram esquecidos nominalmente, pelo nervosismo do momento.

Aos meus pais, que com amor e apoio incondicional, me incentivaram todo 0 tempo, sempre acreditando no meu potencial.

A Nessa e Carol, irmãs tão amadas, agradeço pela amizade e apoio.

A minha vó Victória, que sempre vibrou com minhas conquistas.

Ao meu orientador, Professor Jorge Alberto Soares Tenório, pelas oportunidades oferecidas, confiança, amizade, apoio e orientação na conclusão deste trabalho.

À Professora Andrea Moura Bernardes que me acolheu no LACOR-UFRGS durante parte do desenvolvimento deste trabalho. Agradeço pela orientação, amizade, paciência e por acreditar na minha capacidade.

Ao Professor Valentín Pérez Herranz que me recebeu em seu grupo de pesquisa na Universidade Politécnica de Valencia, agradeço pela orientação e grandes contribuições para o desenvolvimento deste estudo.

Agradeço aos demais professores que me auxiliaram durante todos estes anos, com incentivos e sugestões, são eles: Marco Antônio Siqueira Rodrigues, Denise Crocce Romano Espinosa, Jane Zoppas Ferreira, Emma Maria Ortega Navarro, Ivo André Homrich Schneider, Álvaro Meneguzzi, Hugo Marcelo Veit, entre outros.

A toda minha família, tios, tias e primos, pelo carinho e palavras de incentivo.

Aos queridos amigos da USP, Viviane, Luciana, Kellie, Adriana, Victor, Eduardo, Fernando, Denis e Girley, que muito contribuíram nesta caminhada, dividindo bons e maus momentos. Em especial a Flávia Paulucci Cianga Silvas e Hugo Hashimoto, grandes amigos, que estiveram presentes ajudando no possível e no que muitas vezes parecia impossível.

Aos amigos da UFRGS, José Luiz, Patrícia, Kátia, Tiago, Jean, Angeli, Rodrigo, Lenisa, Vicente, que estiveram presentes durante o desenvolvimento deste trabalho, 
incentivando nos momentos de desespero e compartilhando muitas risadas. Em especial, a Tatiane Benvenuti e Carolina de Moraes da Trindade, amigas que tantas vezes me deram força para continuar e companheiras de tantos experimentos.

Ao Lucas Stéphano Viegas, aluno de Iniciação Científica, fundamental no desenvolvimento deste trabalho.

Ao querido amigo Martín Bischoff, que sempre esteve disponível ajudando no que fosse preciso.

Ao meu professor de inglês Marlo Fauri, que ajudou na tradução de artigos, ensaios de apresentação e que se tornou um amigo muito especial.

Aos amigos da Universidade Politécnica de Valencia, Ramón, Jordi, Isaac, Carlos, Cristina, Virgínia e Marie Pierre que carinhosamente me receberam em seu grupo de estudo. Em especial ao Manuel César Martí-Calatayud, meu chefinho e grande amigo.

Aos demais amigos com os quais dividi ótimos momentos em Valencia, Álvaro, Rubens, Inês, entre tantos outros.

À Carbonífera Criciúma S/A e ao SIECESC pela disponibilização de informações e por permitir a coleta de amostras.

À CAPES, pela concessão das bolsas de estudo no Brasil e também no exterior na Universidade Politécnica de Valencia.

Por fim, e mais importante, agradeço a Deus, por ter me feito capaz de concluir este doutorado e por colocar em minha caminhada estas pessoas maravilhosas que tive o privilégio de conviver nos últimos quatro anos.

Muito obrigada! 
"Apesar dos nossos defeitos, precisamos enxergar que somos pérolas únicas no teatro da vida e entender que não existem pessoas de sucesso e pessoas fracassadas. $O$ que existem são pessoas que lutam pelos seus sonhos ou desistem deles." 


\section{RESUMO}

O principal impacto causado pela atividade de mineração de carvão é a poluição hídrica proveniente da drenagem ácida de minas (DAM), que pode ter efeitos toxicológicos nos ecossistemas aquáticos, como mortalidade, disfunções no crescimento, menores taxas de reprodução, deformidades e lesões. A DAM é formada através da oxidação de minerais de sulfeto, principalmente pirita $\left(\mathrm{FeS}_{2}\right)$ e caracteriza-se por uma solução de pH ácido e metais dissolvidos ( $\mathrm{Fe}, \mathrm{Al}$ e $\mathrm{Mn}$ ). Novas metodologias para o tratamento de efluentes contaminados com metais estão sendo estudadas e a eletrodiálise (ED) surge como uma destas tecnologias que tem se mostrado eficaz para a recuperação de água e concentração de eletrólitos. É considerada uma tecnologia atrativa aos mais diversos segmentos, uma vez que apresenta muitas vantagens sobre os processos tradicionais, tais como: não exige mudanças de fases; funciona de forma contínua; não necessita da adição de reagentes e não gera resíduos poluentes ao ambiente. A ED é uma técnica de separação por membranas, no qual espécies iônicas em solução são transportadas através de membranas de troca-iônica por influência da aplicação de um campo elétrico que permite a separação de ânions e cátions metálicos com a vantagem de remover os metais contaminantes e simultaneamente recuperar água e outros compostos de interesse industrial, como o ácido sulfúrico. No entanto, para a aplicação da ED alguns parâmetros devem ser estudados, buscando as melhores condições de uso. O parâmetro mais importante a ser analisado é o transporte dos íons através das membranas, avaliado no presente estudo através da cronopotenciometria e da obtenção das curvas de corrente-potencial (CVCs). Curvas cronopotenciométricas foram obtidas a partir de soluções sintéticas que representavam a composição de uma DAM a fim de se avaliar a passagem de ânions sulfato através de uma membrana aniônica (HDX 200), e o transporte de cátions metálicos, tais como $\mathrm{Na}^{+}$e $\mathrm{Fe}^{3+}$, através de uma membrana catiônica (HDX 100). E as CVCs foram obtidas a partir das próprias DAMs também para a avaliação do transporte de íons e determinação de densidade de corrente limite a ser empregada na ED. Os resultados mostraram que os cátions avaliados desempenharam um papel significativo para o equilíbrio químico que leva à formação de diferentes espécies de complexos de cargas e mobilidade distintas. Diagramas de especiação em conjunto com os cronopotenciogramas permitiram a identificação de espécies complexas que conduzem a um transporte lento de íons através das membranas. A ED mostrou-se eficaz para a recuperação de água, removendo mais de $97,00 \%$ dos contaminantes, e para a recuperação de ácido sulfúrico a partir da DAM, sendo obtidos percentuais de concentração de sulfatos superiores a $38,55 \%$ e incrementos na acidez de até $236,88 \%$.

Palavras-chave: drenagem ácida de minas, eletrodiálise, tratamento de efluentes ácidos, recuperação de ácido sulfúrico. 


\begin{abstract}
The main impact caused by coal mining activity is water pollution from acid mine drainage (AMD), that can have serious toxicological effects on aquatic ecosystems, such as mortality, growth disorders, lower rates reproduction, deformities and injuries. The AMD is formed by the oxidation of sulfide minerals, mainly pyrite $\left(\mathrm{FeS}_{2}\right)$ and is characterized by a acid $\mathrm{pH}$ and dissolved metals (Fe, $\mathrm{Al}$ and $\mathrm{Mn}$ ). New approaches for the wastewater contaminated with metals treatment are being studied and electrodialysis (ED) emerges as a new technology and has proven effective for the recovery of water and electrolyte concentration. The ED is considered an attractive technology to some segments since it presents several advantages on the traditional processes, such as: does not require phase changes; runs continuously, does not need reagents addition and does not generate waste polluting environment. Electrodialysis is a membrane separation technique in which ionic species in solution are transported, through ion-exchange membranes, under the influence of an electric field which allows anions and metallic cations separation, possessing the advantages of removing contaminant metals and simultaneously recovering water and other compounds of industrial interest, such as sulfuric acid. However, to implement the ED some parameters should be studied seeking the best conditions. The most important parameter to be studied is the ions transport across membranes, assessed in this study by chronopotentiometry and obtaining the current-voltage curves (CVCs). Chronopotentiometry curve were obtained from synthetic solutions representing the AMD composition in order to assess the passage of anions sulfate through a membrane anion (HDX 200), and transport of metallic cations such as $\mathrm{Na}^{+}$and $\mathrm{Fe}^{3+}$, through a cation membrane (HDX 100). The CVCs were obtained from raw AMD also to evaluate the ions transport and determination of threshold current density to be employed in ED. The results showed that the cations evaluated played a significant role in the chemical balance which leads to the formation of different species of complexes of different fillers and mobility. Speciation diagrams with chronopotentiograms allowed the identification of complex species that lead to a slow ions transport across membranes. The ED was effective for water recovery removing more than $97.00 \%$ of contaminants and to sulfuric acid recovery from the AMD, where has been obtained percentage of sulfate concentration above $38.55 \%$ and an increase in acidity up to $236.88 \%$.
\end{abstract}

Keywords: acid mine drainage, electrodialysis, wastewater treatment acids, sulfuric acid recovery. 


\section{LISTA DE ILUSTRAÇÕES}

Figura 1 - Consumo de energia primária no mundo (\% por combustível)...............27

Figura 2 - Fluxograma do beneficiamento do carvão...........................................29

Figura 3 - Rejeito de carvão na região de Criciúma, SC.......................................32

Figura 4 - Rio Sangão, impactado pela DAM - Criciúma, SC................................32

Figura 5 - Comparação das constantes de velocidade em função do $\mathrm{pH}$ para a oxidação da pirita por $\mathrm{Fe}^{3+}$ (Reação 4); oxidação do $\mathrm{Fe}^{2+}$ pelo $\mathrm{O}_{2}$ (Reação 2); e

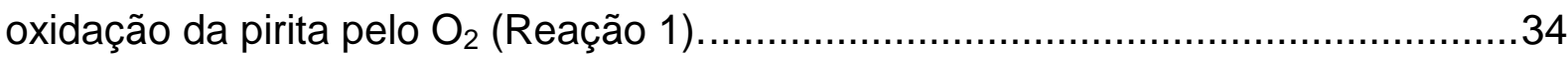

Figura 6 - Mecanismo de operação da ED com 5 compartimentos.

Figura 7 - Estrutura esquemática de membranas íon-seletiva catiônica e aniônica 41

Figura 8 - Curva potencial-corrente'.

Figura 9 - Curva cronopotenciométricas característica para diferentes densidades de corrente.

Figura 10 - Desenvolvimento dos processos com membranas de troca iônica.......50

Figura 11 - Fluxograma geral da metodologia experimental.

Figura 12 - Pontos de coleta das DAMs em uma carbonífera em operação.

Figura 13 - Ponto de coleta da DAM MA - percolado do Módulo de Rejeito A........57

Figura 14 - Ponto de coleta da DAM MB - percolado do Módulo de Rejeito B........58

Figura 15 - Ponto de coleta da DAM LX - drenagem subterrânea do Módulo de Rejeito B.

Figura 16 - Ponto de coleta da DAM PL - drenagem pluvial de toda a área da carbonífera.

Figura 17 - Ponto de coleta da DAM BA - bacia de adução que antecede o processo de tratamento atual da carbonífera

Figura 18 - Ponto de coleta da DAM CB - boca de mina abandonada.

Figura 19 - (a) Membrana catiônica - HDX 100; (b) Membrana aniônica - HDX 200.

Figura 20 - Montagem experimental utilizada para os ensaios cronopotenciométricos. 
Figura 21 - Interface do software GPES para aquisição de dados dos ensaios cronopotenciométricos.

Figura 22 - Célula de bancada (I) de três compartimentos, sob agitação. 68

Figura 23 - Célula de ED de bancada (II) de três compartimentos. 70

Figura 24 - Montagem de uma célula de ED para determinação das curvas de polarização.

Figura 25 - Montagem experimental de célula de ED de bancada (III) com cinco compartimentos.

Figura 26 - Célula de ED de bancada (IV) de três compartimentos. 75

Figura 27 - Curvas cronopotenciométricas obtidas para membranas HDX 200 com

Figura 28 - Diagrama de especiação do $\mathrm{Fe}^{3+}$ para soluções de $\mathrm{Fe}_{2}\left(\mathrm{SO}_{4}\right)_{3} 2 \cdot 10^{-2} \mathrm{M}$.

Figura 29 - Curvas cronopotenciométricas obtidas para membranas HDX 100 com

Figura 30 - Cronopotenciogramas obtidos com a membrana HDX 100 para solução mista de $\mathrm{Fe}_{2}\left(\mathrm{SO}_{4}\right)_{3} 2 \cdot 10^{-2} \mathrm{M}+\mathrm{Na}_{2} \mathrm{SO}_{4} 2 \cdot 10^{-2} \mathrm{M}$.

Figura 31 - CVC obtidas para a membrana aniônica HDX 200 com diversas concentrações de eletrólitos.

Figura 32 - CVCs obtidas para a membrana catiônica HDX 100 com diversas concentrações de eletrólitos.

Figura 33 - Quantificação de Fe no compartimento central e cátodo do ensaio 1ED-SS.

Figura 34 - Quantificação de Fe no compartimento central e cátodo do ensaio 2ED-SS.

Figura 35 - Quantificação de Fe no compartimento central e cátodo do ensaio 3ED-SS.

Figura 36 - Quantificação de Fe no compartimento central e cátodo do ensaio 4ED-SS.

Figura 37 - Configuração experimental do ensaio 1ED-SS-AC.............................96

Figura 38 - Concentração de $\mathrm{SO}_{4}{ }^{2-}$ ao longo do ensaio 1ED-SS-AC. ....................97

Figura 39 - Concentração de Fe ao longo do ensaio 1ED-SS-AC..........................97 


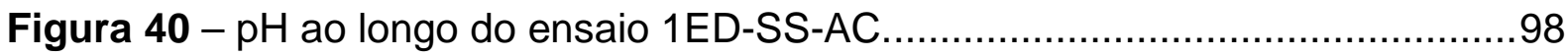

Figura 41 - Configuração experimental do ensaio 2ED-SS-AC a 4ED-SS-AC. .......98

Figura 42 - Concentração de $\mathrm{SO}_{4}{ }^{2-}$ ao longo do ensaio 2ED-SS-AC. ....................99

Figura 43 - Concentração de Fe ao longo do ensaio 2ED-SS-AC.........................100

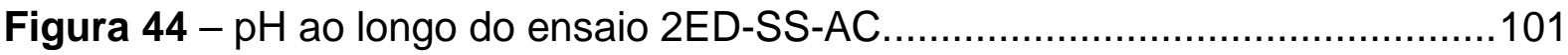

Figura 45 - Acidez do compartimento ânodo ao longo do ensaio 2ED-SS-AC......101

Figura 46 - Concentração de $\mathrm{SO}_{4}{ }^{2-}$ ao longo do ensaio 3ED-SS-AC. ..................102

Figura 47 - Concentração de Fe ao longo do ensaio 3ED-SS-AC.........................102

Figura 48 - pH ao longo do ensaio 3ED-SS-AC.............................................103

Figura 49 - Concentração de $\mathrm{SO}_{4}{ }^{2-}$ ao longo do ensaio 4ED-SS-AC...................104

Figura 50 - Concentração de Fe ao longo do ensaio 4ED-SS-AC.........................104

Figura 51 - pH ao longo do ensaio 4ED-SS-AC.............................................105

Figura 52 - Concentração de $\mathrm{SO}_{4}{ }^{2-}$ ao longo do ensaio 1ED-SS-AC-II. .................107

Figura 53 - Concentração de Fe ao longo do ensaio 1ED-SS-AC-II......................107

Figura 54 - pH ao longo do ensaio 1ED-SS-AC-II. .........................................108

Figura 55 - Acidez inicial e final do compartimento ânodo do ensaio 1 ED-SS-AC-II.

Figura 56 - Concentração de $\mathrm{SO}_{4}{ }^{2-}$ ao longo do ensaio 2ED-SS-AC-II. ................110

Figura 57 - Concentração de Fe ao longo do ensaio 2ED-SS-AC-II......................110

Figura 58 - pH ao longo do ensaio 2ED-SS-AC-II. .............................................111

Figura 59 - Acidez inicial e final do compartimento ânodo do ensaio 2ED-SS-AC-II.

Figura 60 - Curva de polarização da membrana aniônica para a DAM PL............112

Figura 61 - Curva de polarização da membrana catiônica para a DAM PL...........112

Figura 62 - Curva de polarização da membrana aniônica para a DAM BA. ..........112

Figura 63 - Curva de polarização da membrana catiônica para a DAM BA...........112

Figura 64 - Curva de polarização da membrana aniônica para a DAM CB. ..........112

Figura 65 - Curva de polarização da membrana catiônica para a DAM CB. .........112 
Figura 66 - Monitoramento do $\mathrm{pH}$ da ED para a DAM BA.

Figura 67 - Monitoramento da condutividade da ED para a DAM BA.

Figura 68 - Extração de ânions durante as 6 h de ED da DAM BA.

Figura 69 - Extração dos cátions $\mathrm{Fe}^{3+}, \mathrm{Fe}^{2+}, \mathrm{Mn}^{2+}, \mathrm{Co}^{2+}$ e $\mathrm{Zn}^{2+}$ durante as $6 \mathrm{~h}$ de ED da DAM BA.

Figura 70 - Extração dos cátions $\mathrm{Na}^{+}, \mathrm{K}^{+}, \mathrm{Mg}^{2+}$ e $\mathrm{Ca}^{2+}$ durante as 6 h de ED da

DAM BA.

Figura 71 - Monitoramento do $\mathrm{pH}$ da ED para a DAM CB.

Figura 72 - Monitoramento da condutividade da ED para a DAM CB.

Figura 73 - Extração de ânions durante as 6 h de ED da DAM CB.

Figura 74 - Extração dos cátions $\mathrm{Fe}^{3+}, \mathrm{Mn}^{2+}$ e $\mathrm{Zn}^{2+}$ durante as $6 \mathrm{~h}$ de ED da

DAM CB.

Figura 75 - Extração dos cátions $\mathrm{Na}^{+}, \mathrm{K}^{+}, \mathrm{Mg}^{2+}$ e $\mathrm{Ca}^{2+}$ durante as $6 \mathrm{~h}$ de ED da DAM CB.

Figura 76 - Concentração de $\mathrm{SO}_{4}{ }^{2-}$ ao longo do ensaio com DAM MB. 123

Figura 77 - Concentração de Fe ao longo do ensaio com DAM MB. 123

Figura $78-\mathrm{pH}$ ao longo do ensaio com DAM MB 124

Figura 79 - Acidez inicial e final do compartimento ânodo do ensaio com DAM MB. 125

Figura 80 - Ânodo após 16 h de ED com DAM MB. 125

Figura 81 - Cátodo após 16 h de ED com DAM MB. 125 


\section{LISTA DE TABELAS}

Tabela 1 - Classificação do carvão mineral.........................................................26

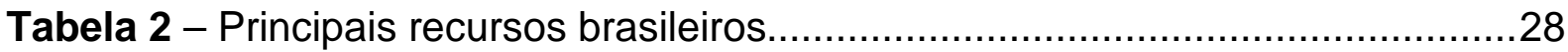

Tabela 3 - Principais tipos e métodos de lavra de carvão.....................................28

Tabela 4 - Características de depósitos de rejeito de carvão da região Sul do Brasil.

Tabela 5 - Características típicas de DAM.

Tabela 6 - Estações de tratamento de efluentes da DAM em operação no Brasil...37

Tabela 7 - Metodologias utilizadas para a caracterização química das s de DAM...61

Tabela 8 - Composição das soluções sintéticas.

Tabela 9 - Características das membranas HDX 100 e HDX 200..........................62

Tabela 10 - Configurações experimentais utilizadas para ensaios de ED com soluções sintéticas.

Tabela 11 - Configurações experimentais utilizadas para ensaios de ED com soluções sintéticas.

Tabela 12 - Ensaios de ED com DAMs em bancada. .......................................73

Tabela 13 - Caracterização química das DAMs ................................................78

Tabela 14 - Características das soluções sintéticas. ............................................80

Tabela 15 - Parâmetros extraídos das CVCs para a membrana aniônica/solução. .88

Tabela 16 - Parâmetros extraídos das CVCs para a membrana catiônica/solução. 90

Tabela 17 - Densidade de corrente limite para as membranas aniônicas e catiônicas.

Tabela 18 - Monitoramento do ensaio de ED para a DAM BA............................115

Tabela 19 - Monitoramento do ensaio de ED para a DAM CB............................117

Tabela 20 - Monitoramento dos ensaios de ED para a DAM PL e DAM CB.........120

Tabela 21 - Concentração iônica inicial e final do compartimento diluído 


\section{LISTA DE ABREVIATURAS, SIGLAS E SÍMBOLOS}

$\lambda$ - Condutividade

$\tau-$ Tempo de transição

$\eta_{\Omega}-$ Sobrepotencial ôhmico

$\eta_{c}-$ Potencial de concentração

$\eta_{t}$ - Diferença de potencial

$A$ - Ampère

ABNT - Associação Brasileira de Normas Técnicas

CVC - Curva Corrente-Potencial

DAM - Drenagem Ácida de Minas

DAM BA - DAM proveniente da bacia de adução que antecede o processo de tratamento atual da carbonífera

DAM CB - DAM proveniente de uma boca de mina abandonada

DAM LX - DAM proveniente da drenagem subterrânea do Módulo de Rejeito $B$

DAM MA - DAM proveniente do percolado do Módulo de Rejeito A

DAM MB - DAM proveniente do percolado do Módulo de Rejeito $B$

DAMPL - DAM proveniente da drenagem pluvial de toda a área da carbonífera

ED - Eletrodiálise

ha - hectare

I - corrente $(\mathrm{mA})$

$\mathrm{i}$ - densidade de corrente $\left(\mathrm{mA} \cdot \mathrm{cm}^{-2}\right)$

IEA - Agência Internacional de Energia

$\mathrm{I}_{\text {lim }}$ - densidade de corrente limite $\left(\mathrm{mA} \cdot \mathrm{cm}^{-2}\right)$

$\mathrm{MPa}$ - Megapascal

MW - megawatts

N.M. - não houve monitoramento

NBR - Norma Brasileira

PEAD - Polietileno de Alta Densidade

ppm - parte por milhão

PVC - Policloreto de vinila 
$\mathrm{R}_{1}$ - Resistência da membrana na região ôhmica

ROM - Carvão bruto

SIECESC - Sindicato da Indústria de Extração de Carvão do Estado de Santa

Catarina

$U_{m}$ - Diferença de potencial 


\section{SUMÁRIO}

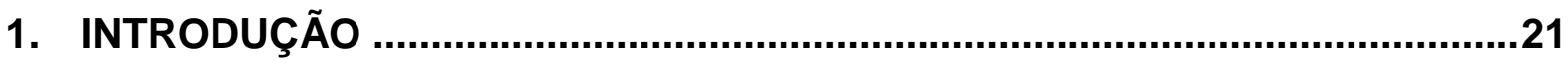

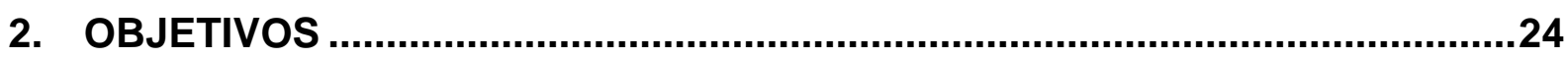

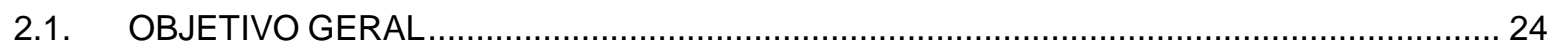

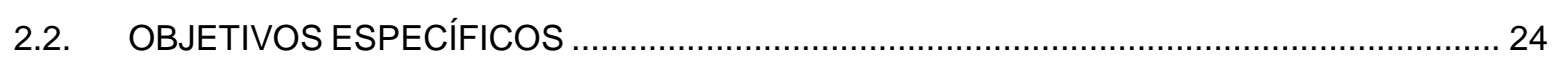

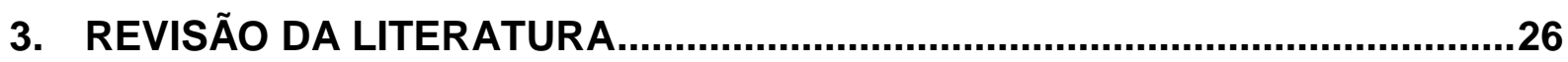

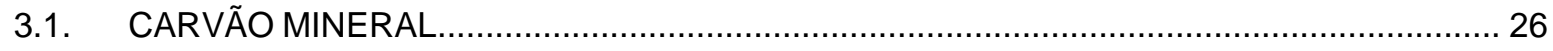

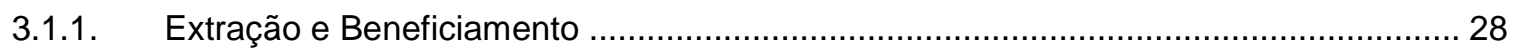

3.1.2. Impacto Ambiental dos Rejeitos provenientes da Mineração de Carvão ...................... 30

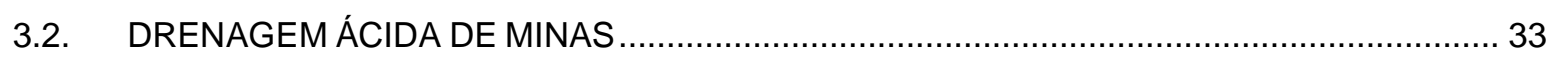

3.2.1. Tratamento da Drenagem Ácida de Minas............................................................ 36

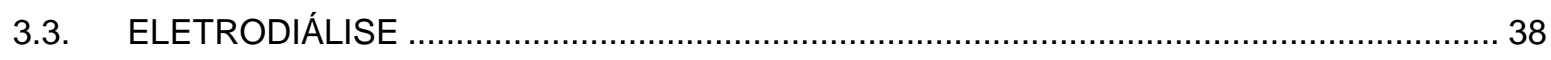

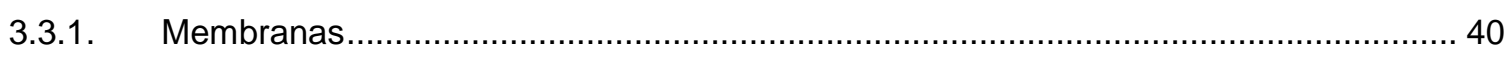

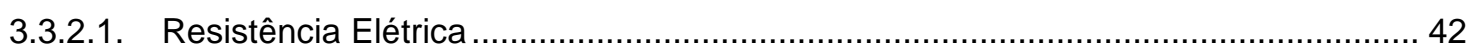

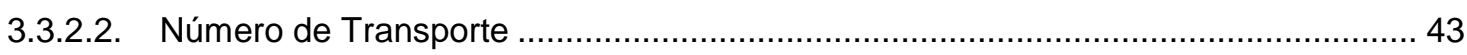

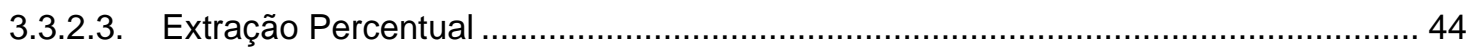

3.3.2.4. Polarização por Concentração e Corrente Limite ................................................... 44

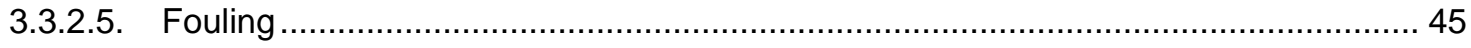

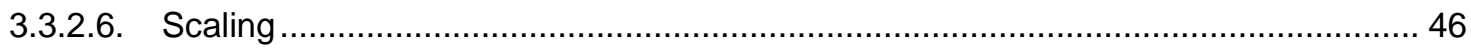

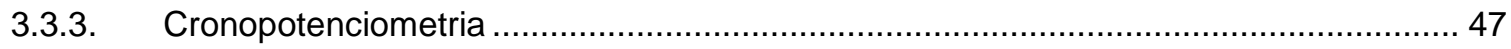

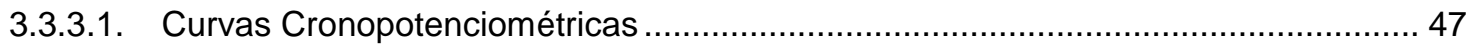

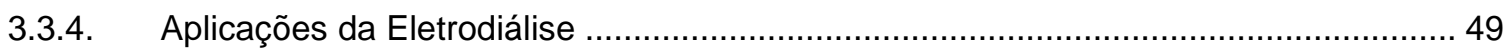

3.3.4.1. Eletrodiálise no Tratamento de Efluentes .......................................................... 51

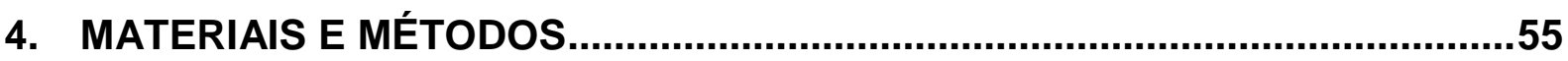

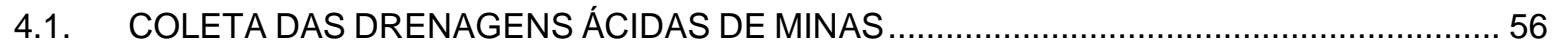

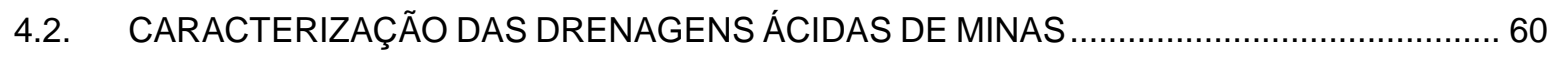

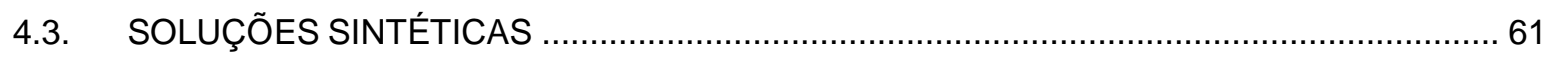

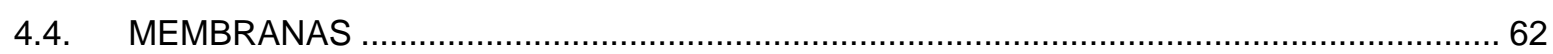

4.5. CRONOPOTENCIOMETRIA COM SOLUÇÕES SINTÉTICAS ......................................... 63

4.6. ELETRODIÁLISE COM SOLUÇÕES SINTÉTICAS EM BANCADA (I) ............................... 66

4.7. ELETRODIÁLISE COM SOLUÇÃO SINTÉTICA VISANDO A RECUPERAÇÃO DE ÁCIDO

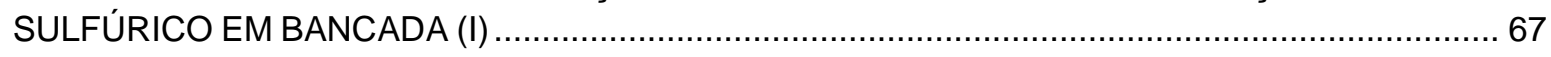

4.8. ELETRODIÁLISE COM SOLUÇÃO SINTÉTICA VISANDO A RECUPERAÇÃO DE ÁCIDO

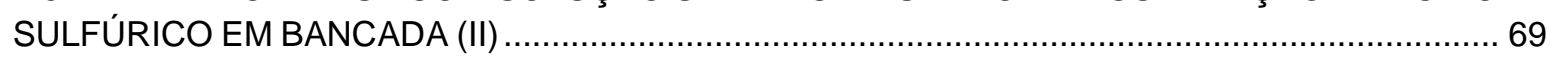

4.9. CURVAS DE POLARIZAÇÃO COM DRENAGENS ÁCIDAS DE MINAS .............................. 71 
4.10. ELETRODIÁLISE COM DRENAGENS ÁCIDAS DE MINAS EM BANCADA

4.11. ELETRODIÁLISE COM DRENAGEM ÁCIDA DE MINAS VISANDO A RECUPERAÇÃO DE ÁCIDO SULFÚRICO EM BANCADA (IV)

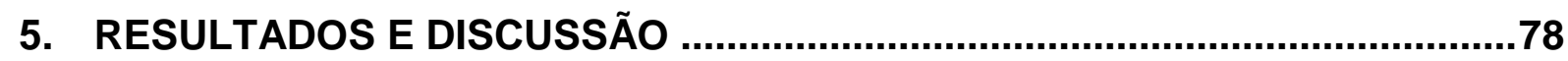

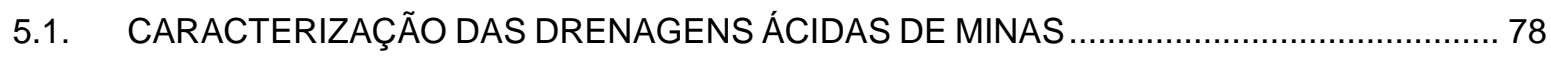

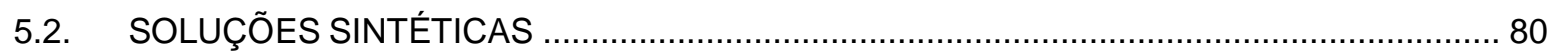

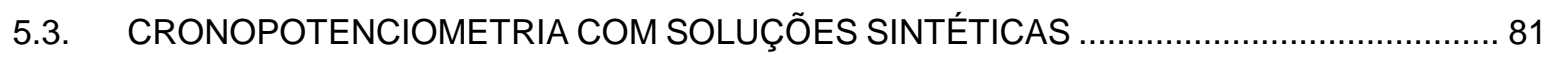

5.4. ELETRODIÁLISE COM SOLUÇÕES SINTÉTICAS EM BANCADA (I) ................................. 92

5.5. ELETRODIÁLISE COM SOLUÇÃO SINTÉTICA VISANDO A RECUPERAÇÃO DE ÁCIDO

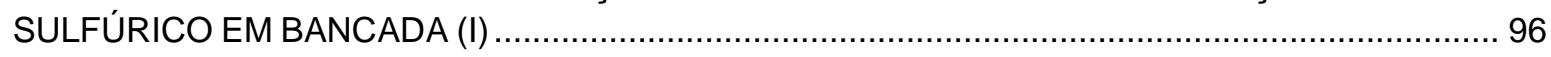

5.6. ELETRODIÁLISE COM SOLUÇÃO SINTÉTICA VISANDO A RECUPERAÇÃO DE ÁCIDO

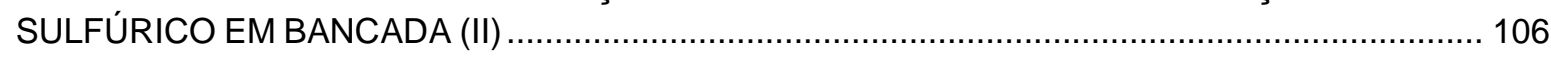

5.7. CURVAS DE POLARIZAÇÃO COM DRENAGENS ÁCIDAS DE MINAS ............................ 112

5.8. ELETRODIÁLISE COM DRENAGENS ÁCIDAS DE MINAS EM BANCADA (III) ................ 113 5.9. ELETRODIÁLISE COM DRENAGEM ÁCIDA DE MINAS VISANDO A RECUPERAÇÃO DE

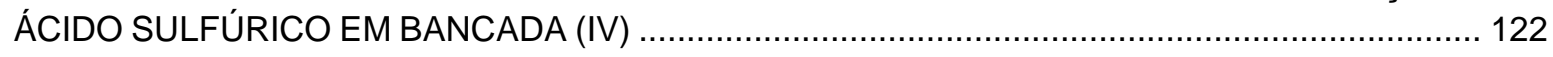

6. CONCLUSÕES ........................................................................................ 128

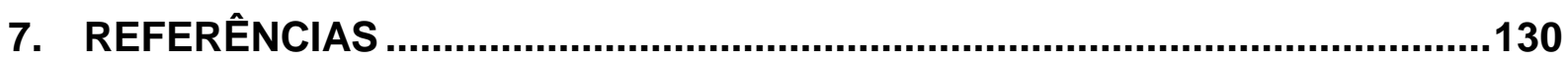




\section{INTRODUÇ $\tilde{A} O$}




\section{INTRODUÇÃO}

Atrelado aos benefícios sociais e econômicos trazidos pela mineração de carvão à comunidade na qual se instala, há o impacto ambiental. Assim, a tomada de medidas preventivas e reparatórias é essencial para o controle da poluição gerada pela mineração.

Um dos principais impactos causados pela atividade de mineração de carvão é a poluição hídrica causada pela drenagem ácida de minas (DAM), que se caracteriza por uma solução de pH ácido, aproximadamente igual a 2,0, e metais dissolvidos (Fe, Al, Mn, entre outros). ${ }^{1,2}$

Atualmente, as indústrias de mineração têm optado pelo processo convencional de tratamento de efluentes. As metodologias convencionais se baseiam na transferência de fase, líquido passando a sólido, através da precipitação dos metais, geralmente pela adição de hidróxidos. Desta forma, são gerados lodos que representam um novo problema, pois precisam ser descartados de acordo com sua classificação, segundo a NBR 10004/2004 da ABNT, como um resíduo sólido $0^{3,4,5}$.

A escassez de água tem motivado o desenvolvimento de tecnologias que substituam os métodos convencionais de tratamento de efluentes, buscando 0 reaproveitamento da água. A tecnologia de membranas oferece vantagens que atraem a atenção das indústrias devido à sua modularidade e rentabilidade em pequena escala, sendo que as técnicas de eletromembranas, em particular, no tratamento da poluição na própria fonte de geração ${ }^{6}$. A eletrodiálise (ED) é uma destas tecnologias, e vem sendo aplicada atualmente na recuperação de metais, tratamento de efluentes e na recuperação de compostos de interesse industrial, tais como ácidos orgânicos e inorgânicos.

A ED está baseada em um processo de separação por membranas, no qual os íons de uma solução são separados por aplicação de um campo elétrico, possibilitando desta forma, tanto o aproveitamento da solução que se torna mais diluída pela extração dos íons como água, como da solução concentrada. No entanto, para a aplicação da ED alguns parâmetros devem ser estudados buscando as melhores condições de uso, tais como: resistência elétrica, transporte iônico, 
extração percentual, polarização por concentração, densidade de corrente limite, entre outros ${ }^{7,8}$.

O parâmetro mais importante a ser estudado é o transporte dos íons através das membranas. Este parâmetro pode ser avaliado por meio da cronopotenciometria e da obtenção das curvas de corrente-potencial. Estes dois métodos permitem avaliar fenômenos relacionados a polarização por concentração e a densidade de corrente limite, que influenciam diretamente na eficiência do processo, pois quando a densidade de corrente aplicada excede o limite pode ocorrer a precipitação de sais na superfície das membranas, diminuindo a vida útil das mesmas, aumentando o consumo de energia e, consequentemente, diminuindo a eficiência do processo ${ }^{9}$.

O ácido sulfúrico, insumo utilizado de forma direta e indireta em praticamente todas as indústrias, é considerado uma matéria-prima de grande importância em qualquer economia nacional. A velocidade de consumo de ácido sulfúrico, assim como a produção de aço ou energia elétrica pode ser utilizada como indicador de desenvolvimento de um país ${ }^{10}$.

Considerando que o sulfato é o íon presente em maior quantidade na DAM, no presente trabalho buscou-se estudar a aplicação da ED no tratamento da DAM visando a recuperação de ácido sulfúrico e, consequentemente, possibilitando o reúso da água. Além de obter um concentrado dos metais. 


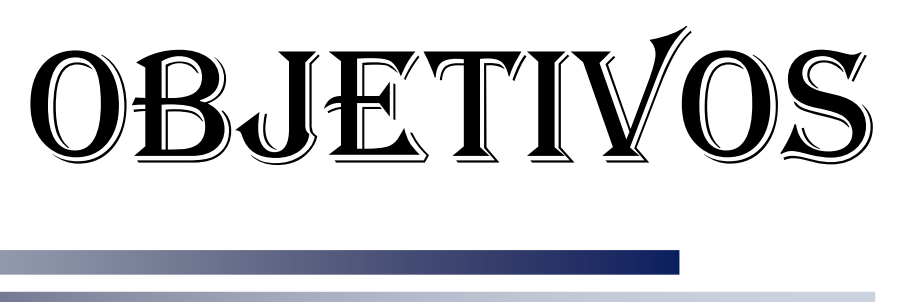




\section{OBJETIVOS}

\subsection{OBJETIVO GERAL}

Estudar a aplicação da técnica de eletrodiálise para o tratamento da drenagem ácida de minas proveniente da mineração de carvão mineral, visando a recuperação de ácido sulfúrico, água e obtenção de um concentrado de metais.

\subsection{OBJETIVOS ESPECÍFICOS}

$>\quad$ Caracterizar drenagens ácidas de minas provenientes de diferentes fontes geradoras na região de Criciúma/SC.

> Avaliar o transporte dos principais íons da drenagem ácida de minas $\left(\mathrm{SO}_{4}{ }^{2-}\right.$, $\mathrm{Fe}^{3+}$ e $\mathrm{Na}^{+}$), através de membranas aniônicas (HDX 200) e catiônicas (HDX 100), por cronopotenciometria a partir de soluções sintéticas.

> Verificar a extração de ferro por eletrodiálise a partir de soluções sintéticas.

> Estudar a aplicação da eletrodiálise para a recuperação de ácido sulfúrico, água e a obtenção de um concentrado de metais a partir de soluções sintéticas.

> Investigar o transporte dos íons, de drenagens ácidas de minas reais, através das membranas HDX 100 e HDX 200, através da obtenção de curvas de correntepotencial.

> Verificar as extrações percentuais de cátions e ânions por eletrodiálise a partir de drenagens ácidas de minas, visando a recuperação de água.

> Estudar a aplicação da eletrodiálise para a recuperação de ácido sulfúrico, água e a obtenção de um concentrado de metais a partir de drenagem ácida de minas. 


\section{REVISÃO DA LITERATURA}




\section{REVISÃO DA LITERATURA}

\subsection{CARVÃO MINERAL}

O carvão mineral é a mais abundante fonte de energia primária no planeta, e como todo combustível fóssil é formado a partir da decomposição de matéria orgânica durante milhões de anos ${ }^{11}$. É classificado em função dos seus estágios de carbonificação do menor para o maior, seguindo a ordem: turfa $\rightarrow$ linhito $\rightarrow$ hulha ou carvão betuminoso $\rightarrow$ antracito, conforme apresentado na Tabela $1^{12}$.

\begin{tabular}{lc}
\multicolumn{2}{c}{ Tabela 1-Classificação do carvão mineral ${ }^{2}}$. \\
\hline Tipo & \% de Carbono \\
\hline Linfa & até 45 \\
Hulha ou Carvão betuminoso & 60 a 75 \\
Antracito & 75 a 85 \\
\hline
\end{tabular}

Apesar de ser um combustível potencialmente poluente, a exemplo do petróleo, o carvão também pode ser utilizado em larga escala, sendo comumente usado em usinas termelétricas (produção de energia elétrica) e como matéria-prima na produção de coques - tipo fundição e siderúrgico ${ }^{12}$.

O rejeito piritoso, oriundo da extração do carvão mineral, quando tratado em unidades químicas, origina enxofre, óxido de ferro, ácido sulfúrico e adubos nitrogenados. Já os gases provenientes da destilação do carvão mineral são fonte de sulfato de amônio, alcatrão, naftaleno, benzeno, tolueno, xileno e nafta leve. Os alcatrões são utilizados em pavimentações. Os piches são usados em impermeabilizações e óleos pesados como creosotado, desinfetante e antracênico, entre outros inúmeros subprodutos ${ }^{13}$.

Devido à disponibilidade de reservas geograficamente espalhadas no mundo e ao desenvolvimento crescente de tecnologias limpas, o carvão deve continuar desempenhando um importante papel como fonte de energia no cenário mundial ${ }^{11}$.

Nos últimos 10 anos, a demanda de energia mundial aumentou cerca de $25 \%$. As projeções da Agência Internacional de Energia (IEA) também indicam que a demanda de energia irá aumentar entre o período atual e o ano de $2030^{13}$. 
As fontes fornecedoras de energia, tais como o gás, o petróleo e o carvão, irão continuar prevalecendo em relação ao consumo de energia - atendendo aos cerca de $85 \%$ do aumento na demanda de energia mundial nos próximos 30 anos. Energias renováveis estão crescendo rapidamente, mas em uma proporção pequena, e até o ano de 2030 elas devem suprir cerca de $14 \%$ do total da demanda energética $^{13}$, conforme apresentado na Figura 1.

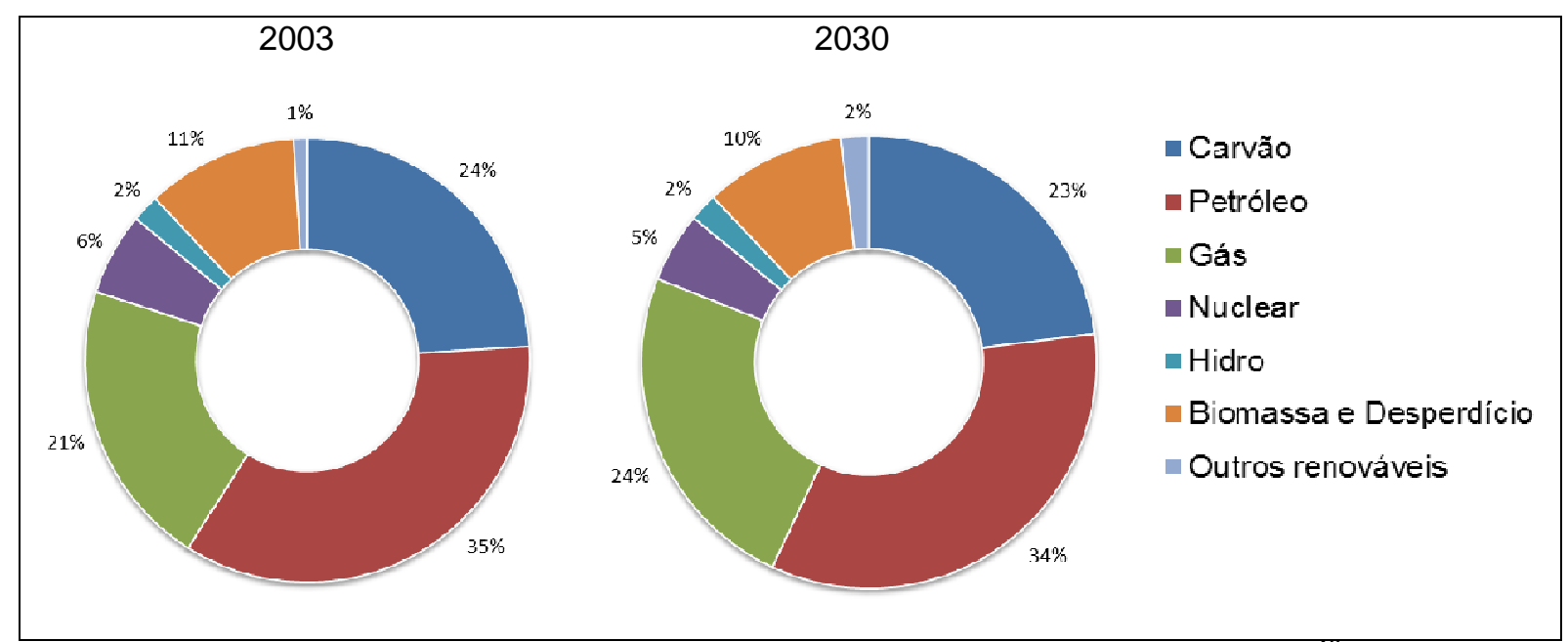

Figura 1 - Consumo de energia primária no mundo (\% por combustível) ${ }^{13}$.

No Brasil, inicialmente o carvão foi utilizado no transporte ferroviário e marítimo e na produção de gás para iluminação pública. Atualmente, o principal uso da combustão direta do carvão é na geração de eletricidade, por meio de usinas termoelétricas. Essa tecnologia está bem desenvolvida e é economicamente competitiva ${ }^{13}$.

As reservas brasileiras de 32 bilhões de toneladas de carvão representam um potencial de $18.600 \mathrm{MW}$ para cem anos de operação e estão localizadas nos estados do Paraná (PR), Santa Catarina (SC) e Rio Grande do Sul (RS) ${ }^{13,14}$, conforme apresentado na Tabela 2. 
Tabela 2 - Principais recursos brasileiros ${ }^{13}$.

\begin{tabular}{clc}
\hline \multicolumn{1}{c}{ ESTADO } & \multicolumn{1}{c}{ JAZIDA } & $\begin{array}{c}\text { RECURSO } \\
\text { (bilhões de toneladas) }\end{array}$ \\
\hline \multirow{3}{*}{ Paraná } & Cambuí & 44 \\
& Sapopema & 45 \\
& Outros & 14 \\
\hline \multirow{5}{*}{ Santa Catarina } & Barro Branco & 1.045 \\
& Bonito & 1.601 \\
& Pré-Bonito & 414 \\
& Outros & 289 \\
\hline \multirow{5}{*}{ Rio Grande do Sul } & Candiota & 12.275 \\
& Leão & 2.439 \\
& Charqueadas & 2.993 \\
& Iruí / Capané & 2.688 \\
& Morungava & 3.128 \\
& Santa Terezinha/Torres & 5.068 \\
& Outros & 207 \\
\hline TOTAL & & 32.250 \\
\hline
\end{tabular}

\subsubsection{Extração e Beneficiamento}

A exploração do carvão se dá de duas maneiras: a céu aberto ou subterrânea, através de diferentes métodos, conforme apresenta a Tabela $3^{15}$.

Tabela 3 - Principais tipos e métodos de lavra de carvão ${ }^{15}$.

\begin{tabular}{|c|c|c|}
\hline Lavra & Método & Principais Características \\
\hline \multirow{3}{*}{ 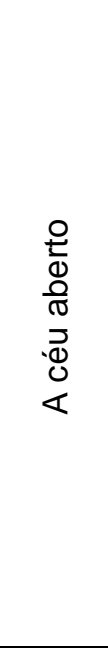 } & $\begin{array}{l}\text { Lavras em } \\
\text { tiras }\end{array}$ & $\begin{array}{l}\text { - remoção inicial da cobertura superficial que recobre as camadas de } \\
\text { carvão; } \\
\text { - grande quantidade de estéril retirada. }\end{array}$ \\
\hline & $\begin{array}{l}\text { Lavra de } \\
\text { descobertura } \\
\text { com dragline }\end{array}$ & $\begin{array}{l}\text { - abertura de um corte inicial, remoção do carvão neste corte e } \\
\text { disposição do material de cobertura do próximo corte dentro deste } \\
\text { inicial; } \\
\text { - empregado em depósitos de carvão com camadas horizontais ou } \\
\text { moderadamente inclinadas, com espessuras constantes do material } \\
\text { de cobertura. }\end{array}$ \\
\hline & $\begin{array}{l}\text { Lavra em } \\
\text { bancadas / } \\
\text { escavadeira }\end{array}$ & $\begin{array}{l}\text { - abertura de uma cava colocando a cobertura extraída em uma área } \\
\text { de bota-fora temporária e remoção do carvão desta cava inicial e } \\
\text { depósito da cobertura para a área já lavrada; } \\
\text { - empregado em depósitos com camadas de carvão espessas, } \\
\text { horizontais ou levemente inclinadas e que apresentem baixa razão de } \\
\text { cobertura. }\end{array}$ \\
\hline 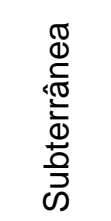 & $\begin{array}{l}\text { Método de } \\
\text { câmaras e } \\
\text { pilares }\end{array}$ & $\begin{array}{l}\text { - o carvão é extraído a partir de câmaras retangulares deixando partes } \\
\text { do carvão entre as câmaras como pilares; } \\
\text { - empregado em depósitos de carvão com camadas horizontais ou } \\
\text { moderadamente inclinadas, nos quais o teto é sustentado } \\
\text { primeiramente por pilares naturais. }\end{array}$ \\
\hline
\end{tabular}


Em Santa Catarina, o carvão ocorre na bacia Sul-Catarinense, com cerca de $21 \%$ das reservas medidas oficiais brasileiras (1.525.021.083 t) e $22 \%$ das provadas e prováveis (201.921.000 t). Trata-se de um carvão pouco coqueificável e de médio a baixo valor energético, admitindo algum beneficiamento e transporte a curta distância. As partes a céu aberto e subterrâneas rasas já foram quase todas mineradas, e desta forma há uma crescente dificuldade das jazidas se manterem em ritmo intenso de lavra, com minas profundas e estruturalmente difíceis ${ }^{16}$.

A mecanização das minas obriga a retirada de todo o material presente, carvão e intercalações. Assim é necessário uma pré-lavagem na boca-da-mina para eliminar o estéril ${ }^{17}$.

O beneficiamento é feito visando o aproveitamento econômico do carvão bruto (ROM) minerado ${ }^{18}$. O fluxograma apresentado na Figura 2 demonstra os processos padrões utilizados, porém dependendo das características físico-químicas do minério, podem ocorrer modificações tanto na sequência das etapas como na escolha dos processos.

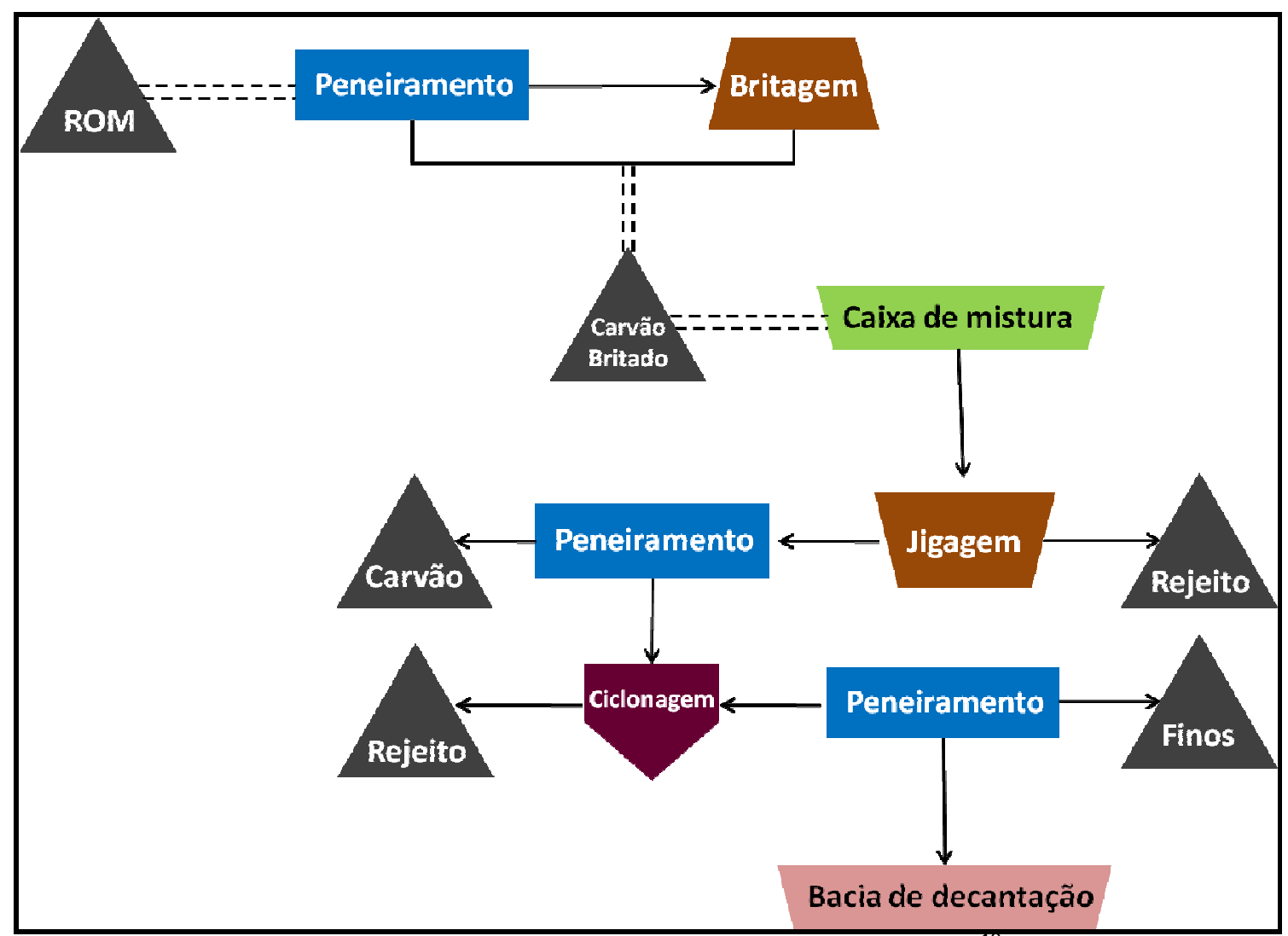

Figura 2 - Fluxograma do beneficiamento do carvão ${ }^{19}$. 
A presença de sedimentos como folhelhos, siltitos e argilitos e também de pirita faz com que seja necessário o beneficiamento do minério bruto para então se obter carvão energético e metalúrgico, além de outros produtos.

O início da exploração de carvão mineral, na região de Santa Catarina se deu com a escavação manual de bocas de minas, nas encostas, onde afloram as camadas de carvão. Estas escavações eram realizadas nas porções mais alteradas e brandas da camada onde era possível a exploração, mas com o avanço das galerias o minério se tornava muito duro para ser explorado manualmente. Assim, eram abandonadas as frentes de lavras, dando-se início a abertura de uma nova boca de mina ${ }^{20}$.

\subsubsection{Impacto Ambiental dos Rejeitos provenientes da Mineração de Carvão}

Os problemas ambientais causados pela mineração de carvão se agravam devido ao grau de impurezas do carvão brasileiro, que apresenta uma média de $25 \%$ de carvão aproveitável e $75 \%$ de rejeito piritoso, que é a parte não aproveitável, composta de matéria carbonosa misturada à pirita, argilas, arenitos e folhelhos ${ }^{21,22,23}$.

A maior parte do carvão bruto (ROM) é constituída de silitos, argilitos, arenitos, lâminas de carvão com nódulos de pirita, sendo que esses materiais piritosos e carbonosos têm pouco valor para fins de combustão direta, sendo rejeitados ao longo do processo de beneficiamento e chegam a representar $63 \%$ do carvão bruto. Os $37 \%$ restantes compõem o carvão energético e os finos metalúrgicos e energéticos ${ }^{24}$.

Os rejeitos oriundos do beneficiamento de carvão são classificados de acordo com o teor de enxofre contido, em rejeitos piritosos e rejeitos carbonosos. O rejeito piritoso, também conhecido como rejeito primário, é composto pelos estéreis mais pesados que compõem a camada de ROM, é o resíduo mais poluente, pois contém a maior quantidade de pirita, e com isto um teor de enxofre de aproximadamente $10 \%$, e uma concentração de carvão em torno de $8 \%$. Os rejeitos carbonosos são compostos basicamente pelos mesmos estéreis que constituem os piritosos, porém 
possuem quantidades menores de pirita, e dessa maneira possuem uma quantidade de enxofre inferior (3\%) predominando os siltitos e argilitos carbonosos ${ }^{24,25}$.

Quando a mina de carvão é a céu aberto, o rejeito, normalmente, é devolvido à cava durante a operação de recuperação do terreno, mas quando a mina é subterrânea a prática observada tem sido o depósito em pilhas na superfície. Sendo assim, no Estado do Rio Grande do Sul, onde a maior parte da mineração ocorre a céu aberto, observa-se que os problemas ambientais são menores quando comparados a Santa Catarina, onde a exploração predominantemente é subterrânea, agravando a situação ${ }^{10}$. $\mathrm{Na}$ Tabela 4 são apresentadas algumas características dos depósitos de rejeito de carvão da região Sul do Brasil ${ }^{26}$.

Tabela 4 - Características de depósitos de rejeito de carvão da região Sul do Brasil ${ }^{26}$.

\begin{tabular}{|c|c|c|}
\hline Depósito / Localização & Massa (t) & Situação \\
\hline $\begin{array}{l}\text { Módulo de Rejeitos da } \\
\text { UM-II CCSA } \\
\text { Forquilhinha, SC }\end{array}$ & 13.000 .000 & $\begin{array}{l}\text { Em operação } \\
\text { Gera uma DAM com alta concentração de metais } \\
\text { Tratamento por processo ativo }\end{array}$ \\
\hline $\begin{array}{l}\text { Depósito de Rejeitos da } \\
\text { Nova Próspera Mineração } \\
\text { Criciúma, SC }\end{array}$ & 115.000 & $\begin{array}{l}\text { Desativado } \\
\text { Parte do potencial de geração de DAM está } \\
\text { esgotado - abandonado há mais de } 13 \text { anos } \\
\text { Não há tratamento para a DAM }\end{array}$ \\
\hline $\begin{array}{l}\text { Depósito de Rejeitos do } \\
\text { Capão da Roça, Copelmi } \\
\text { Mineração } \\
\text { Charqueadas, RS }\end{array}$ & 1.800 .000 & $\begin{array}{l}\text { Em recuperação } \\
\text { Gera uma DAM menos concentrada } \\
\text { Tratamento por processo ativo }\end{array}$ \\
\hline
\end{tabular}

Estima-se que haja na região carbonífera de Santa Catarina um passivo ambiental de cerca de 200 milhões de toneladas de rejeito de carvão. Além do impacto físico deste resíduo sólido, esse material é responsável pela geração de centenas de milhares de $\mathrm{m}^{3}$ diários de águas ácidas ${ }^{26}$ que já impactaram aproximadamente $2 / 3$ da malha hidrográfica da região ${ }^{27}$. Os rios da região apresentam valores de $\mathrm{pH}$ abaixo de 3, ou seja de caráter ácido, e sulfatos de ferro. Além disso, há locais assoreados pela deposição de finos e ultrafinos do carvão, comprovada pela turbidez dos rios e concentrações de sólidos sedimentáveis ${ }^{11,28}$.

Na Figura 3 e na Figura 4 são apresentadas imagens de um depósito de rejeito de carvão e do Rio Sangão, que recebe essa água ácida proveniente das pilhas de rejeito, respectivamente. 


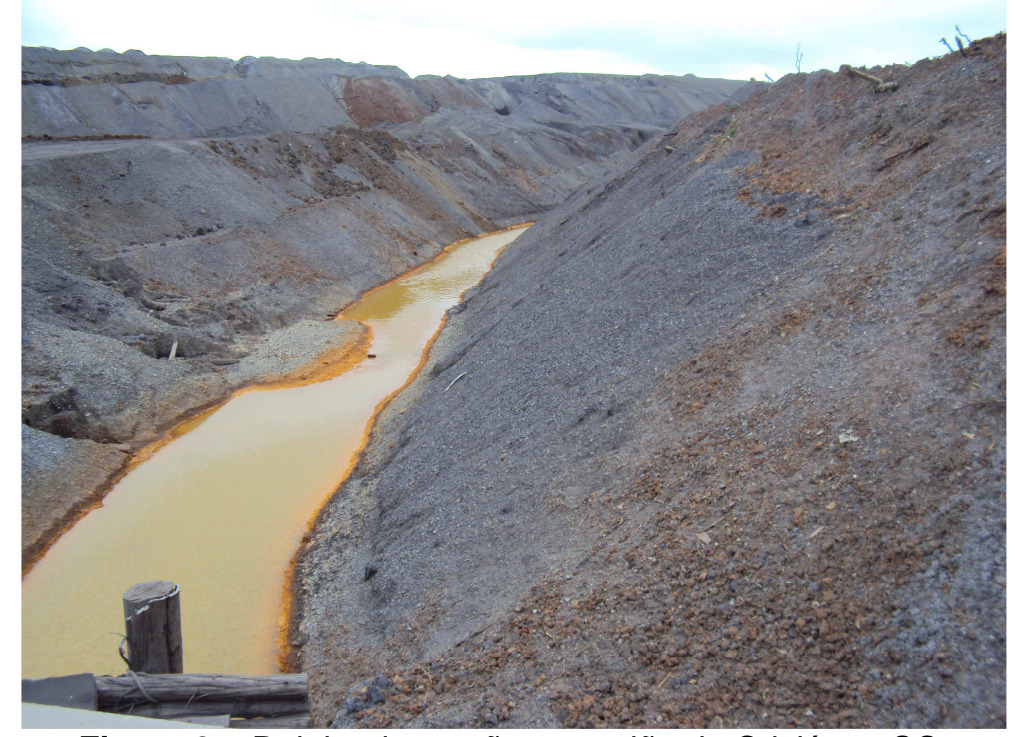

Figura 3 - Rejeito de carvão na região de Criciúma, SC.

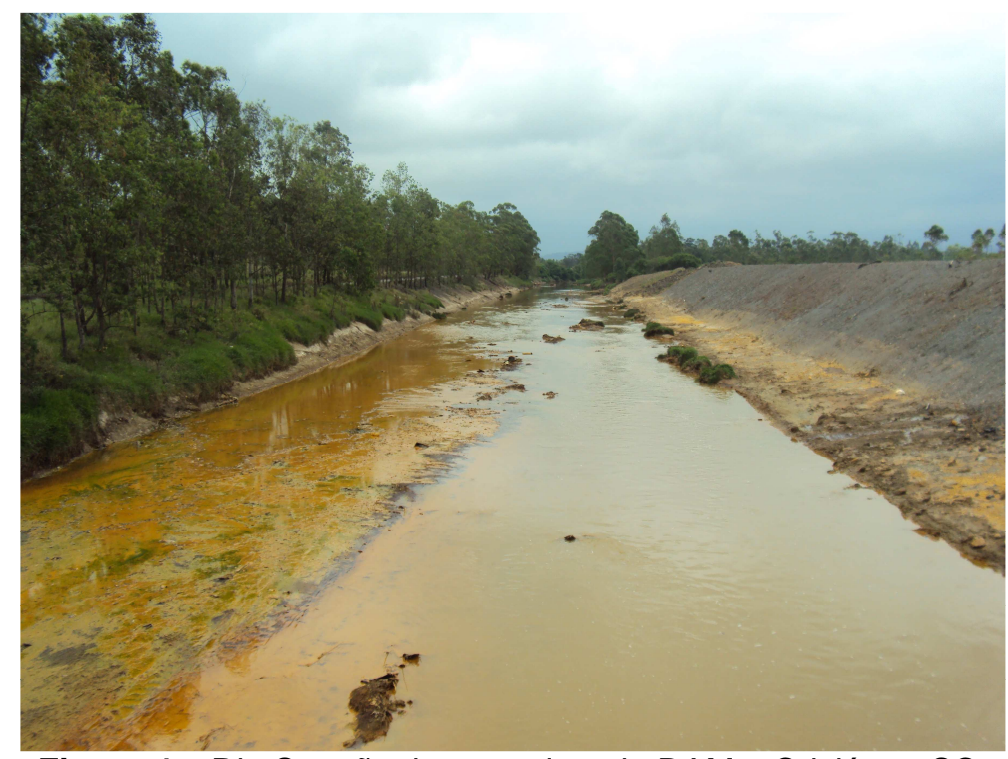

Figura 4 - Rio Sangão, impactado pela DAM - Criciúma, SC.

Os estéreis e rejeitos da mineração de carvão, ricos no mineral sulfeto de ferro $\left(\mathrm{FeS}_{2}\right)$ oxidam-se em presença do ar, da água e da ação de bactérias Thiobacillus ferrooxidans, formando ácido sulfúrico $\left(\mathrm{H}_{2} \mathrm{SO}_{4}\right)$ desencadeando o processo de acidificação de drenagens e a dissolução de metais, que pode ocorrer em minas abandonadas ou em operação, originando a $\mathrm{DAM}^{29}$.

Apesar da importância do carvão mineral para o desenvolvimento, deve-se considerar que sua exploração sem planejamento ambiental, ou seja, sem plano de gerenciamento para disposição de resíduos, pode trazer consequências para o meio ambiente, tais como a poluição hídrica. 


\subsection{DRENAGEM ÁCIDA DE MINAS}

Um dos principais impactos causados pela atividade de mineração de carvão é a poluição hídrica causada pela DAM, formada devido a oxidação de minerais sulfetados, principalmente pirita $\left(\mathrm{FeS}_{2}\right)$, que caracteriza-se por uma solução de baixo $\mathrm{pH}$ (aproximadamente 2,0), e metais dissolvidos ( $\mathrm{Fe}, \mathrm{Al}, \mathrm{Mn}$ entre outros) $)^{1,2}$.

Para que ocorra a formação da DAM são necessárias três condições ${ }^{30}$ :

- o resíduo deve conter quantidade de sulfetos superior a dos álcalis presentes no meio;

- a permeabilidade do resíduo deve ser tal que o oxigênio e a água sejam capazes de infiltrar;

- o resíduo deve estar em ambiente úmido ou exposto às águas de modo que a água da chuva seja capaz de percolá-lo ou as águas circundantes de transportá-lo ao meio ambiente.

A oxidação da pirita em presença de água resulta na formação de ácido sulfúrico, o qual promove a lixiviação de ferro na forma de $\mathrm{Fe}^{2+}$ e $\mathrm{Fe}^{3+}$, sulfatos e outros metais ${ }^{2,31}$. Este efluente pode provocar uma série de efeitos toxicológicos nos ecossistemas aquáticos, tais como mortalidade, crescimento desordenado, diminuição nas taxas de reprodução, deformações e lesões ${ }^{2}$. As reações envolvidas na formação da DAM ocorrem por processos químicos e biológicos, conforme as reações a seguir ${ }^{30,32,33,34}$ :

$$
\begin{aligned}
& \mathrm{FeS}_{2}+7 / 2 \mathrm{O}_{2}+\mathrm{H}_{2} \mathrm{O} \rightarrow \mathrm{Fe}^{2+}+2 \mathrm{SO}_{4}{ }^{2-}+2 \mathrm{H}^{+} \\
& \mathrm{Fe}^{2+}+1 / 4 \mathrm{O}_{2}+\mathrm{H}^{+} \rightarrow \mathrm{Fe}^{3+}+1 / 2 \mathrm{H}_{2} \mathrm{O} \\
& \mathrm{Fe}^{3+}+3 \mathrm{H}_{2} \mathrm{O} \rightarrow \mathrm{Fe}(\mathrm{OH})_{3}+3 \mathrm{H}^{+} \\
& \mathrm{FeS}_{2}+14 \mathrm{Fe}^{3+}+8 \mathrm{H}_{2} \mathrm{O} \rightarrow 15 \mathrm{Fe}^{2+}+2 \mathrm{SO}_{4}{ }^{2-}+16 \mathrm{H}^{+}
\end{aligned}
$$

A Reação 1 apresenta a oxidação da pirita com liberação de $\mathrm{Fe}^{2+}$ e dois $\mathrm{H}^{+}$. $\mathrm{Na}$ Reação $2 \circ \mathrm{Fe}^{2+}$ é oxidado a $\mathrm{Fe}^{3+}$ que se hidrolisa para formar hidróxido férrico (um composto insolúvel em pH superior a 3,5) e no processo, como é mostrado na Reação 3, três novos $\mathrm{H}^{+}$são liberados. Assim, para cada mol de pirita $\left(\mathrm{FeS}_{2}\right)$ cinco 
$\mathrm{H}^{+}$são liberados. No entanto, como um $\mathrm{H}^{+}$é consumido para a oxidação do $\mathrm{Fe}^{2+}$ para $\mathrm{Fe}^{3+}$, apenas quatro $\mathrm{H}^{+}$são realmente produzidos ${ }^{30}$.

Após iniciada a oxidação da pirita, o $\mathrm{Fe}^{3+}$ pode ser reduzido pela própria pirita, como mostra a Reação 4. Portanto, a pirita continua se oxidando enquanto $\mathrm{Fe}^{3+}$ for produzido. Neste caso, tem-se que a conversão de $\mathrm{Fe}^{2+}$ a $\mathrm{Fe}^{3+}$ é a etapa limitante na reação de oxidação da pirita ${ }^{30}$.

No entanto, como a oxidação de $\mathrm{Fe}^{2+}$ a $\mathrm{Fe}^{3+}$ na faixa de $\mathrm{pH}$ igual a 3 é muito lenta (aproximadamente 100 dias), a oxidação da pirita nesta faixa de $\mathrm{pH}$ também se torna lenta, a menos que esta oxidação do ferro seja catalisada por mircroorganismos, que atuam nesta faixa de $\mathrm{pH}$. E é exatamente nesta faixa de $\mathrm{pH}$, entre 2,5 e 3,5, que as bactérias Thiobacillus ferrooxidans rapidamente oxidam $\mathrm{Fe}^{2+}$ a $\mathrm{Fe}^{3+}$. Também, bactérias oxidantes de enxofre, tais como a Thiobacillus thiooxidans e Thiobacillus ferrooxidans podem eliminar a necessidade de íon férrico na presença de oxigênio e alguns substratos orgânicos ${ }^{30}$.

As reações de 1 a 4 podem ser representadas pela Figura 5. Para $\mathrm{pH}$ abaixo de 4,5 a oxidação da pirita pelo íon férrico acontece mais rapidamente do que pelo oxigênio, e mais rapidamente do que $\mathrm{Fe}^{2+}$ dissolvido é oxidado a $\mathrm{Fe}^{3+}$ pelo oxigênio. Por esta razão, a Reação 2 é apresentada como a etapa limitante para a oxidação da pirita. No entanto, bactérias que oxidam ferro, especialmente a Thiobacillus ferrooxidans, podem acelerar a taxa de oxidação do $\mathrm{Fe}^{2+}$ a um fator de $10^{6}$, conforme ilustrado na Figura $5^{30,35}$.

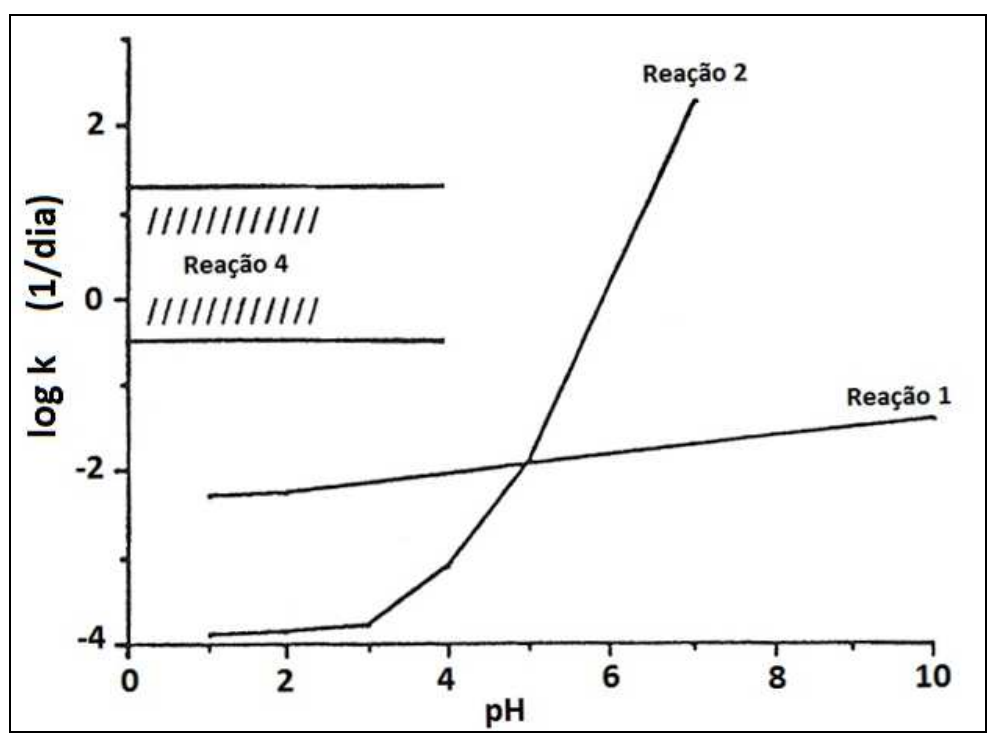

Figura 5 - Comparação das constantes de velocidade em função do $\mathrm{pH}$ para a oxidação da pirita por $\mathrm{Fe}^{3+}$ (Reação 4); oxidação do $\mathrm{Fe}^{2+}$ pelo $\mathrm{O}_{2}$ (Reação 2); e oxidação da pirita pelo $\mathrm{O}_{2}(\text { Reação } 1)^{30}$. 
As bactérias Thiobacillus ferrooxidans são organismos acidofílicos e quimilitotróficos e estão sempre presentes em ambientes geológicos contendo pirita. Assim, na presença da Thiobacillus ferrooxidans e $\mathrm{pH}$ ao redor de 2,0-3,0, a oxidação da pirita pode ser descrita pelas Reações 2 e $4^{30,36}$.

Em pH neutro a alcalino, a taxa de oxidação do $\mathrm{Fe}^{2+}$ sobe rapidamente, mas a concentração de $\mathrm{Fe}^{3+}$ também diminui devido à precipitação de hidróxido de ferro, conforme descrito na Reação 3. Como provavelmente a participação de bactérias na oxidação da pirita é baixa em pH neutro a alcalino, acredita-se que em tais ambientes o oxigênio é mais importante na oxidação da pirita do que o íons férricos ${ }^{30}$. Mas esta ideia, é contrariada por um estudo que aponta o $\mathrm{Fe}^{3+}$ como oxidante preferencial para a pirita em pH neutro, e a importância do oxigênio seria oxidar o $\mathrm{Fe}^{2+}$ e sustentar o ciclo de oxidação ${ }^{30}$.

Finalmente, a Reação 3 tem lugar em pH abaixo de 3, em que a reação é prontamente reversível dissolução/precipitação, servindo como uma fonte de $\mathrm{Fe}^{3+} \mathrm{e}$ sendo o passo mais importante para a liberação de ácido para o meio ambiente ${ }^{30}$.

Outros minerais sulfetados, além da pirita, também são encontrados nos rejeitos da mineração de carvão, tais como: marcasita $\left(\mathrm{FeS}_{2}\right)$, calcopirita $\left(\mathrm{CuFeS}_{2}\right)$, calcosita $\left(\mathrm{Cu}_{2} \mathrm{~S}\right)$, esfalerita $(\mathrm{ZnS})$, galena $(\mathrm{PbS})$, millerita $(\mathrm{NiS})$, pirrotita $\left(\mathrm{Fe}_{\mathrm{x}} \mathrm{S}_{\mathrm{x}}\right.$, onde $0<x>0,2)$, arsenopirita $\left(\mathrm{FeAsS}_{2}\right)$ e cinabre $(\mathrm{HgS})$. A diversidade de minerais que podem estar presentes influencia diretamente nas características da DAM. Na Tabela 5 são apresentadas características típicas de diferentes DAM $^{37}$.

Tabela 5 - Características típicas de DAM ${ }^{37}$.

\begin{tabular}{|c|c|c|c|}
\hline & $\begin{array}{l}\text { Espécie } \\
\text { química } \\
\text { associada }\end{array}$ & $\begin{array}{c}\text { Faixa de } \\
\text { concentração }\end{array}$ & Impacto Ambiental \\
\hline $\mathrm{pH}$ & $\mathrm{H}_{2} \mathrm{SO}_{4}$ & $2-4$ & - Mobilização de íons metálicos. \\
\hline Ferro & $\begin{array}{l}\mathrm{Fe}^{2+}, \mathrm{Fe}^{3+}, \mathrm{Fe}_{2} \mathrm{O}_{3} \\
\text { e hidróxidos }\end{array}$ & $\begin{array}{c}100-3.000 \\
\left(m g L^{-1}\right)\end{array}$ & $\begin{array}{l}\text { - Coloração e turbidez nas águas; } \\
\text { - Incremento do pH; } \\
\text { - Precipitação do } \mathrm{Fe}^{2+}\end{array}$ \\
\hline Outros Metais & $\begin{array}{c}\mathrm{Cu}, \mathrm{Mg}, \mathrm{Zn}, \mathrm{Cd} \\
\mathrm{Hg}, \mathrm{Pb}, \mathrm{As}\end{array}$ & $\begin{array}{l}1-200 \\
\left(m g L^{-1}\right)\end{array}$ & $\begin{array}{l}\text { - Redução da flora e fauna aquática; } \\
\text { - Bioacumulação; } \\
\text { - Redução da qualidade da água } \\
\text { potável de abastecimento }\end{array}$ \\
\hline Sólidos Totais & $\mathrm{Ca}, \mathrm{Mn}, \mathrm{Al}, \mathrm{SO}_{4}{ }^{2-}$ & $\begin{array}{l}100-30.000 \\
\left(\mathrm{mg}^{-1} \mathrm{~L}^{-1}\right)\end{array}$ & $\begin{array}{l}\text { - Redução da qualidade da água de } \\
\text { abastecimento }\end{array}$ \\
\hline
\end{tabular}

No Brasil, principalmente nos estados de Santa Catarina e Rio Grande do Sul, estes impactos ambientais têm sido observados. Na região de Criciúma, 
aproximadamente dois terços da malha hidrográfica está comprometida e os rios da região apresentam $\mathrm{pH}$ inferior a 3 , além de elevados teores de sulfatos de ferro. Observa-se também locais assoreados pela deposição de finos e ultrafinos do carvão, que provocam turbidez e aumentam a concentração de sólidos sedimentáveis ${ }^{27}$.

O abandono destes rejeitos pirotosos na região carbonífera já comprometeu áreas superiores a 5.000ha, devido à lixiviação das pilhas de rejeito que contribuem para a acidificação do solo e águas superficiais ${ }^{27}$.

Diante desta situação, estudos vêm sendo desenvolvidos em busca de soluções para este grave problema ambiental. Considerando que as reações de geração de DAM são auto-catalíticas e, portanto, de difícil controle, a maioria dos estudos se concentra em técnicas de prevenção, ou seja, que busquem evitar o contato dos minerais sulfetados com água e oxigênio.

\subsubsection{Tratamento da Drenagem Ácida de Minas}

A primeira etapa para o tratamento de efluentes, de forma geral, consiste na caracterização do efluente, ou seja, a verificação de seu estado físico e a determinação da sua composição química.

Considerando que a maioria dos metais se apresenta nos efluentes como cátions, a forma mais simples de tratamento é a transformação destes metais em hidróxidos, conforme apresenta a Reação $5^{38}$.

$$
\mathrm{Me}^{\mathrm{z+}}+\mathrm{zOH}^{-} \leftrightarrow \mathrm{Me}(\mathrm{OH})_{\mathrm{z}} \quad \text { Reação } 5
$$

Os metais formam compostos insolúveis quando submetidos a um ajuste de $\mathrm{pH}$ por meio da adição de substâncias alcalinas. Mas os metais apresentam diferentes faixas de $\mathrm{pH}$ para precipitação, o que pode dificultar a sedimentação total. Portanto, se mais um íon metálico coexistir no efluente o tratamento por precipitação na forma de hidróxidos torna-se mais difícil ${ }^{38}$. 
Atualmente, no Brasil, as indústrias de mineração têm optado por este processo convencional de tratamento ativo de efluentes que consiste na neutralização seguida da precipitação de metais na forma de hidróxidos ${ }^{39,40}$, conforme apresentado na Tabela 6.

Tabela 6 - Estações de tratamento de efluentes da DAM em operação no Brasil ${ }^{26}$.

\begin{tabular}{|c|c|c|}
\hline Empresa/Unidade & Método de Tratamento & $\begin{array}{c}\text { Vazão } \\
\text { Tratada } \\
\left(\mathrm{m}^{3} / \mathrm{h}\right)\end{array}$ \\
\hline Cambuí & $\begin{array}{l}\text { Neutralização/Precipitação e separação sólido-líquido } \\
\text { em bacia de sedimentação. }\end{array}$ & 50 \\
\hline $\begin{array}{l}\text { Carbonífera Criciúma } \\
\text { S/A - UM II - Verdinho }\end{array}$ & $\begin{array}{l}\text { Neutralização com soda ou cal baseado na interação } \\
\text { com finos em suspensão e aeração mecânica promovida } \\
\text { no processo de beneficiamento mineral seguido de } \\
\text { sedimentação em lagoas. }\end{array}$ & 1.200 \\
\hline Minageo Santa Augusta & $\begin{array}{l}\text { Neutralização/Precipitação e separação sólido-líquido } \\
\text { em bacia de sedimentação. }\end{array}$ & 20 \\
\hline Metropolitana Mel & $\begin{array}{l}\text { Neutralização/Precipitação e separação sólido-líquido } \\
\text { em bacia de sedimentação. }\end{array}$ & 150 \\
\hline $\begin{array}{l}\text { Metropolitana Caixa de } \\
\text { Embarque }\end{array}$ & $\begin{array}{l}\text { Neutralização/Precipitação seguido de separação sólido- } \\
\text { líquido por flotação por ar dissolvido. }\end{array}$ & 12 \\
\hline $\begin{array}{l}\text { Metropolitana } \\
\text { Esperança/Fontanella }\end{array}$ & $\begin{array}{l}\text { Neutralização/Precipitação seguido de separação sólido- } \\
\text { líquido por flotação por ar dissolvido. }\end{array}$ & 270 \\
\hline Metropolitana Ingusa & $\begin{array}{l}\text { Neutralização/Precipitação e separação sólido-líquido } \\
\text { em bacia de sedimentação. }\end{array}$ & 50 \\
\hline $\begin{array}{l}\text { Rio Deserto Barro } \\
\text { Branco }\end{array}$ & $\begin{array}{l}\text { Neutralização/Precipitação e separação sólido-líquido } \\
\text { em bacia de sedimentação. }\end{array}$ & 125 \\
\hline $\begin{array}{l}\text { Rio Deserto Novo } \\
\text { Horizonte }\end{array}$ & $\begin{array}{l}\text { Neutralização/Precipitação e separação sólido-líquido } \\
\text { em bacia de sedimentação. }\end{array}$ & 150 \\
\hline $\begin{array}{l}\text { Rio Deserto Cruz de } \\
\text { Malta }\end{array}$ & $\begin{array}{l}\text { Neutralização/Precipitação e separação sólido-líquido } \\
\text { em bacia de sedimentação. }\end{array}$ & 150 \\
\hline Cooperminas & $\begin{array}{l}\text { Neutralização/Precipitação separação sólido-líquido em } \\
\text { sedimentador lamelar. }\end{array}$ & 200 \\
\hline $\begin{array}{l}\text { Copelmi Capão da } \\
\text { Roça }\end{array}$ & $\begin{array}{l}\text { Neutralização/Precipitação e separação sólido-líquido } \\
\text { em bacia de sedimentação. }\end{array}$ & 43 \\
\hline
\end{tabular}

Entretanto, o tratamento passivo, de reações naturais, químicas e biológicas, que ocorrem em um reator químico-microbiológico controlado, também é aplicado para tratamento da DAM $^{41,42}$.

A baixa cinética de remoção dos íons contaminantes e o tempo de permanência do efluente nas lagoas (aproximadamente 10 dias) são os problemas enfrentados pelos sistemas passivos. Pois a eficiência da remoção é limitada pelo substrato presente nas lagoas, e desta forma os sistemas de neutralização, floculação e separação sólido-líquido tornam-se mais aplicáveis ${ }^{37}$.

Outros estudos de tratamento ativo também estão sendo realizados para 0 controle da DAM, buscando-se viabilidade técnica e econômica dos processos de 
flotação e sedimentação lamelar ${ }^{43,44,45}$. Estes sistemas ativos são vantajosos diante dos tratamentos passivos, pois apresentam elevada taxa de aplicação em unidades de tratamento do efluente e maior eficiência na remoção de íons ${ }^{46}$.

Além desses sistemas, supracitados, novas tecnologias para o tratamento de efluentes, de forma geral, vêm sendo estudadas em substituição aos sistemas de tratamento convencionais, tais como: $\operatorname{adsorção~}^{19}$, troca iônica ${ }^{47}$, processos de separação por membranas (osmose reversa ${ }^{48}$, ultrafiltração, nanofiltração e eletrodiálise $^{7}$ ).

\subsection{ELETRODIÁLISE}

A eletrodiálise (ED) surge como uma nova tecnologia para o tratamento de efluentes e tem se mostrado eficaz para a recuperação de água e concentração de eletrólitos ${ }^{7}$.

A ED já é considerada uma tecnologia limpa de tratamento de efluentes, sendo atrativa aos mais diversos segmentos uma vez que apresenta vantagens sobre os processos tradicionais, tais como: não exige mudanças de fases; funciona de forma contínua; não necessita da adição de reagentes e não gera resíduos poluentes ao ambiente ${ }^{49}$.

$\mathrm{Na}$ ED utilizam-se membranas carregadas ionicamente, e íon-seletivas, ou seja, que permitem somente a passagem de cátions ou ânions. As membranas catiônicas (MC) impedem a passagem de ânions, enquanto que as membranas aniônicas (MA) impedem a passagem de cátions.

A força propulsora na ED é um campo elétrico aplicado perpendicularmente às membranas, que força a separação dos íons, promovendo a migração destes para os eletrodos. Os cátions migram em direção ao cátodo e os ânions em direção ao ânodo. Desta forma, uma solução tratada por ED gera duas novas soluções, uma mais concentrada e outra mais diluída que a solução inicial ${ }^{7,50}$.

O mecanismo de operação da ED é demonstrado na Figura 6. 


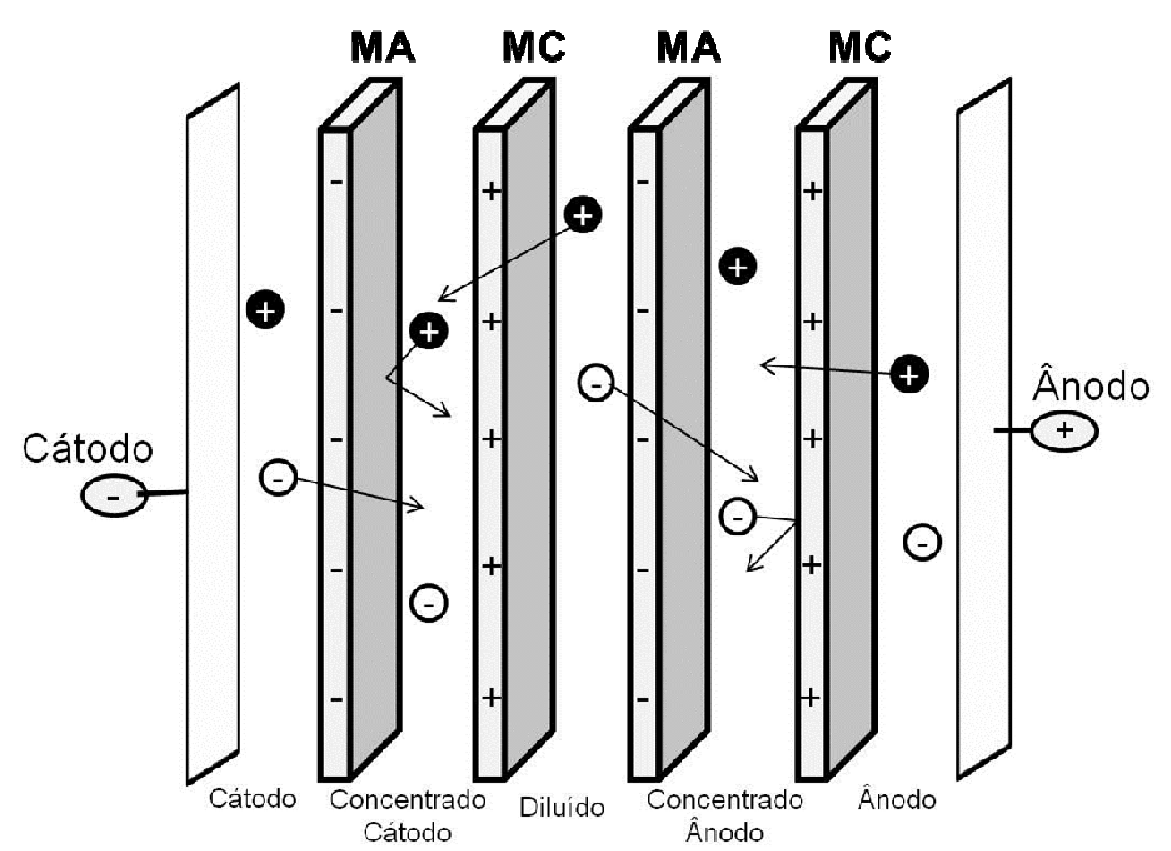

Figura 6 - Mecanismo de operação da ED com 5 compartimentos.

O processo de ED remove essencialmente íons com cargas elétricas positivas e negativas. Não são removidos materiais particulados e substâncias neutras ou iônicas de peso molecular maior que os canais iônicos da membrana ${ }^{51}$.

As seguintes condições garantem melhores resultados para a aplicação da ED nos processos de tratamento ${ }^{52,53}$ :

- ser aplicada em soluções aquosas, com até pequenas quantidades de solventes orgânicos;

- evitar a precipitação e o acúmulo de hidróxidos ou sais insolúveis;

- pH das soluções próximo ao neutro, garantindo maior vida útil das membranas;

- quantidade de sólidos suspensos menor que 1 ppm e tamanho das partículas inferior a $5 \mu \mathrm{m}$;

- evitar o uso de oxidantes fortes, também para aumentar a vida útil das membranas;

- evitar o uso de eletrólitos orgânicos de alto peso molecular, pois estes causam fouling nas membranas, fênomeno apresentado posteriormente no item 3.3.2.5;

- trabalhar com temperaturas abaixo de $60{ }^{\circ} \mathrm{C}$. 


\subsubsection{Membranas}

Existem basicamente dois tipos de membranas utilizadas no processo de ED, membranas catiônicas e aniônicas. As membranas consistem em polímeros com ligações cruzadas com tamanhos de poros de nível molecular, ou seja, são essencialmente impermeáveis à água mesmo sob pressão, mas permitem o fluxo de íons.

As propriedades de cada membrana dependem da matriz polimérica empregada na sua fabricação, bem como da concentração das cargas fixas. A estabilidade mecânica, química e térmica da membrana serão determinadas pela matriz polimérica. $O$ tipo e concentração de cargas fixadas determinam a seletividade e resistência elétrica ${ }^{51}$.

Geralmente, a matriz polimérica das membranas é reforçada por um tecido de fibra sintética, teflon ou nylon, na forma de tela ou rede, conferindo maior estabilidade dimensional e resistência mecânica à membrana ${ }^{51}$.

As membranas devem ter seletividade e permeabilidade iônica, ou seja, baixa resistência elétrica. Devem ser estáveis e resistentes ao ambiente e a elevadas temperaturas (até $40^{\circ} \mathrm{C}$ ). A estabilidade química deve ser mantida em uma larga faixa de $\mathrm{pH}$ (1 a 10) e também na presença de oxidantes. Também devem resistir à pressão osmótica quando trabalharem entre 200 e 30.000 ppm de solução salina e apresentar vida útil longa. Em geral, uma previsão real para a vida útil das membranas é de 10 anos, podendo durar mais, se houver projeto, operação e manutenção ${ }^{54,51}$.

Os grupos que geralmente estão presentes nas membranas catiônicas são os seguintes: $-\mathrm{SO}_{3}{ }^{-},-\mathrm{COO}^{-},-\mathrm{PO}_{3}{ }^{2-},-\mathrm{PO}_{3} \mathrm{H}^{-},-\mathrm{C}_{6} \mathrm{H}_{4} \mathrm{O}^{-}$, sendo os mais comuns o $-\mathrm{SO}_{3}{ }^{-}$e o $-\mathrm{COO}^{-54,55,56}$.

Nas membranas aniônicas os grupos geralmente fixados na estrutura são: $-\mathrm{NH}_{3}{ }^{+},-\mathrm{NRH}_{2}{ }^{+},-\mathrm{NR}_{2} \mathrm{H}^{+},-\mathrm{NR}_{3}{ }^{+},-\mathrm{PR}_{3}{ }^{+},-\mathrm{SR}_{2}{ }^{+}$, sendo que os mais utilizados são 0 $-\mathrm{R}_{3} \mathrm{~N}^{+}$e $\mathrm{O}-\mathrm{R}_{2} \mathrm{NH}^{+(54,55,56)}$.

Nas membranas de troca iônica, os grupos negativos estão em equilíbrio elétrico com os cátions em movimento nos interstícios do polímero. Por outro lado, ânions em movimento, chamados de contra-íons, são mais ou menos excluídos da 
matriz polimérica, devido à sua carga idêntica dos grupos fixos. Esta exclusão dos contra-íons é chamada de "Exclusão de Donnan", e por isso a membrana catiônica (com cargas negativas fixas à matriz polimérica) permite somente a passagem de cátions e o mesmo acontece com a membrana aniônica, permitindo somente a transferência de ânions ${ }^{55,57}$.

Na Figura 7 apresenta-se a estrutura esquemática de membranas íon-seletivas catiônica e aniônica, respectivamente, nas quais os grupos iônicos fixos estão em equilíbrio elétrico com os íons livres (contra-íons) nos interstícios do polímero ${ }^{58,59}$.

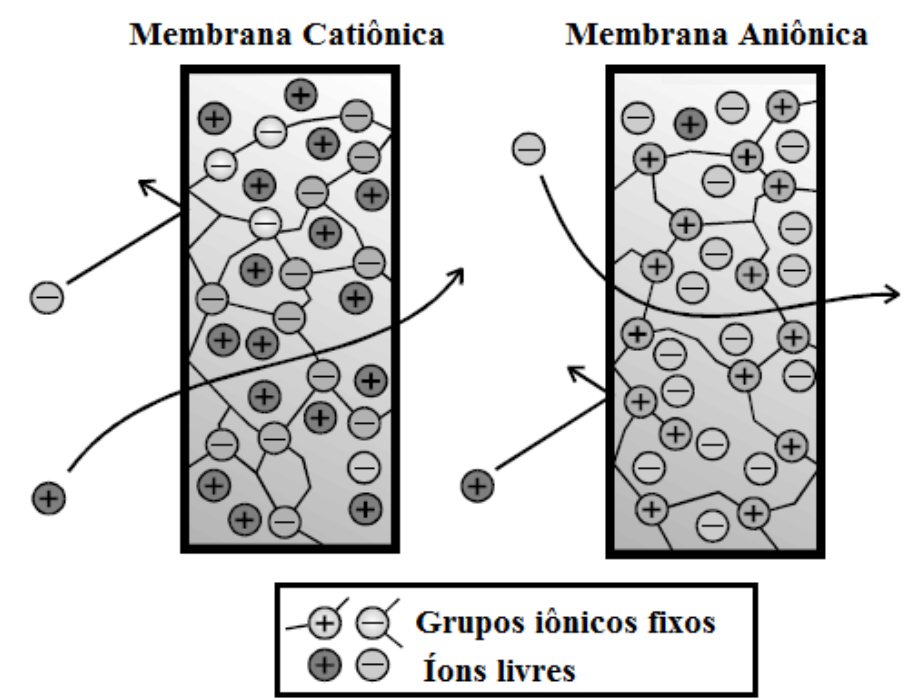

Figura 7 - Estrutura esquemática de membranas íon-seletiva catiônica e aniônica ${ }^{59}$.

Diante do exposto, tem-se que a viabilidade técnica da aplicação do processo de ED é dependente do comportamento eletroquímico das membranas íon-seletivas, ou seja, é necessário se conhecer sua estabilidade, condutividade e seletividade.

Vale ressaltar que também são parâmetros de avaliação e controle de um sistema de ED a condutividade elétrica, a concentração e o pH da solução a ser empregada no processo, bem como a corrente elétrica e o potencial a ser aplicado. Além de outros parâmetros, tais como: polarização por concentração e densidade de corrente limite. 


\subsubsection{Parâmetros de Avaliação da Eletrodiálise}

A avaliação da eficiência do processo de ED se dá pela análise dos seguintes parâmetros: resistência elétrica, número de transporte e extração percentual ${ }^{60}$. Ainda devem ser observados outros parâmetros técnicos, próprios da ED, que são responsáveis pela limitação da técnica, tais como: polarização por concentração e corrente limite, fouling e scaling.

\subsubsection{Resistência Elétrica}

Determinada a partir da resistência aparente, que considera a resistência das membranas e das soluções, conforme Equação $1^{61}$.

$$
R_{a}=\frac{U \cdot A}{n \cdot i} \quad \text { Equação } 1
$$

Onde,

$R_{a}=$ resistência aparente do sistema (ohm);

$U=$ diferença de potencial entre os dois eletrodos $(\mathrm{V})$;

$A=$ área das membranas $\left(\mathrm{cm}^{2}\right)$;

$n=$ número de pares de membranas;

$i=$ densidade de corrente $\left(\mathrm{mA} \cdot \mathrm{cm}^{-2}\right)$.

A resistência da membrana varia com a natureza do polímero e o processo utilizado para sua fabricação e depende também da espessura da membrana, ou seja, quanto mais hidrofílica for à membrana menor a resistência ${ }^{61}$.

E sua resistência varia se a solução é ou não agitada, e é inversamente proporcional à concentração total de íons. 


\subsubsection{Número de Transporte}

Determina a transferência iônica de diferentes íons através das membranas, de acordo com a Equação $2^{(3,62)}$.

$$
t_{i}=\frac{z_{i} \cdot J_{i} \cdot F \cdot 1000}{j} \quad \text { Equação } 2
$$

Onde,

$t_{i}=$ número de transporte da espécie i;

$z_{i}=$ valência da espécie $\mathrm{i}$;

$F=$ constante de Faraday $(\mathrm{C} / \mathrm{mol})$;

$j=$ densidade de corrente $\left(\mathrm{mA} / \mathrm{cm}^{2}\right)$

$J_{i}=$ fluxo da espécie $\mathrm{i}\left(\mathrm{mol} / \mathrm{cm}^{2} \mathrm{~s}\right)$, sendo que o fluxo da espécie i pode ser calculado pela Equação 3.

$$
J_{i}=\frac{V\left(C_{i}^{s}-C_{i}^{0}\right)}{A \cdot t^{s}}
$$

\section{Equação 3}

Onde,

$V=$ volume do compartimento;

$C_{i}^{s}=$ concentração da espécie i no tempo $\mathrm{T}^{\mathrm{s}}(\mathrm{mol} / \mathrm{L})$;

$C_{i}{ }^{0}=$ concentração inicial da espécie i $(\mathrm{mol} / \mathrm{L})$;

$A=$ área da membrana $\left(\mathrm{cm}^{2}\right)$;

$t^{s}=$ tempo da amostragem (s).

Sendo assim, a taxa de transferência de espécies iônicas pelas membranas dependerá da concentração iônica da solução e da mobilidade dos íons através da membrana, calculada pela Equação 2, e será influenciada pelos seguintes fatores ${ }^{63,64}$ : carga da espécie na forma ionizada; tamanho da molécula; condutividade iônica; concentração molar da espécie; características da membrana; $\mathrm{pH}$ do meio e temperatura. 


\subsubsection{Extração Percentual}

Determina percentualmente quanto de massa ou a concentração do íon, em análise, que foi transferido do compartimento diluído para o concentrado, de acordo com a Equação $4^{(65)}$.

$$
E_{P}(\%)=\frac{C i-C f}{C i} \times 100 \quad \text { Equação } 4
$$

Onde,

$E_{P}=$ extração percentual (\%);

$C i=$ concentração inicial do íon no compartimento diluído;

$C f=$ concentração final do íon no compartimento diluído;

\subsubsection{Polarização por Concentração e Corrente Limite}

A polarização representa o fenômeno que ocorre quando aplica-se uma corrente elétrica superior à corrente que a superfície da membrana pode transmitir ${ }^{66}$. Como na ED normalmente as células apresentam fluxo turbulento de solução, a polarização ocorre na camada limite formada na superfície da membrana e não no seio da solução. Neste caso, quando a corrente aplicada exceder o limite da capacidade da membrana de transmissão, a concentração de íons na camada limite cairá a zero. E da mesma forma, no outro lado da membrana ocorrerá um acúmulo de íons, já que estes chegam a uma velocidade superior do que conseguem se difundir para a solução ${ }^{60,67}$.

Se na ED a densidade de corrente limite ( $\mathrm{l}_{\text {lim}}$ ) for ultrapassada, haverá diminuição da eficiência do processo, pois ocorrerá aumento na resistência elétrica da solução e dissociação da água, que provocarão o aumento no consumo de energia ${ }^{66}$. 
É possível obter-se o valor dessa densidade de corrente limite por meio das curvas de polarização, também chamadas curvas corrente-potencial (CVC). Na Figura 8 observa-se uma CVC típica, na qual são evidenciadas três regiões bem definidas.

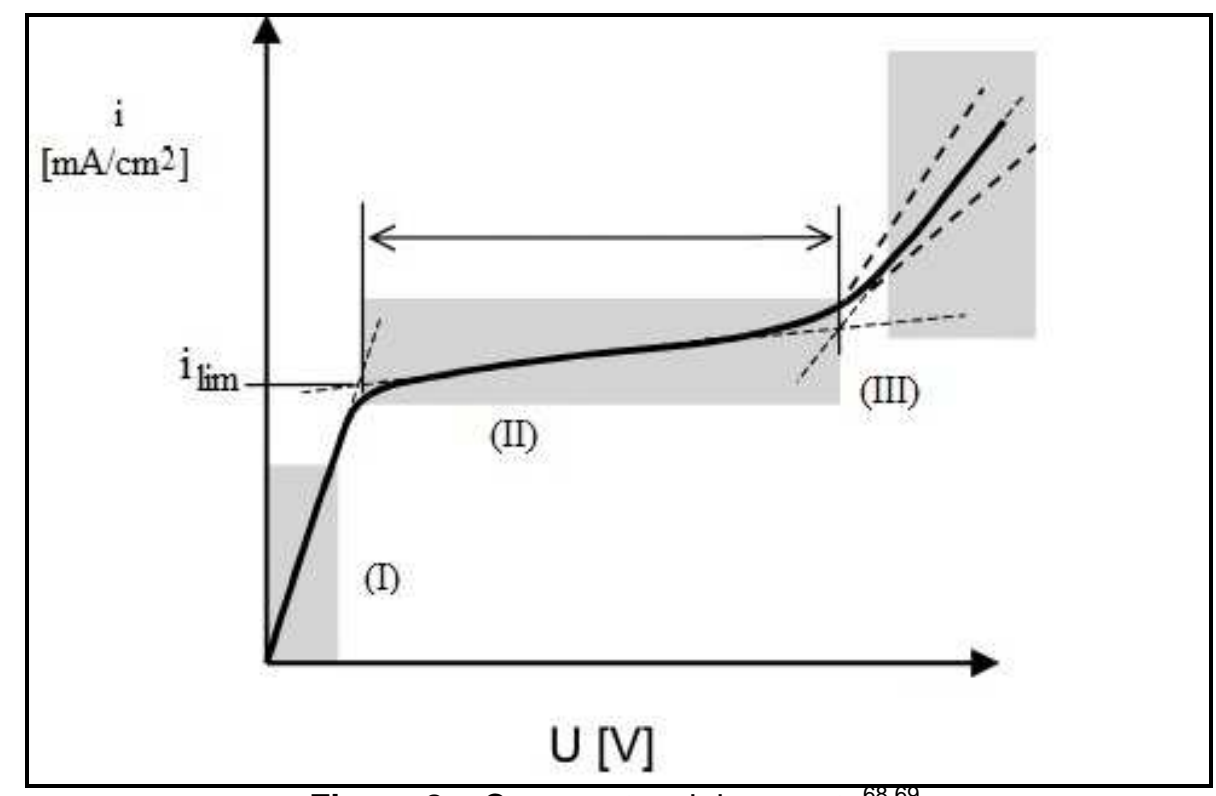

Figura 8 - Curva potencial-corrente ${ }^{68,69}$.

$\mathrm{Na}$ Figura 8, visualiza-se uma primeira região (I), linear, que pode ser analisada como um estado de quase equilíbiro na interface membrana/solução, em que a resistência do sistema pode ser atribuída ao transporte iônico no interior da membrana. Uma segunda região (II), na qual a densidade de corrente varia ligeiramente com o potencial, formando uma região de platô, correspondente à corrente limite, onde com o aumento da densidade de corrente a polarização por concentração se torna mais evidente, ou seja, a concentração na camada limite do diluído diminui e consequentemente a resistência aumenta. E por fim, a terceira região (III), na qual ultrapassou-se o limite da corrente e ocorre o aumento da intensidade da corrente juntamente com o potencial aplicado, possivelmente pela condução da corrente pelas espécies $\mathrm{H}^{+}$e $\mathrm{OH}^{-}$, da dissociação da água ${ }^{60,66,70}$.

\subsubsection{Fouling}

O fouling é uma das maiores limitações da operação da ED, pois é caracterizado pelo depósito de qualquer espécie sobre a superfície da membrana, 
provocando a diminuição da capacidade de difusão dos íons através da membrana, com consequente aumento da resistência. Geralmente estas espécies que se depositam são macromoléculas orgânicas ou bactérias (biofouling) ${ }^{71,72}$.

Este problema ocorre mais frenquentemente em membranas aniônicas, uma vez que os compostos orgânicos são carregados negativamente. Em ocasiões esporádicas o fouling é irreversível e mesmo após a limpeza da membrana o desempenho da membrana não é restaurado ${ }^{71,72}$.

Influenciam no fouling na membrana os seguintes parâmetros físicos do soluto: a carga, a hidrofobicidade, o tamanho molecular e a solubilidade. A precipitação na membrana é afetada pelas interações eletrostáticas e hidrofóbicas entre o soluto e a superfície da membrana ${ }^{71}$.

A fim de se evitar o fouling pode-se empregar algumas técnicas, tais como: pré-filtração, eliminação dos microorganismos por esterilização ou por dosagem de cloro, acidificação do meio, evitando-se a formação de precipitados, operações com eletrodo reverso e o uso de membranas específicas anti-fouling ${ }^{71,72}$.

\subsubsection{Scaling}

O scaling se caracteriza pela precipitação de eletrólitos sólidos sobre a superfície da membrana, causados pelo aumento no produto de solubilidade. Pode ser resultado da ED realizada acima da corrente limite, na qual ocorre a dissociação da água e consequentemente a mudança no $\mathrm{pH}$ do meio, que influenciará na solubilidade, uma vez que esta varia em função do $\mathrm{pH}^{71}$.

A eficiência da ED é afetada pelo scaling, pois os materiais que precipitam na superfície da membrana necessitam ser removidos com soluções de limpeza e esta limpeza é dependente da concentração da solução de alimentação. O scaling ocorre mais frenquentemente na presença de íons de cálcio e magnésio, no caso de águas naturais $^{71}$. Quando a ED é aplicada para o tratamento de efluentes industrias o scaling pode ocorrer pela precipitação de metais. 


\subsubsection{Cronopotenciometria}

Auxiliando na obtenção de alguns dos parâmetros de controle da ED utiliza-se a técnica de cronopotenciometria, que consiste em um método de caracterização eletroquímico, que permite a identificação dos diferentes fenômenos de transferência de massa que ocorrem na interface de uma membrana ${ }^{73}$.

É a partir das curvas cronopotenciométricas que se obtêm informações sobre o transporte de íons através das membranas e também a limitação desta transferência que pode ocorrer em um dos lados da membrana, devido à polarização por concentração. Além disso, outros fenômenos, tais como a precipitação das espécies ou a ocorrência de eletroconvecção também podem ser elucidadas a partir da forma dos cronopotenciogramas ${ }^{68,74,75,76}$.

\subsubsection{Curvas Cronopotenciométricas}

A obtenção das curvas cronopotenciométricas se dá a partir do registro do potencial da membrana em função do tempo de aplicação de uma densidade de corrente constante entre dois eletrodos posicionados nos extremos de uma célula de ED, composta por uma membrana de troca iônica que separa dois compartimentos que contenham a mesma solução.

A forma de uma curva cronopotenciométrica é dependente da densidade de corrente (i) aplicada, podendo existir três respostas diferentes, conforme apresentado na Figura 9, a saber:

> para densidades de corrente inferiores à densidade de corrente limite $\left(\mathrm{i}<\mathrm{i}_{\text {lim }}\right)$;

para densidades de corrente aproximadamente iguais à densidade de corrente limite $\left(\mathrm{i} \sim \mathrm{i}_{\text {lim }}\right)$;

$>$ para densidades de corrente superiores à densidade de corrente limite ( $>\mathrm{i}_{\text {lim }}$ ). 


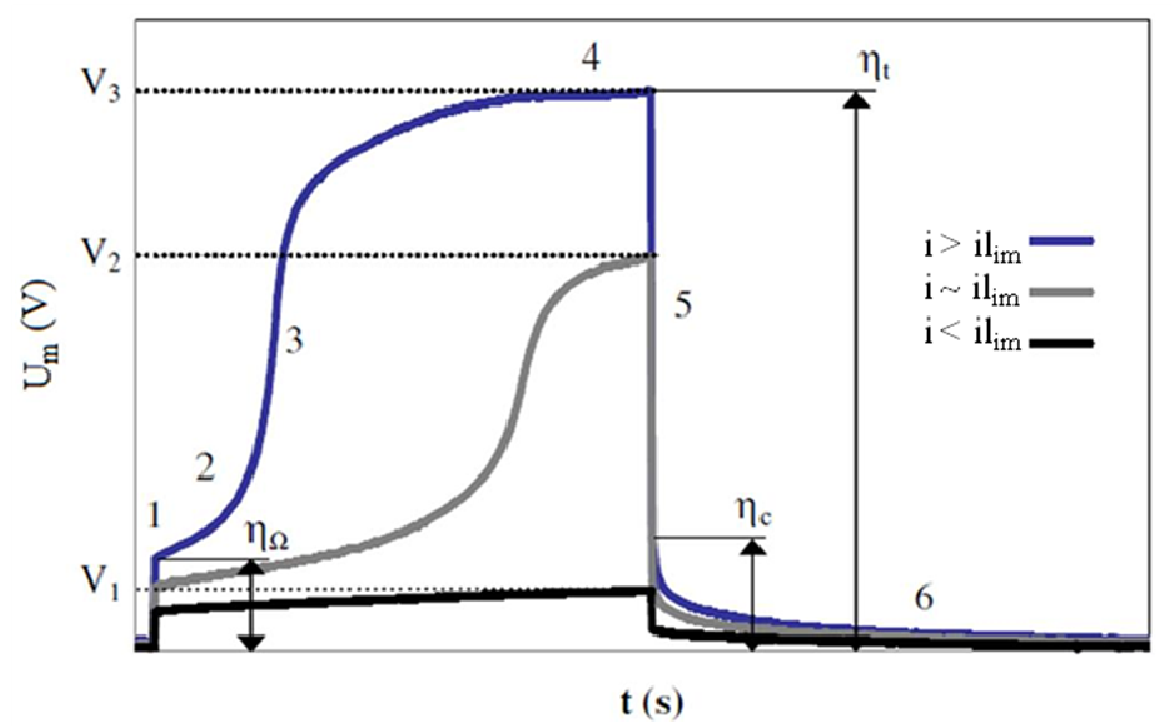

Figura 9 - Curva cronopotenciométricas característica para diferentes densidades de corrente. ${ }^{77}$

Para aplicações de densidades de corrente inferiores à densidade de corrente limite $\left(\mathrm{i}<\mathrm{i}_{\text {lim }}\right.$ ) as curvas cronopotenciométricas obtidas são semelhantes ao pulso de corrente da diferença de potencial entre dois eletrodos dispostos próximos a superfície da membrana.

Quando são aplicadas densidades de corrente aproximadamente iguais à densidade de corrente limite ( $\left.\mathrm{i} \sim \mathrm{i}_{\text {lim }}\right)$ o tempo de transição do potencial $\left(\cup_{\mathrm{m}}\right)$, ou seja, o ponto de inflexão do $U_{m}$ é mais longo sofrendo um alto incremento em função do esgotamento dos íons no compartimento diluído.

E para densidades de corrente superiores à densidade de corrente limite ( $\mathrm{i}>\mathrm{i}_{\mathrm{lim}}$ ) a resposta do cronopotenciograma em diferença de potencial aumenta em valor e em tempo necessário para que o esgotamento dos íons na proximidade da membrana se reduza.

As regiões apresentadas no cronopotenciograma da Figura 9 são descritas a seguir ${ }^{78,79,80}$ :

Região 1: No instante em que se aplica o pulso de corrente observa-se uma diferença de potencial imediata devido à resistência ôhmica oferecida pelo conjunto solução/membrana. O valor deste sobrepotencial é conhecido por sobrepotencial ôhmico $\left(\eta_{\Omega}\right)$.

Região 2: Após atingir o sobrepotencial ôhmico é possível que o potencial entre os eletrodos sofra um ligeiro aumento em função da formação de pequenos 
gradientes de concentração. Nos casos em que a densidade de corrente aplicada é inferior a corrente limite geralmente esta região alcança o potencial total de membrana sem que apareça a Região 3.

Região 3: Se dá com o esgotamento dos íons na camada próxima à superfície da membrana no compartimento anódico para membranas catiônicas e vice-versa. Quando a concentração do eletrólito na superfície da membrana for igual a zero, se produzirá um rápido aumento do potencial $\left(U_{m}\right)$. $O$ instante em que ocorre esse rápido aumento é conhecido como tempo de transição $(\tau)$ e a diferença de potencial é determinada a partir do ponto de inflexão.

Região 4: Após ser atingido o ponto de inflexão na Região 3 se alcança o valor estacionário de diferença de potencial $\left(\eta_{t}\right)$. Nesta região aparecem novos mecanismos de transferência de matéria como eletroconvecção ou transporte de prótons e hidroxilas como consequência da dissociação da água. Este é o valor empregado posteriormente para a construção das curvas de corrente-potencial.

Região 5: Resultado da interrupção da corrente, apresenta a baixa de potencial imediata.

Região 6: Após a interrupção da corrente, em alguns casos, surge um sobrepotencial conhecido como potencial de concentração $\left(\eta_{c}\right)$, devido a diferença de concentração criada próximo à superfície da membrana como consequência da polarização por concentração.

\subsubsection{Aplicações da Eletrodiálise}

A ED é utilizada desde 1950 na dessalinização de águas superficiais e subterrâneas. Desde então, o processo vem evoluindo e na Figura 10 é apresentada a cronologia deste desenvolvimento ${ }^{64}$. 


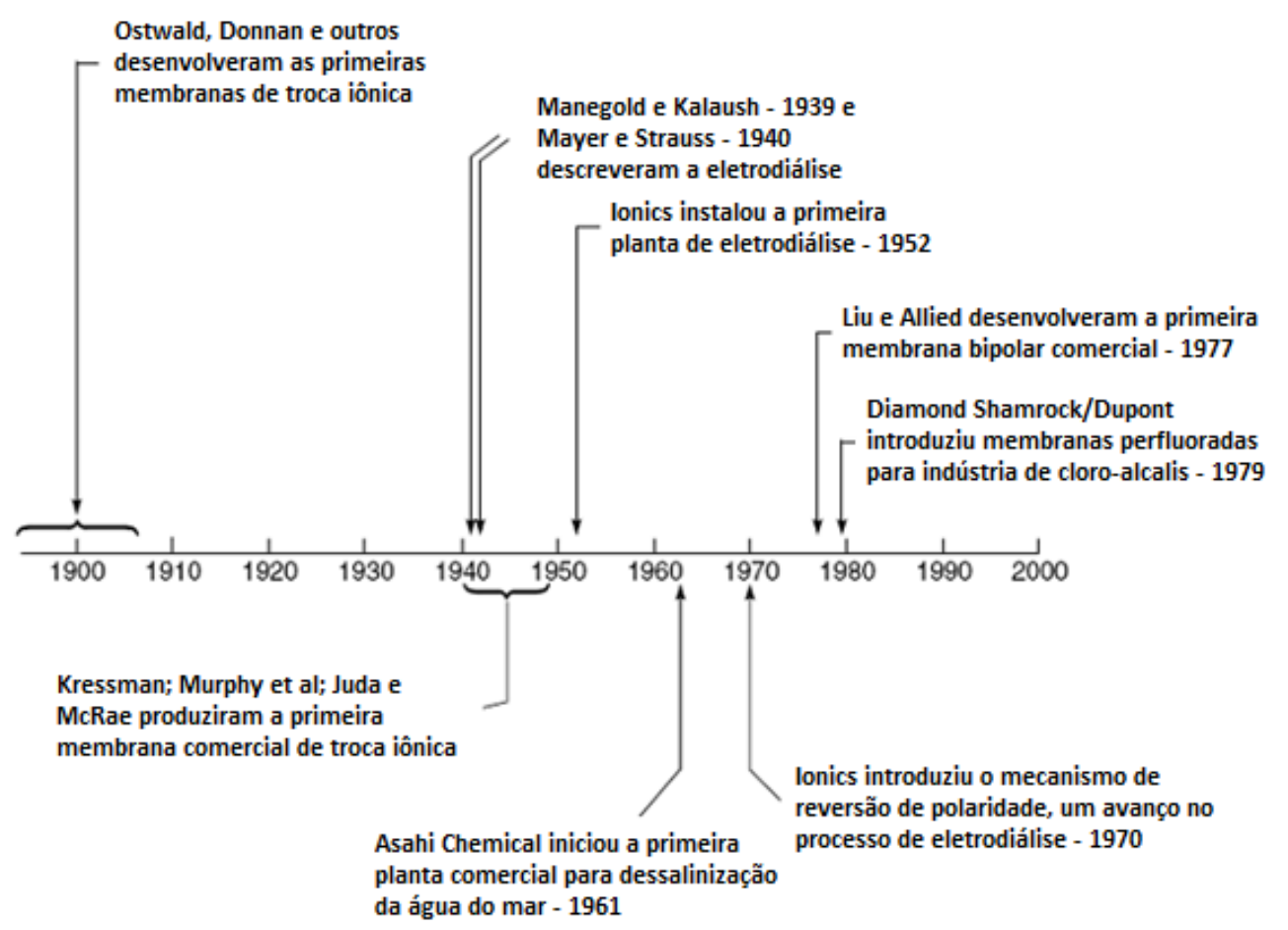

Figura 10 - Desenvolvimento dos processos com membranas de troca iônica ${ }^{64}$.

O processo de desenvolvimento da ED iniciou-se em 1890 quando Ostwald postulou o "potencial de membrana" ilustrando as propriedades de membranas semipermeáveis permitirem a passagem de cátions e ânions. Em 1911, Donnan confirmou que o potencial de membrana era decorrente da diferença de concentração existente entre a solução e a membrana. Ainda demonstrou matematicamente a concentração de equilíbrio, chamado de "potencial de exclusão de Donnan"7.

Dando continuidade aos estudos, em 1940, Meyer e Strauss descreveram a ED desenvolvendo o primeiro sistema utilizando membranas catiônicas e aniônicas de forma alternada ${ }^{7}$.

Nos anos seguintes, o processo foi se desenvolvendo e ganhando mercado, em processos industriais e no tratamento de efluentes.

Atualmente, o processo de ED tem sido aplicado em muitos ramos tais como: dessalinização de água, recuperação de ácidos, recuperação de metais, separação de proteínas e misturas de aminoácidos, estabilização do vinho, tratamento de efluentes industriais e municipais, dentre outras aplicações. Na Europa a ED é 
amplamente empregada nos processos de dessalinização de água para abastecimento, superando a osmose e a destilação ${ }^{51,64}$.

\subsubsection{Eletrodiálise no Tratamento de Efluentes}

O tratamento de efluentes industriais por ED pode ser usado com dois objetivos, o de descartar o efluente de acordo com a legislação ambiental e o de reusar algum componente do efluente no próprio processo, seja ele um cátion, um ânion ou mesmo a água ${ }^{51}$. Estudos apresentam o processo de ED tanto para a recuperação de água como para a recuperação de ácido a partir de efluentes industriais $^{81,82,83,84,85,86}$.

Um exemplo de reúso da água foi desenvolvido na Espanha em Barranco Seco nas Ilhas Canárias, onde em novembro de 2002 foi instalada uma unidade de ED reversa com capacidade de $20.000 \mathrm{~m}^{3} /$ dia para tratamento de águas residuárias, buscando o reúso da água na irrigação, principalmente em fazendas de frutas e vegetais. Para prevenir o fouling nas membranas da ED reversa, uma ultrafiltração foi instalada à montante deste processo. Estes dois processos acoplados, ultrafiltração seguida de ED reversa, demonstraram ser capazes de alcançar o tratamento desejado, com água de qualidade a baixos custos $^{83}$.

Para a recuperação de metais, a maior aplicação da ED é no tratamento de efluentes da indústria de galvanoplastia, para a recuperação de níquel, cádmio, cobre e cromo ${ }^{7,51}$.

Estudos de ED para o tratamento de soluções aquosas ácidas contendo sulfato de cobre e outros metais estão sendo realizados, demonstrando que cátions monovalentes são transportados mais rapidamente que os divalentes e que a taxa de transporte é dependente do tamanho do cátion, do número de carga e do número de hidratação $0^{84}$.

Recentemente, um estudo realizado por Cifuentes et al. (2009), mostrou-se eficaz para a separação de cobre e ferro e recuperação da água de soluções usadas em operações de eletrólise de cobre, utilizando-se ED. Em uma célula com cinco compartimentos com recirculação dos eletrólitos foram avaliadas as seguintes 
variáveis: densidade de corrente aplicada, fluxo de recirculação e o tempo de operação $0^{84}$.

A taxa de remoção dos íons mostrou-se mais eficaz com o aumento da densidade de corrente aplicada e também com o aumento do fluxo da solução. Foram obtidas taxas de remoção de até $96,6 \%$ de $\mathrm{Cu}$ e $99,5 \%$ de $\mathrm{Fe}^{2+}$, após 24 horas de ensaio, demonstrando assim ser possível a recuperação da água ${ }^{84}$.

Neste estudo observou-se que $\circ \mathrm{Cu}$ e $\circ \mathrm{Fe}$ foram transportados para 0 compartimento onde se concentram os cátions, ou seja, eles passaram juntos através da membrana catiônica. Portanto, ambos os metais são separados da água através da ED, mas não um do outro, sendo necessária, neste caso, uma etapa posterior de eletroobtenção para a separação destes metais ${ }^{84}$.

Os autores sugerem ainda que seria possível recuperar o ácido sulfúrico desta solução, utilizando-se o mesmo sistema de ED, com a colocação de uma membrana bipolar, referenciando outro trabalho desenvolvido pelo mesmo grupo de autores ${ }^{84}$.

O estudo desenvolvido para a recuperação de ácido sulfúrico das soluções usadas em operações de eletrólise de cobre, utilizando-se a ED com membrana bipolar, demonstrou ser eficaz. Foi avaliada a influência da densidade de corrente e da temperatura no processo, e também foram comparados dois sistemas, uma célula de ED com seis compartimentos e uma mais simples com três compartimentos ${ }^{85}$.

Dos resultados observou-se que a taxa de recuperação do ácido aumentou com o aumento na densidade de corrente e com o aumento na temperatura. Ainda observou-se que os mesmos resultados obtidos para a célula de seis compartimentos foram obtidos para a célula de três, mas com a vantagem de nesta montagem mais simples este processo ser realizado com um potencial menor na célula, ou seja, com um consumo menor de energia ${ }^{85}$.

Outro trabalho desenvolvido com o objetivo de recuperar água e ácido de uma solução contendo metais, no caso da solução enxágue da decapagem com ácido clorídrico, apresentou bons resultados ${ }^{86}$.

No trabalho, supracitado, o efluente submetido ao tratamento por ED apresentava a seguinte composição: $24 \mathrm{eq} \mathrm{H}^{+} / \mathrm{m}^{3}$ de ácido clorídrico, $100 \mathrm{~g} \mathrm{Fe} \mathrm{tot}_{\mathrm{to}} / \mathrm{m}^{3}$, $2,7 \mathrm{~g} \mathrm{Ni}^{2+} / \mathrm{m}^{3}$ e $0,6 \mathrm{~g} \mathrm{Cr}^{3+} / \mathrm{m}^{3}$. Esta solução apresentava uma condutividade igual a 
$8,4 \mathrm{mS} \cdot \mathrm{cm}^{-2}$. Foram usados dois sistemas para o tratamento deste efluente: (1) $E D_{1}$ mais troca catiônica mais $\mathrm{ED}_{2}$; (2) troca catiônica mais $\mathrm{ED}_{1}$ mais $\mathrm{ED}_{2}{ }^{\left({ }^{(6)}\right)}$.

Com o sistema 1 foi obtida água livre de ácido, mas contendo traços de sais metálicos, com uma condutividade final de $30 \mu \mathrm{S} \cdot \mathrm{cm}^{-2}$. Já com o sistema 2 os resultados foram melhores, pois além de estar livre de ácido, a água também estava livre dos sais metálicos, e com $3 \mu \mathrm{S} / \mathrm{cm}^{2}$ de condutividade final ${ }^{86}$.

Para a recuperação do ácido, os concentrados obtidos nas $E D_{1}$ dos dois sistemas foram submetidos a uma ED monoseletiva, sendo obtido um ácido contendo 1180 eq H $\mathrm{H}^{+} / \mathrm{m}^{3}$ com $70 \mathrm{~g} \mathrm{Fe}_{\text {tot }} / \mathrm{m}^{3}$ de contaminação, pelo sistema $1 \mathrm{e}$ $2000 \mathrm{eq} \mathrm{H} / \mathrm{m}^{3}$ com $24 \mathrm{~g} \mathrm{Fe}_{\text {tot }} / \mathrm{m}^{3}$ pelo sistema $2^{86}$.

Comparando os dois sistemas, observou-se que os produtos, água e ácido, obtidos a partir do sistema 1 são de menor qualidade quando comparados aos obtidos pelo sistema 2, porém o custo operacional do sistema 1 é menor do que o custo operacional do sistema $2^{(86)}$. 
MATERIAIS E MÉTODOS 


\section{MATERIAIS E MÉTODOS}

Neste capítulo será descrita a metodologia experimental adotada para esta pesquisa, bem como as técnicas, os materiais e os equipamentos empregados para sua execução. Na Figura 11 apresenta-se o fluxograma geral da metodologia desenvolvida.

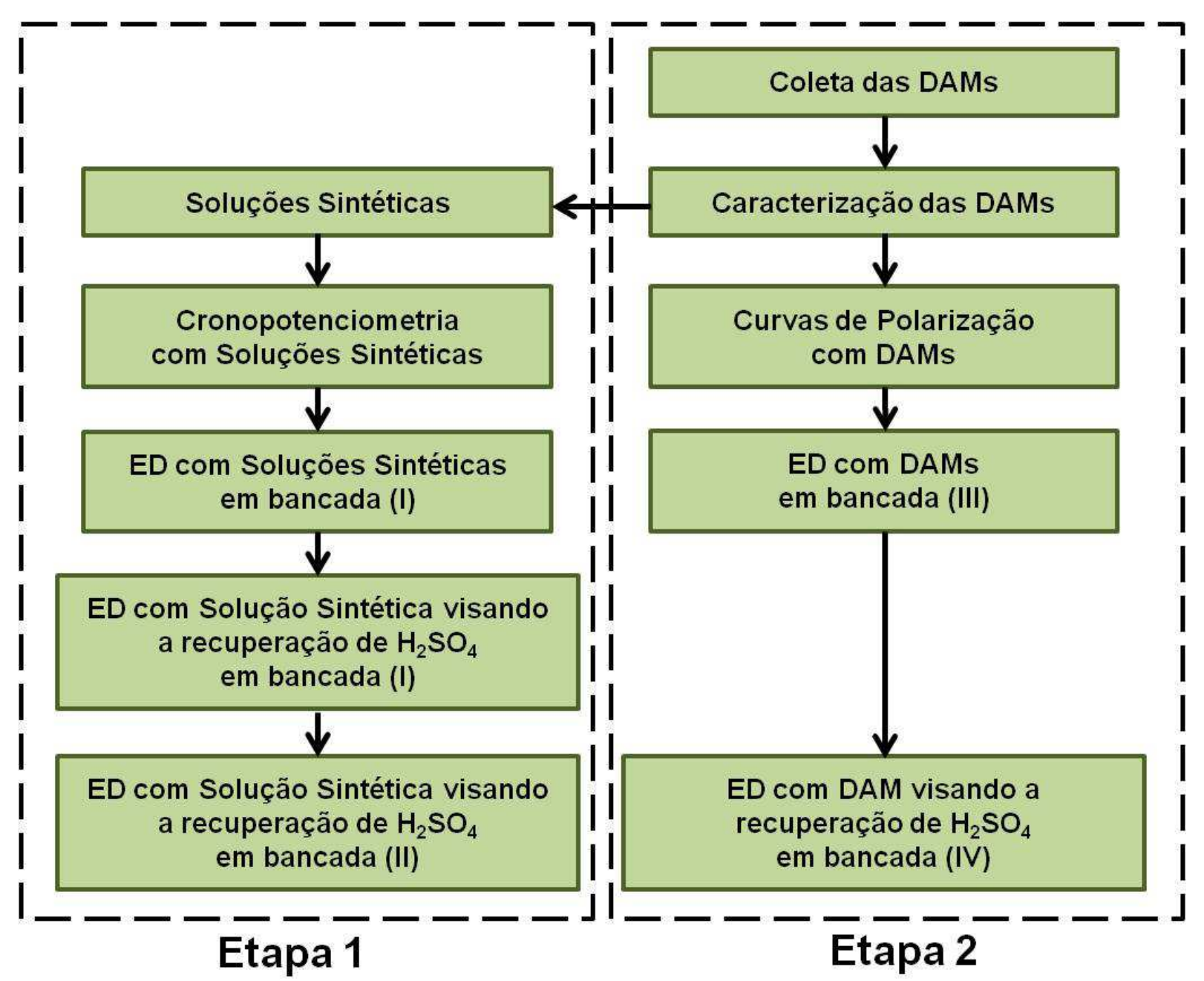

Figura 11 - Fluxograma geral da metodologia experimental.

Após a coleta e caracterização das DAMs, este estudo foi dividido em duas etapas, sendo a primeira delas desenvolvido com soluções sintéticas preparadas com base na caracterização e a segunda com as próprias DAMs.

Este estudo foi desenvolvido na Universidade de São Paulo, junto ao Departamento de Engenharia Metalúrgica e de Materiais com orientação do Professor Jorge Alberto Soares Tenório. 
A Etapa 1, que englobou ensaios cronopotenciométricos e ED, foi desenvolvida no Laboratório de Engenharia Eletroquímica e Corrosão do Departamento de Engenharia Química e Nuclear da Universidade Politécnica de Valencia, na Espanha, sob supervisão do Professor Valentín Pérez Herranz.

E parte da Etapa 2, de ensaios realizados com DAMs reais, foi desenvolvida no Laboratório de Corrosão, Proteção e Reciclagem de Materiais (LACOR) do Departamento de Materiais da Escola de Engenharia da Universidade Federal do Rio Grande do Sul (UFRGS), sob supervisão da Professora Andréa Moura Bernardes.

\subsection{COLETA DAS DRENAGENS ÁCIDAS DE MINAS}

As DAMs, utilizadas neste estudo, foram coletadas nas fontes geradoras em dezembro de 2009, no Estado de Santa Catarina, na região de Criciúma.

Para representar diferentes situações de geração de DAM, foram coletadas em cinco pontos de geração distintos em uma carbonífera em operação, no município de Forquilhinha/SC, conforme apresentado na Figura 12, a saber: DAM MA, DAM MB, DAM LX, DAM PL e DAM BA. 


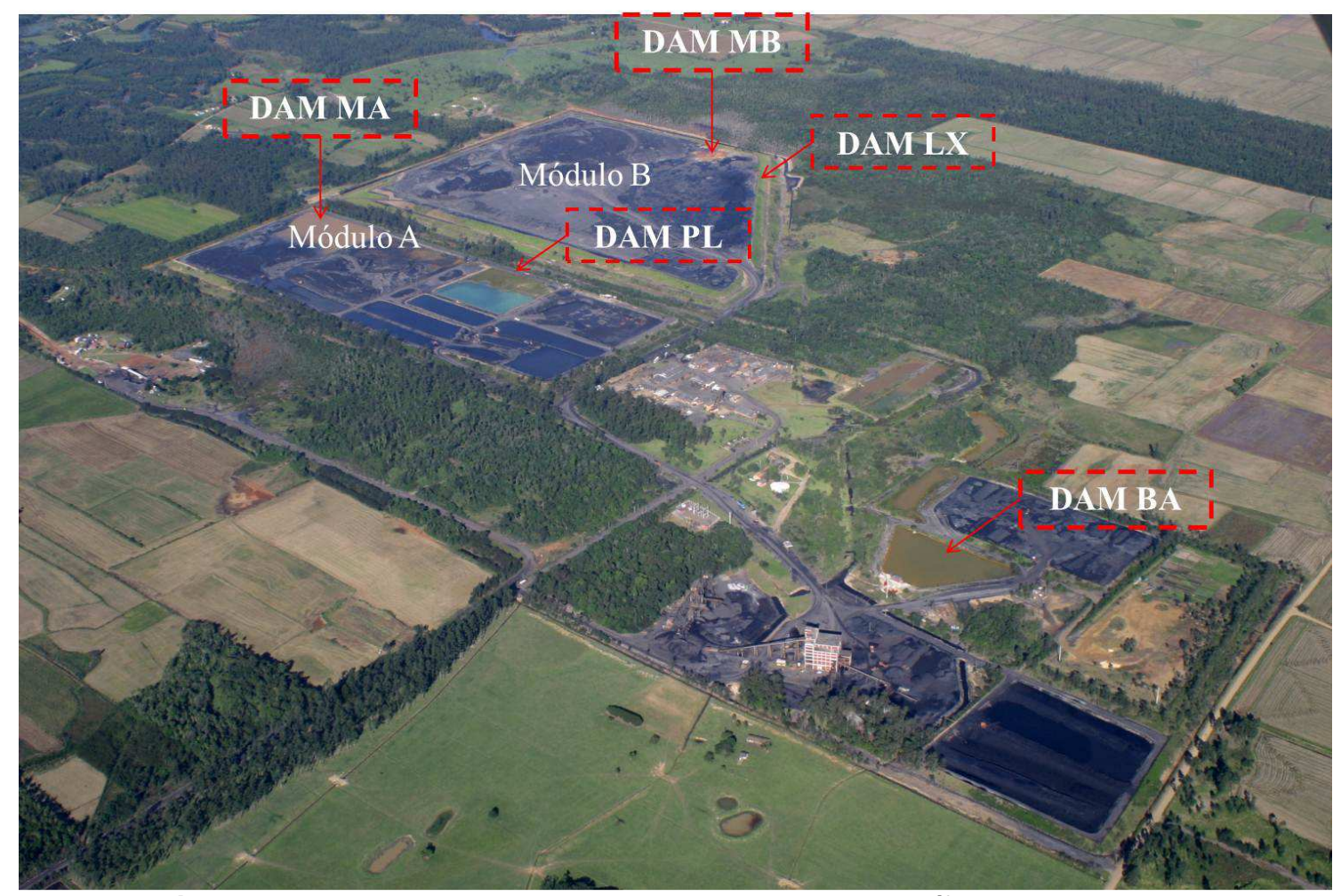

Figura 12 - Pontos de coleta das DAMs em uma carbonífera em operação.

As DAMs MA e MB são resultado da percolação dos módulos de rejeito $A$ e $B$, respectivamente, nos quais são armazenados rejeitos oriundos das etapas de beneficiamento do carvão mineral. Na Figura 13 e na Figura 14 são apresentados em detalhe os pontos de coleta das duas DAMs, MA e MB. E na Figura 15 apresenta-se o ponto de coleta da DAM proveniente da drenagem subterrânea do módulo de rejeito $B$, a DAM $L X$.

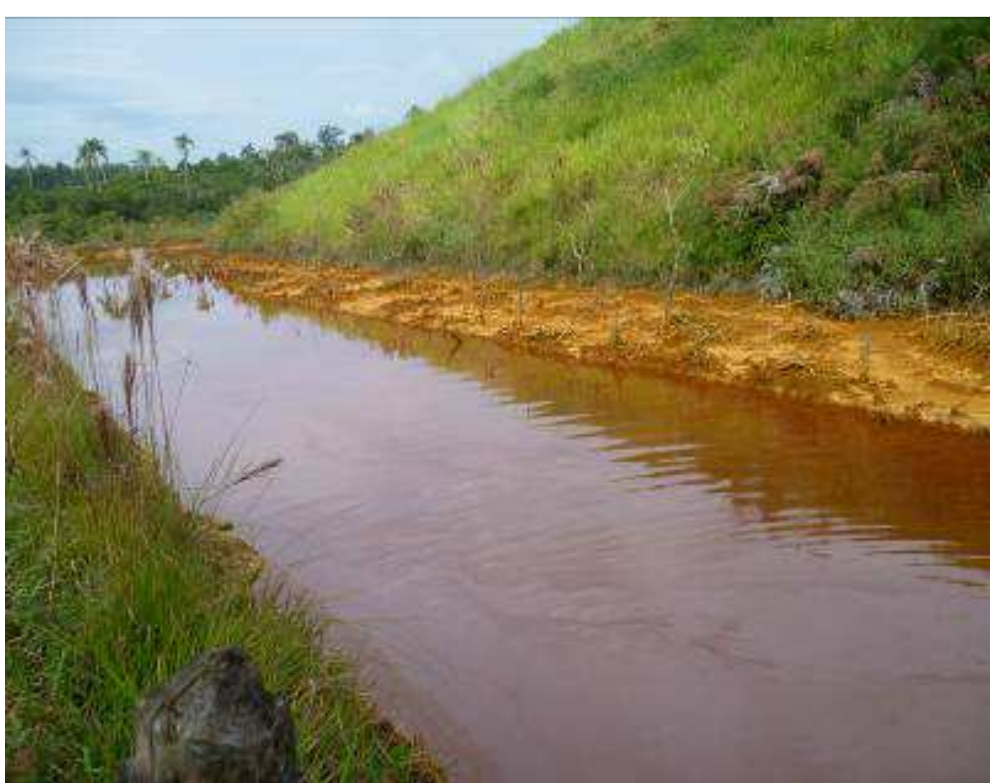

Figura 13 - Ponto de coleta da DAM MA - percolado do Módulo de Rejeito A. 


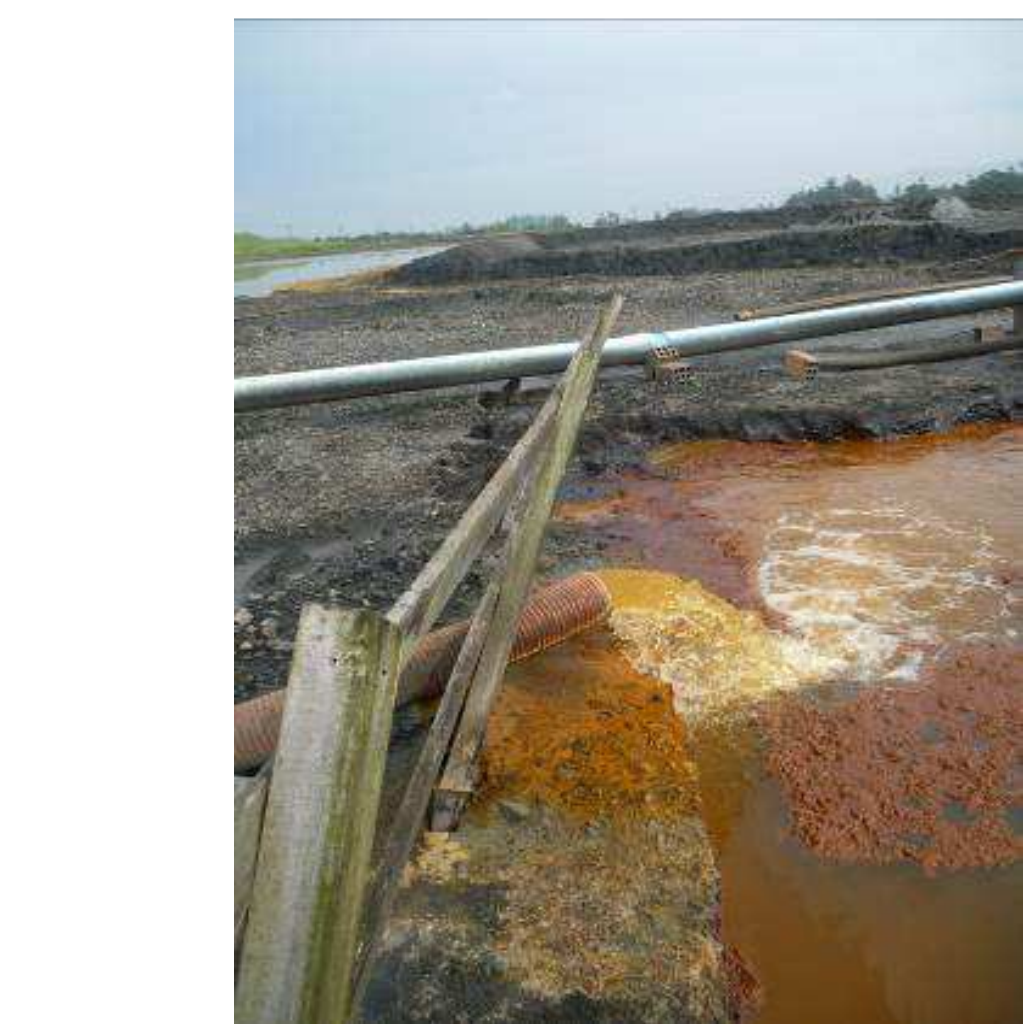

Figura 14 - Ponto de coleta da DAM MB - percolado do Módulo de Rejeito B.

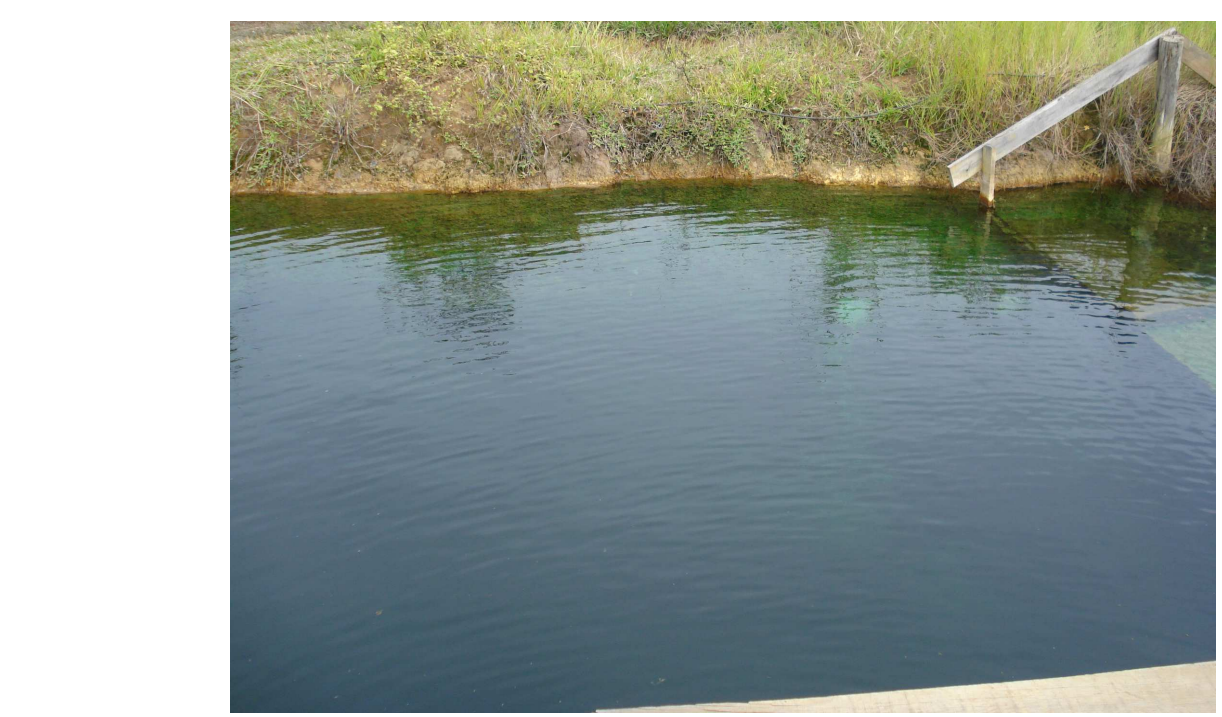

Figura 15 - Ponto de coleta da DAM LX - drenagem subterrânea do Módulo de Rejeito B.

Já a DAM PL apresentada na Figura 16, foi coletada no poço de bombeamento, que recebe a drenagem pluvial de toda a área da carbonífera, sendo esta uma drenagem mais diluída quando comparada às demais drenagens da carbonífera. Na Figura 17, apresenta-se a bacia de adução, na qual coletou-se a DAM BA, que recebe todo o efluente da carbonífera e antecede o processo de tratamento atualmente empregado de neutralização seguido de precipitação. 


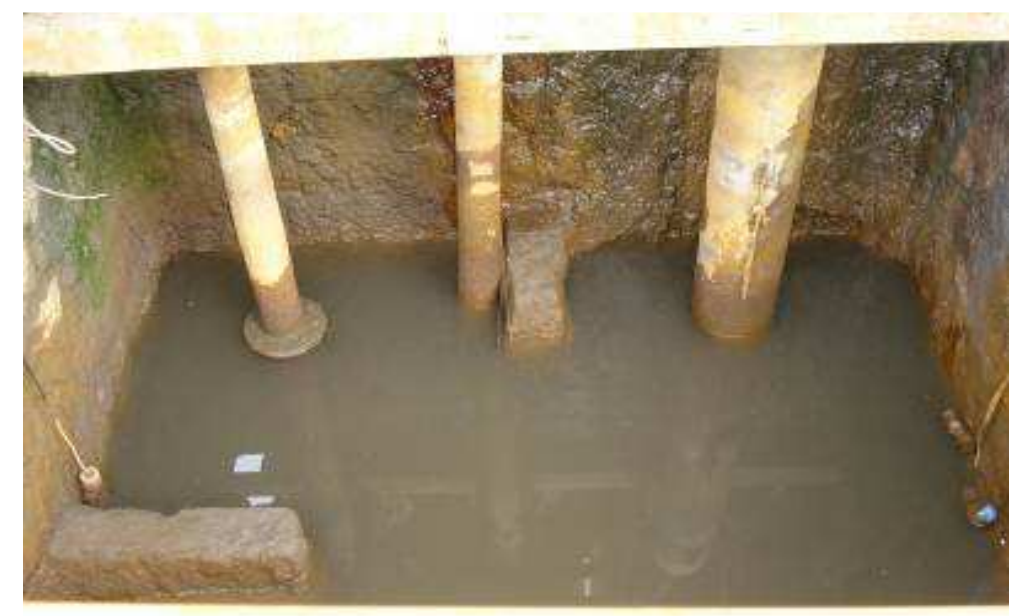

Figura 16 - Ponto de coleta da DAM PL - drenagem pluvial de toda a área da carbonífera.

Figura 17 - Ponto de coleta da DAM BA - bacia de adução que antecede o processo de tratamento

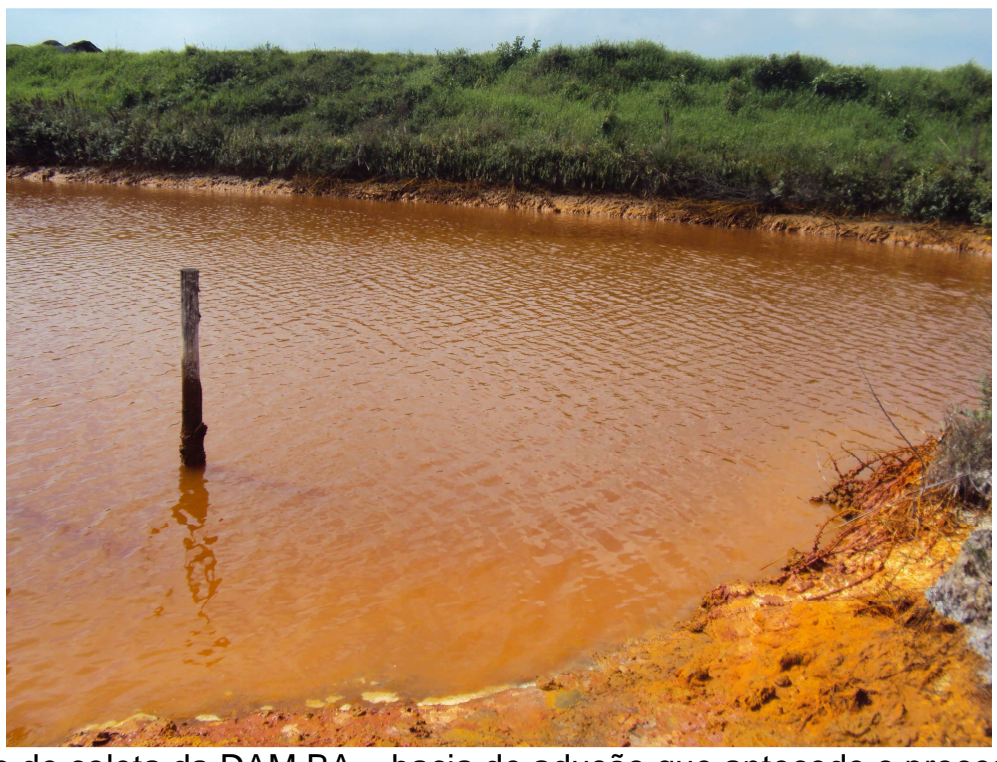
atual da carbonífera.

Outra situação na qual ocorre a geração de DAM na região de Criciúma é nas bocas de minas abandonadas, que no passado foram abertas para a exploração manual do carvão mineral e que desde suas aberturas continuam a gerar DAM. Estima-se a ocorrência de aproximadamente 1000 bocas de minas abandonadas na região e até novembro de 2008 foram cadastradas aproximadamente 768 bocas de minas nesta situação ${ }^{15}$. Portanto, a fim de representar este tipo de DAM, coletou-se a DAM CB, apresentada na Figura 18, proveniente de uma boca de mina abandonada. 


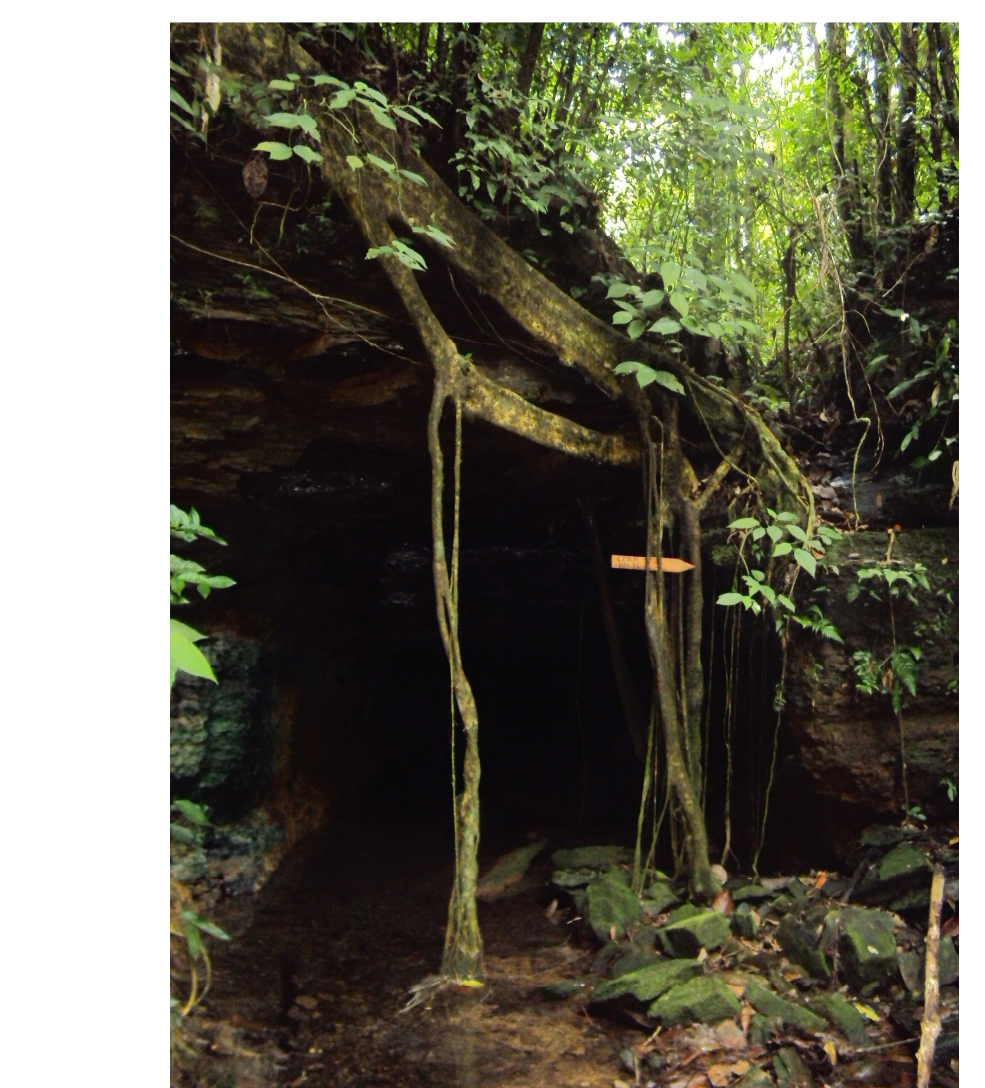

Figura 18 - Ponto de coleta da DAM CB - boca de mina abandonada.

As DAMs foram coletadas em bombonas de polietileno de alta densidade (PEAD), transportadas para o laboratório e armazenadas fechadas durante todo 0 desenvolvimento do trabalho.

\subsection{CARACTERIZAÇÃO DAS DRENAGENS ÁCIDAS DE MINAS}

Após as coletas, as DAMs foram deixadas em repouso para a sedimentação dos sólidos e em seguida foram filtradas em membrana 0,45 $\mu \mathrm{m}$ para então serem quimicamente caracterizadas, de acordo com os seguintes parâmetros: $\mathrm{pH}$, condutividade $(\lambda), \mathrm{Na}^{+}, \mathrm{K}^{+}, \mathrm{Mg}^{2+}, \mathrm{Ca}^{2+}, \mathrm{Fe}^{3+}, \mathrm{Cu}^{2+}, \mathrm{Zn}^{2+}, \mathrm{Mn}^{2+}, \mathrm{Fe}^{2+}, \mathrm{F}^{-}, \mathrm{Cl}^{-}, \mathrm{NO}_{3}^{-} \mathrm{e}$ $\mathrm{SO}_{4}{ }^{2-}$. Para a caracterização foi utilizado o método potenciométrico e cromatografia iônica, cujos equipamentos estão listados na Tabela 7. 
Tabela 7 - Metodologias utilizadas para a caracterização química das s de DAM.

\begin{tabular}{|c|c|c|}
\hline Parâmetros & Metodologia & Equipamento \\
\hline $\mathrm{pH}$ & Potenciométrico & $\begin{array}{c}\text { pH-metro } \\
\text { (PHTEK®) }\end{array}$ \\
\hline Condutividade & Potenciométrico & $\begin{array}{c}\text { Condutivímetro } \\
\text { (LUTRON } \Theta \text { - Modelo CD-4301) }\end{array}$ \\
\hline $\begin{array}{c}\mathrm{Na}^{+}, \mathrm{K}^{+}, \mathrm{Mg}^{2+}, \mathrm{Ca}^{2+}, \mathrm{Fe}^{3+}, \mathrm{Cu}^{2+} \\
\mathrm{Zn}^{2+}, \mathrm{Mn}^{2+}, \mathrm{Fe}^{2+}, \mathrm{F}^{-}, \mathrm{Cl}^{-}, \mathrm{NO}_{3}^{-}, \mathrm{SO}_{4}^{2-}\end{array}$ & Cromatografia lônica & $\begin{array}{l}\text { Cromatógrafo lônico } \\
\text { (DIONEX } \text { - Modelo CS3000) }^{-}\end{array}$ \\
\hline
\end{tabular}

\subsection{SOLUÇÕES SINTÉTICAS}

Após a caracterização química das DAMs, foi possível observar quais eram os íons presentes nas drenagens para a preparação das soluções sintéticas com os cátions e ânions mais abundantes. Desta análise, foi definido que as soluções sintéticas seriam compostas pelos cátions de íon férrico $\left(\mathrm{Fe}^{3+}\right)$ e íon sódio $\left(\mathrm{Na}^{+}\right)$e pelo ânion sulfato $\left(\mathrm{SO}_{4}{ }^{2-}\right)$. As soluções sintéticas foram preparadas a partir da dissolução de sulfato férrico $\left(\mathrm{Fe}_{2}\left(\mathrm{SO}_{4}\right)_{3}\right)$ e sulfato de sódio $\left(\mathrm{Na}_{2} \mathrm{SO}_{4}\right)$ em água destilada. Na Tabela 8 são apresentadas as composições das soluções sintéticas.

Tabela 8 - Composição das soluções sintéticas.

\begin{tabular}{ccc}
\hline Solução & Composição & Concentração Molar (M) \\
\hline $\mathbf{1}$ & $\mathrm{Fe}_{2}\left(\mathrm{SO}_{4}\right)_{3}$ & $1 \cdot 10^{-3}$ \\
$\mathbf{2}$ & $\mathrm{Fe}_{2}\left(\mathrm{SO}_{4}\right)_{3}$ & $5 \cdot 10^{-3}$ \\
$\mathbf{3}$ & $\mathrm{Fe}_{2}\left(\mathrm{SO}_{4}\right)_{3}$ & $1 \cdot 10^{-2}$ \\
$\mathbf{4}$ & $\mathrm{Fe}_{2}\left(\mathrm{SO}_{4}\right)_{3}$ & $2 \cdot 10^{-2}$ \\
\hline $\mathbf{5}$ & $\mathrm{Na}_{2} \mathrm{SO}_{4}$ & $1 \cdot 10^{-2}$ \\
$\mathbf{6}$ & $\mathrm{Na}_{2} \mathrm{SO}_{4}$ & $2 \cdot 10^{-2}$ \\
$\mathbf{7}$ & $\mathrm{Na}_{2} \mathrm{SO}_{4}$ & $6 \cdot 10^{-2}$ \\
\hline $\mathbf{8}$ & $\mathrm{Fe}_{2}\left(\mathrm{SO}_{4}\right)_{3}+\mathrm{Na}_{2} \mathrm{SO}_{4}$ & $2 \cdot 10^{-2}+1 \cdot 10^{-2}$ \\
$\mathbf{9}$ & $\mathrm{Fe}_{2}\left(\mathrm{SO}_{4}\right)_{3}+\mathrm{Na}_{2} \mathrm{SO}_{4}$ & $2 \cdot 10^{-2}+2 \cdot 10^{-2}$ \\
$\mathbf{1 0}$ & $\mathrm{Fe}_{2}\left(\mathrm{SO}_{4}\right)_{3}+\mathrm{Na}_{2} \mathrm{SO}_{4}$ & $2 \cdot 10^{-2}+6 \cdot 10^{-2}$ \\
\hline
\end{tabular}

Todas as soluções sintéticas preparadas foram submetidas aos ensaios de cronopotenciometria, sendo avaliadas tanto para a membrana catiônica quanto para a membrana aniônica, proporcionando assim a avaliação da influência da concentração no transporte dos íons.

Para os ensaios de ED foram utilizadas apenas as soluções sintéticas 2, 4 e 8 :

$$
\begin{aligned}
& \mathrm{Fe}_{2}\left(\mathrm{SO}_{4}\right)_{3} 5 \cdot 10^{-3} \\
& \mathrm{Fe}_{2}\left(\mathrm{SO}_{4}\right)_{3} 2 \cdot 10^{-2} \mathrm{e}
\end{aligned}
$$


$>\mathrm{Fe}_{2}\left(\mathrm{SO}_{4}\right)_{3}+\mathrm{Na}_{2} \mathrm{SO}_{4} 2 \cdot 10^{-2}+1 \cdot 10^{-2}$.

Para a recuperação de ácido sulfúrico apenas a solução 8 foi empregada, sendo esta solução considerada a solução sintética que mais se aproximava da concentração real de íons $\mathrm{Fe}^{3+}, \mathrm{Na}^{+}$e $\mathrm{SO}_{4}{ }^{2-}$ em uma DAM.

\subsection{MEMBRANAS}

As membranas, utilizadas neste estudo, foram fornecidas pela empresa brasileira Hidrodex ${ }^{\circledR}$ que forneceu também as principais características de cada membrana, descritas na Tabela 9, sendo a HDX 100 a membrana catiônica e a HDX 200 a aniônica.

Tabela 9 - Características das membranas HDX 100 e HDX $200^{51}$.

\begin{tabular}{|c|c|c|c|}
\hline \multirow[b]{2}{*}{ Parâmetro } & \multicolumn{2}{|c|}{ Membrana } & \multirow[b]{2}{*}{ Unidade } \\
\hline & $\begin{array}{l}\text { Catiônica } \\
\text { HDX } 100\end{array}$ & $\begin{array}{c}\text { Aniônica } \\
\text { HDX200 }\end{array}$ & \\
\hline Grupamento iônico ligado & $-\mathrm{SO}_{3}^{-}$ & $-\mathrm{NR}_{3}^{+}$ & -- \\
\hline Contenção de água & $35-50$ & $30-45$ & $\%$ \\
\hline Capacidade de troca iônica & $\geq 2,0$ & $\geq 1,8$ & $\mathrm{~mol} / \mathrm{kg}$ (seca) \\
\hline $\begin{array}{l}\text { Resistência da superfície } \\
(0,1 \mathrm{~mol} \mathrm{NaCl})\end{array}$ & $\leq 20$ & $\leq 20$ & $\Omega \cdot \mathrm{cm}^{2}$ \\
\hline $\begin{array}{l}\text { Passagem Seletiva } \\
(0,1 \mathrm{~mol} \mathrm{KCl} / 0,2 \mathrm{~mol} \mathrm{KCl})\end{array}$ & $\geq 90$ & $\geq 89$ & $\%$ \\
\hline Resistência de ruptura & $\geq 0,6$ & $\geq 0,6$ & $\mathrm{MPa}$ \\
\hline Grau de expansão & $\leq 2$ & $\leq 2$ & $\%$ \\
\hline Permeabilidade de água & $\begin{array}{c}\leq 0,1 \\
\text { (abaixo de } 0,2 \mathrm{MPa})\end{array}$ & $\begin{array}{c}\leq 0,2 \\
\text { (abaixo de } 0,035 \mathrm{MPa})\end{array}$ & $\mathrm{mL} / \mathrm{h} \cdot \mathrm{cm}^{2}$ \\
\hline
\end{tabular}

São membranas heterogêneas reforçadas por fibras de nylon, diferenciadas visivelmente pela coloração, sendo a membrana catiônica (HDX 100) rosa, que apresenta grupamentos de ácido sulfônico ligados a matriz da membrana, e a aniônica (HDX 200) verde que possui grupos de aminas quaternárias. Na Figura 19 são apresentadas as duas membranas. 

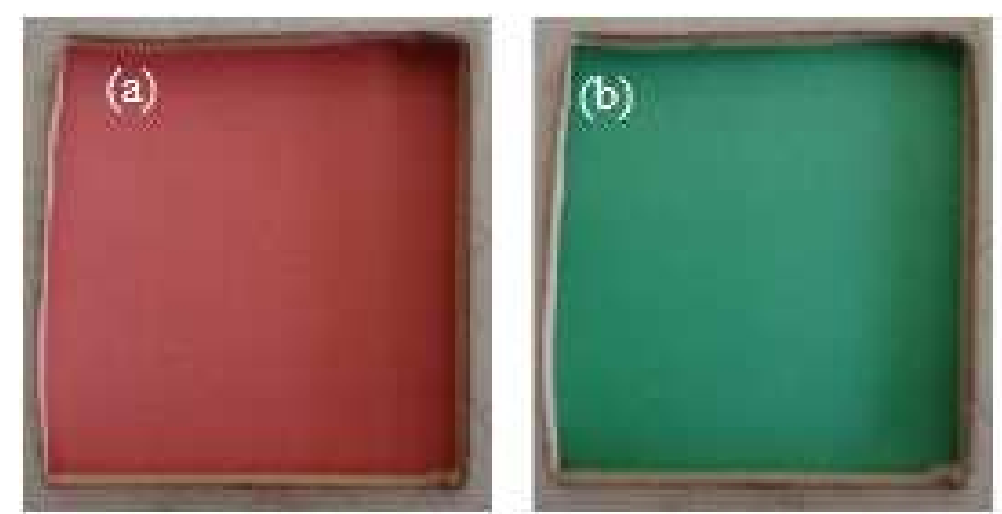

Figura 19 - (a) Membrana catiônica - HDX 100; (b) Membrana aniônica - HDX 200.

A área efetiva das membranas variou de acordo com a montagem experimental. Neste estudo foram utilizadas quatro montagens distintas:

Célula de ED de bancada (I), empregada nos ensaios realizados com as soluções sintéticas, com área efetiva das membranas de $3,52 \mathrm{~cm}^{2}$ para os ensaios cronopotenciométricos e a área efetiva de $12,57 \mathrm{~cm}^{2}$ para os ensaios de ED visando a recuperação de ácido sulfúrico em bancada.

Célula de ED de bancada (II), utilizada para os ensaios de recuperação de ácido sulfúrico a partir de solução sintética, com área efetiva das membranas de $100 \mathrm{~cm}^{2}$.

Célula de ED de bancada (III), para os ensaios de ED realizados com as DAMs e área efetiva das membranas de $16 \mathrm{~cm}^{2}$.

Célula de ED de bancada (IV), empregada na recuperação de ácido sulfúrico a partir de DAM, também com área efetiva de membrana de $16 \mathrm{~cm}^{2}$.

\subsection{CRONOPOTENCIOMETRIA COM SOLUÇÕES SINTÉTICAS}

Considerando que a cronopotenciometria é um método de caracterização eletroquímico, que permite entre outras coisas avaliar o comportamento das membranas diante de soluções com diferentes concentrações, optou-se por variar a concentração das soluções de sulfato férrico para estes ensaios (soluções de 1 a 4), bem como avaliar a influência da presença do $\mathrm{Fe}^{3+}$ realizando ensaios com soluções apenas de sulfato de sódio (soluções de 5 a 7), também em diferentes 
concentrações. Também foram avaliadas por cronopotenciometria misturas de soluções de $\mathrm{Fe}_{2}\left(\mathrm{SO}_{4}\right)_{3}$ e $\mathrm{Na}_{2} \mathrm{SO}_{4}$, com diferentes concentrações de $\mathrm{Na}_{2} \mathrm{SO}_{4}$, de modo a avaliar a influência de um cátion monovalente na mistura.

Portanto, ensaios cronopotenciométricos foram realizados para ambas as membranas, catiônicas e aniônicas, com todas as soluções apresentadas na Tabela 8.

Antes de cada ensaio, as membranas foram deixadas de molho durante 24 horas, sob agitação, na solução a ser avaliada, obtendo-se desta forma um equilíbrio entre as cargas fixas da membrana e os contra-íons da solução.

A configuração experimental utilizada para estes experimentos é representada esquematicamente pela Figura 20.

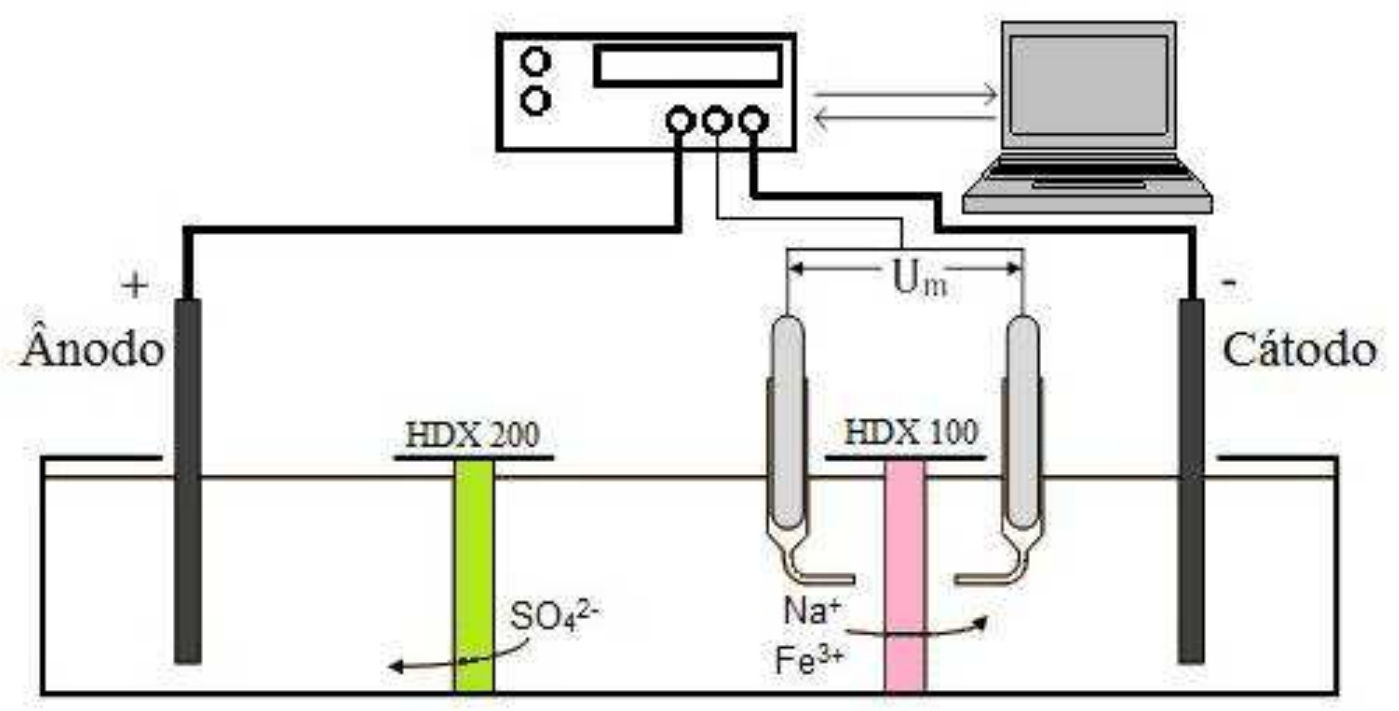

Figura 20 - Montagem experimental utilizada para os ensaios cronopotenciométricos.

A montagem experimental foi composta pela célula de ED de bancada (I) com três compartimentos com capacidade de $130 \mathrm{~mL}$ cada, entre os quais foram colocadas membranas catiônicas (HDX 100) e aniônicas (HDX 200), com área de $3,52 \mathrm{~cm}^{2}$. Um potenciostato/galvanostato (Autolab, PGSTAT 20) foi utilizado para a aplicação de impulsos de corrente de diferentes valores entre o eletrodo de trabalho e o contra-eletrodo, ambos de grafite. A resposta da diferença de potencial através da membrana em estudo $\left(U_{m}\right)$ foi registrada por meio de dois eletrodos de referência de $\mathrm{Ag} / \mathrm{AgCl}$ imersos em capilares de Luggin. Cada impulso de corrente foi aplicado 
durante 300 segundos, e depois, o sistema foi deixado em repouso por mais 300 segundos.

A aquisição dos dados foi realizada diretamente no software GPES Manager, fornecido pelo próprio fabricante do potenciostato/galvanostato. Na Figura 21 apresenta-se a interface do software, através da qual se controlam os parâmetros do ensaio.

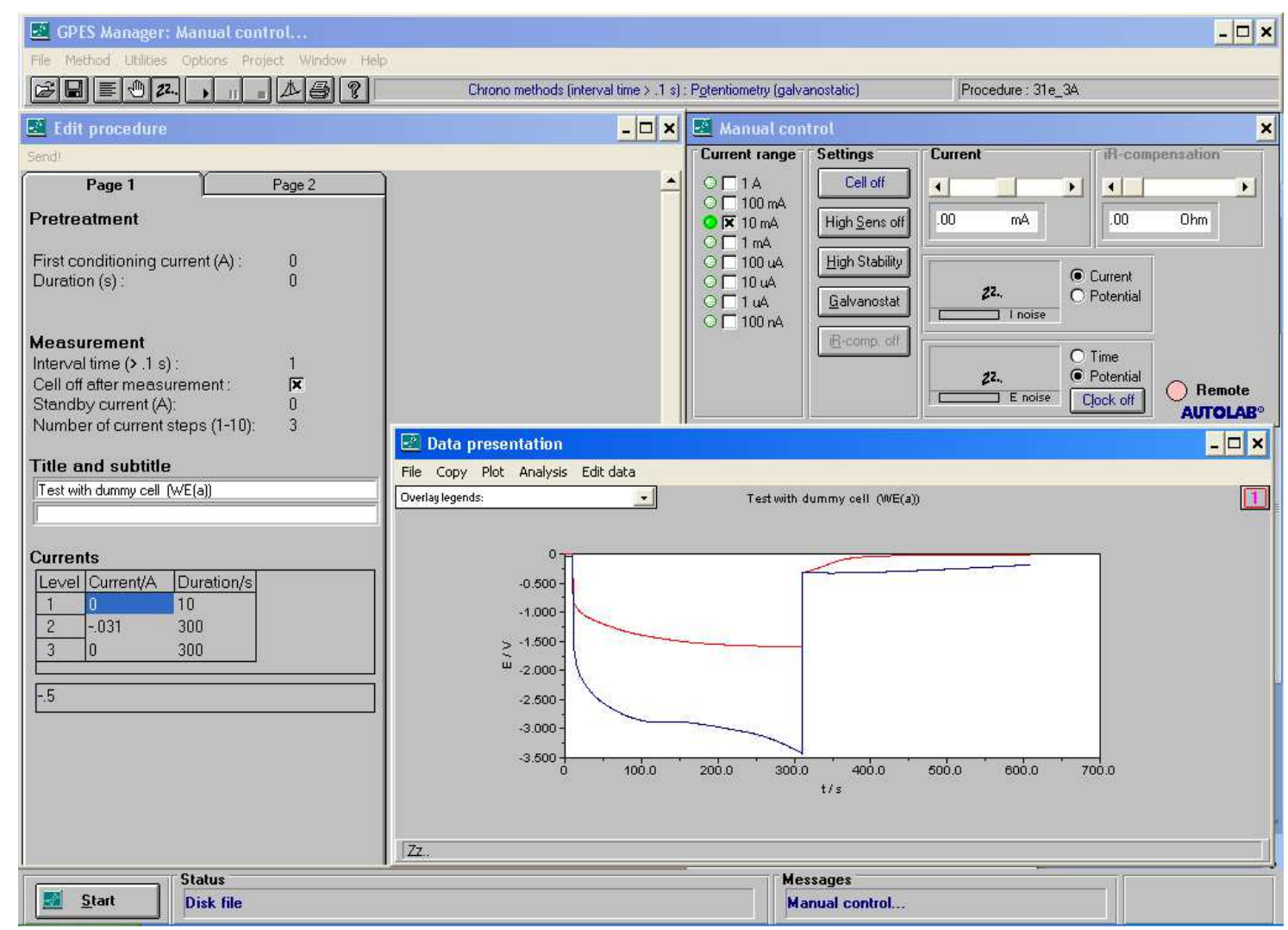

Figura 21 - Interface do software GPES para aquisição de dados dos ensaios cronopotenciométricos.

A partir dos cronopotenciogramas, as diferentes curvas de corrente-potencial de cada membrana e de cada solução sintética foram descritas a partir do valor final de $U_{m}$ registrado no cronopotenciograma e do valor correspondente de corrente aplicada. 


\subsection{ELETRODIÁLISE COM SOLUÇÕES SINTÉTICAS EM BANCADA (I)}

Os ensaios de ED com soluções sintéticas foram realizados com o objetivo de avaliar o transporte de ferro através da membrana catiônica HDX 100.

A montagem experimental empregada foi semelhante à utilizada para os ensaios cronopotenciométricos, ou seja, célula de bancada (I) com três compartimentos, separados por membranas catiônicas (HDX 100) e aniônicas (HDX 200), para estes ensaios com área de $12,57 \mathrm{~cm}^{2}$, na seguinte ordem: cátodo, membrana catiônica, membrana aniônica e ânodo.

Foram realizados ensaios com as soluções, configurações e densidades de correntes apresentadas na Tabela 10.

Tabela 10 - Configurações experimentais utilizadas para ensaios de ED com soluções sintéticas.

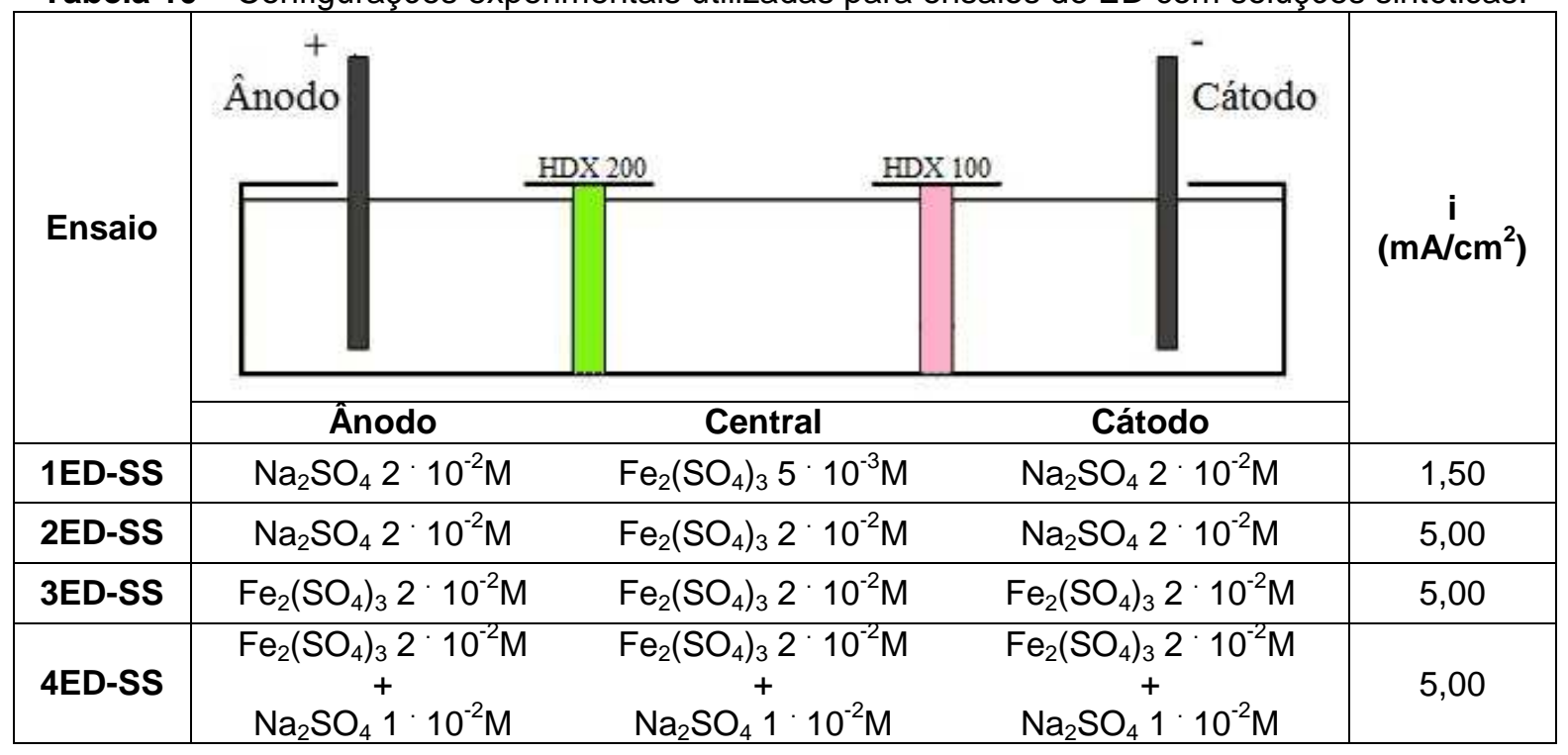

Para os ensaios de ED também foi utilizado o potenciostato/galvanostato (Autolab, PGSTAT 20) para a aplicação da corrente entre os eletrodos, ambos de grafite, mas desta vez a aplicação de corrente foi constante durante todo o período de cada ensaio.

Para a verificação do transporte do ferro a cada hora de ensaio foram coletas alíquotas do compartimento central e do compartimento catódico, para quantificação de ferro total por Absorção Atômica (Espectrofotômetro de Absorção Atômica Perkin-Elmer® - Analyst 100). E ao final de cada ensaio quantificou-se também ferro total no compartimento anódico. 


\subsection{ELETRODIÁLISE COM SOLUÇÃO SINTÉTICA VISANDO A RECUPERAÇÃO DE ÁCIDO SULFÚRICO EM BANCADA (I)}

Com o objetivo de recuperar ácido sulfúrico a partir da DAM, foram realizados ensaios com as soluções sintéticas e configurações apresentadas na Tabela 11.

Tabela 11 - Configurações experimentais utilizadas para ensaios de ED com soluções sintéticas.

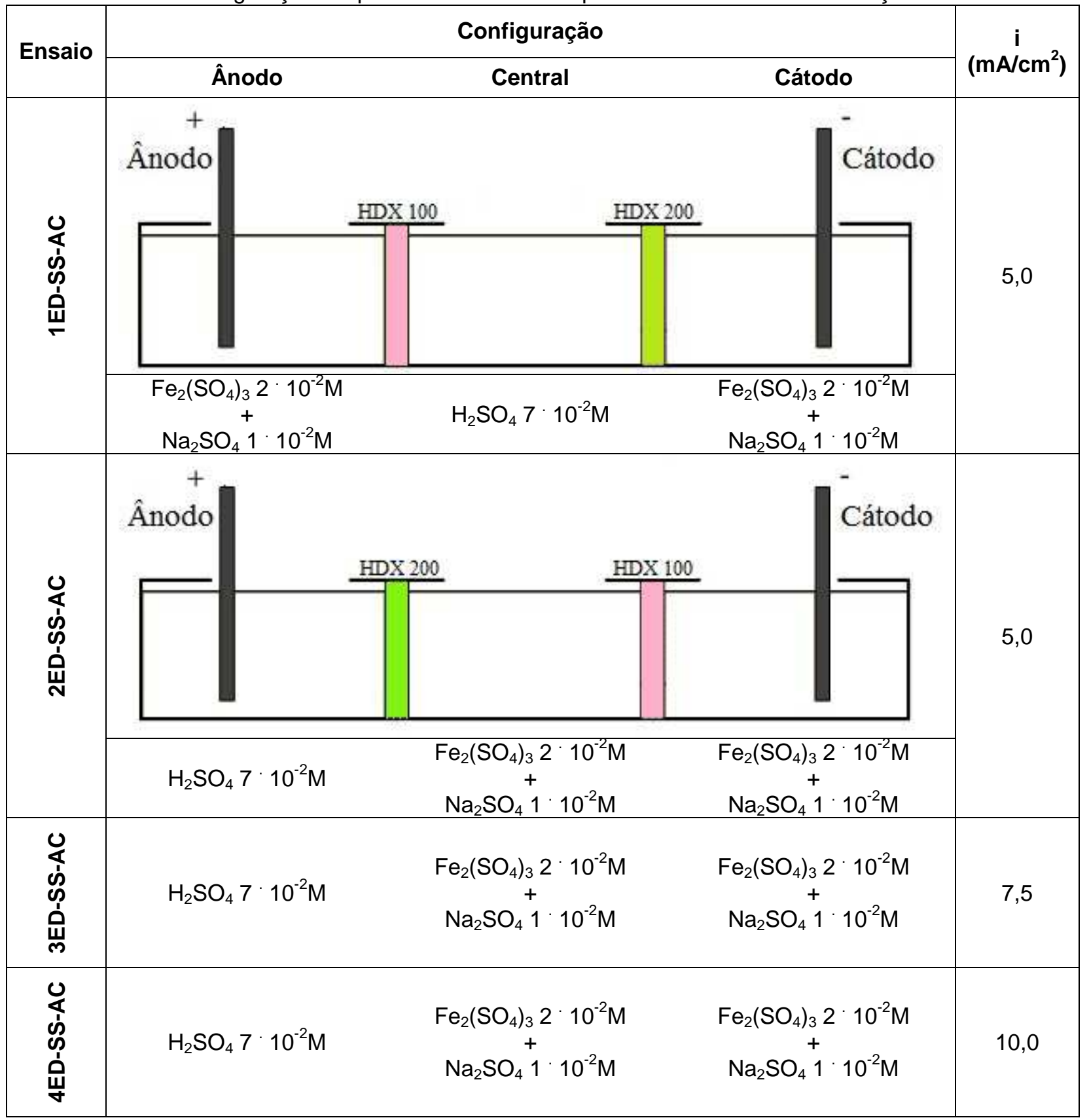

Conforme apresentado na Tabela 11 empregaram-se duas montagens experimentais diferentes, utilizando-se a célula de bancada (I) de três compartimentos. Os ensaios foram realizados sob agitação, promovida por barra magnética sobre agitadores mecânicos, conforme Figura 22. 


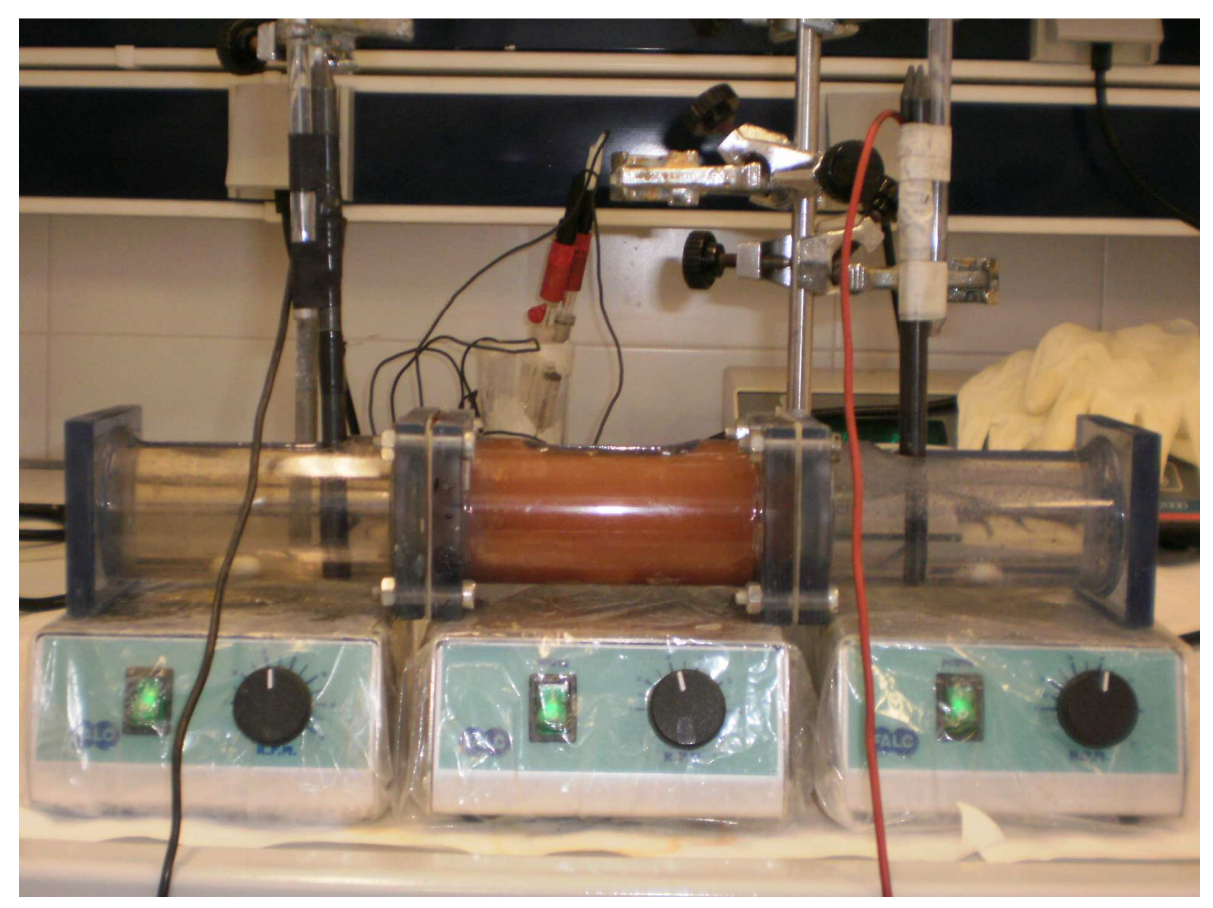

Figura 22 - Célula de bancada (I) de três compartimentos, sob agitação.

Para o ensaio número 1ED-SS-AC optou-se pela seguinte montagem: ânodo, membrana catiônica, membrana aniônica e cátodo, objetivando a recuperação de ácido sulfúrico no compartimento central, pois desta forma os sulfatos presentes na solução do compartimento catódico passariam para o compartimento central, através da membrana aniônica HDX 200, aumentando a concentração de sulfatos. E os prótons $\mathrm{H}^{+}$gerados no ânodo passariam através da membrana catiônica HDX 100, promovendo assim a produção de ácido sulfúrico no compartimento central.

Após a realização deste primeiro ensaio, observou-se um inconveniente nesta configuração, pois o ácido sulfúrico obtido estaria contaminado com ferro. Portanto, optou-se por uma nova configuração, utilizada para os demais ensaios (2ED-SS-AC, 3ED-SS-AC e 4ED-SS-AC).

Nesta nova configuração objetivou-se a recuperação de ácido sulfúrico no compartimento do ânodo, seguindo a seguinte ordem de montagem experimental: ânodo, membrana aniônica, membrana catiônica e cátodo. Assim os sulfatos presentes na solução do compartimento central passariam através da membrana HDX 200, aumentando a concentração de sulfatos e os prótons gerados pelo ânodo se manteriam neste mesmo compartimento, já que não poderiam passar através da membrana aniônica. 
A cada hora de ensaio foram coletadas alíquotas para a determinação da concentração de ferro total e sulfatos nos compartimentos central e cátodo e central e ânodo, respectivamente. Também foi monitorado, a cada hora, o $\mathrm{pH}$ de cada compartimento e também o potencial total da célula. A fim de comprovar a produção de ácido sulfúrico, ao final do ensaio 2ED-SS-AC, determinou-se a acidez da solução final obtida no compartimento do ânodo, pela titulação ácido-base com solução padrão de hidróxido de sódio $(\mathrm{NaOH}) 0,1 \mathrm{M}$.

\subsection{ELETRODIÁLISE COM SOLUÇÃO SINTÉTICA VISANDO A RECUPERAÇÃO DE ÁCIDO SULFÚRICO EM BANCADA (II)}

Com o objetivo de aumentar a recuperação de ácido sulfúrico a partir da DAM, foi repetida em uma célula de bancada com escala ampliada, célula de ED de bancada (II), a mesma configuração aplicada nos ensaios 2ED-SS-AC a 4ED-SS-AC realizados na célula de bancada (I), para que fosse possível aumentar o volume de solução de cada compartimento.

$\mathrm{Na}$ Figura 23 apresenta-se a célula de bancada (II) utilizada para estes ensaios, na qual se pode observar que o compartimento central é maior que o compartimento do cátodo e do ânodo, pois nestes ensaios foram empregados os seguintes volumes de solução: $750 \mathrm{~mL}$ de solução sintética $\left(\mathrm{Fe}_{2}\left(\mathrm{SO}_{4}\right)_{3} 2 \cdot 10^{-2} \mathrm{M}+\right.$ $\mathrm{Na}_{2} \mathrm{SO}_{4} 1 \cdot 10^{-2} \mathrm{M}$ ) nos compartimento cátodo; $3000 \mathrm{~mL}$ desta mesma solução sintética no compartimento central; e $750 \mathrm{~mL}$ de solução de $\mathrm{H}_{2} \mathrm{SO}_{4} 7 \cdot 10^{-2} \mathrm{M}$ no compartimento ânodo. 


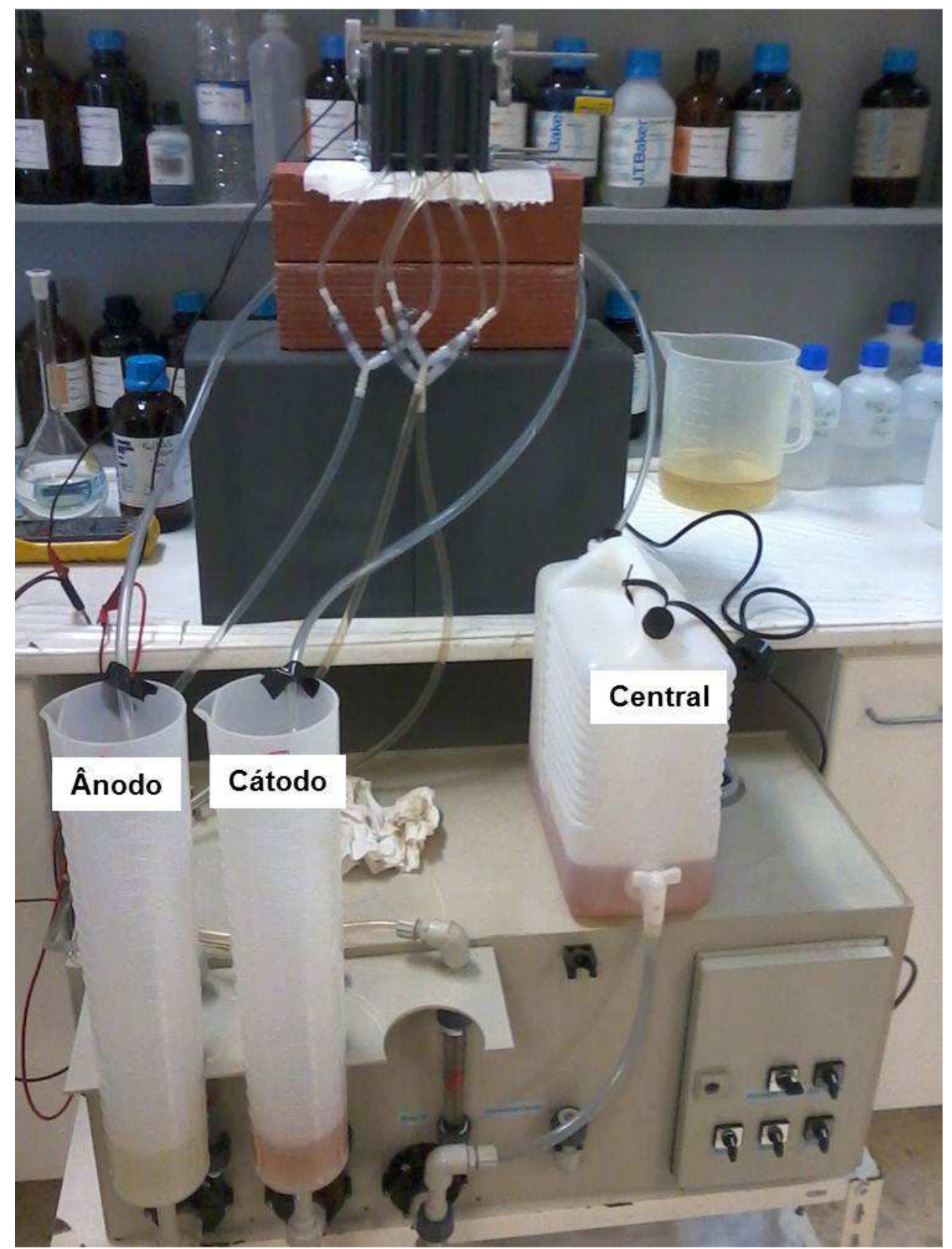

Figura 23 - Célula de ED de bancada (II) de três compartimentos.

Com a configuração supracitada foram realizados dois ensaios na célula de bancada (II), sendo que no primeiro ensaio aplicou-se uma densidade de corrente igual a $5,0 \mathrm{~mA} \cdot \mathrm{cm}^{-2}$ e no segundo $10,0 \mathrm{~mA} \cdot \mathrm{cm}^{-2}$, ambos foram conduzidos por 16 horas e mantidos à um fluxo de recirculação de $50 \mathrm{~L} / \mathrm{h}$ para todos os compartimentos. Eletrodos de titânio metálico revestidos com óxido de titânio e óxido de rutênio $\left(70 \mathrm{TiO}_{2} / 30 \mathrm{RuO}_{2}\right)$ foram empregados como cátodo e ânodo.

A cada hora de ensaio, foram coletadas alíquotas para análise de ferro total e sulfatos, sendo o ferro analisado nos compartimentos central e cátodo e os sulfatos nos compartimentos central e ânodo. Também foram monitorados o $\mathrm{pH}$ de todos os compartimentos a cada hora de ensaio, bem como a diferença de potencial da 
célula. E ao final de cada ensaio, de modo a comprovar a produção de ácido sulfúrico, também foi quantificada a acidez da solução obtida no compartimento ânodo, através de titulação ácido-base com solução padrão de $\mathrm{NaOH}$ 0,1 M.

\subsection{CURVAS DE POLARIZAÇÃO COM DRENAGENS ÁCIDAS DE MINAS}

Para a definição da corrente a ser aplicada durante a ED, inicialmente determinou-se a densidade de corrente limite. Este ensaio foi realizado em uma célula de ED de bancada (III) com cinco compartimentos, a fim de se obter a curva de polarização, a partir da qual define-se a densidade de corrente a ser aplicada nos ensaios de ED para as diferentes s de DAM.

A montagem desta célula se deu com a colocação alternada, em uma montagem tipo filtro prensa, das membranas catiônicas (HDX 100) e aniônicas (HDX 200), com área efetiva de membrana de $16 \mathrm{~cm}^{2}$.

A célula foi disposta da seguinte forma: no compartimento central, chamado compartimento diluído adicionou-se a solução de DAM e nos outros compartimentos, denominados Cátodo, Ânodo, Concentrado Cátodo e Concentrado Ânodo, foram colocadas soluções de sulfato de sódio $\left(\mathrm{Na}_{2} \mathrm{SO}_{4}\right)$ para a manutenção da condutividade no sistema. Cada recipiente foi conectado a uma bomba que promoveu a recirculação das soluções. Nos extremos da célula, estavam o cátodo e o ânodo, ambos de titânio metálico revestidos com óxido de titânio e óxido de rutênio $\left(70 \mathrm{TiO}_{2} / 30 \mathrm{RuO}_{2}\right)$, aos quais foram aplicadas sucessivas correntes.

As correntes aplicadas variaram gradualmente de $1 \mathrm{em} 1 \mathrm{~mA}$, a cada dois minutos, com intervalo de três minutos sem aplicação de corrente. A cada variação de corrente foram coletados os valores de diferença de potencial entre os eletrodos e também das membranas aniônicas e catiônicas, com o auxílio de multímetros, utilizando-se como eletrodos fios de platina, colocados nas extremidades de cada membrana, conforme representado esquematicamente na Figura 24. 


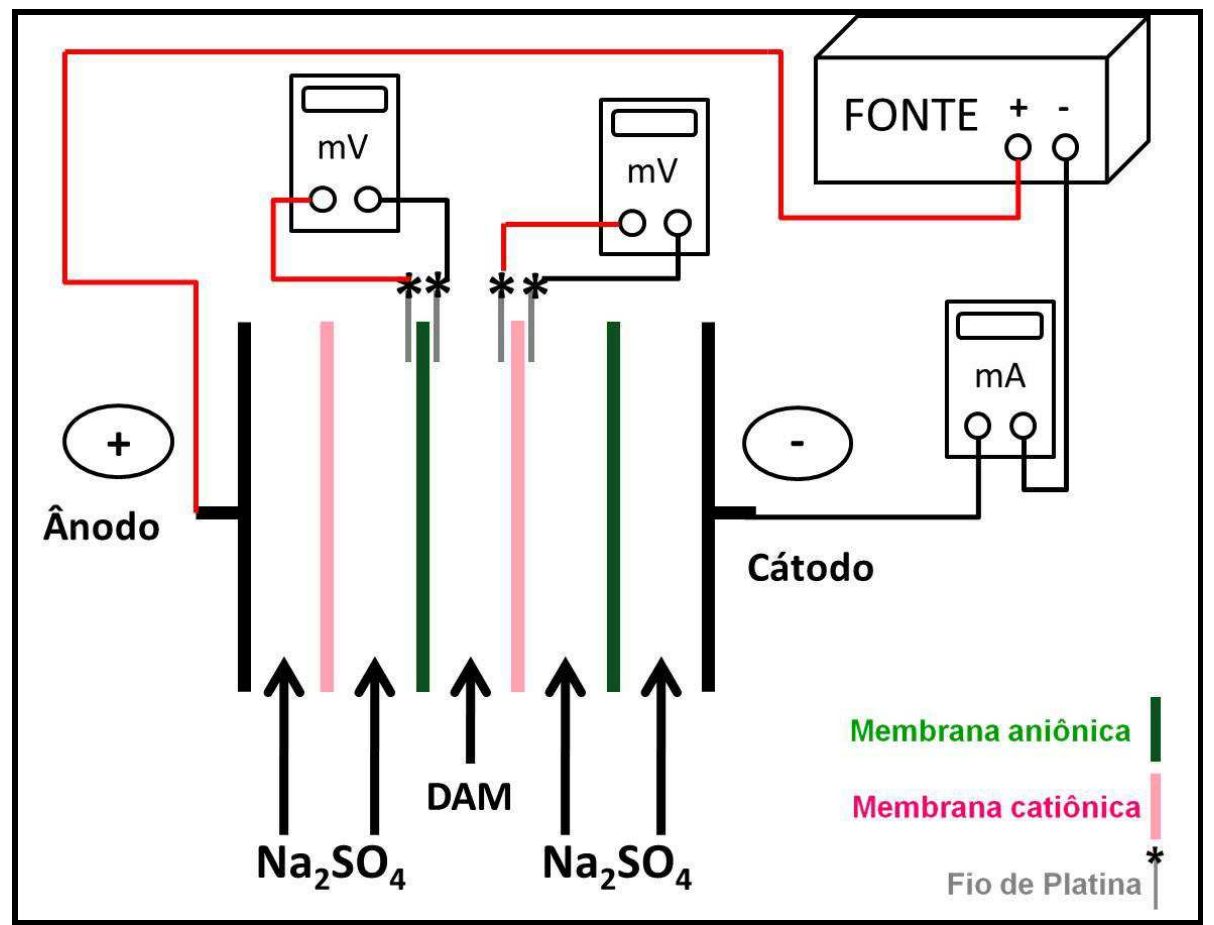

Figura 24 - Montagem de uma célula de ED para determinação das curvas de polarização.

Este ensaio foi realizado em triplicata para as seguintes DAMs: DAM PL, DAM BA e DAM CB.

\subsection{ELETRODIÁLISE COM DRENAGENS ÁCIDAS DE MINAS EM BANCADA}

Os ensaios de ED também foram realizados na célula de bancada (III) com cinco compartimentos, sendo que para estes ensaios a montagem experimental se deu da mesma forma que a utilizada para a determinação das curvas de polarização. A densidade de corrente aplicada foi previamente determinada através das curvas de polarização. Na Figura 25, apresenta-se a célula de bancada (III) utilizada. 


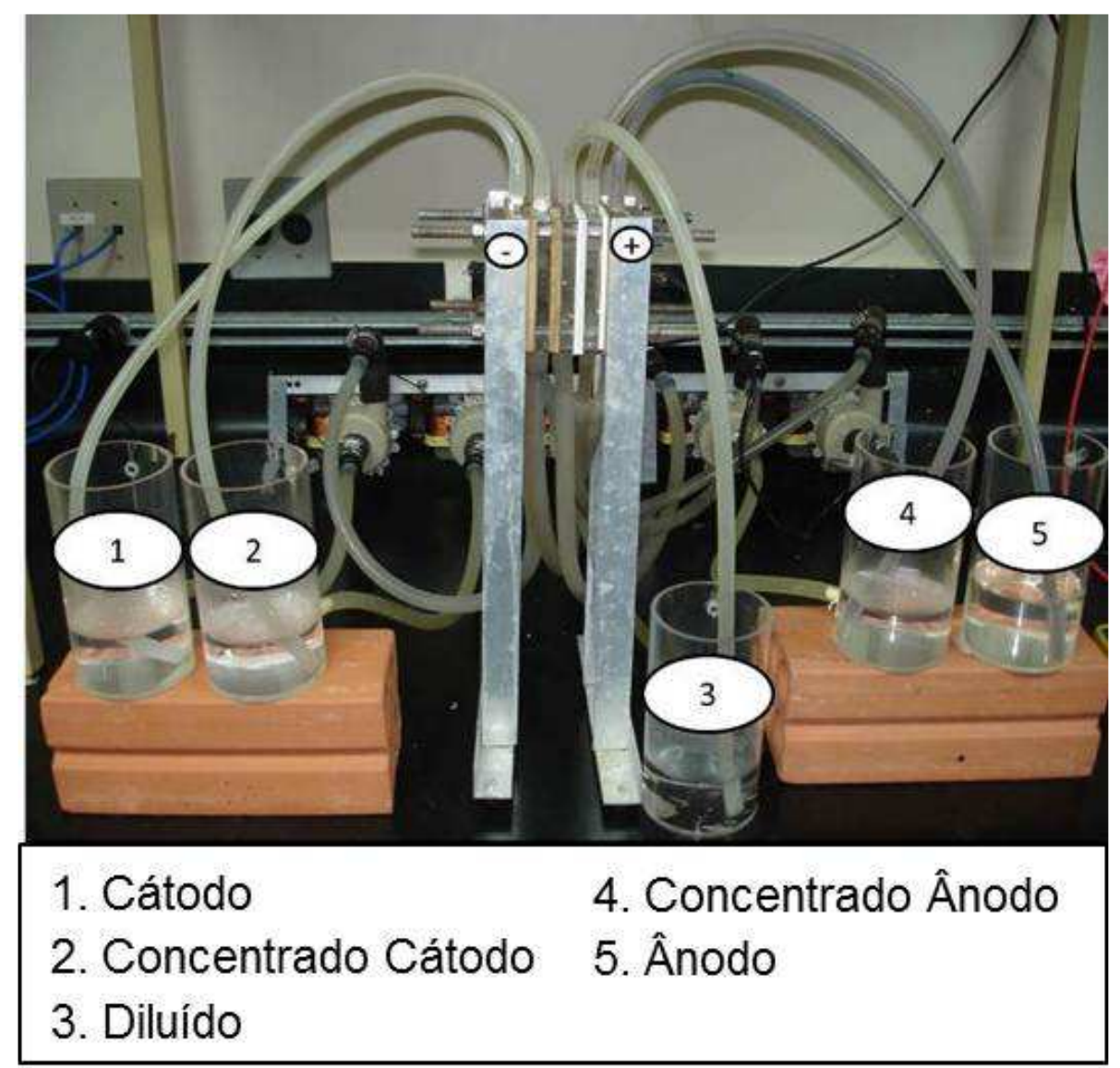

Figura 25 - Montagem experimental de célula de ED de bancada (III) com cinco compartimentos.

Os ensaios de ED realizados com DAMs em bancada são apresentados na Tabela 12, na qual se identifica a DAM utilizada, a densidade de corrente aplicada e também o tempo de ensaio.

Tabela 12 - Ensaios de ED com DAMs em bancada.

\begin{tabular}{cc|ccc}
\hline Ensaio & DAM & $\begin{array}{c}\mathbf{i} \\
\left(\mathbf{m A} \cdot \mathbf{c m}^{-2}\right)\end{array}$ & $\begin{array}{c}\text { I } \\
(\mathbf{m A})\end{array}$ & $\begin{array}{c}\text { Tempo de ensaio } \\
(\mathbf{h})\end{array}$ \\
\hline 1ED-DAM & BA & 3,8 & 60,0 & 6 \\
2 ED-DAM & CB & 1,0 & 16,0 & 6 \\
3 ED-DAM & PL & 2,6 & 41,6 & 55 \\
4 ED-DAM & CB & 1,0 & 16,0 & 24 \\
\hline
\end{tabular}

Inicialmente, foram realizados dois ensaios, sendo um com a DAM BA e o outro com a DAM CB. Estes ensaios preliminares foram conduzidos por 6 horas cada, sendo aplicado uma densidade de corrente de $3,8 \mathrm{~mA} \cdot \mathrm{cm}^{-2}$ para o ensaio com a DAM BA e $1,0 \mathrm{~mA} \cdot \mathrm{cm}^{-2}$ para a DAM CB. Considerando que a área da membrana da célula de bancada (III) é igual a $16 \mathrm{~cm}^{2}$, ao sistema total aplicou-se a corrente de 60,0 e 16,0 mA, respectivamente. 
Os ensaios foram monitorados, sendo medidos o $\mathrm{pH}$ e a condutividade dos compartimento a cada 30 minutos e sendo coletadas alíquotas para verificação da extração percentual a cada 1 hora de ensaio.

A partir dos resultados destes ensaios preliminares, fixou-se que os ensaios subsequentes seriam conduzidos até que a redução na condutividade elétrica da solução do compartimento diluído fosse igual ou menor que a condutividade apresentada pela água de abastecimento que é de aproximadamente $300 \mu \mathrm{S} \cdot \mathrm{cm}^{-1}$.

Desta forma, os testes foram conduzidos por diferentes períodos de tempo para cada DAM avaliada, sendo elas a DAM PL e a DAM CB.

Para o ensaio 3ED-DAM realizado com a DAM PL, aplicou-se uma densidade de corrente de 2,6 $\mathrm{mA} \cdot \mathrm{cm}^{-2}$, ou seja, uma corrente total para o sistema de 41,6 mA, por um período de 55 horas. E para o ensaio 4ED-DAM, com a DAM CB, aplicou-se $1,0 \mathrm{~mA} \cdot \mathrm{cm}^{-2}(16 \mathrm{~mA}$ - corrente aplicada ao sistema) durante 24 horas de ensaio.

$\mathrm{O} \mathrm{pH}$ e a condutividade das soluções de todos os compartimentos foram monitorados durante todos os ensaios a cada 1 hora de ensaio. A fim de se verificar a extração percentual de cátions e ânions, também foram coletadas alíquotas a cada hora e após os ensaios de ED para análise química.

4.11. ELETRODIÁLISE COM DRENAGEM ÁCIDA DE MINAS VISANDO A RECUPERAÇÃO DE ÁCIDO SULFÚRICO EM BANCADA (IV)

A fim de comprovar a eficiência dos ensaios realizados com solução sintética, na célula de bancada (II) para a recuperação de ácido sulfúrico, realizou-se um ensaio com a DAM MB seguindo a mesma configuração utilizado para o ensaio de ED com solução sintética visando a recuperação de ácido sulfúrico na célula de bancada (II), descrito no item 4.8 .

Na Figura 23, apresenta-se a célula de bancada (IV) utilizada para este ensaio, na qual se pode observar que o compartimento central é maior que o compartimento do cátodo e do ânodo, pois neste ensaio também foram empregados os seguintes volumes de solução: $750 \mathrm{~mL}$ de DAM no compartimento cátodo; $3000 \mathrm{~mL}$ de DAM no compartimento central; e $750 \mathrm{~mL}$ de solução de ácido sulfúrico $7 \cdot 10^{-2} \mathrm{M}$ no 
compartimento ânodo. Eletrodos de titânio metálico revestidos com óxido de titânio e óxido de rutênio $\left(70 \mathrm{TiO}_{2} / 30 \mathrm{RuO}_{2}\right)$ foram empregados como cátodo e ânodo.

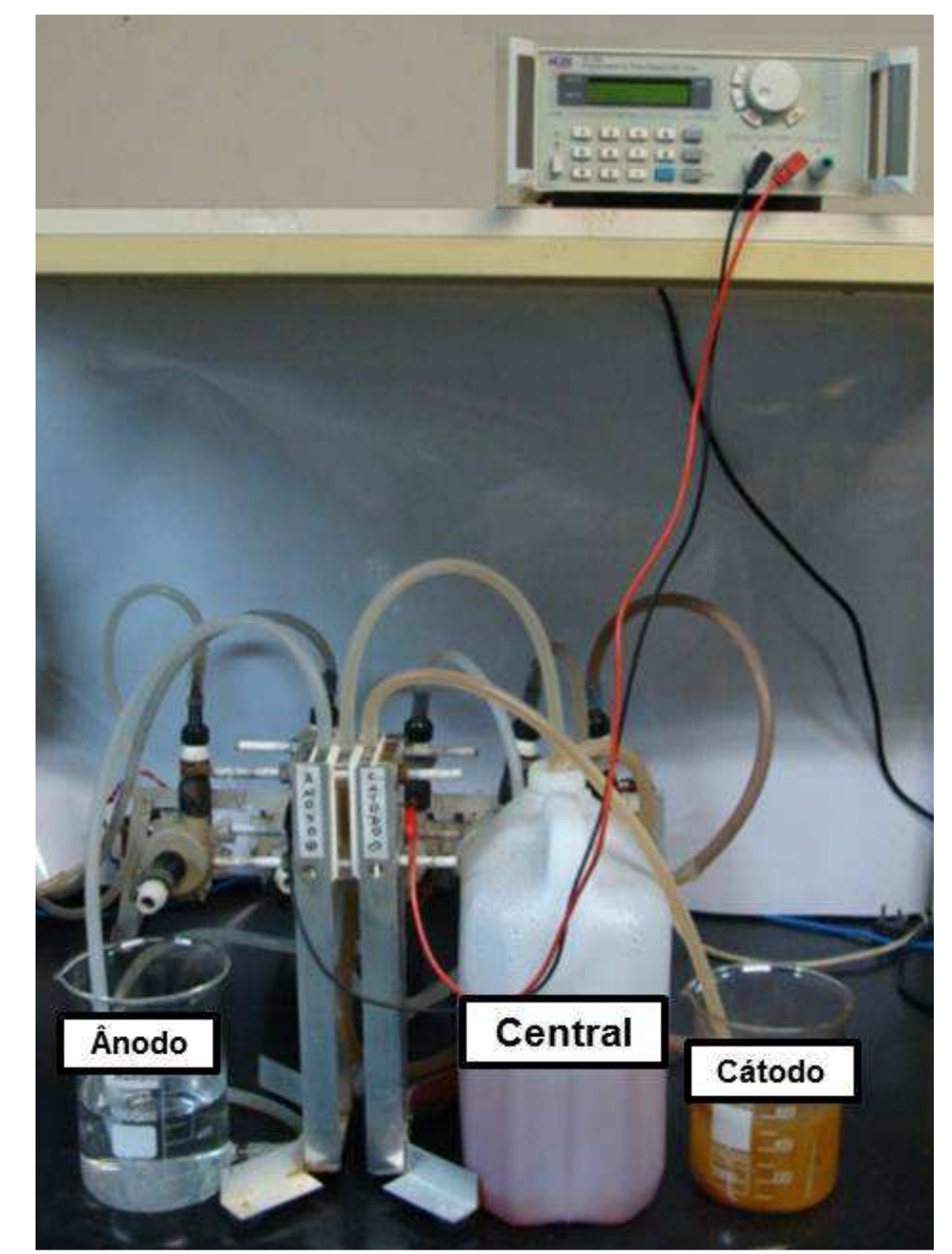

Figura 26 - Célula de ED de bancada (IV) de três compartimentos.

A este ensaio aplicou-se uma densidade de corrente de $5,0 \mathrm{~mA} \cdot \mathrm{cm}^{-2}$ por 16 horas e considerando a área da membrana de $16 \mathrm{~cm}^{2}$, aplicou-se uma corrente de $80 \mathrm{~mA}$. O sistema foi mantido a fluxo de recirculação de $80 \mathrm{~L} / \mathrm{h}$ para todos os compartimentos.

A cada hora de ensaio foram coletadas alíquotas para análise de ferro total e sulfatos, sendo o ferro analisado nos compartimentos central e cátodo e os sulfatos nos compartimentos central e ânodo. Também foram monitorados o pH de todos os compartimentos a cada hora de ensaio, bem como a diferença de potencial da célula. Ao final do ensaio, de modo a comprovar a produção de ácido sulfúrico, 
também foi quantificada a acidez da solução obtida no compartimento ânodo, através de titulação ácido-base com solução padrão de $\mathrm{NaOH}$ 0,1 M. 


\section{RESULTADOS E DISCUSS $\tilde{A} 0$}




\section{RESULTADOS E DISCUSSÃO}

\subsection{CARACTERIZAÇÃO DAS DRENAGENS ÁCIDAS DE MINAS}

Conforme descrito no item 4.1, para este estudo foram coletadas seis DAMs, sendo cinco delas geradas em uma carbonífera em operação, em diferentes etapas do processo de beneficiamento do carvão mineral e uma delas em uma boca de mina abandonada. A diferença na origem da geração de cada DAM se manifestou nas características apresentadas por elas, tais como: cor, condutividade, $\mathrm{pH}$ e composição química.

Considerando que, para a melhor operação de um processo de ED, a concentração de sólidos suspensos deve ser menor que $1 \mathrm{mg} \cdot \mathrm{L}^{-1(52)}$, as DAMs foram microfiltradas em membrana de 0,45 $\mu \mathrm{m}$ previamente à caracterização química, bem como antes de cada ensaio realizado posteriormente.

A caracterização química das DAMs é apresentada na Tabela 13.

\begin{tabular}{|c|c|c|c|c|c|c|c|}
\hline & \multirow{2}{*}{ Parâmetros } & \multicolumn{6}{|c|}{ DAM } \\
\hline & & MA & MB & LX & PL & BA & CB \\
\hline & $\mathrm{pH}$ & 2,6 & 2,5 & 3,0 & 2,8 & 3,0 & 2,8 \\
\hline & $\begin{array}{c}\lambda \\
\left(\mu S^{\cdot} \mathbf{c m}^{-1}\right)\end{array}$ & 7100 & 8050 & 9970 & 4490 & 4200 & 1155 \\
\hline \multirow{8}{*}{ لَّ } & $\mathrm{Na}^{+}$ & 454 & 385 & 414 & 296 & 221 & 1059 \\
\hline & $\mathrm{K}^{+}$ & 1241 & 106 & 143 & 20 & 65 & 64 \\
\hline & $\mathbf{M g}^{2+}$ & 138 & 155 & 199 & 71 & 67 & 19 \\
\hline & $\mathrm{Ca}^{2+}$ & 311 & 258 & 232 & 230 & 239 & 143 \\
\hline & $\mathrm{Fe}^{3+}$ & 1473 & 2088 & N.D. & 80 & 1378 & 1 \\
\hline & $\mathrm{Zn}^{2+}$ & 5 & 3 & 25 & 2 & 1 & 1 \\
\hline & $\mathrm{Mn}^{2+}$ & 23 & 33 & 50 & 9 & N.D. & 1 \\
\hline & $\mathrm{Fe}^{2+}$ & N.D. & N.D. & 2822 & N.D. & 40 & N.D. \\
\hline \multirow{4}{*}{ 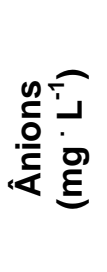 } & $F^{-}$ & N.D. & N.D. & N.D. & 9 & N.D. & N.D. \\
\hline & $\mathrm{Cl}^{-}$ & 310 & 284 & 294 & 194 & 292 & 70 \\
\hline & $\mathrm{NO}_{3}^{-}$ & N.D. & N.D. & 348 & 24 & N.D. & 143 \\
\hline & $\mathrm{SO}_{4}{ }^{2-}$ & 7337 & 7862 & 6300 & 1570 & 3522 & 518 \\
\hline
\end{tabular}


Pode ser observado na Tabela 13 que todas as DAMs exibiram baixos valores de $\mathrm{pH}$ variando entre 2,5 e 3,0, altas concentrações iônicas, comprovada pelos valores de condutividade que vão de 1155 a $9970 \mu \mathrm{S} \cdot \mathrm{cm}^{-1}$, e diferenças entre as quantidades de cátions e ânions, que serão abordadas a seguir.

A partir da caracterização química apresentada na Tabela 13, as concentrações de $\mathrm{Fe}^{3+}$ e $\mathrm{Fe}^{2+}$ distinguem-se para cada DAM, pois o ferro está presente na forma de $\mathrm{Fe}^{3+}$ nas DAMs MA, MB, PL e CB, e na DAM LX apresenta-se na forma de $\mathrm{Fe}^{2+}$. Já na DAM BA, ambas as formas de ferro são encontradas, sendo a relação $\mathrm{Fe}^{3+} / \mathrm{Fe}^{2+}$ presente na DAM BA igual a 35 .

A presença das duas formas de ferro, $\mathrm{Fe}^{3+}$ e $\mathrm{Fe}^{2+}$, se confirma pela diferença na coloração das DAMs, pois as DAMs MA, MB, $P L$ e BA, com maiores concentrações de $\mathrm{Fe}^{3+}$ apresentavam coloração amarelo-alaranjada, cor característica da presença de $\mathrm{Fe}^{3+}$. A DAM LX era de coloração verde, característica do $\mathrm{Fe}^{2+}$, confirmada pela presença deste íon na concentração de $2822 \mathrm{mg} \cdot \mathrm{L}^{-1}$ para esta DAM. Já a DAM CB apresentou-se incolor, coloração justificada pela baixa concentração de $\mathrm{Fe}^{3+}$, apenas $1 \mathrm{mg} \cdot \mathrm{L}^{-1}$.

O cátion sódio está presente em todas as DAMs, em concentrações que variam de $221 \mathrm{mg} \cdot \mathrm{L}^{-1}$ na DAM BA a $1059 \mathrm{mg} \cdot \mathrm{L}^{-1}$ na $\mathrm{DAM} C B$, mas não representa uma preocupação para o processo de ED por ser um cátion de comportamento bastante conhecido nos processos de membranas, sendo muitas vezes utilizado para a caracterização de membranas.

A presença de cálcio e magnésio nas DAMs deve ser considerada, pois a presença destes íons no efluente representa um risco à eficiência do processo, pois são responsáveis pela ocorrência do fenômeno de scaling nas membranas ${ }^{87,88}$.

Outra observação importante, a partir dos dados apresentados na Tabela 13 são as concentrações de $\mathrm{SO}_{4}{ }^{2-}$, ânion comum a todas as DAMs. A variabilidade na concentração de $\mathrm{SO}_{4}{ }^{2-}$ se confirma pela diferença 15 vezes maior na concentração de $\mathrm{SO}_{4}{ }^{2-}$ da DAM MB (7862 mg ' $\left.\mathrm{L}^{-1}\right)$ em comparação com a DAM CB $\left(518 \mathrm{mg} \cdot \mathrm{L}^{-1}\right)$, sendo estas as DAMs com maiores e menores concentrações de sulfatos, respectivamente.

O outro ânion comum a todas as DAMs é o cloreto, porém em quantidades inferiores às concentrações de sulfatos, sendo a menor relação $\mathrm{SO}_{4}{ }^{2-} / \mathrm{Cl}^{-}$encontrada 
para a DAM CB que é igual a 7, o que confirma que o ânion de influência na composição das DAMs é o ânion sulfato.

A variabilidade das características químicas apresentadas por cada DAM demonstra a influência do ponto de geração, e converge com a diversidade de caracterizações químicas encontradas na literatura para outras caracterizações de $\mathrm{DAM}^{2,39,41,89}$.

\subsection{SOLUÇÕES SINTÉTICAS}

Conforme descrito no item 4.3, a composição das soluções sintéticas foi definida a partir da caracterização química das DAMs.

A Tabela 14 apresenta a concentração em massa considerada de cada íon para as soluções sintéticas e também o pH de cada solução. Em destaque a solução $\mathrm{Fe}_{2}\left(\mathrm{SO}_{4}\right)_{3}+\mathrm{Na}_{2} \mathrm{SO}_{4} 2 \cdot 10^{-2}+1 \cdot 10^{-2}$, considerada a solução sintética que mais se aproximava da concentração real de íons $\mathrm{Fe}^{3+}, \mathrm{Na}^{+}$e $\mathrm{SO}_{4}{ }^{2-}$ em uma DAM.

Tabela 14 - Características das soluções sintéticas.

\begin{tabular}{cccccc}
\hline \multirow{2}{*}{ Composição } & $\begin{array}{c}\text { Concentração } \\
\text { Molar }(\mathbf{M})\end{array}$ & \multicolumn{3}{c}{$\begin{array}{c}\text { Concentração em massa } \\
\left(\mathbf{m g}^{\mathbf{2}} \mathbf{L}^{-1}\right)\end{array}$} & \multirow{2}{*}{ pH } \\
\cline { 3 - 5 } & $\mathbf{\mathbf { F e } ^ { 3 + }}$ & $\mathbf{N a}^{+}$ & $\mathbf{S O}_{4}{ }^{2-}$ & \\
\hline $\mathrm{Fe}_{2}\left(\mathrm{SO}_{4}\right)_{3}$ & $1 \cdot 10^{-3}$ & 112 & - & 288 & 2,3 \\
$\mathrm{Fe}_{2}\left(\mathrm{SO}_{4}\right)_{3}$ & $5 \cdot 10^{-3}$ & 558 & - & 1441 & 2,2 \\
$\mathrm{Fe}_{2}\left(\mathrm{SO}_{4}\right)_{3}$ & $1 \cdot 10^{-2}$ & 1117 & - & 2882 & 2,0 \\
$\mathrm{Fe}_{2}\left(\mathrm{SO}_{4}\right)_{3}$ & $2 \cdot 10^{-2}$ & 2234 & -- & 5764 & 1,9 \\
\hline $\mathrm{Na}_{2} \mathrm{SO}_{4}$ & $1 \cdot 10^{-2}$ & -- & 460 & 961 & 5,5 \\
$\mathrm{Na}_{2} \mathrm{SO}_{4}$ & $2 \cdot 10^{-2}$ & -- & 920 & 1921 & 5,8 \\
$\mathrm{Na}_{2} \mathrm{SO}_{4}$ & $6 \cdot 10^{-2}$ & -- & 2759 & 5764 & 5,9 \\
\hline $\mathrm{Fe}_{2}\left(\mathrm{SO}_{4}\right)_{3}+\mathrm{Na}_{2} \mathrm{SO}_{4}$ & $\mathbf{2} \cdot \mathbf{1 0}^{-2}+\mathbf{1} \cdot \mathbf{1 0 ^ { - 2 }}$ & $\mathbf{2 2 3 4}$ & $\mathbf{4 6 0}$ & $\mathbf{5 7 6 4 + 9 6 1}$ & $\mathbf{1 , 9}$ \\
$\mathrm{Fe}_{2}\left(\mathrm{SO}_{4}\right)_{3}+\mathrm{Na}_{2} \mathrm{SO}_{4}$ & $2 \cdot 10^{-2}+2 \cdot 10^{-2}$ & 2234 & 920 & $5764+1921$ & 2,0 \\
$\mathrm{Fe}_{2}\left(\mathrm{SO}_{4}\right)_{3}+\mathrm{Na}_{2} \mathrm{SO}_{4}$ & $2 \cdot 10^{-2}+6 \cdot 10^{-2}$ & 2234 & 2759 & $5764+5764$ & 2,1 \\
\hline
\end{tabular}

Vale destacar que foi utilizado apenas o ferro na forma de íon férrico $\left(\mathrm{Fe}^{3+}\right)$ para a preparação de todas as soluções sintéticas, considerando que das seis DAMs avaliadas foi encontrado nesta forma em maior quantidade em cinco delas, além de que a DAM que apresenta maior quantidade de íon ferroso $\left(\mathrm{Fe}^{2+}\right)$ poderia ter o $\mathrm{Fe}^{2+}$ oxidado a íon férrico $\left(\mathrm{Fe}^{3+}\right)^{90}$. 


\subsection{CRONOPOTENCIOMETRIA COM SOLUÇÕES SINTÉTICAS}

Conforme dito anteriormente, a cronopotenciometria permite identificar a limitação dos fenômenos de transferência de massa originados pela polarização por concentração. Quando se dá este processo, um incremento no potencial $\left(U_{m}\right)$ é observado durante a aplicação do impulso de corrente, causado pela diminuição significativa da concentração dos contra-íons na superfície da membrana em relação à concentração da solução no compartimento. Neste ponto, a densidade de corrente limite (ilim) do sistema de membrana/solução é alcançada, sendo o ponto de inflexão do $U_{m}$ para cada pulso de corrente, normalmente conhecido como o tempo de transição, $\tau$.

A forma dos cronopotenciogramas obtidos para a membrana aniônica variou com as espécies presentes nas soluções, mas não com a concentração delas, portanto na Figura 27 são mostrados os cronopotenciogramas obtidos para as soluções sintéticas 4, 6 e 9, que representam as soluções de $\mathrm{Fe}_{2}\left(\mathrm{SO}_{4}\right)_{3}, \mathrm{Na}_{2} \mathrm{SO}_{4} \mathrm{e}$ as soluções mistas de $\mathrm{Fe}_{2}\left(\mathrm{SO}_{4}\right)_{3}$ e $\mathrm{Na}_{2} \mathrm{SO}_{4}$, respectivamente. 


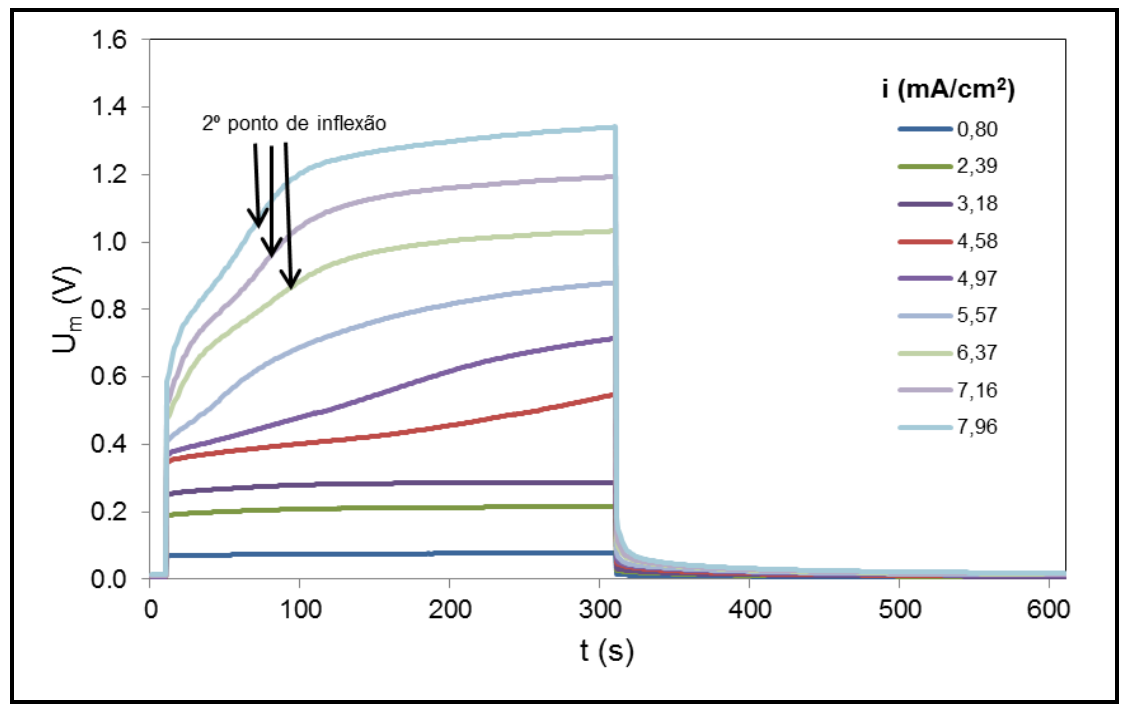

(a)

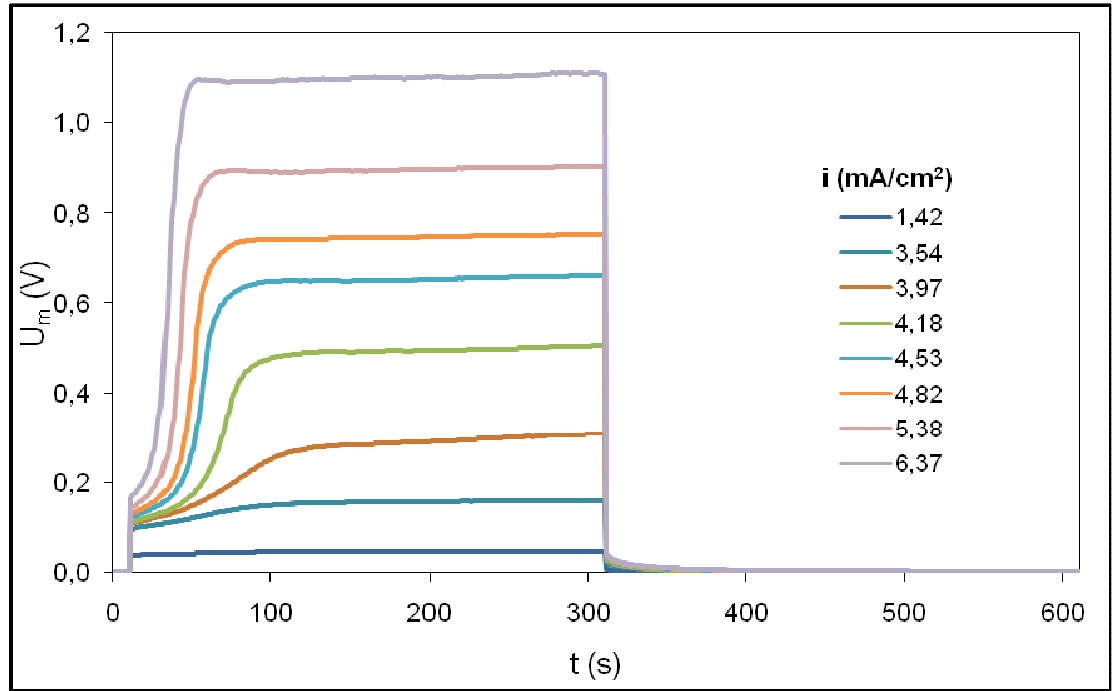

(b)

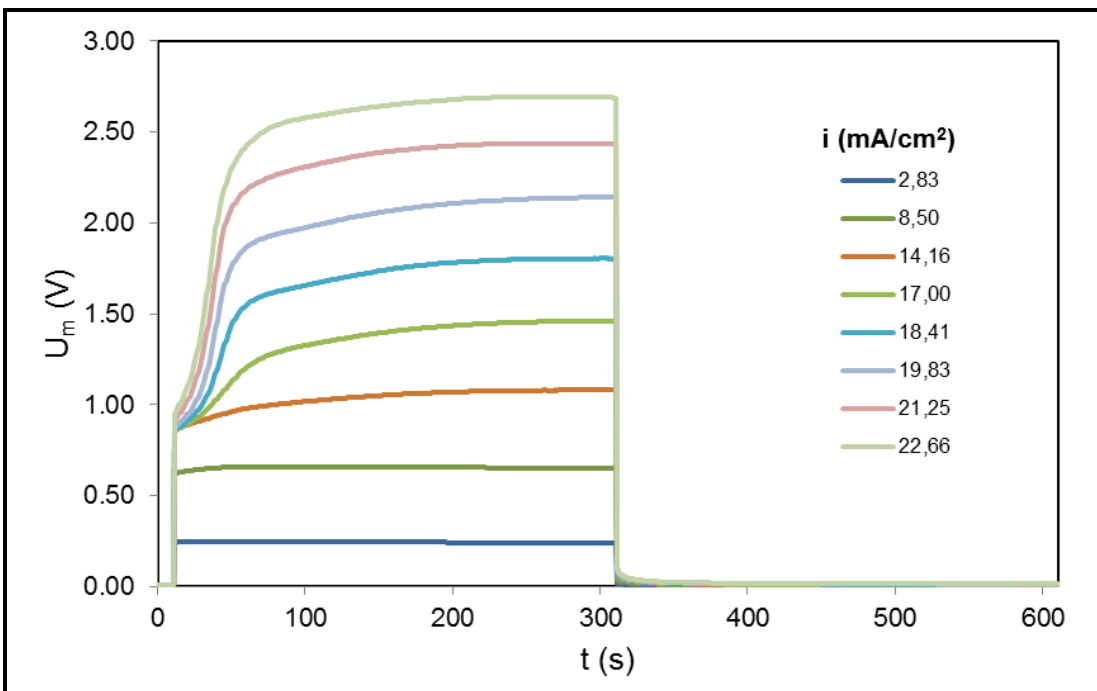

(c)

Figura 27 - Curvas cronopotenciométricas obtidas para membranas HDX $200 \mathrm{com}$ (a) solução de $\mathrm{Fe}_{2}\left(\mathrm{SO}_{4}\right)_{3} 2 \cdot 10^{-2} \mathrm{M}$, (b) solução de $\mathrm{Na}_{2} \mathrm{SO}_{4} 2 \cdot 10^{-2} \mathrm{M} \mathrm{e}$ (c) solução mista de $\mathrm{Fe}_{2}\left(\mathrm{SO}_{4}\right)_{3} 2 \cdot 10^{-2} \mathrm{M}+\mathrm{Na}_{2} \mathrm{SO}_{4} 2 \cdot 10^{-2} \mathrm{M}$. 
Os cronopotenciogramas obtidos com a membrana aniônica para soluções com $\mathrm{Fe}_{2}\left(\mathrm{SO}_{4}\right)_{3}$ na ausência e na presença de $\mathrm{Na}_{2} \mathrm{SO}_{4}$, bem como os obtidos para as soluções de $\mathrm{Na}_{2} \mathrm{SO}_{4}$, correspondem à forma típica de um cronopotenciograma ${ }^{91}$.

No início do impulso de corrente apresenta-se um aumento imediato no potencial $\left(U_{m}\right)$, associado à resistência ôhmica da membrana e das camadas adjacentes da solução. Em valores de densidade de corrente inferior a densidade de corrente limite $\left(\mathrm{i}_{\text {lim }}\right.$ ) este valor permanece quase constante até que a corrente é desligada. No entanto, quando a corrente se aproxima do valor limite, surge também um aumento na queda de potencial de membrana, resultado da diminuição na concentração de sulfatos no lado catódico da membrana aniônica. Finalmente, para valores iguais ou superiores a $\mathrm{i}_{\text {lim }} u m$ aumento acentuado no $U_{m}$ corresponde ao tempo de transição observado.

No entanto, foi observado em todos os casos uma semelhança.na forma dos cronopotenciogramas. No caso de soluções de $\mathrm{Fe}_{2}\left(\mathrm{SO}_{4}\right)_{3}$ sem $\mathrm{Na}_{2} \mathrm{SO}_{4}$ um segundo ponto de inflexão pode ser observado para valores maiores de corrente aplicada (Figura 27 (a)). Este segundo aumento no potencial pode ocorrer pela concorrência de diferentes espécies aniônicas na composição da solução.

Considerando as diferentes espécies presentes em equilíbrio, no caso de soluções de sulfato férrico, o diagrama de especiação do íon $\mathrm{Fe}^{3+}$ é apresentado na Figura 28.

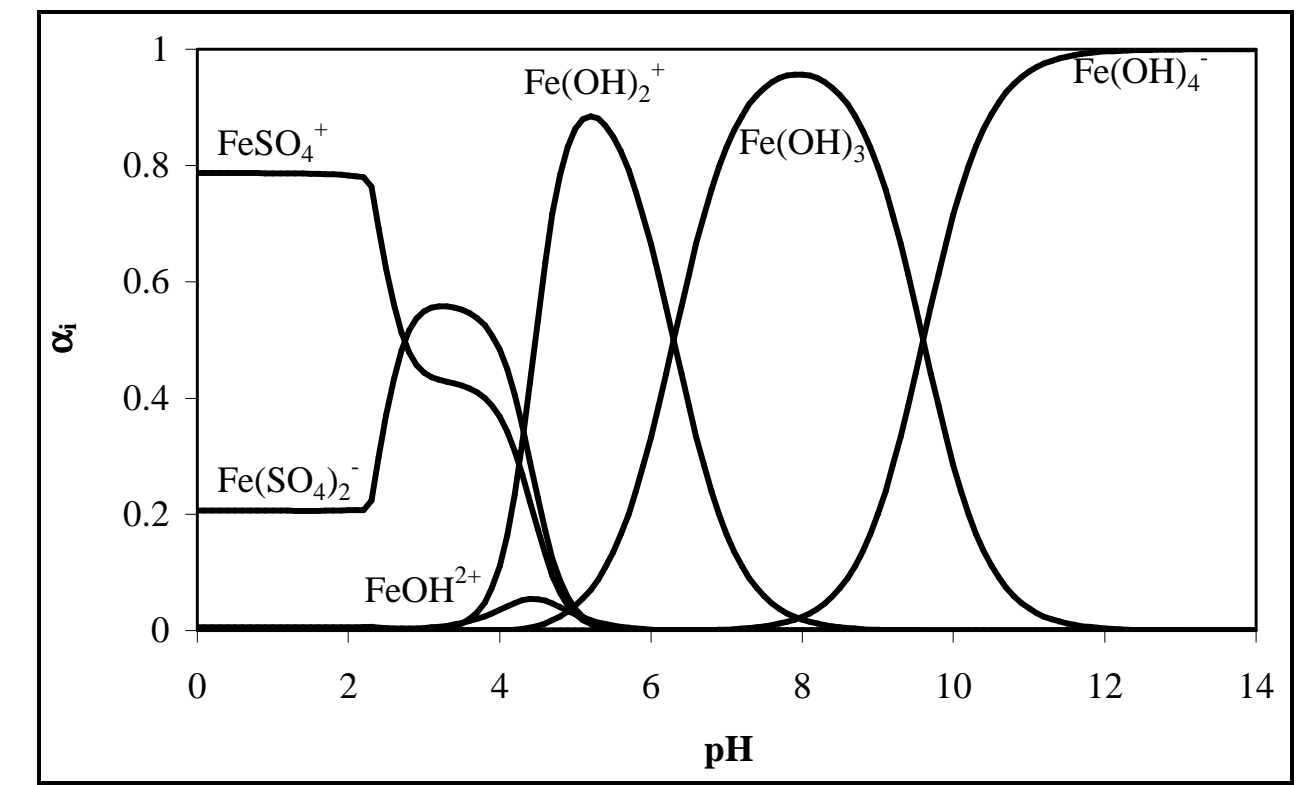

Figura 28 - Diagrama de especiação do $\mathrm{Fe}^{3+}$ para soluções de $\mathrm{Fe}_{2}\left(\mathrm{SO}_{4}\right)_{3} 2 \cdot 10^{-2} \mathrm{M}$. 
Observa-se na Figura 28 que os íons $\mathrm{SO}_{4}{ }^{2-}$ não são os únicos ânions presentes em solução de $\mathrm{Fe}_{2}\left(\mathrm{SO}_{4}\right)_{3}$. Como o pH das soluções, que contém ferro, oscila entre 1,9 e 2,3, também está presente em equilíbrio o complexo $\left[\mathrm{Fe}\left(\mathrm{SO}_{4}\right)^{2}\right]^{92}$. Portanto, o esgotamento do complexo carregado negativamente pode ser responsável pelo segundo ponto de inflexão no potencial observado para maiores valores de corrente aplicada $\left(\mathrm{i}>5,57 \mathrm{~mA} \cdot \mathrm{cm}^{-2}\right)$.

Supostamente, a passagem de íons $\mathrm{SO}_{4}{ }^{2-}$ através da membrana aniônica ocorre em primeiro lugar, uma vez que os íons $\mathrm{SO}_{4}{ }^{2-}$ são menores do que os íons $\left[\mathrm{Fe}\left(\mathrm{SO}_{4}\right)^{2-}\right]$. Consequentemente, esse transporte mais lento de íons $\left[\mathrm{Fe}\left(\mathrm{SO}_{4}\right)^{2}\right]$ pode explicar os valores mais elevados de tempos de transição para esta espécie e o fato de seu esgotamento ocorrer apenas para valores de densidade de corrente aplicada maiores que $5,57 \mathrm{~mA} \cdot \mathrm{cm}^{-2}$.

Além disso, vale ressaltar que a predominância de íons $\mathrm{SO}_{4}{ }^{2-}$ em condições de equilíbrio $\left(1,20 \cdot 10^{-2} \mathrm{M}\right)$ é maior do que a de íons $\left[\mathrm{Fe}\left(\mathrm{SO}_{4}\right)^{2}\right]\left(8,30 \cdot 10^{-3} \mathrm{M}\right)$. E no caso de soluções com $\mathrm{Na}_{2} \mathrm{SO}_{4}$, a predominância de íons sulfato é ainda maior em comparação com a concentração de outras espécies aniônicas complexas, o que explica a ausência de aumentos adicionais no potencial após o primeiro tempo de transição da Figura 27 (c), com a mistura de $\mathrm{Fe}_{2}\left(\mathrm{SO}_{4}\right)_{3}$ e $\mathrm{Na}_{2} \mathrm{SO}_{4}$.

No caso da membrana catiônica, a influência de dois cátions diferentes na composição das soluções também foi estudada. A célula de ED é composta de membranas aniônicas e catiônicas, e, portanto, a passagem de cátions presentes na composição das soluções através das membranas catiônicas pode ser um fator limitante do processo global de ED, tanto para o tratamento como para a recuperação de ácido sulfúrico a partir de DAM.

Neste caso foram avaliadas as espécies catiônicas predominantes em DAMs, íons férrico e sódio, para os quais se apresentam os cronopotenciogramas das soluções sintéticas 4 e 6 na Figura 29, representativos das soluções de $\mathrm{Na}_{2} \mathrm{SO}_{4} \mathrm{e}$ $\mathrm{Fe}_{2}\left(\mathrm{SO}_{4}\right)_{3}$, respectivamente. 


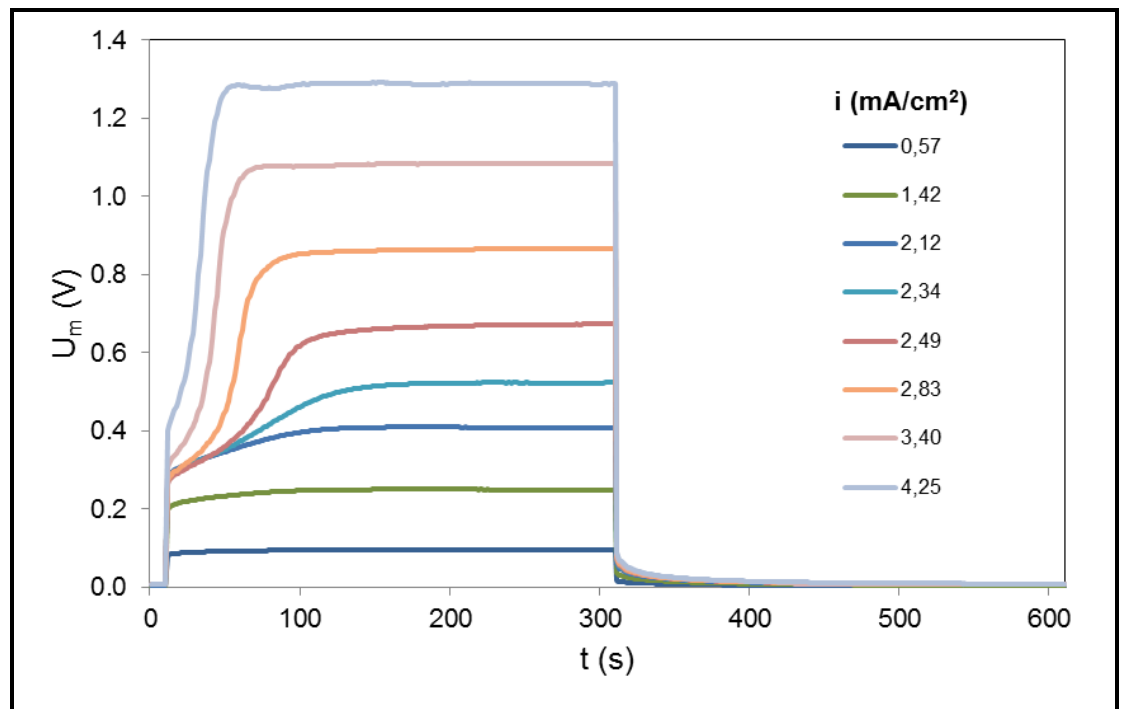

(a)

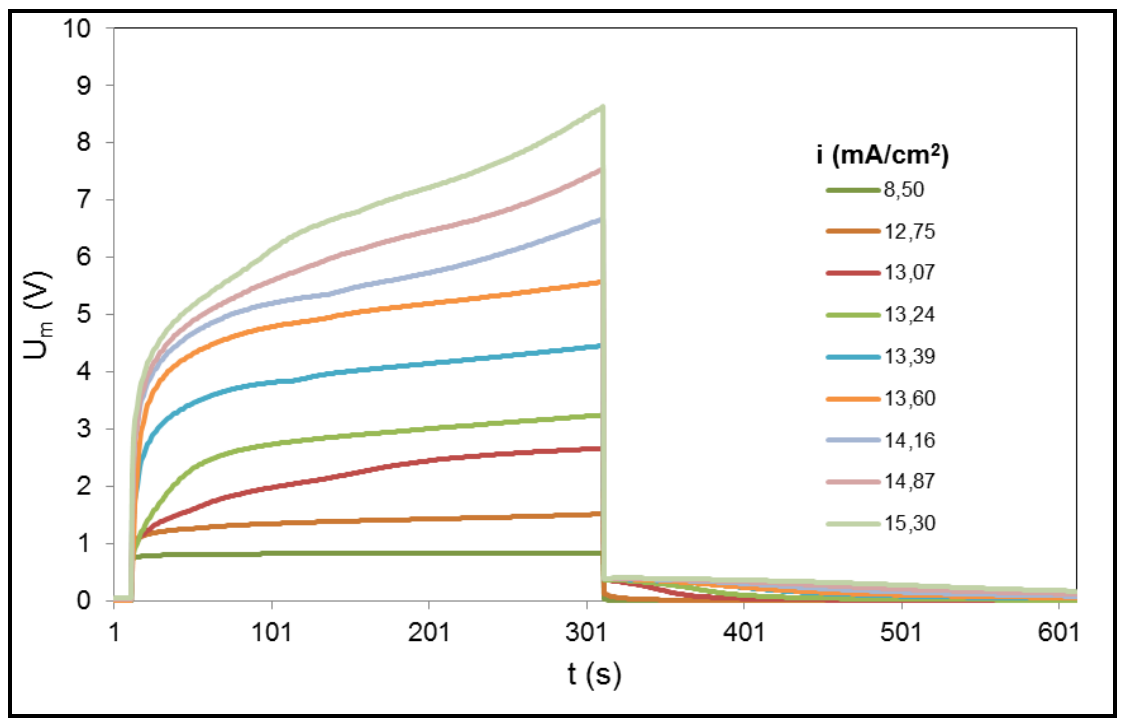

(b)

Figura 29 - Curvas cronopotenciométricas obtidas para membranas HDX $100 \mathrm{com}$ (a) solução de $\mathrm{Na}_{2} \mathrm{SO}_{4} 2 \cdot 10^{-2} \mathrm{M}$ e (b) solução de $\mathrm{Fe}_{2}\left(\mathrm{SO}_{4}\right)_{3} 2 \cdot 10^{-2} \mathrm{M}$.

Para as soluções de $\mathrm{Na}_{2} \mathrm{SO}_{4}$ (Figura 29 (a)), a forma das curvas cronopotenciométricas apresentam o caráter típico, conforme dito anteriormente para as membranas aniônicas. Em valores baixos de densidade de corrente $(0,57 \mathrm{e}$ $1,42 \mathrm{~mA} \cdot \mathrm{cm}^{-2}$, por exemplo), o comportamento do sistema corresponde a um padrão ôhmico, ou seja, o aumento do potencial $\left(U_{\mathrm{m}}\right)$ é linearmente proporcional a densidade de corrente, e neste caso, não há um aumento significativo no $U_{m}$ durante os 300 segundos de aplicação de impulso. Para valores de densidade de corrente superiores a densidade de corrente limite $\left(3,40\right.$ e 4,25 $\left.\mathrm{mA} \cdot \mathrm{cm}^{-2}\right)$ observa-se um aumento acentuado no $U_{\mathrm{m}}$ devido a rápida diminuição na concentração de cátions 
no compartimento central. Pode ser observado que os tempos de transição $(\tau)$ diminuem para valores crescentes de corrente aplicada. Para tempos maiores do que $\tau$, o $\cup_{m}$ permanece praticamente constante até o fim do impulso.

Ao contrário, a forma do cronopotenciograma obtido para soluções de $\mathrm{Fe}_{2}\left(\mathrm{SO}_{4}\right)_{3}$ (Figura 29 (b)) é bastante diferente. O aumento no potencial $\left(\mathrm{U}_{\mathrm{m}}\right)$ em correntes mais elevadas do que o valor limite é crescente, apresentando um aumento contínuo no $U_{m}$ até o fim do impulso.

Observou-se após as cronopotenciometrias a formação de precipitados avermelhados no lado anódico da membrana catiônica para alguns ensaios, o que pode estar associado com o aumento contínuo do potencial $\left(U_{m}\right)$ com o tempo e também com o repouso prolongado do $U_{m}$ observado no cronopotenciograma após a interrupção da corrente. A camada avermelha formada na superfície da membrana é atribuída à precipitação de $\mathrm{Fe}(\mathrm{OH})_{3}$, devido à sua cor e ao fato de que aparecem apenas quanto utilizam-se soluções com $\mathrm{Fe}_{2}\left(\mathrm{SO}_{4}\right)_{3}$. Além disso, a formação de precipitados de hidróxido de ferro na superfície da membrana promove um aumento, significativamente superior, no potencial da membrana aos observados para as soluções na ausência de espécies de ferro, como pode ser deduzida a partir da comparação dos valores das ordenadas, de ambos os cronopotenciogramas da Figura 29.

O cronopotenciograma obtido para a membrana de catiônica com a mistura de $\mathrm{Fe}_{2}\left(\mathrm{SO}_{4}\right)_{3}$ e $\mathrm{Na}_{2} \mathrm{SO}_{4}$ é apresentada na Figura 30. Considerando baixos valores de densidade de corrente $\left(5,67\right.$ a $\left.11,90 \mathrm{~mA} \cdot \mathrm{cm}^{-2}\right)$ a resposta cronopotenciométrica é análoga à observada no caso de soluções com $\mathrm{Na}_{2} \mathrm{SO}_{4}$, havendo um aumento acentuado no potencial devido ao esgotamento de íons $\mathrm{Na}^{+}$. No entanto, para

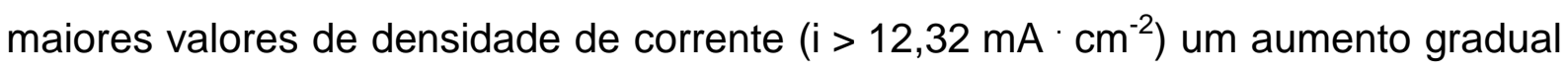
da queda de potencial de membrana é observado, o que é bastante semelhante à observada em soluções contendo apenas $\mathrm{Fe}_{2}\left(\mathrm{SO}_{4}\right)_{3}$ e pode, assim, ser atribuída à precipitação de $\mathrm{Fe}(\mathrm{OH})_{3}$ na superfície da membrana de frente para o compartimento central.

Além disto, a partir do diagrama de especiação mostrado na Figura 28 observa-se que o $\mathrm{Fe}^{3+}$ está presente principalmente na forma de complexo $\left[\mathrm{FeSO}_{4}{ }^{+}\right]$. Esses íons são maiores e têm uma menor carga do que os íons $\mathrm{Fe}^{3+}$, contribuindo 
assim com a sua menor mobilidade para os altos valores de queda de potencial de membrana registrado em soluções de sulfato férrico.

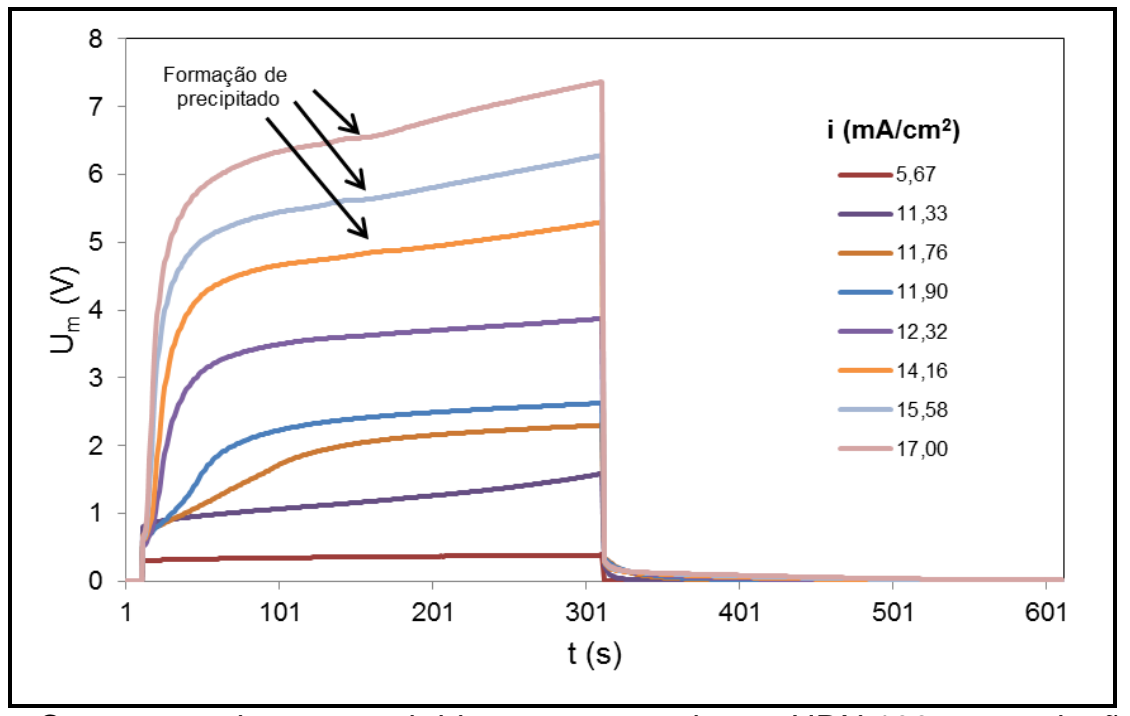

Figura 30 - Cronopotenciogramas obtidos com a membrana HDX 100 para solução mista de $\mathrm{Fe}_{2}\left(\mathrm{SO}_{4}\right)_{3} 2 \cdot 10^{-2} \mathrm{M}+\mathrm{Na}_{2} \mathrm{SO}_{4} 2 \cdot 10^{-2} \mathrm{M}$.

As curvas de corrente-potencial (CVCs) de ambas as membranas de troca iônica foram descritas a partir dos últimos valores dos potenciais registrados nos cronopotenciogramas antes da interrupção das correntes. As CVCs das membranas descrevem os diferentes padrões do comportamento da membrana como uma função do intervalo de corrente aplicada.

As curvas típicas das membranas apresentam três regiões características: a primeira região de baixas correntes em que uma relação direta entre densidade de corrente e potencial descreve um comportamento ôhmico do sistema considerado, membrana/solução ${ }^{9}$, uma segunda região em que um platô é observado na curva como consequência de um aumento na resistência da membrana, principalmente devido à escassez de contra-íons nas camadas de difusão, e uma terceira zona na qual o transporte iônico através da membrana é mais uma vez reforçado com incrementos adicionais do $U_{m}^{64,93,94}$.

As CVCs obtidas para as diferentes soluções com a membrana aniônica são apresentadas na Figura 31. 


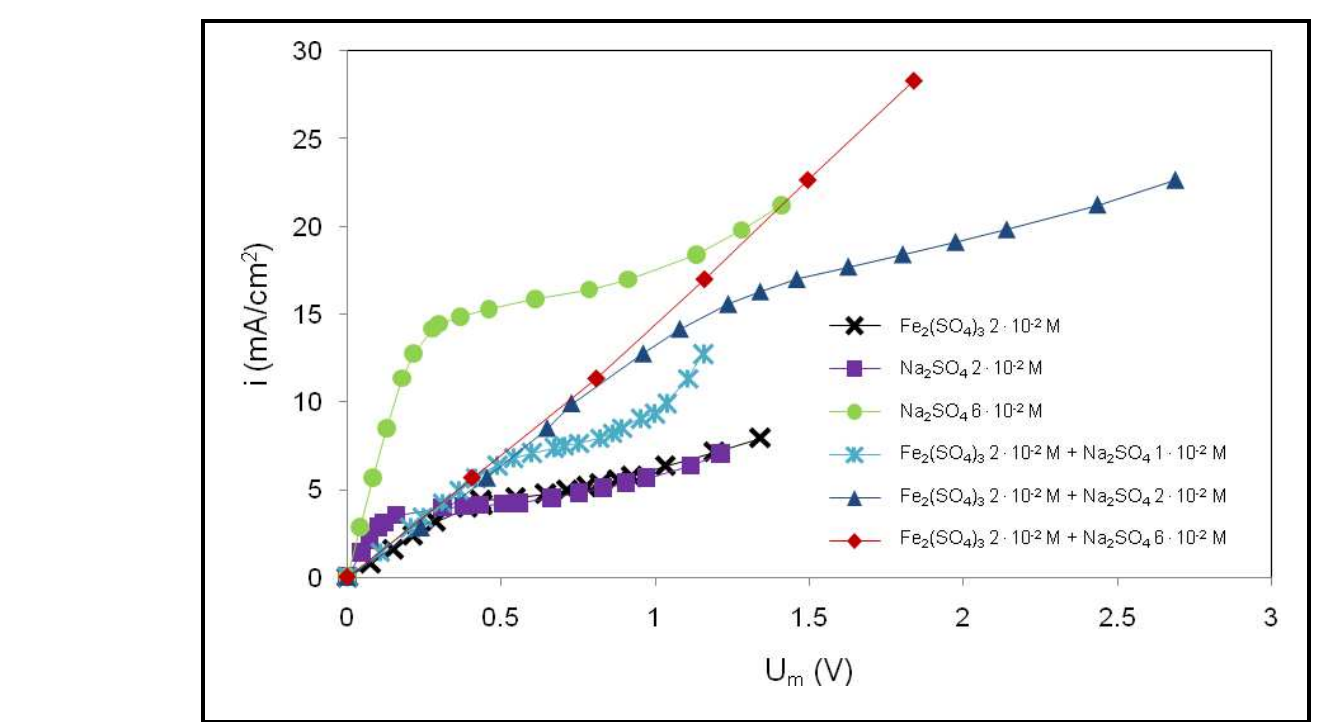

Figura 31 - CVC obtidas para a membrana aniônica HDX 200 com diversas concentrações de eletrólitos.

A partir da Figura 31 observa-se que as três regiões características estão presentes nas curvas. Portanto, é possível extrair diferentes parâmetros a partir das curvas, tais como a resistência da membrana na região ôhmica $\left(R_{1}\right)$, a partir do inverso da inclinação da referida região, e os valores de densidade de corrente limite (ilim) a partir da interseção da primeira região com a região de platô.

Os resultados de resistência das membranas $\left(R_{1}\right)$ e valores de densidade de corrente limite ( $\mathrm{i}_{\text {lim) }}$ ) são apresentados para a membrana aniônica HDX 200 para cada solução na Tabela 15.

Tabela 15 - Parâmetros extraídos das CVCs para a membrana aniônica/solução.

\begin{tabular}{|c|c|c|c|c|}
\hline \multirow{2}{*}{ Membrana } & Composição da solução & $\begin{array}{c}\boldsymbol{\lambda} \\
\left(\mathbf{m S}^{-} \mathbf{c m}^{-1}\right)\end{array}$ & $\begin{array}{c}\mathbf{R}_{\mathbf{1}} \\
\left(\mathbf{\Omega} \cdot \mathbf{c m}^{2}\right)\end{array}$ & $\begin{array}{c}\mathbf{i}_{\text {lim }} \\
\left(\mathbf{m A} \cdot \mathbf{c m}^{-2}\right)\end{array}$ \\
\hline \multirow{4}{*}{$\mathrm{HDX} 200$} & $\mathrm{Fe}_{2}\left(\mathrm{SO}_{4}\right)_{3} 2 \cdot 10^{-2} \mathrm{M}$ & 2,60 & 89,54 & 4,00 \\
\cline { 2 - 5 } & $\mathrm{Na}_{2} \mathrm{SO}_{4} 2 \cdot 10^{-2} \mathrm{M}$ & 1,09 & 35,73 & 3,75 \\
\cline { 2 - 5 } & $\mathrm{Na}_{2} \mathrm{SO}_{4} 6 \cdot 10^{-2} \mathrm{M}$ & 2,63 & 15,70 & 14,48 \\
\cline { 2 - 5 } & $\mathrm{Fe}_{2}\left(\mathrm{SO}_{4}\right)_{3} 2 \cdot 10^{-2} \mathrm{M}+\mathrm{Na}_{2} \mathrm{SO}_{4} 1 \cdot 10^{-2} \mathrm{M}$ & 5,53 & 77,48 & 6,80 \\
\cline { 2 - 5 } & $\mathrm{Fe}_{2}\left(\mathrm{SO}_{4}\right)_{3} 2 \cdot 10^{-2} \mathrm{M}+\mathrm{Na}_{2} \mathrm{SO}_{4} 2 \cdot 10^{-2} \mathrm{M}$ & 2,61 & 76,47 & 16,36 \\
\cline { 2 - 5 } & $\mathrm{Fe}_{2}\left(\mathrm{SO}_{4}\right)_{3} 2 \cdot 10^{-2} \mathrm{M}+\mathrm{Na}_{2} \mathrm{SO}_{4} 6 \cdot 10^{-2} \mathrm{M}$ & 3,28 & 68,56 & $>30$ \\
\hline
\end{tabular}

Observa-se na Figura 31 que as curvas obtidas com soluções que contêm apenas $\mathrm{Na}_{2} \mathrm{SO}_{4}$ apresentam um aumento nos valores da densidade de corrente limite com o aumento da concentração da solução. Esta dependência justifica-se pela quantidade de íons $\mathrm{SO}_{4}{ }^{2-}$ presentes nas soluções, que são os ânions principais a serem transportados através da membrana HDX 200. Além disso, um aumento de 
três vezes na concentração da solução corresponde a um aumento nos valores de densidade de corrente limite quase na mesma magnitude.

Por outro lado, a resistência ôhmica diminui com o aumento na concentração de $\mathrm{Na}_{2} \mathrm{SO}_{4}$, isso porque ocorre um aumento na condutividade da solução.

Observa-se que os resultados obtidos com soluções contendo $\mathrm{Fe}_{2}\left(\mathrm{SO}_{4}\right)_{3}$ apresentam a mesma dependência entre os valores de densidade de corrente limite e a concentração das soluções. No entanto, a magnitude das alterações nos valores de densidade de corrente limite não é a mesma que a de soluções de $\mathrm{Na}_{2} \mathrm{SO}_{4}$ apesar de os principais ânions a serem transportados através das membranas aniônicas também serem os íons $\mathrm{SO}_{4}{ }^{2-}$.

Por exemplo, se soluções de $\mathrm{Na}_{2} \mathrm{SO}_{4}$ e $\mathrm{Fe}_{2}\left(\mathrm{SO}_{4}\right)_{3}$ ambas $2 \cdot 10^{-2} \mathrm{M}$, são comparadas, o limitante de corrente, neste último caso deve ser, em princípio, três vezes em relação ao primeiro, porque a quantidade total de sulfatos é três vezes maior. No entanto, praticamente o mesmo valor de $\mathrm{i}_{\text {lim }}$ é obtido a partir de ambas as CVCs, de acordo com a Figura 31. Como comentado anteriormente, isto se justifica pela associação parcial dos íons $\mathrm{SO}_{4}{ }^{2-}$ aos íons $\mathrm{Fe}^{3+}$ em soluções de sulfato férrico que dão origem a outras espécies complexas, tais como $\left[\mathrm{FeSO}_{4}{ }^{+}\right]$ou $\left[\mathrm{Fe}\left(\mathrm{SO}_{4}\right)^{2-}\right]$ e, portanto, a concentração de íons $\mathrm{SO}_{4}{ }^{2-}$ livre é reduzida.

Quanto aos resultados de resistência das membranas $\left(R_{1}\right)$, um aumento na resistência da membrana é observado quando o íon férrico está presente, o que indica um comportamento diferente nas soluções de sulfato férrico e sulfato de sódio. Para valores constantes de concentração de $\mathrm{Na}_{2} \mathrm{SO}_{4}$, a adição de $\mathrm{Fe}_{2}\left(\mathrm{SO}_{4}\right)_{3}$ implica em maior quantidade de espécies complexas, os quais apresentam menor mobilidade devido ao tamanho das espécies, o que representam um aumento na resistência da membrana. A partir dos resultados das CVCs obtidos constatou-se a baixa mobilidade de $\left[\mathrm{Fe}\left(\mathrm{SO}_{4}\right)^{2-}\right]$ através da membrana aniônica o que promove um aumento nos valores de resistência da membrana.

As CVCs obtidos com a membrana catiônica HDX 100 são mostrados na Figura 32. Neste caso, a competição entre diferentes espécies carregadas positivamente para a passagem através da membrana foi avaliada. 


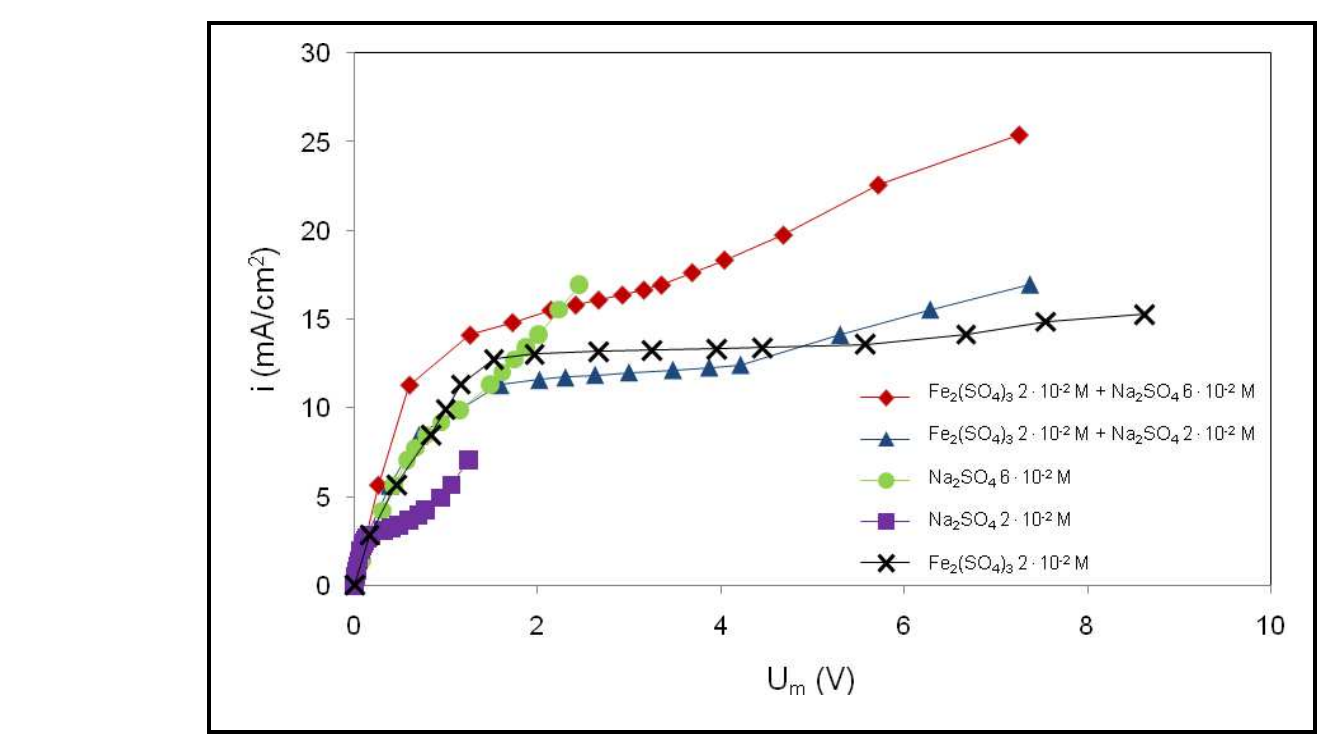

Figura 32 - CVCs obtidas para a membrana catiônica HDX 100 com diversas concentrações de eletrólitos.

Observa-se que as curvas obtidas com soluções de $\mathrm{Fe}_{2}\left(\mathrm{SO}_{4}\right)_{3}$ mostram um comportamento anormal porque os platôs são significativamente mais largos e a inclinação da terceira região é pequena quando comparada com outras CVCs da literatura ou com as obtidas para as soluções de sulfato de sódio ${ }^{95}$. Estas características peculiares observadas para os sulfatos férricos provavelmente resultam da precipitação de hidróxidos e do aumento contínuo da queda de potencial de membrana que foi anteriormente observado nas curvas cronopotenciométricas.

Os resultados de resistência das membranas $\left(R_{1}\right)$ e valores de densidade de corrente limite ( $\mathrm{l}_{\text {lim) }}$ são apresentados para a membrana catiônica HDX 100 para cada solução na Tabela 16.

Tabela 16 - Parâmetros extraídos das CVCs para a membrana catiônica/solução.

\begin{tabular}{|c|c|c|c|c|}
\hline Membrana & Composição da solução & $\begin{array}{c}\lambda \\
\left(\mathrm{mS}^{-} \mathrm{cm}^{-1}\right)\end{array}$ & $\begin{array}{c}R_{1} \\
\left(\Omega \cdot \mathbf{c m}^{2}\right) \\
\end{array}$ & $\left(\mathrm{mA}^{\left.\mathbf{I}_{\lim } \cdot \mathbf{c m}^{-2}\right)}\right.$ \\
\hline \multirow{6}{*}{ HDX 100} & $\mathrm{Fe}_{2}\left(\mathrm{SO}_{4}\right)_{3} 2 \cdot 10^{-2} \mathrm{M}$ & 2,60 & 105,46 & 13,00 \\
\hline & $\mathrm{Na}_{2} \mathrm{SO}_{4} 2 \cdot 10^{-2} \mathrm{M}$ & 1,09 & 178,70 & 2,25 \\
\hline & $\mathrm{Na}_{2} \mathrm{SO}_{4} 6 \cdot 10^{-2} \mathrm{M}$ & 2,63 & 72,46 & 8,00 \\
\hline & $\mathrm{Fe}_{2}\left(\mathrm{SO}_{4}\right)_{3} 2 \cdot 10^{-2} \mathrm{M}+\mathrm{Na}_{2} \mathrm{SO}_{4} 1 \cdot 10^{-2} \mathrm{M}$ & 5,53 & 67,48 & 15,58 \\
\hline & $\mathrm{Fe}_{2}\left(\mathrm{SO}_{4}\right)_{3} 2 \cdot 10^{-2} \mathrm{M}+\mathrm{Na}_{2} \mathrm{SO}_{4} 2 \cdot 10^{-2} \mathrm{M}$ & 2,61 & 86,69 & 11,19 \\
\hline & $\mathrm{Fe}_{2}\left(\mathrm{SO}_{4}\right)_{3} 2 \cdot 10^{-2} \mathrm{M}+\mathrm{Na}_{2} \mathrm{SO}_{4} 6 \cdot 10^{-2} \mathrm{M}$ & 3,28 & 61,30 & 16,25 \\
\hline
\end{tabular}

Além disso, o valor obtido para densidade de corrente limite de soluções de $\mathrm{Fe}_{2}\left(\mathrm{SO}_{4}\right)_{3} 2 \cdot 10^{-2} \mathrm{M}\left(\mathrm{i}\right.$ im $\left.=13,00 \mathrm{~mA} \cdot \mathrm{cm}^{-2}\right)$ é significativamente mais elevado do que o valor obtido para a mesma concentração de $\mathrm{Na}_{2} \mathrm{SO}_{4}\left(i_{\text {lim }}=2,25 \mathrm{~mA} \cdot \mathrm{cm}^{-2}\right)$. A 
acidez de soluções férricas parece desempenhar um papel importante, uma vez que valores de $\mathrm{pH}$ próximos a 2 foram medidos nestas soluções. Portanto, o transporte de íons $\mathrm{H}^{+}$através da membrana contribui para os valores elevados de $\mathrm{i}_{\mathrm{lim}}$ em relação aos obtidos para soluções de sulfato de sódio.

$\mathrm{O}$ valor de densidade de corrente limite (i $\mathrm{i}_{\text {lim }}$ ) obtido para a mistura $\mathrm{Fe}_{2}\left(\mathrm{SO}_{4}\right)_{3}$ $2 \cdot 10^{-2} \mathrm{M}$ e $\mathrm{Na}_{2} \mathrm{SO}_{4} 2 \cdot 10^{-2} \mathrm{M}\left(\mathrm{i}_{\text {lim }}=11,19 \mathrm{~mA} \cdot \mathrm{cm}^{-2}\right)$ é semelhante ao valor obtido para soluções sem íons $\mathrm{Na}^{+}\left(i_{\text {lim }}=13,00 \mathrm{~mA} \cdot \mathrm{cm}^{-2}\right)$. Isto indica que a origem da região do platô no caso de soluções férricas é promovida principalmente pela formação de precipitados de ferro, devido à passagem de prótons através da membrana e da alcalinização do pH na superfície da membrana.

No entanto, para concentrações mais elevadas de $\mathrm{Na}_{2} \mathrm{SO}_{4}\left(6 \cdot 10^{-2} \mathrm{M}\right)$ na mistura com sulfato férrico, a precipitação de hidróxidos é retardada e ocorre em valores de densidade de corrente mais elevados (acima de 16,25 $\mathrm{mA} \cdot \mathrm{cm}^{-2}$ ), porque a concentração de íons $\mathrm{Na}^{+}$é maior e aumenta a capacidade de transporte de cátions através da membrana.

No que se refere aos valores de resistência da membrana $\left(R_{1}\right)$, eles estão de acordo com a concentração de espécies susceptíveis ao transporte através da membrana, uma vez que um aumento na concentração de ambas as soluções $\mathrm{Fe}_{2}\left(\mathrm{SO}_{4}\right)_{3}$ e $\mathrm{Na}_{2} \mathrm{SO}_{4}$ promove a redução dos valores de $\mathrm{R}_{1}$.

Finalmente, enfatiza-se a relevância dos valores aumentados de $U_{m}$ quando hidróxidos de ferro precipitam sobre a superfície da membrana catiônica. O aumento da resistência da membrana afeta o processo global de recuperação de $\mathrm{H}_{2} \mathrm{SO}_{4}$, porque implica em um desperdício de energia e bloqueio das membranas.

Portanto, um tratamento preliminar de remoção do $\mathrm{Fe}^{3+}$ poderia aumentar a eficácia global do processo. Outras possíveis alternativas incluem a operação em densidades de corrente significativamente menores do que os valores de densidade de corrente limite ou da utilização de membranas catiônicas com um transporte melhorado de íons férricos que poderiam evitar a precipitação de hidróxidos na sua superfície. 


\subsection{ELETRODIÁLISE COM SOLUÇÕES SINTÉTICAS EM BANCADA (I)}

Conforme dito no item 4.6 os ensaios de ED com soluções sintéticas em bancada (I) tinham por objetivo avaliar o transporte de Fe através da membrana catiônica HDX 100.

Para tanto foram realizados 4 ensaios, variando-se as soluções em cada compartimento bem como a densidade de corrente aplicada durante os ensaios, conforme Tabela 10.

Nos ensaios 1ED-SS e 2ED-SS a solução de $\mathrm{Fe}_{2}\left(\mathrm{SO}_{4}\right)_{3}$ foi colocada apenas no compartimento central nas concentrações de $5 \cdot 10^{-3} \mathrm{M} \mathrm{e} 2 \cdot 10^{-2} \mathrm{M}$, respectivamente. $\mathrm{E}$ nos compartimentos do ânodo e do cátodo uma solução de $\mathrm{Na}_{2} \mathrm{SO}_{4}$ na concentração de $2 \cdot 10^{-2} \mathrm{M}$. Esta configuração permitiu avaliar a passagem de $\mathrm{Fe}$ através da membrana catiônica para o compartimento do cátodo, pois todo $\mathrm{Fe}$ presente neste compartimento proveu do compartimento diluído.

No ensaio 1ED-SS aplicou-se uma densidade de corrente de $1,5 \mathrm{~mA} \cdot \mathrm{cm}^{-2}$ durante 7 horas, e os resultados da quantificação de Fe total no compartimento central e no compartimento cátodo são apresentados na Figura 33.

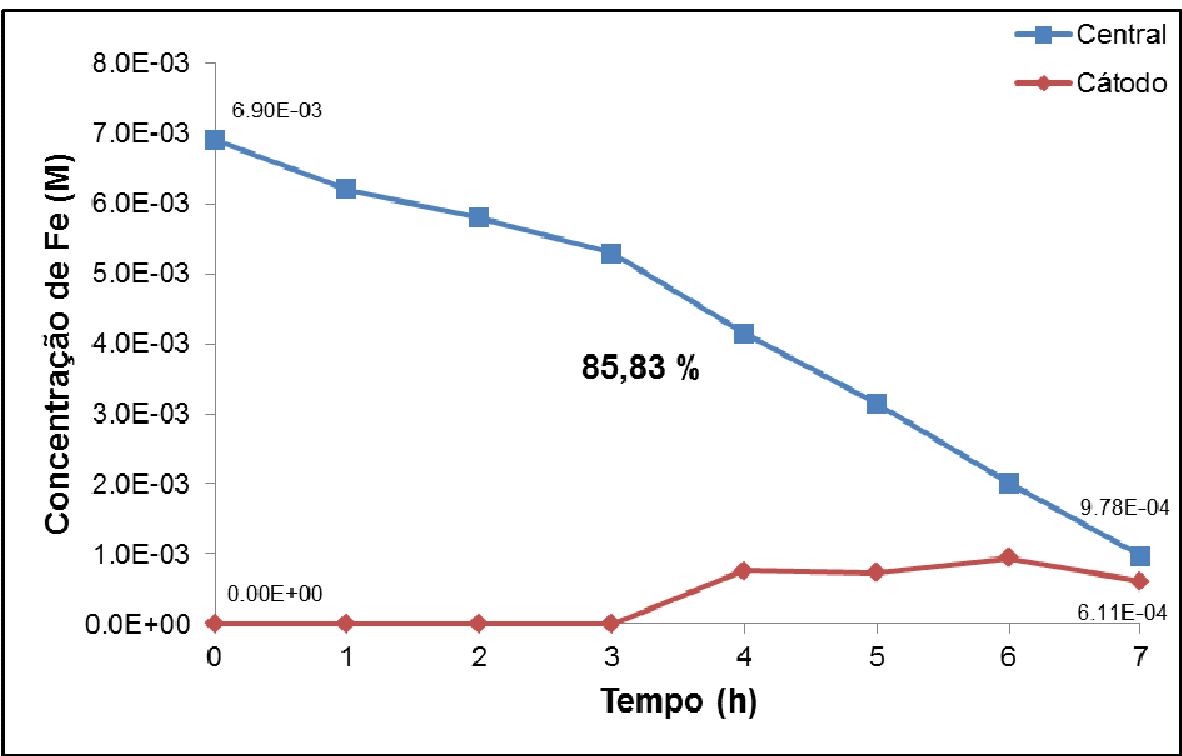

Figura 33 - Quantificação de Fe no compartimento central e cátodo do ensaio 1ED-SS.

Observa-se na Figura 33 que há redução na concentração de $\mathrm{Fe}$ no compartimento central ao longo das $7 \mathrm{~h}$ de ensaio, sendo a concentração inicial de Fe neste compartimento igual a $6,90 \cdot 10^{-3} \mathrm{M}$ e a concentração final de $9,78 \cdot 10^{-4} \mathrm{M}$, configurando desta forma, uma extração de $85,83 \%$ de Fe. 
Ao mesmo tempo tem-se o aumento na concentração de Fe no compartimento do cátodo. Observa-se que a presença de Fe neste compartimento se dá a partir da terceira hora de ensaio, pois nas primeiras horas de ensaio o íon estava provavelmente atravessando a membrana e ainda não se encontrava dissolvido em solução para ser quantificado. Outra observação a partir da Figura 33 é a redução na concentração de Fe na última hora, justificada pela precipitação do mesmo.

Para o ensaio 2ED-SS, aplicou-se uma densidade de corrente de 5,0 $\mathrm{mA} \cdot \mathrm{cm}^{-2}$ durante $8 \mathrm{~h}$, e os resultados da quantificação de Fe total nos compartimentos central e cátodo são apresentados na Figura 34.

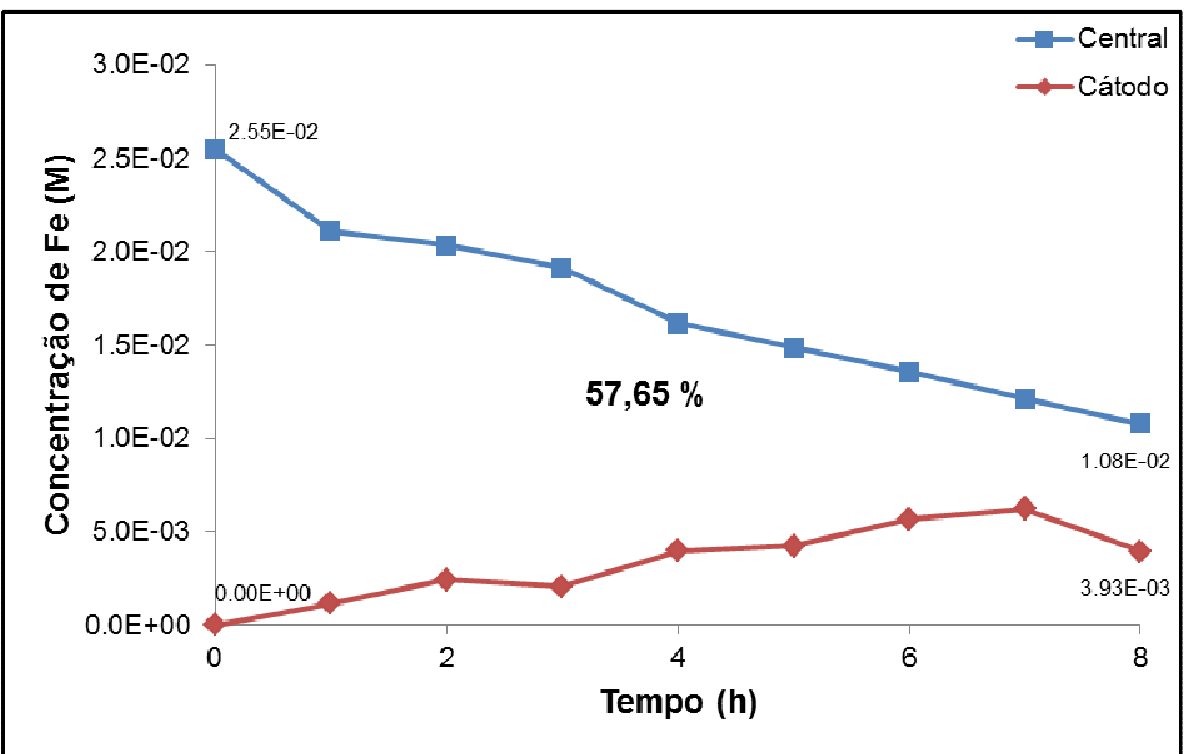

Figura 34 - Quantificação de Fe no compartimento central e cátodo do ensaio 2ED-SS.

$\mathrm{Na}$ Figura 34, observa-se uma redução na concentração de $\mathrm{Fe}$ no compartimento central ao longo das $8 \mathrm{~h}$ de ensaio, porém um pouco menor do que a observada no ensaio 1ED-SS, pois no ensaio 2ED-SS a extração percentual de $\mathrm{Fe}$ foi de $57,65 \%$, considerando a concentração inicial de Fe igual a $2,55 \cdot 10^{-2} \mathrm{M}$ e a final $1,08 \cdot 10^{-2} \mathrm{M}$.

A concentração de Fe também é crescente no compartimento do cátodo, comprovando a passagem de Fe através da membrana catiônica. Observa-se que o Fe surge logo a partir da primeira hora de ensaio, o que provavelmente se dá pela maior densidade de corrente aplicada a este ensaio, quando comparado ao ensaio 1ED-SS, que acelerou o processo de passagem do íon através da membrana. Novamente, observa-se para o compartimento do cátodo (Figura 34) 
uma redução na concentração de Fe na última hora de ensaio, também justificada pela precipitação do mesmo.

Comparando os percentuais de extração do ensaio 1ED-SS com o 2ED-SS, pode-se inferir que a concentração inicial da solução exerce maior influência no processo do que a densidade de corrente aplicada. Pois apesar de a solução empregada no ensaio 2ED-SS ser 4 vezes mais concentrada do que a solução do ensaio 1ED-SS, a densidade de corrente aplicada também foi aproximadamente 4 vezes mais alta.

A fim de avaliar se a passagem do ferro poderia se dar por um processo de difusão e não por aplicação de corrente elétrica, foram avaliadas outras 2 configurações, ensaios 3ED-SS e 4ED-SS, em que a mesma solução contendo $\mathrm{Fe}_{2}\left(\mathrm{SO}_{4}\right)_{3}$ foi colocada no compartimento central e no compartimento dos eletrodos (ânodo e cátodo).

No ensaio 3ED-SS empregou-se a solução de $\mathrm{Fe}_{2}\left(\mathrm{SO}_{4}\right)_{3} 2 \cdot 10^{-2} \mathrm{M}$ nos três compartimentos, também sob uma densidade de corrente de $5,0 \mathrm{~mA} \cdot \mathrm{cm}^{-2}$ durante $8 \mathrm{~h}$ de ensaio. O ferro presente nos compartimentos central e cátodo foram monitorados ao longo das 8 h, e os resultados são mostrados na Figura 35.

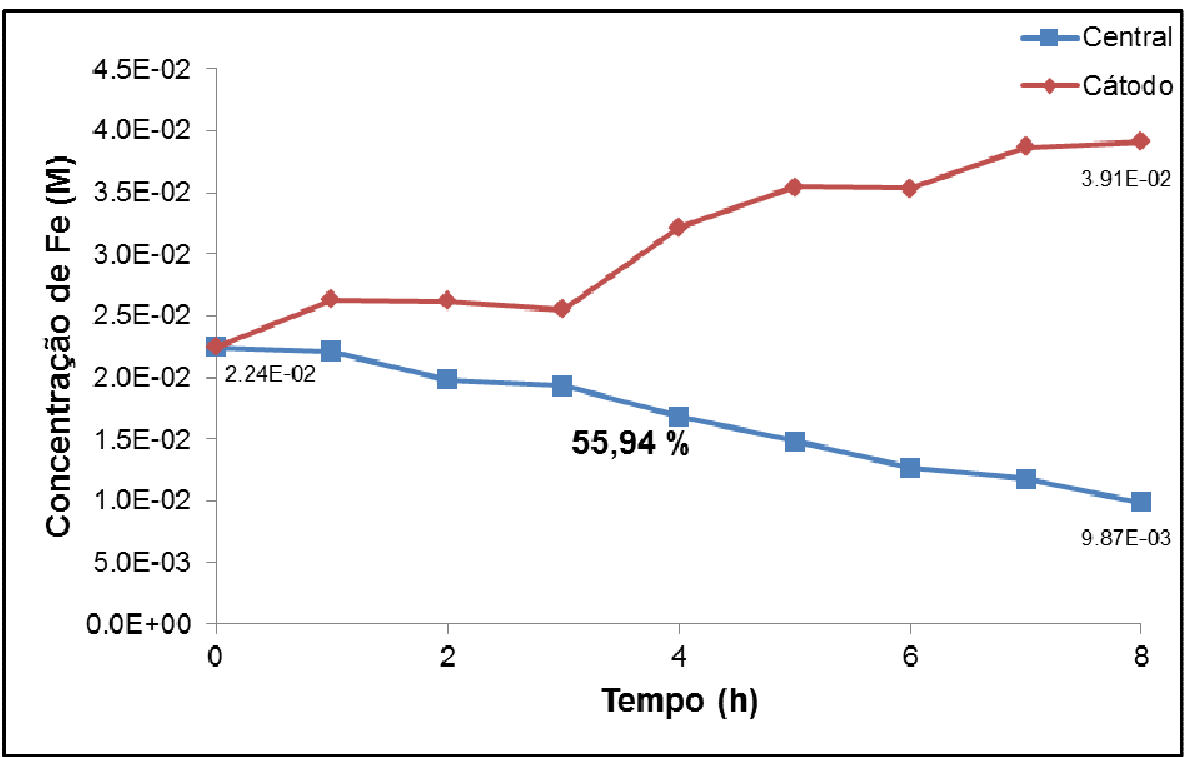

Figura 35 - Quantificação de Fe no compartimento central e cátodo do ensaio 3ED-SS.

Da análise da Figura 35 comprova-se que a passagem do ferro se dá pela aplicação da corrente elétrica e não somente por difusão, pois mesmo havendo a mesma solução nos três compartimentos, observa-se uma redução na concentração 
de $\mathrm{Fe}$ no compartimento central e um aumento na concentração de $\mathrm{Fe}$ no compartimento do cátodo, no qual já iniciava com $2,24 \cdot 10^{-2} \mathrm{M}$ de $\mathrm{Fe}$. A concentração final de Fe total medida no compartimento central foi de $9,87 \cdot 10^{-3} \mathrm{M}$.

A extração percentual obtida no compartimento diluído no ensaio 3ED-SS, de $55,94 \%$, é semelhante a que se obteve no ensaio 2ED-SS. Considerando que nestes dois últimos ensaios, a concentração inicial de ferro no compartimento central bem como a densidade de corrente aplicada eram as mesmas, permite concluir, mais uma vez, que a extração não se dá por difusão e sim por influência da corrente elétrica aplicada.

Um quarto ensaio (ensaio 4ED-SS) foi realizado também aplicando-se $5,0 \mathrm{~mA} \cdot \mathrm{cm}^{-2}$ de densidade de corrente, durante $8 \mathrm{~h}$ com uma configuração semelhante ao ensaio 3ED-SS em que a mesma solução foi colocada nos três compartimentos. Para este ensaio utilizou-se a solução mista de $\mathrm{Fe}_{2}\left(\mathrm{SO}_{4}\right)_{3} 2 \cdot 10^{-2} \mathrm{M}$ e $\mathrm{Na}_{2} \mathrm{SO}_{4} 1 \cdot 10^{-2} \mathrm{M}$ a fim de se avaliar a influência da presença de um cátion monovalente $\left(\mathrm{Na}^{+}\right)$no processo de ED e na extração de ferro. Os resultados da concentração de ferro total no compartimento central e no compartimento do cátodo, ao longo do ensaio, são apresentados na Figura 36.

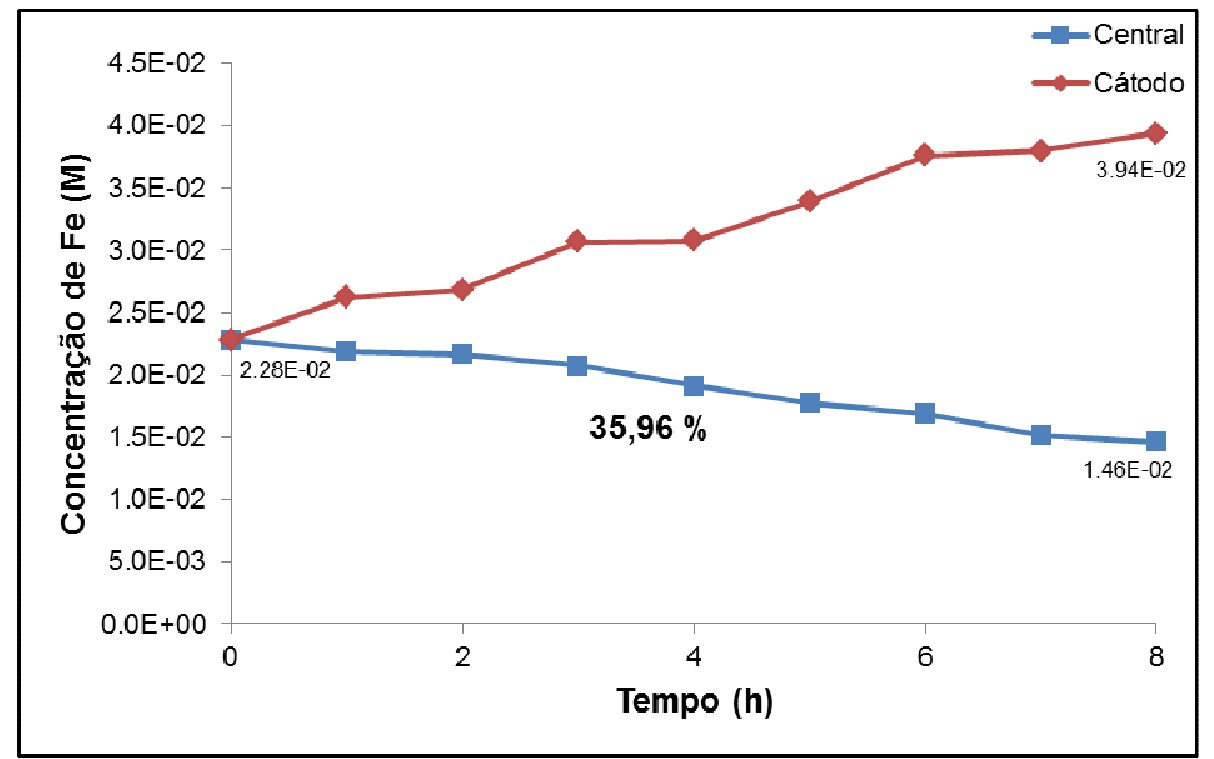

Figura 36 - Quantificação de Fe no compartimento central e cátodo do ensaio 4ED-SS.

Analisando a Figura 36 observa-se que a presença do íon $\mathrm{Na}^{+}$influenciou na extração de ferro, pois para uma mesma configuração em que a concentração inicial de $\mathrm{Fe}$, a densidade de corrente aplicada e o tempo de ensaio foram os mesmos, obteve-se uma extração percentual menor $(35,96 \%)$ que a obtida para o ensaio 
3ED-SS (55,94 \%), justificada pela competição no transporte dos cátions através da membrana catiônica.

Da mesma forma que nos ensaios anteriores tem-se um aumento na concentração de ferro no compartimento do cátodo, comprovando a passagem do Fe através da membrana catiônica por influência da corrente elétrica aplicada.

\subsection{ELETRODIÁLISE COM SOLUÇÃO SINTÉTICA VISANDO A RECUPERAÇÃO DE ÁCIDO SULFÚRICO EM BANCADA (I)}

Foram realizados quatro ensaios objetivando a recuperação de ácido sulfúrico em um dos compartimentos da célula de ED de bancada (I), sendo empregada uma configuração experimental para o ensaio 1ED-SS-AC (Figura 37) e uma diferente para os demais ensaios (2ED-SS-AC a 4ED-SS-AC).

O ensaio 1ED-SS-AC teve por objetivo recuperar ácido sulfúrico no compartimento central, para tanto a montagem se deu conforme apresentado na Figura 37, em que colocou-se inicialmente a solução sintética de $\mathrm{Fe}_{2}\left(\mathrm{SO}_{4}\right)_{3} 2 \cdot 10^{-2} \mathrm{M}$ com $\mathrm{Na}_{2} \mathrm{SO}_{4} 1 \cdot 10^{-2} \mathrm{M}$ nos compartimentos dos eletrodos (ânodo e cátodo) e $\mathrm{H}_{2} \mathrm{SO}_{4} 7 \cdot 10^{-2} \mathrm{M}$ no compartimento central. Desta forma, os sulfatos presentes na solução do compartimento catódico passaram ao compartimento central através da membrana aniônica HDX 200, aumentando a concentração de sulfatos. E os prótons $\mathrm{H}^{+}$gerados no ânodo passaram através da membrana catiônica HDX 100, promovendo assim a produção de ácido sulfúrico no compartimento central, por aumento de concentração.

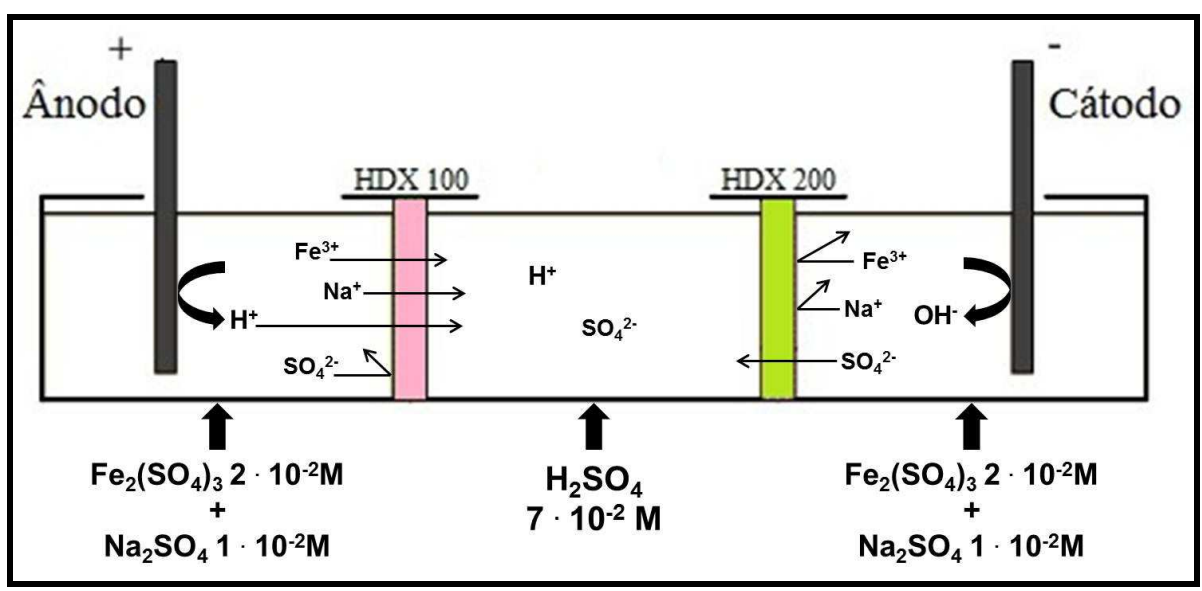

Figura 37 - Configuração experimental do ensaio 1ED-SS-AC. 
Para o ensaio 1ED-SS-AC foram utilizados eletrodos de grafite como ânodo $\mathrm{e}$ cátodo e aplicou-se uma densidade de corrente constante de $5,0 \mathrm{~mA} \cdot \mathrm{cm}^{-2}$. O ensaio teve duração de 8 horas e a cada hora foram coletadas alíquotas para análise da variação na concentração de sulfatos (Figura 38) e de ferro (Figura 39) ao longo do ensaio, e mediu-se o pH de cada compartimento (Figura 40).

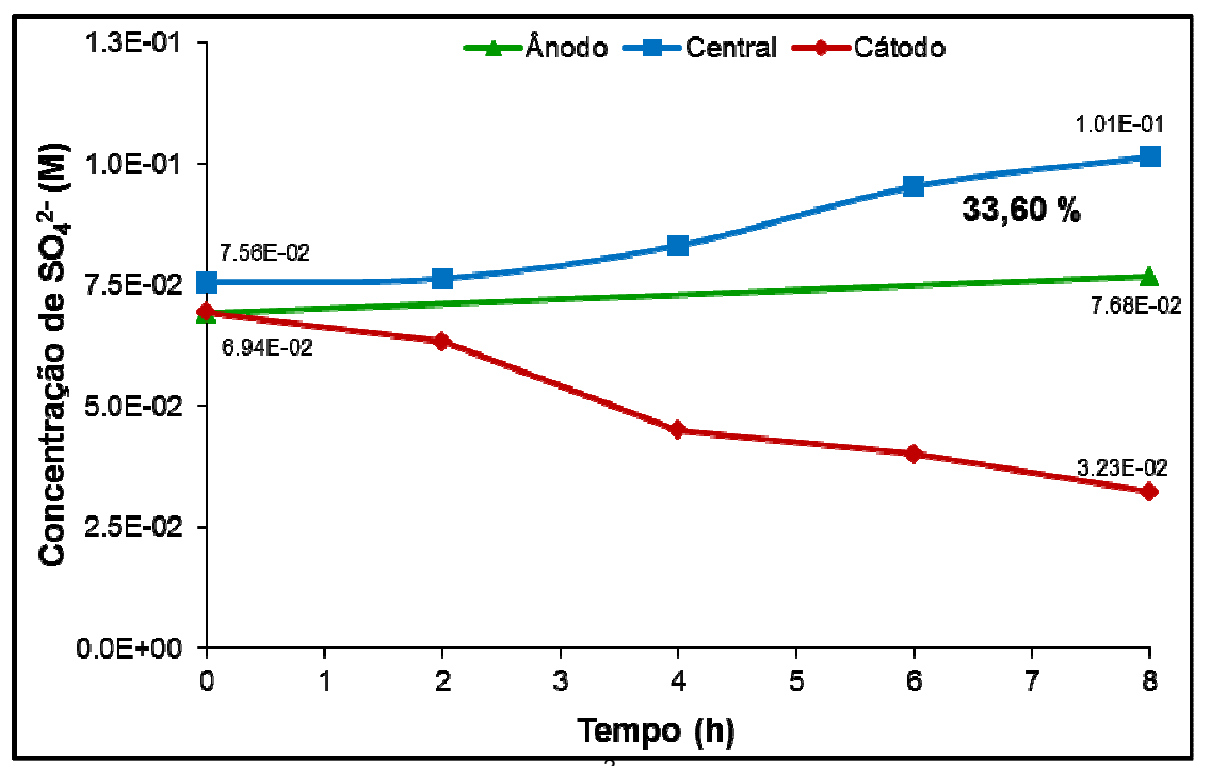

Figura 38 - Concentração de $\mathrm{SO}_{4}{ }^{2-}$ ao longo do ensaio 1ED-SS-AC.

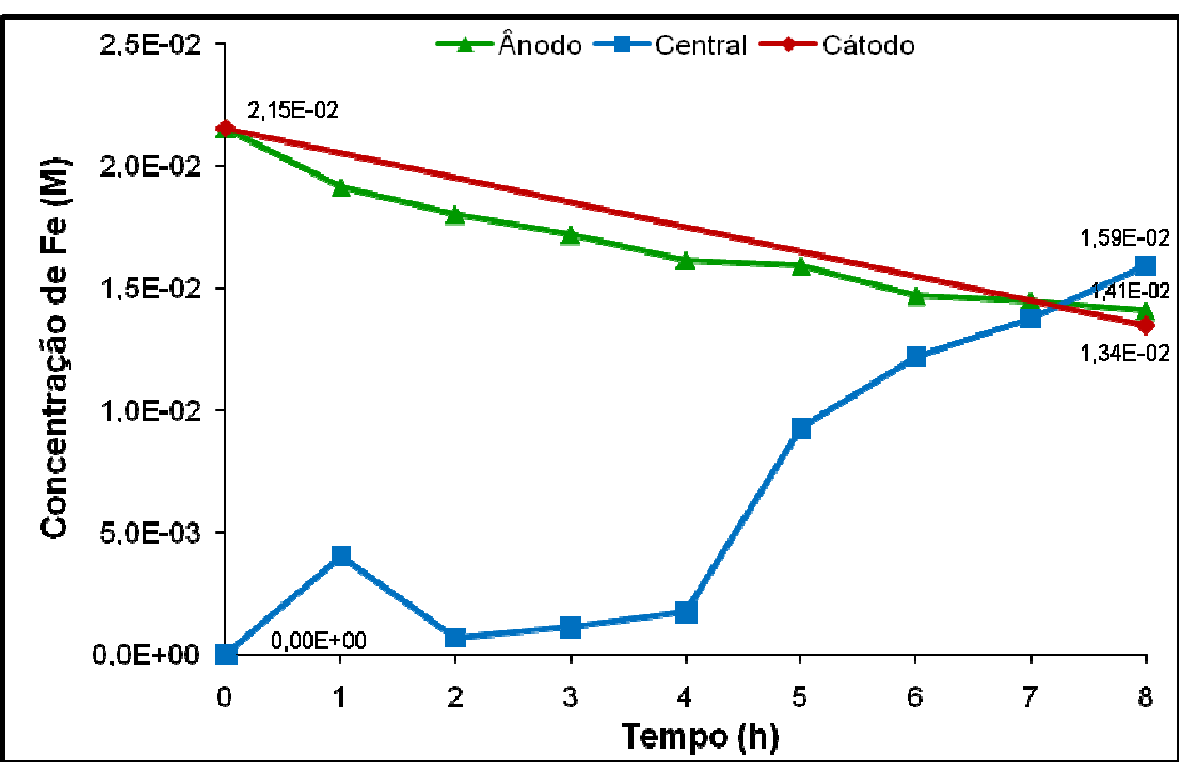

Figura 39 - Concentração de Fe ao longo do ensaio 1ED-SS-AC.

Da análise da Figura 38 observa-se que há um aumento na concentração de sulfatos, de 33,60\%, no compartimento central, bem como se observa a redução no compartimento do cátodo e a estabilidade na concentração de sulfatos no ânodo, conforme previsto para a configuração empregada. 
Em contra partida, observa-se na Figura 39 que há um aumento na concentração de Fe no compartimento central, o que configura um inconveniente para a recuperação do ácido sulfúrico.

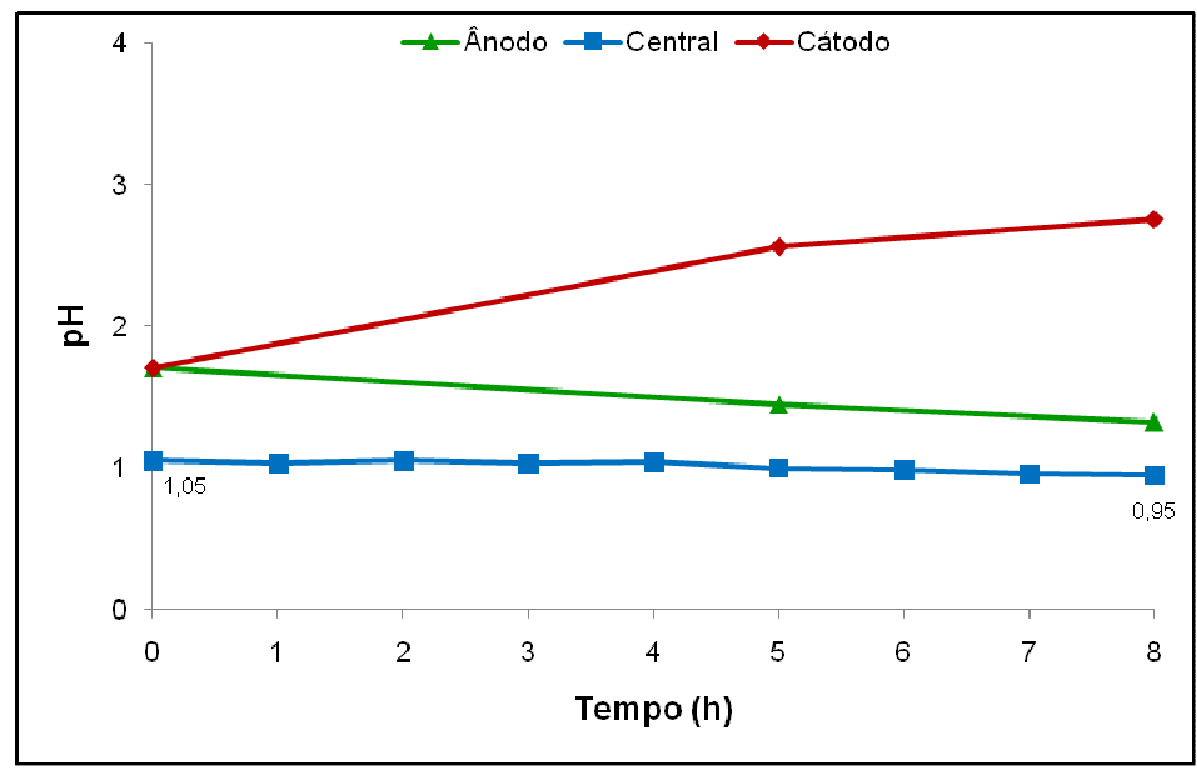

Figura $40-\mathrm{pH}$ ao longo do ensaio 1ED-SS-AC.

O monitoramento do $\mathrm{pH}$ ao longo do ensaio demonstrou que houve uma pequena redução no $\mathrm{pH}$ durante as 8 horas, passando de 1,05 a 0,95. A pequena variação é resultado da passagem de prótons $\mathrm{H}^{+}$através da membrana catiônica (HDX 100), mas se observou que com a montagem experimental utilizada também houve passagem de $\mathrm{OH}^{-}$gerado no cátodo através da membrana aniônica (HDX 200).

A partir dos resultados supracitados, optou-se por uma nova montagem experimental, apresentada na Figura 41, que foi utilizada para os ensaios subsequentes.

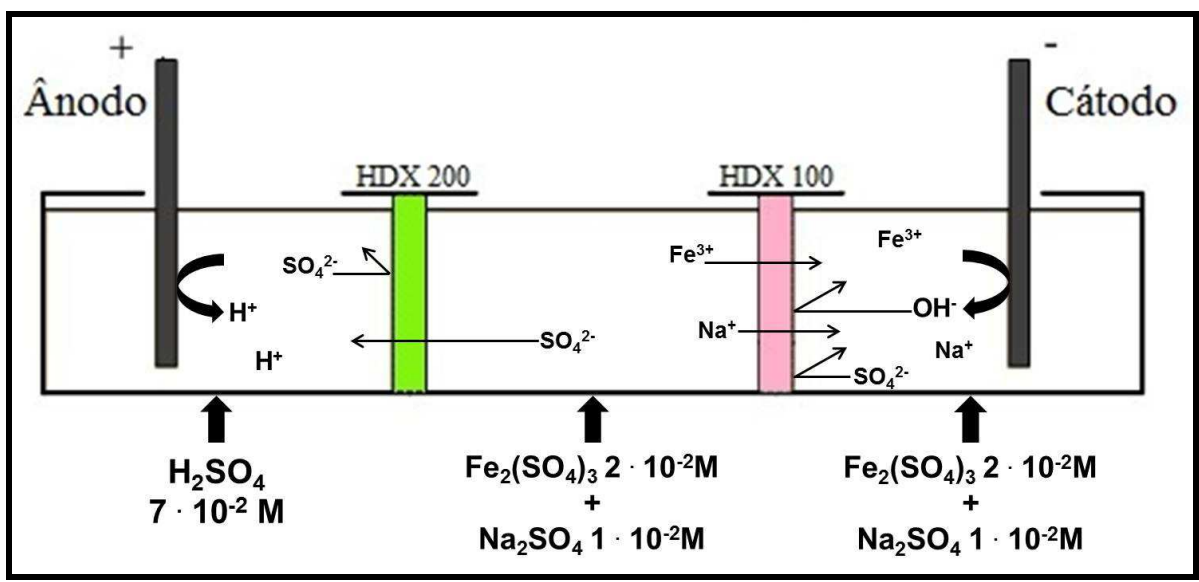

Figura 41 - Configuração experimental do ensaio 2ED-SS-AC a 4ED-SS-AC. 
$\mathrm{Na}$ montagem experimental da Figura 41, utilizada nos ensaios 2ED-SS-AC a 4ED-SS-AC, a solução sintética de $\mathrm{Fe}_{2}\left(\mathrm{SO}_{4}\right)_{3} 2 \cdot 10^{-2} \mathrm{M}$ com $\mathrm{Na}_{2} \mathrm{SO}_{4} 1 \cdot 10^{-2} \mathrm{M}$ foi colocada no compartimento central e cátodo, e a solução de $\mathrm{H}_{2} \mathrm{SO}_{4} 7 \cdot 10^{-2} \mathrm{M}$ no compartimento do ânodo. Assim, os sulfatos presentes no compartimento central passaram ao compartimento do ânodo através da membrana aniônica HDX 200, aumentando a concentração de sulfatos. $\mathrm{E}$ os prótons $\mathrm{H}^{+}$gerados no ânodo permaneceram neste compartimento, uma vez que tinha a passagem impedida por esta mesma membrana aniônica, que separava os compartimentos ânodo e central, promovendo desta forma a produção de ácido sulfúrico, por aumento de concentração, com a vantagem de não ter o ferro como um contaminante.

Para o ensaio 2ED-SS-AC também foram utilizados eletrodos de grafite e aplicada uma densidade de corrente constante de $5,0 \mathrm{~mA} \cdot \mathrm{cm}^{-2}$. O ensaio também teve duração de 8 horas e a cada hora foram coletadas alíquotas para análise da variação na concentração de sulfatos (Figura 42) e de ferro (Figura 43) ao longo do ensaio, e monitorado o pH de cada compartimento (Figura 44). Ao final do ensaio avaliou-se a acidez da solução final contida no compartimento ânodo e comparou-se com a acidez da solução de $\mathrm{H}_{2} \mathrm{SO}_{4} 7 \cdot 10^{-2} \mathrm{M}$, inicialmente colocada neste compartimento. A variação da acidez é exibida na Figura 45.

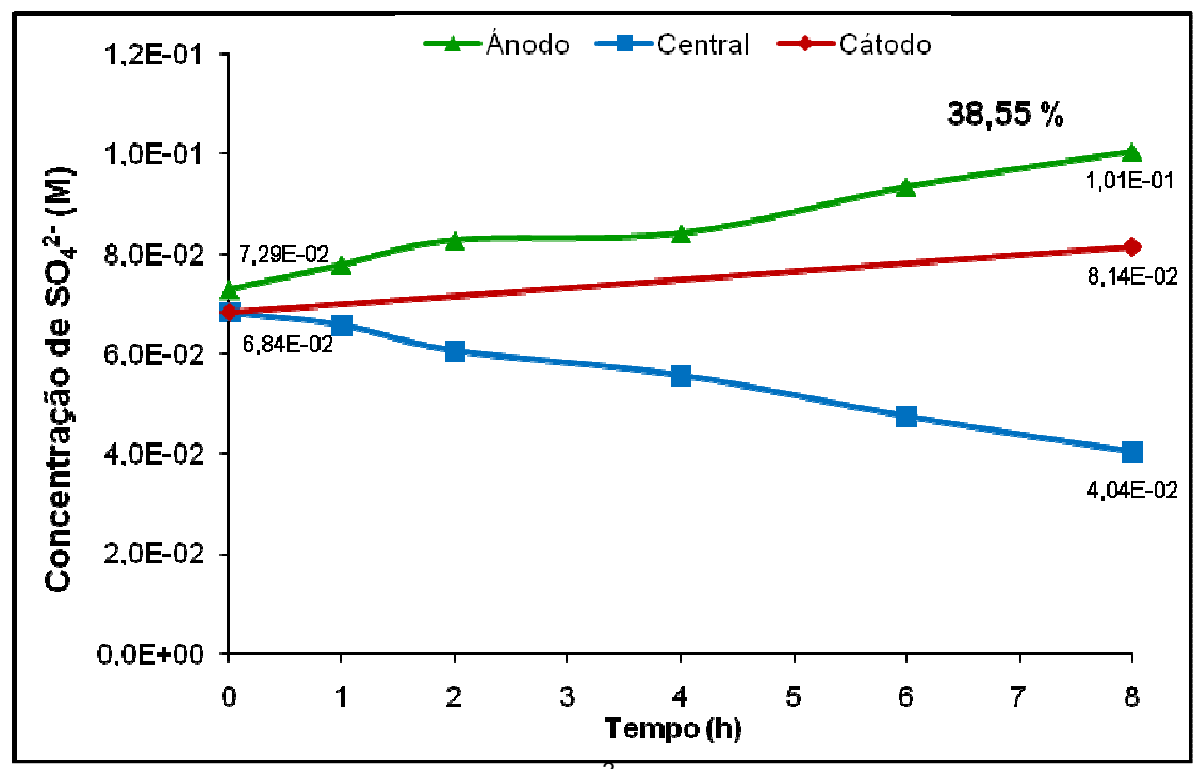

Figura 42 - Concentração de $\mathrm{SO}_{4}{ }^{2-}$ ao longo do ensaio 2ED-SS-AC. 


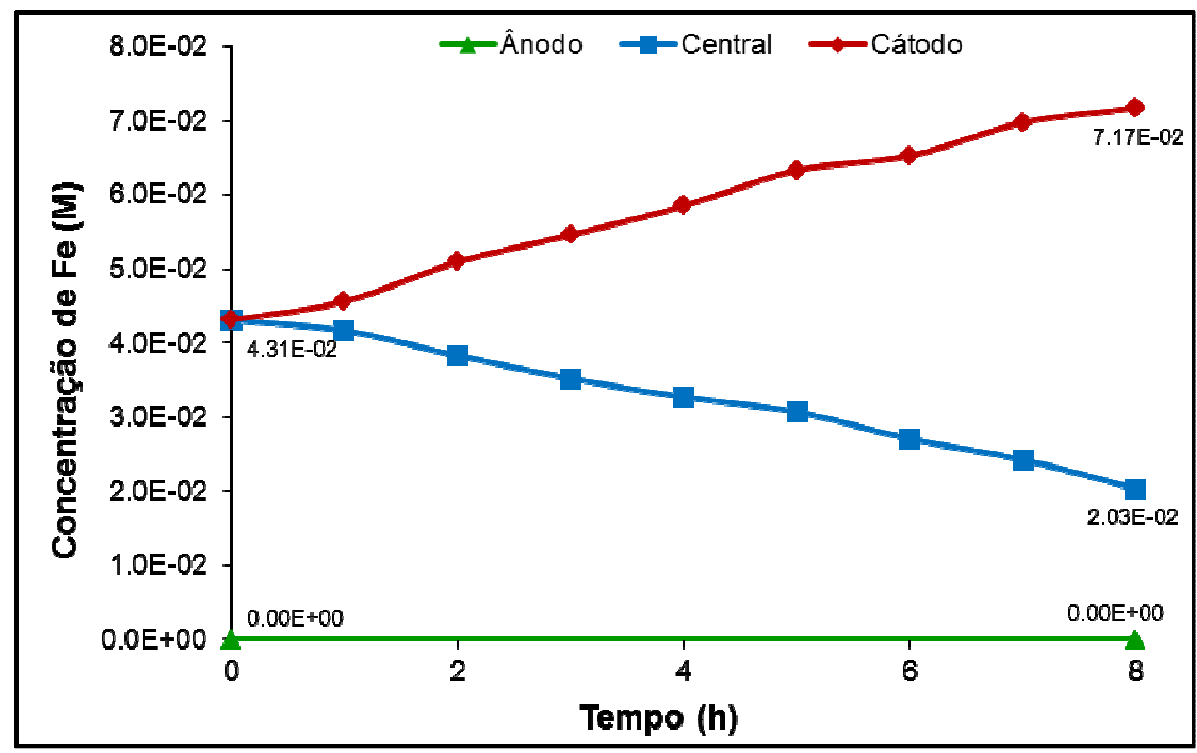

Figura 43 - Concentração de Fe ao longo do ensaio 2ED-SS-AC.

Tem-se na Figura 42 o aumento na concentração de sulfatos, de $38,55 \%$, no compartimento do ânodo, valor semelhante ao observado no aumento da concentração de sulfatos no compartimento central no ensaio 1ED-SS-AC. Considerando que foi aplicada a mesma densidade de corrente $\left(5,0 \mathrm{~mA} \cdot \mathrm{cm}^{-2}\right)$ nestes dois ensaios, pode-se inferir que a taxa de transferência de sulfatos para a densidade de corrente empregada é a mesma independente da configuração experimental utilizada.

Observa-se na Figura 43 a redução na concentração de Fe no compartimento central e o aumento no compartimento do cátodo, possibilitando desta forma a recuperação de água no compartimento central, uma vez que há a diminuição na concentração tanto dos cátions como dos ânions. Outra observação importante na Figura 43 é que não houve contaminação com $\mathrm{Fe}$ do compartimento do ânodo, proporcionando assim a recuperação de um ácido sulfúrico mais puro que o ácido obtido com a configuração do ensaio 1ED-SS-AC. 


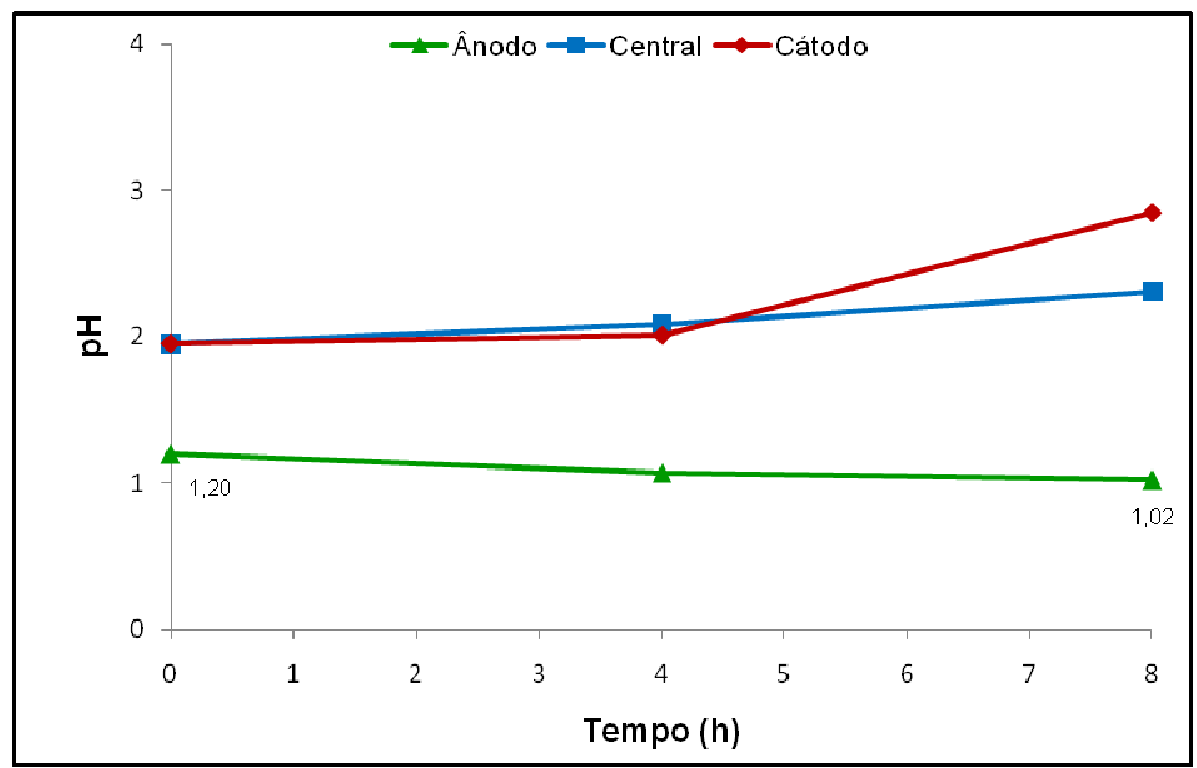

Figura $44-\mathrm{pH}$ ao longo do ensaio 2ED-SS-AC.

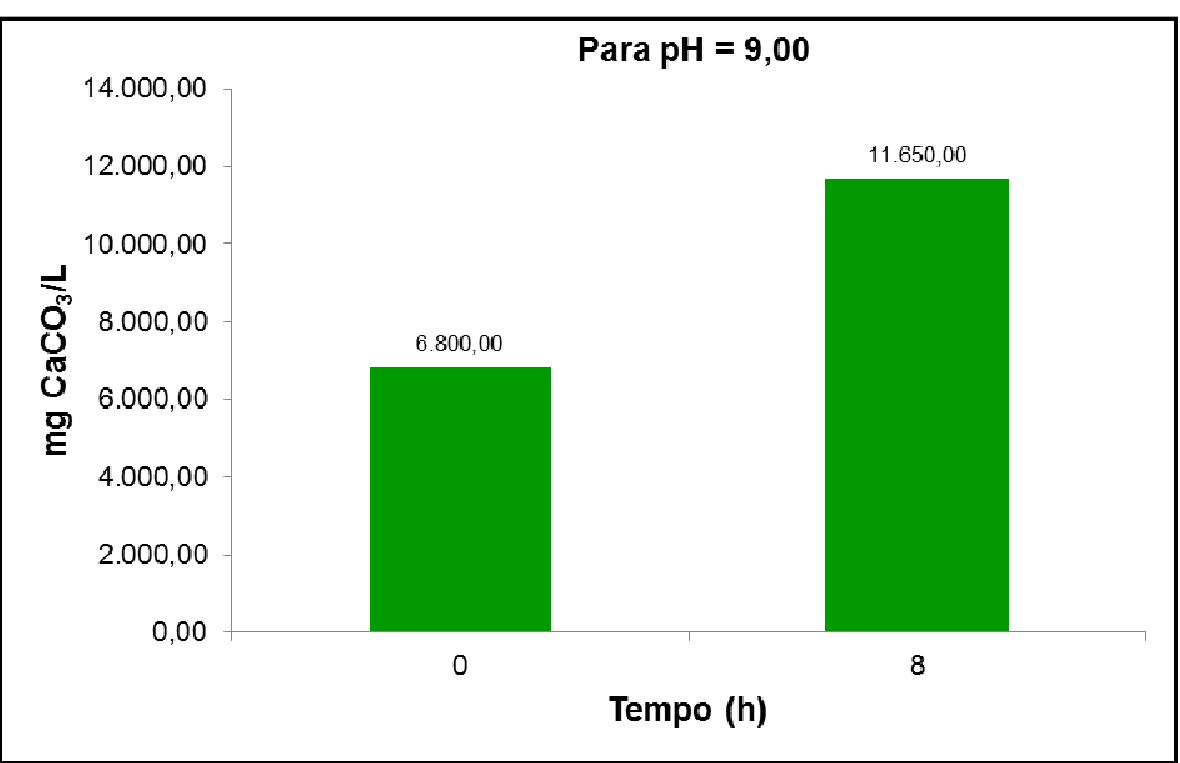

Figura 45 - Acidez do compartimento ânodo ao longo do ensaio 2ED-SS-AC.

O monitoramento do $\mathrm{pH}$ ao longo do ensaio demonstrou que houve redução no $\mathrm{pH}$ durante as 8 horas, passando de 1,20 a 1,02 (Figura 44). Essa redução no pH é comprovada pela maior acidez apresentada pela solução final do compartimento do ânodo na curva da Figura 45. Observa-se nesta figura que houve um aumento de 71,32 \% na acidez da solução, demonstrando assim a eficiência do processo em produzir ácido sulfúrico por aumento de concentração.

Também foi monitorado o potencial total da célula durante todo o ensaio 2ED-SS-AC, que apresentou uma variação de $11,36 \mathrm{~V}$ (potencial inicial) para $16,32 \mathrm{~V}$ após as 8 horas de ensaio. 
Do ensaio 2ED-SS-AC para o ensaio 3ED-SS-AC, modificou-se apenas a densidade de corrente aplicada, de $5,0 \mathrm{~mA} \cdot \mathrm{cm}^{-2}$ para $7,5 \mathrm{~mA} \cdot \mathrm{cm}^{-2}$, neste novo ensaio.

A variação nas concentrações de sulfatos e de ferro ao longo do ensaio 3ED-SS-AC é apresentada na Figura 46 e na Figura 47, respectivamente. $O$ monitorado do $\mathrm{pH}$ de cada compartimento é representado na Figura 48.

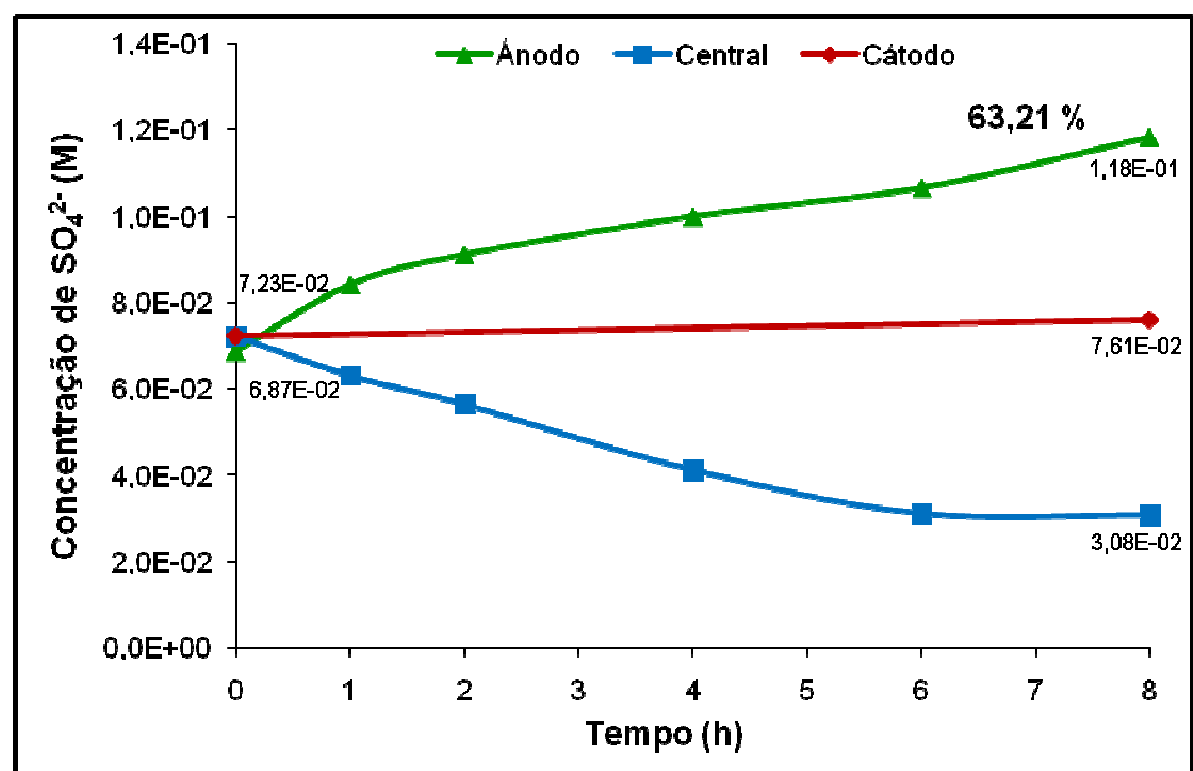

Figura 46 - Concentração de $\mathrm{SO}_{4}{ }^{2-}$ ao longo do ensaio 3ED-SS-AC.

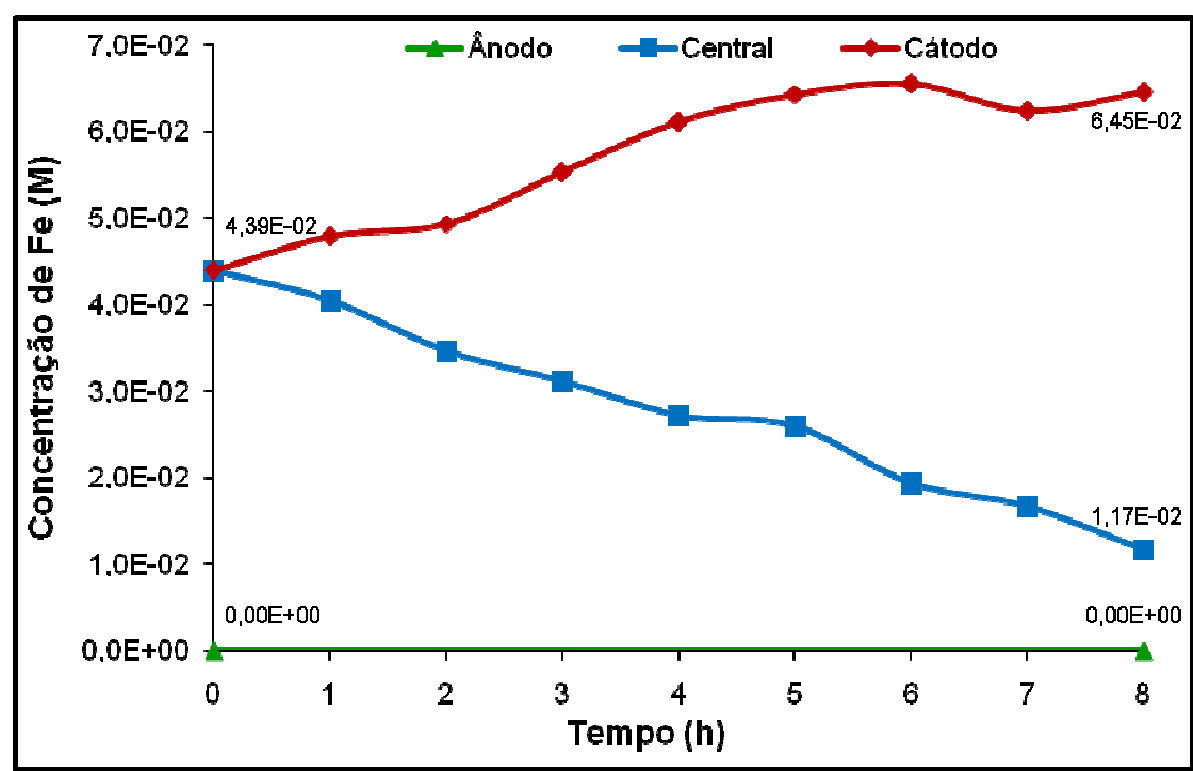

Figura 47 - Concentração de Fe ao longo do ensaio 3ED-SS-AC.

Observa-se, a partir da curva de variação na concentração de sulfatos (Figura 46), um aumento de $63,21 \%$ na concentração de sulfatos no compartimento central, 
demonstrando que o aumento na densidade de corrente aplicada, em relação ao ensaio 2ED-SS-AC, se reflete no percentual de extração do ânion a partir do compartimento central e consequente aumento na recuperação de ácido sulfúrico no compartimento do ânodo.

Da análise da variação na concentração de Fe (Figura 47) observa-se a redução na concentração de $\mathrm{Fe}$ no compartimento central e o aumento no compartimento do cátodo, comportamento semelhante ao do ensaio 2ED-SS-AC, ou seja, possibilitando a recuperação de água no compartimento central. E novamente não houve contaminação com $\mathrm{Fe}$ do compartimento do ânodo, proporcionando também a recuperação de um ácido sulfúrico mais puro.

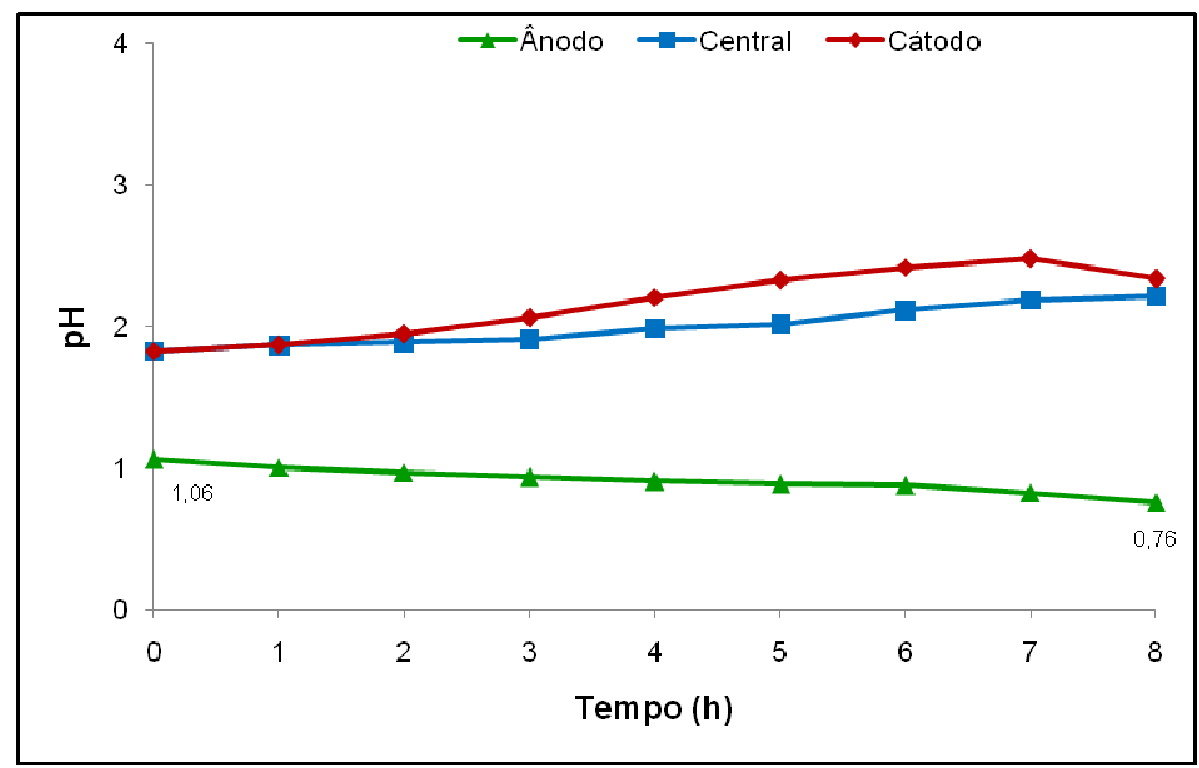

Figura $48-\mathrm{pH}$ ao longo do ensaio 3ED-SS-AC.

O monitoramento do $\mathrm{pH}$ no compartimento do ânodo novamente apresentou redução durante o ensaio, indo de 1,06 para 0,76 , demonstrando assim o aumento na acidez da solução deste compartimento.

A variação no potencial total de célula para o ensaio 3ED-SS-AC foi maior que a observada no ensaio 2ED-SS-AC, passando de 16,02 V (potencial inicial) para 33,65 $V$ após as 8 horas.

Por fim, do ensaio 2ED-SS-AC e 3ED-SS-AC para o ensaio 4ED-SS-AC, também modificou-se apenas a densidade de corrente aplicada, sendo de $10,0 \mathrm{~mA} \cdot \mathrm{cm}^{-2}$, para o ensaio 4ED-SS-AC. 
A variação nas concentrações de sulfatos e de ferro ao longo do ensaio 4ED-SS-AC é apresentada na Figura 49 e na Figura 50, respectivamente. $O$ monitorado do $\mathrm{pH}$ de cada compartimento é representado na Figura 51.

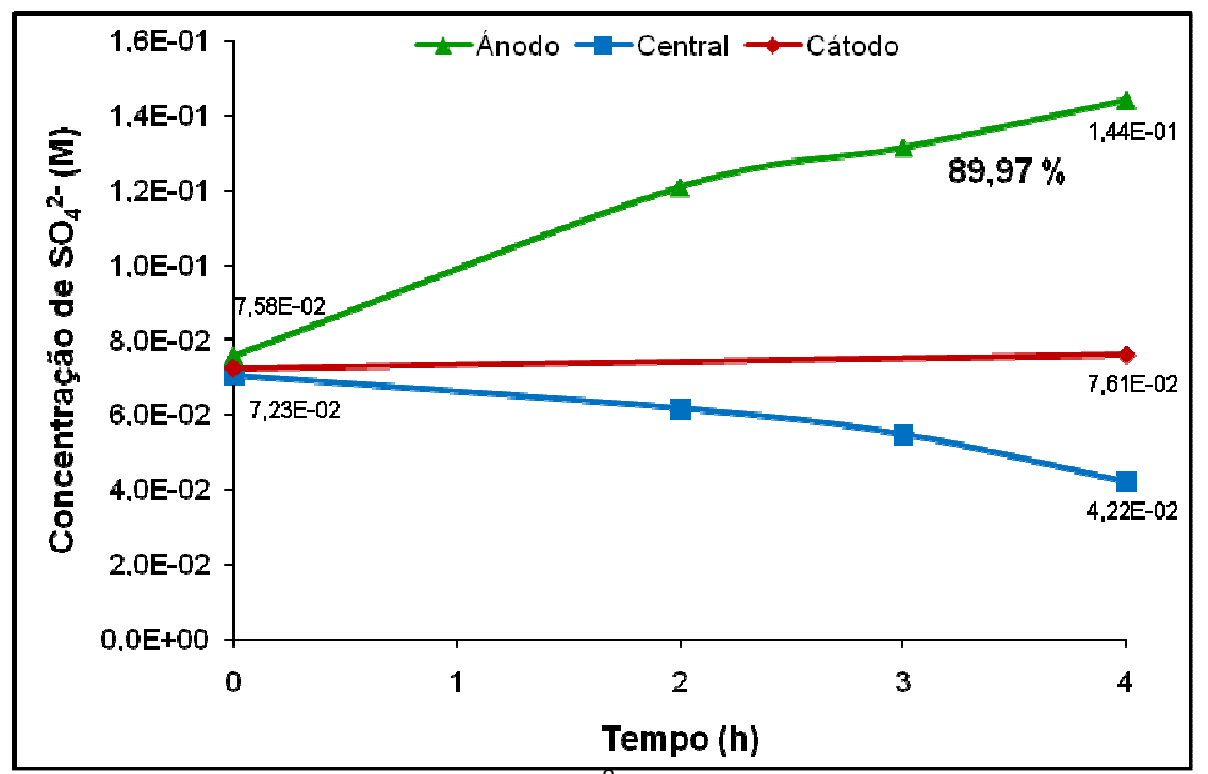

Figura 49 - Concentração de $\mathrm{SO}_{4}{ }^{2-}$ ao longo do ensaio 4ED-SS-AC.

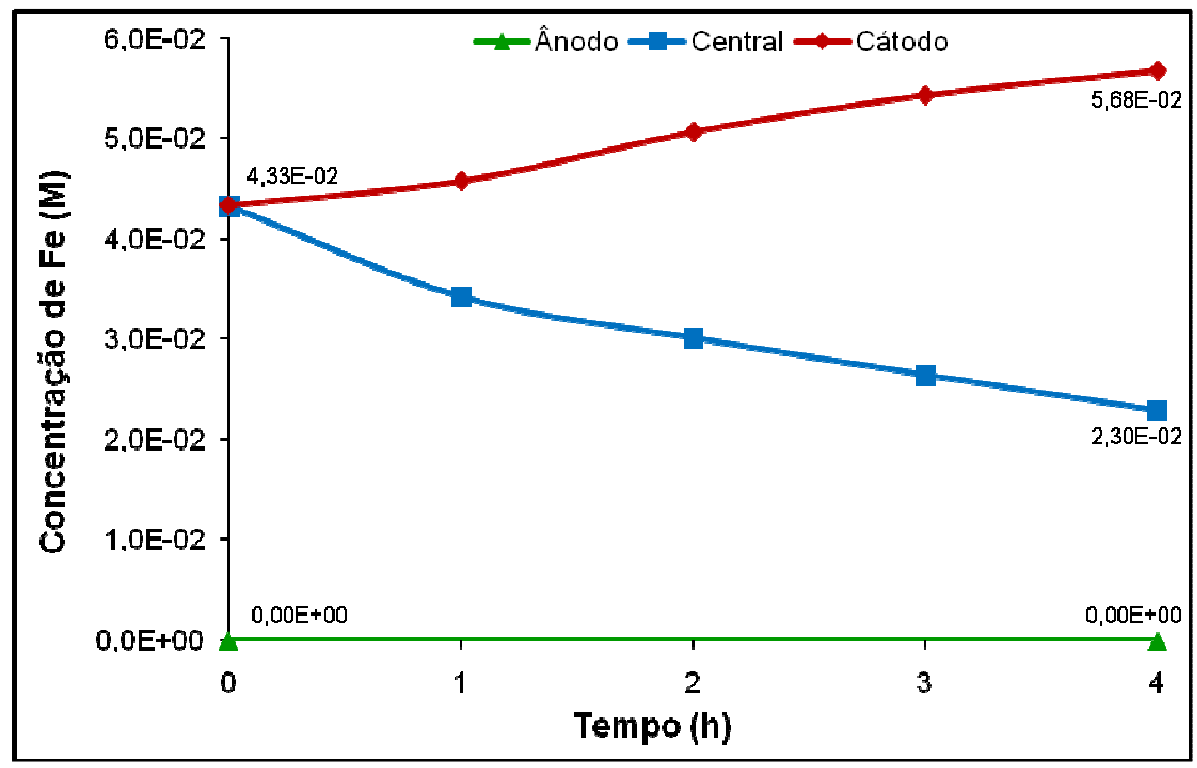

Figura 50 - Concentração de Fe ao longo do ensaio 4ED-SS-AC.

Observa-se, a partir da curva da variação na concentração de sulfatos (Figura 49), um aumento de $89,97 \%$ nesta concentração no compartimento central, demonstrando novamente que o aumento na densidade de corrente aplicada, em relação ao ensaio 2ED-SS-AC e 3ED-SS-AC, se reflete no percentual de extração do ânion a partir do compartimento central e consequente aumento na recuperação de ácido sulfúrico no compartimento do ânodo. 
Da análise da curva da variação da concentração de Fe (Figura 50) observa-se a redução na concentração de $\mathrm{Fe}$ no compartimento central e o aumento no compartimento do cátodo, comportamento semelhante ao dos ensaios 2ED-SS-AC e 3ED-SS-AC, possibilitando a recuperação de água no compartimento central. E novamente não houve contaminação com $\mathrm{Fe}$ do compartimento do ânodo, proporcionando também a recuperação de ácido sulfúrico puro.

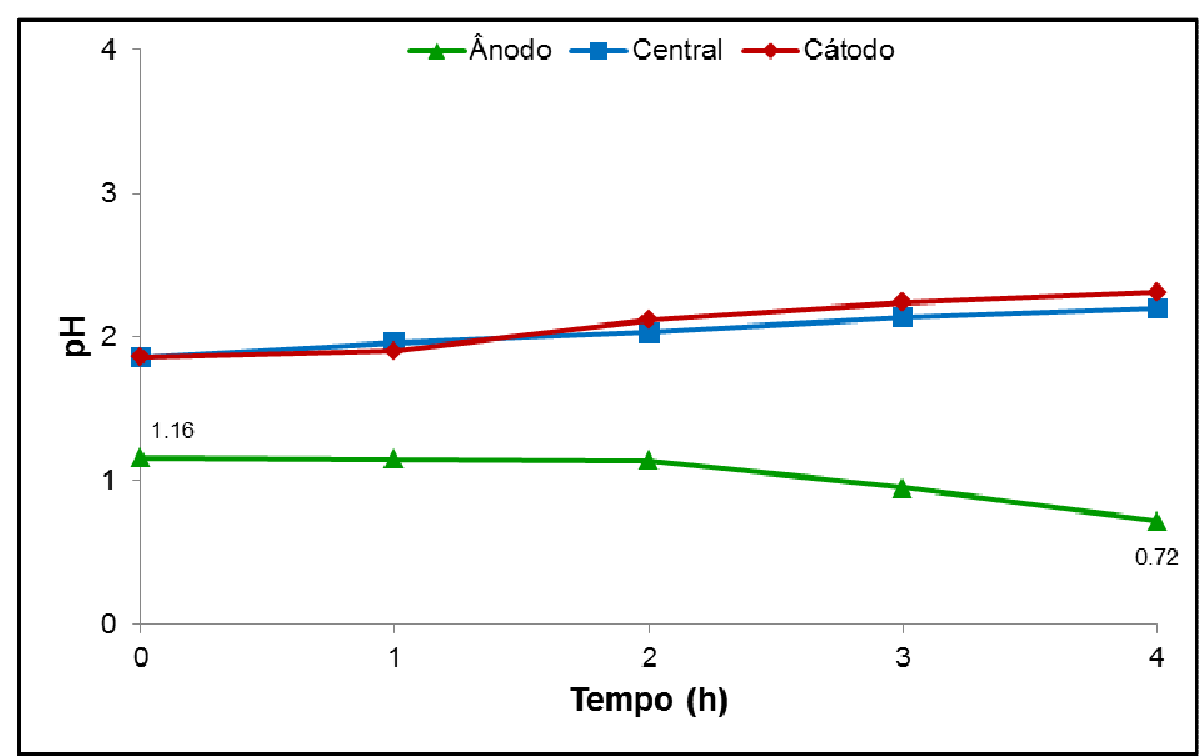

Figura 51 - pH ao longo do ensaio 4ED-SS-AC.

O monitoramento do $\mathrm{pH}$ no compartimento do ânodo novamente apresentou redução durante o ensaio, indo de 1,16 para 0,72 , demonstrando mais uma vez 0 aumento na acidez da solução do ânodo.

Por fim, a variação no potencial observada para este ensaio 4 ED-SS-AC contribuiu para que ele fosse encerrado em 4 horas e não em $8 \mathrm{~h}$ como os anteriores, pois variou de 22,20 V (potencial inicial) para 33,00 V (potencial final) em 4 horas, chegando-se assim ao limite da capacidade da fonte utilizada e também observou-se a formação de precipitado na superfície da membrana catiônica.

Analisando-se os últimos três ensaios, tem-se que quanto maior a densidade de corrente aplicada maior a produtividade de ácido sulfúrico, ou maior o percentual de recuperação deste ácido, embora também seja maior o potencial total da célula e consequentemente aumenta-se o consumo energético, comportamento semelhante ao observado em um estudo de ED de sulfato de sódio para obtenção de ácido e base $^{96}$. 
Outra vantagem da montagem experimental utilizada nos ensaios 2ED-SS-AC a 4ED-SS-AC é que além da recuperação do ácido sulfúrico livre de ferro, no compartimento do ânodo, e da água no compartimento central, ela proporciona a concentração do $\mathrm{Fe}$ no compartimento do cátodo que pode representar uma vantagem para o aproveitamento do Fe para uma nova aplicação. Desta forma, pode-se obter o Fe precipitado sem a adição de reagentes, como realizado, por exemplo, em trabalhos que aproveitam o Fe contido na DAM para a produção de coagulantes $^{26,28,97,98}$, pigmentos ${ }^{99,100}$, adsorventes ${ }^{101}$, entre outras aplicações.

\subsection{ELETRODIÁLISE COM SOLUÇÃO SINTÉTICA VISANDO A RECUPERAÇÃO DE ÁCIDO SULFÚRICO EM BANCADA (II)}

A configuração utilizada nos ensaios 2ED-SS a 4ED-SS, apresentados no item anterior (Figura 41), foi utilizada para os ensaios de ED na bancada (II) visando à recuperação de ácido sulfúrico. Eletrodos de titânio metálico revestidos com óxido de titânio e óxido de rutênio $\left(70 \mathrm{TiO}_{2} / 30 \mathrm{RuO}_{2}\right)$ foram empregados como cátodo e ânodo.

Nestes ensaios, conforme metodologia descrita no item 4.8, foram empregados diferentes volumes de solução em cada compartimento, sendo o volume dos eletrodos, ânodo e cátodo de $750 \mathrm{~mL}$, e do compartimento central, três vezes maior, $3000 \mathrm{~mL}$. Sendo que no compartimento do cátodo e central inicialmente foi colocada uma solução sintética de $\left(\mathrm{Fe}_{2}\left(\mathrm{SO}_{4}\right)_{3} 2 \cdot 10^{-2} \mathrm{M}+\mathrm{Na}_{2} \mathrm{SO}_{4} 1 \cdot 10^{-2} \mathrm{M}\right)$ e no ânodo a solução inicial era de $\mathrm{H}_{2} \mathrm{SO}_{4} 7 \cdot 10^{-2} \mathrm{M}$.

Desta forma, com os diferentes volumes utilizados, garantiu-se 0 não esgotamento dos íons $\mathrm{SO}_{4}{ }^{2-}$ no compartimento central, permitindo uma maior recuperação de ácido no compartimento do ânodo, por aumento de concentração. Observou-se que também houve maior concentração de íons $\mathrm{Fe}^{3+}$ no compartimento do cátodo. Consequentemente, para o tempo de ensaio empregado, no compartimento central não houve diluição suficiente da solução sintética para a recuperação de água neste compartimento. 
Foram realizados dois ensaios, de 16 horas cada, com a aplicação das seguintes densidades de corrente: $5,0 \mathrm{~mA} \cdot \mathrm{cm}^{-2}$ (ensaio 1ED-SS-AC-II) e 10,0 $\mathrm{mA} \cdot \mathrm{cm}^{-2}$ (ensaio 2ED-SS-AC-II).

Os resultados do monitoramento do primeiro ensaio, para a variação na concentração de sulfatos são apresentados na Figura 52, e na Figura 53 para a variação na concentração de ferro.

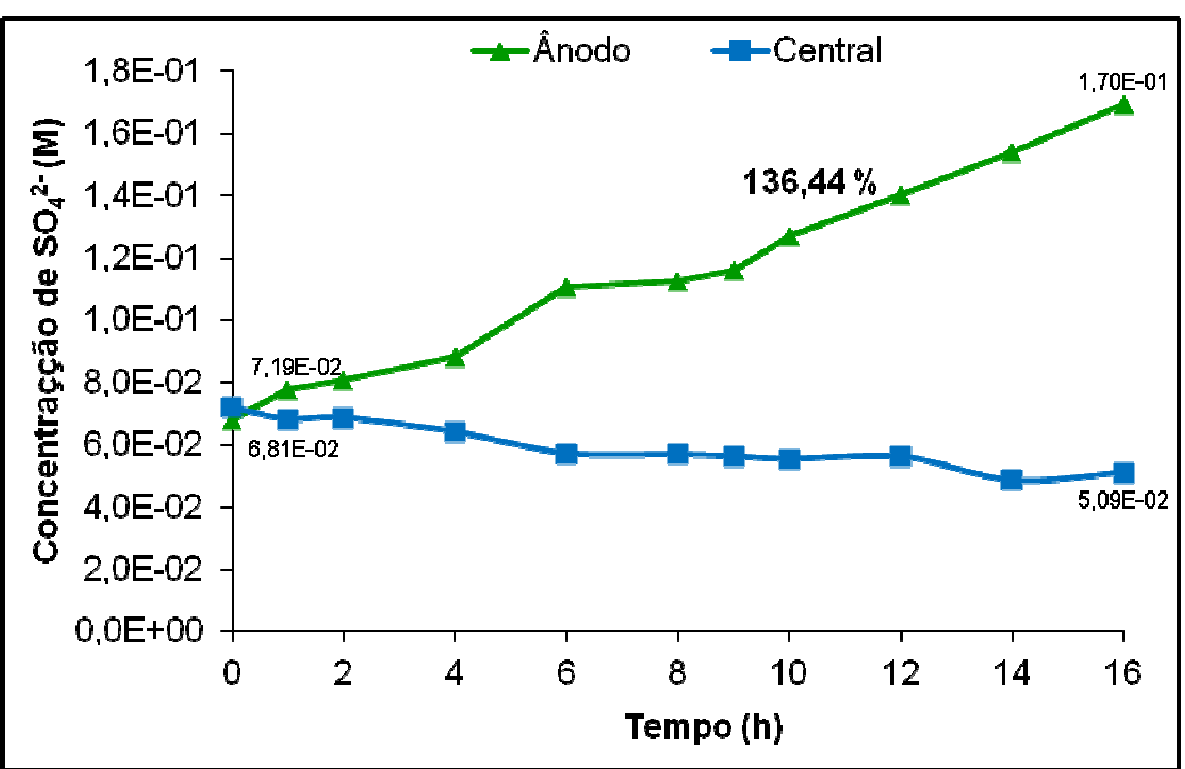

Figura 52 - Concentração de $\mathrm{SO}_{4}{ }^{2-}$ ao longo do ensaio 1ED-SS-AC-II.

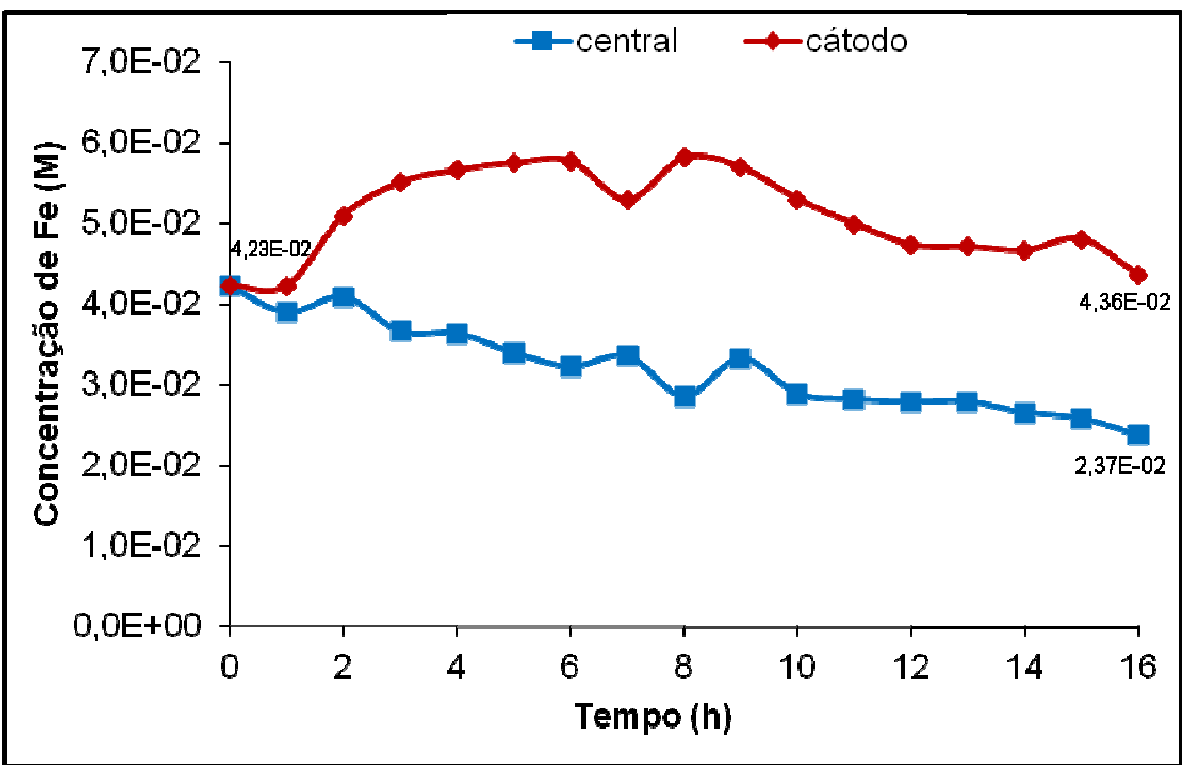

Figura 53 - Concentração de Fe ao longo do ensaio 1ED-SS-AC-II.

Observa-se na Figura 52 que houve um aumento de 136,44 \% na concentração de sulfatos no compartimento do ânodo, durante as 16 horas de ensaio. Para este 
ensaio aplicou-se a mesma densidade de corrente $\left(5,0 \mathrm{~mA} \cdot \mathrm{cm}^{-2}\right)$ aplicada para o ensaio 2ED-SS-AC do item 5.5, realizado para solução sintética, o que demonstra a influência da superfície da membrana no processo, pois mesmo que para o mesmo tempo de ensaio (8 horas) o percentual de aumento na concentração de sulfatos, neste caso é de $65,36 \%$.

Comportamento semelhante ao observado nos ensaios realizados em bancada (I) é exibido na Figura 53, na qual tem-se a redução na concentração de Fe no compartimento central e o aumento no compartimento do cátodo, que possibilita tanto a recuperação de água no compartimento central, pela diminuição na concentração tanto dos cátions como dos ânions, como o melhor aproveitamento do Fe concentrado no compartimento do cátodo e precipitado sem a necessidade de adição de reagentes químicos.

As modificações observadas no $\mathrm{pH}$ ao longo do ensaio são exibidas na Figura 54. E a comparação entre a acidez inicial e final do compartimento do ânodo após as 16 horas de ensaio pode ser visualizada na Figura 55.

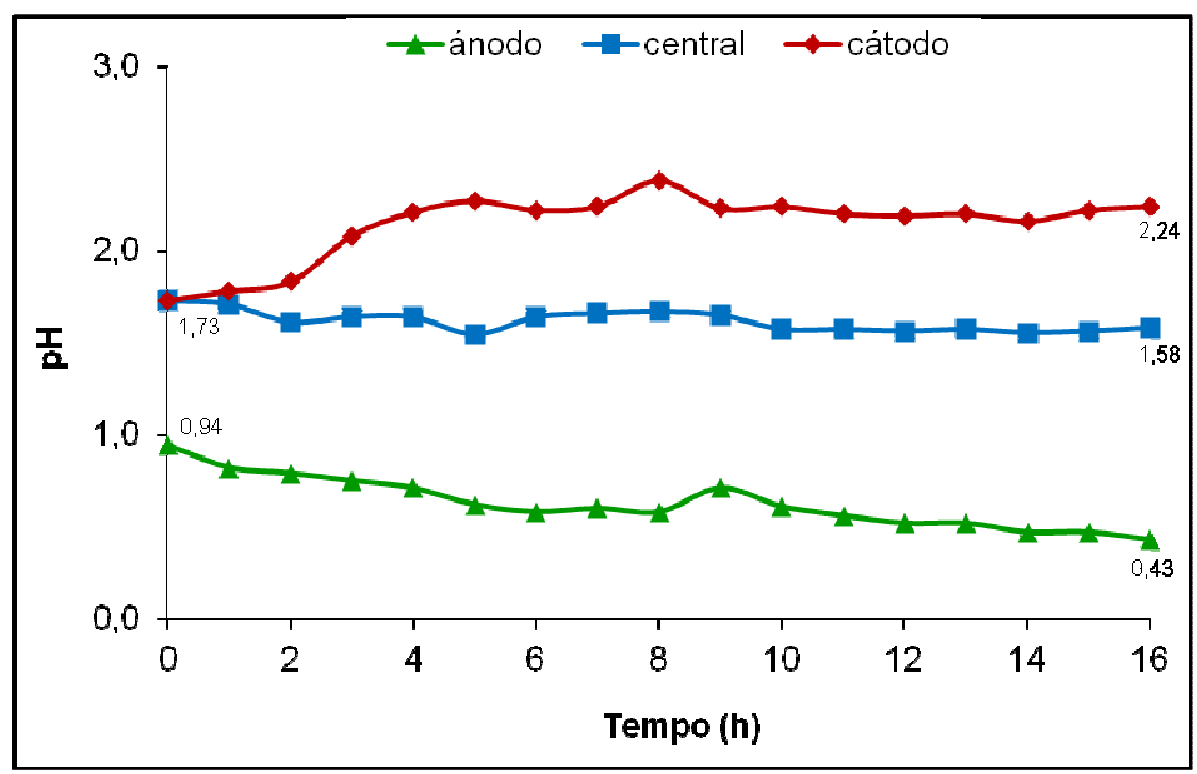

Figura $54-\mathrm{pH}$ ao longo do ensaio 1ED-SS-AC-II. 


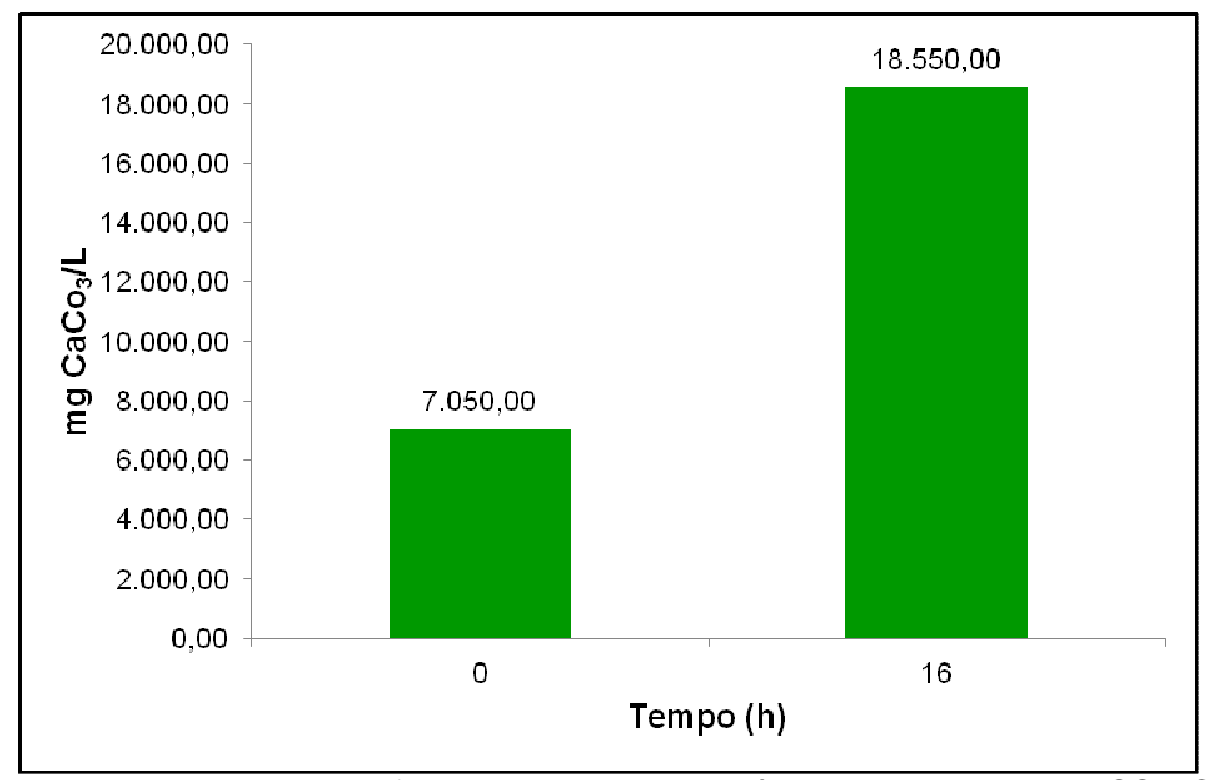

Figura 55 - Acidez inicial e final do compartimento ânodo do ensaio 1 ED-SS-AC-II.

O monitoramento do $\mathrm{pH}$ ao longo do ensaio demonstrou que houve redução no $\mathrm{pH}$ durante as 16 horas, passando de 0,94 a 0,43. Essa redução no pH é comprovada pela maior acidez apresentada pela solução final do compartimento do ânodo na Figura 55. Observa-se que o aumento na acidez da solução foi de $163,12 \%$, demonstrando assim a eficiência do processo em produzir ácido sulfúrico por aumento de concentração, ampliada pelo maior tempo de ensaio e área da membrana, quando comparado aos ensaios realizados em bancada (I) (item 5.5).

Da mesma forma que para o ensaio 1ED-SS-AC-II, na Figura 56 e na Figura 57 apresentam-se os resultados da variação da concentração de sulfatos e de ferro, respectivamente, ao longo do ensaio 2ED-SS-AC-II. E na Figura 58 o monitoramento do $\mathrm{pH}$ a cada hora de ensaio. Por fim, na Figura 59 tem-se a acidez inicial e final do compartimento do ânodo. 


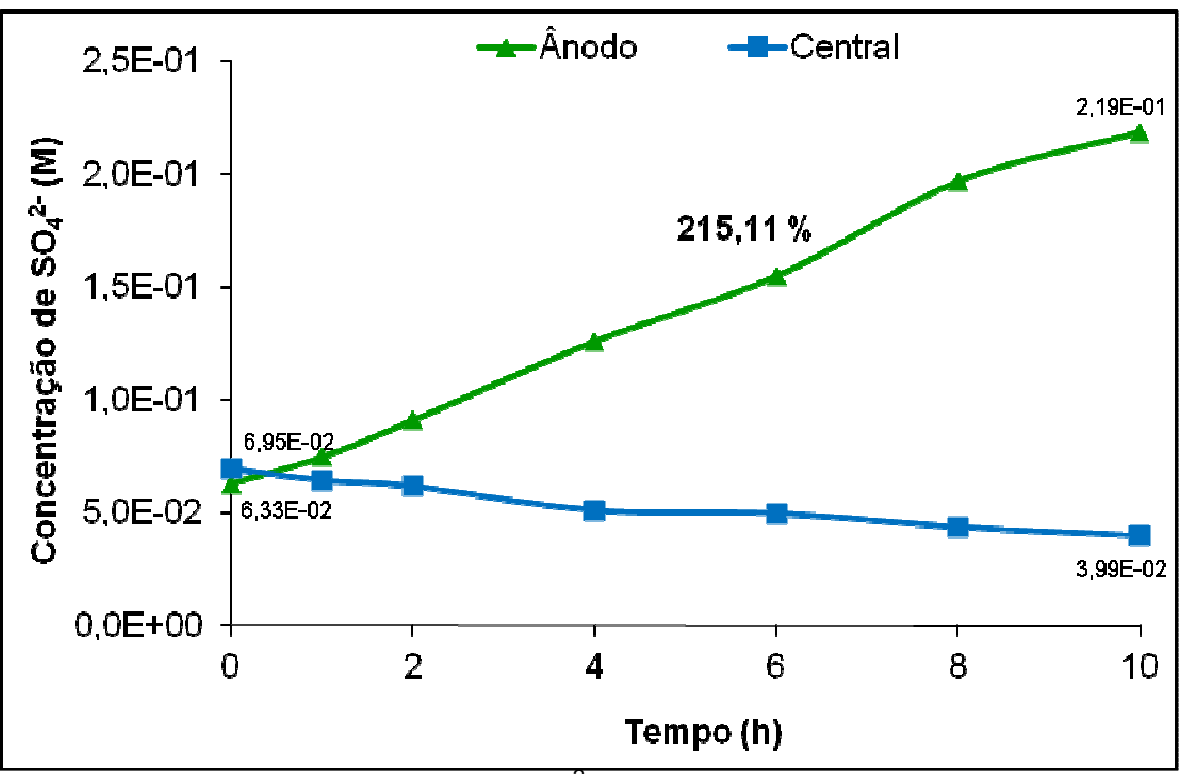

Figura 56 - Concentração de $\mathrm{SO}_{4}{ }^{2-}$ ao longo do ensaio 2ED-SS-AC-II.

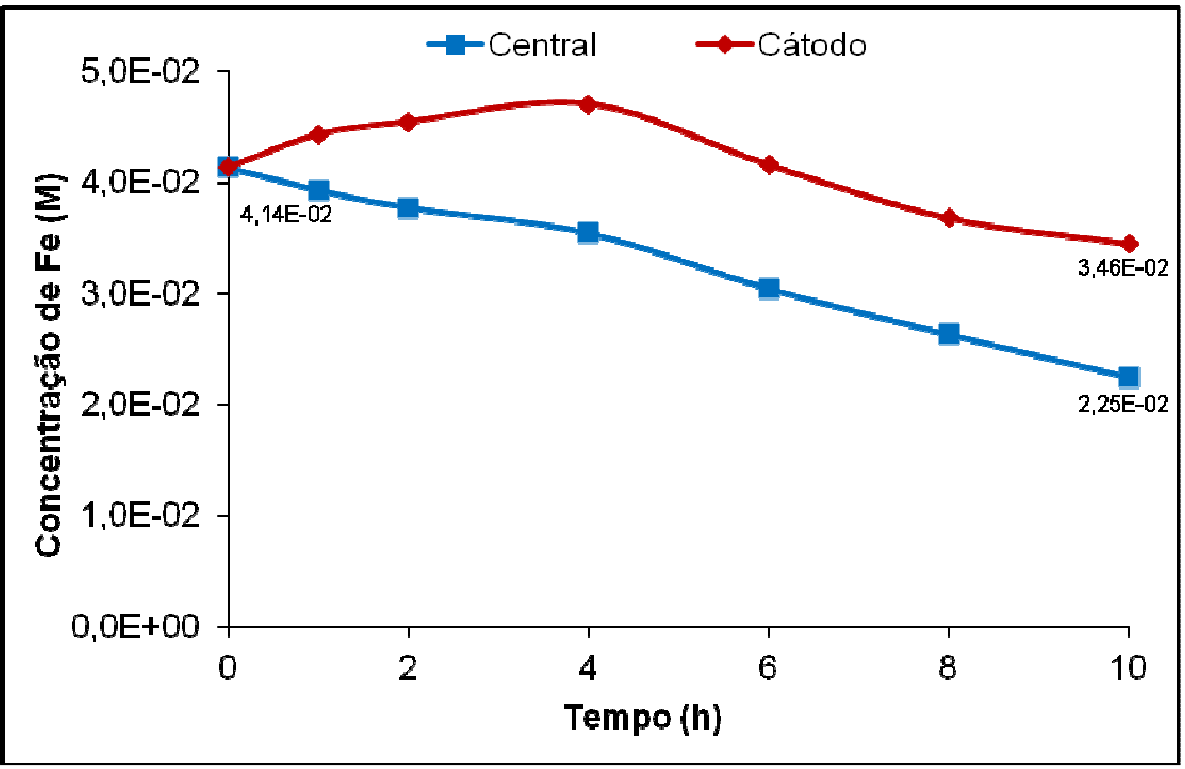

Figura 57 - Concentração de Fe ao longo do ensaio 2ED-SS-AC-II. 


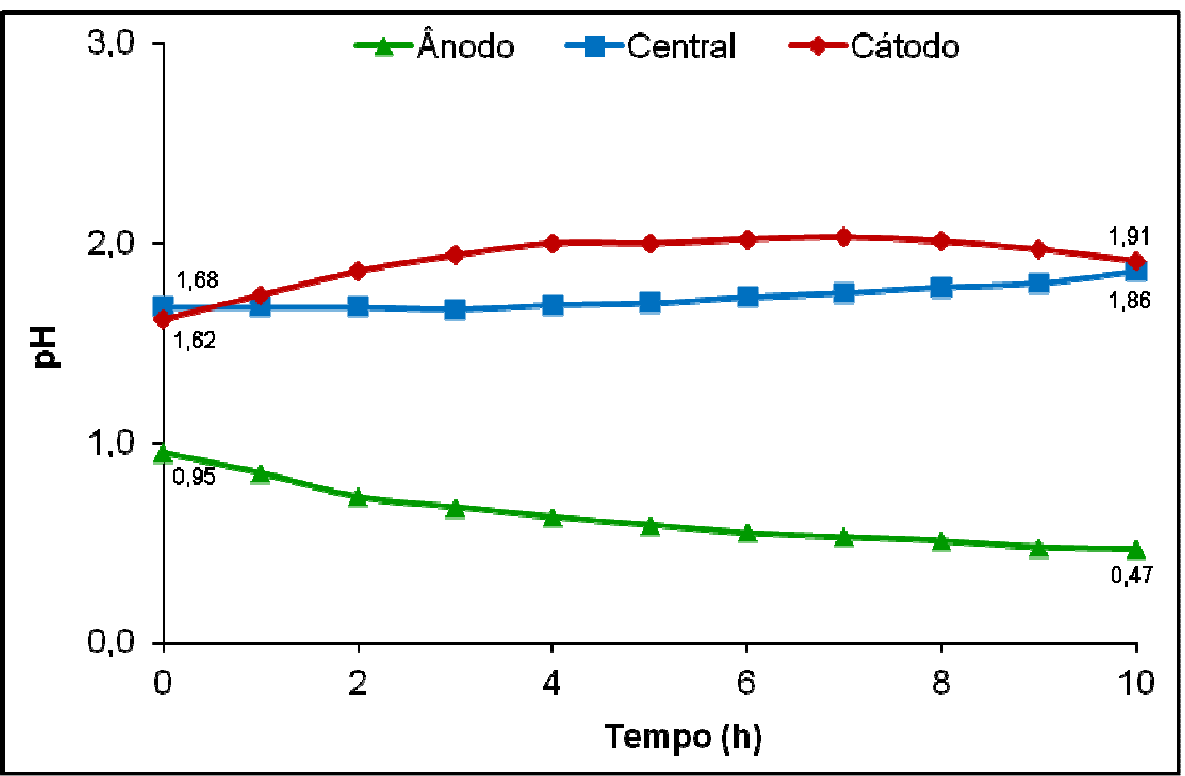

Figura $58-\mathrm{pH}$ ao longo do ensaio 2ED-SS-AC-II.

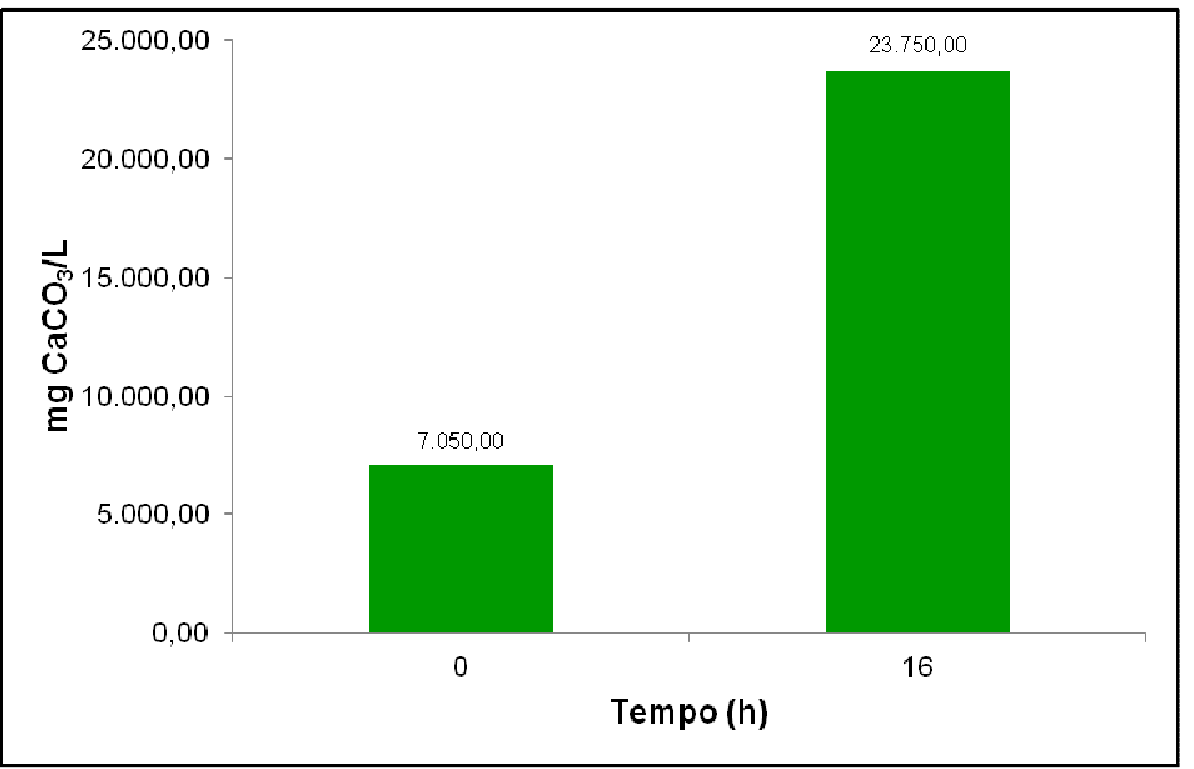

Figura 59 - Acidez inicial e final do compartimento ânodo do ensaio 2ED-SS-AC-II.

A análise dos resultados obtidos para o ensaio 2ED-SS-AC-II comprova que 0 aumento da densidade de corrente aplicada ao sistema influencia diretamente no rendimento, pois de acordo com a Figura 56 a concentração de sulfatos no compartimento do ânodo aumentou $215,11 \%$, na Figura 58 tem-se a redução no pH, que passou de 0,95 para 0,47 e por fim, na Figura 67 o aumento de 236,88\% na acidez confirma a obtenção de ácido sulfúrico neste compartimento.

Os resultados para a concentração de Fe (Figura 57) no compartimento do cátodo, mais uma vez confirmam os resultados anteriores. 


\subsection{CURVAS DE POLARIZAÇÃO COM DRENAGENS ÁCIDAS DE MINAS}

Após a caracterização química das DAMs, a fim de se determinar a $\mathrm{i}_{\lim }$ a ser aplicada nos ensaios de ED, foram realizados os experimentos, em triplicata, para a obtenção das curvas de polarização. Os ensaios mostraram-se reprodutíveis, e as curvas de corrente versus potencial para as membranas aniônicas (HDX 200) e catiônicas (HDX 100), para cada DAM, são apresentadas nas figuras a seguir.

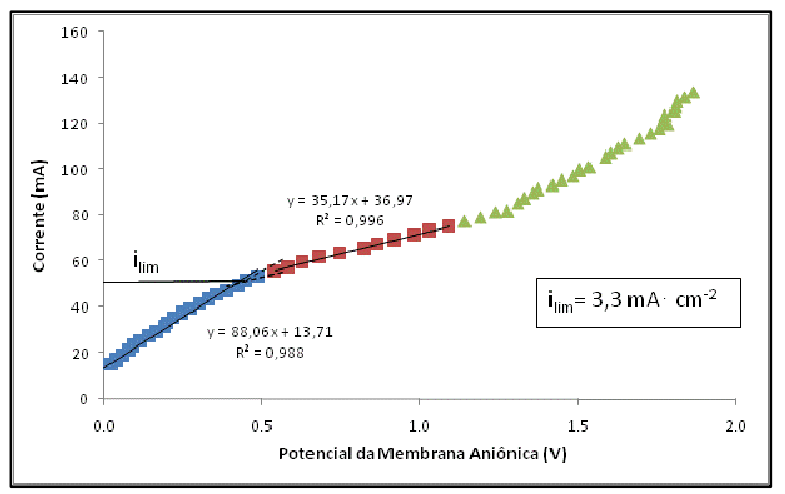

Figura 60 - Curva de polarização da membrana aniônica para a DAM PL.

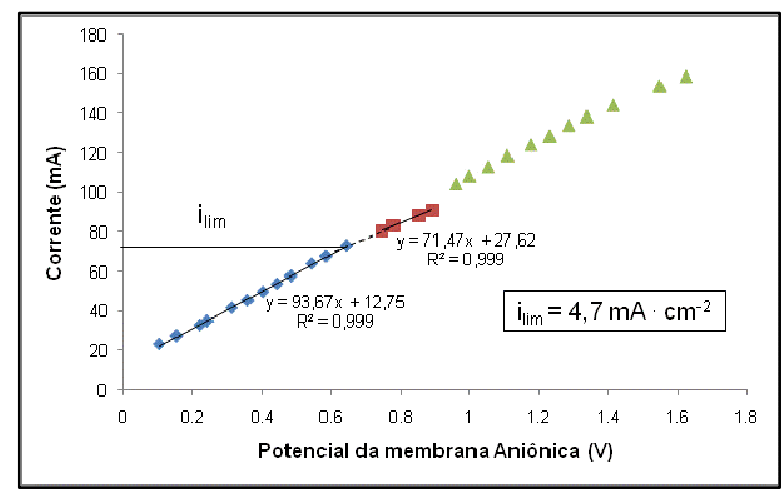

Figura 62 - Curva de polarização da membrana aniônica para a DAM BA.

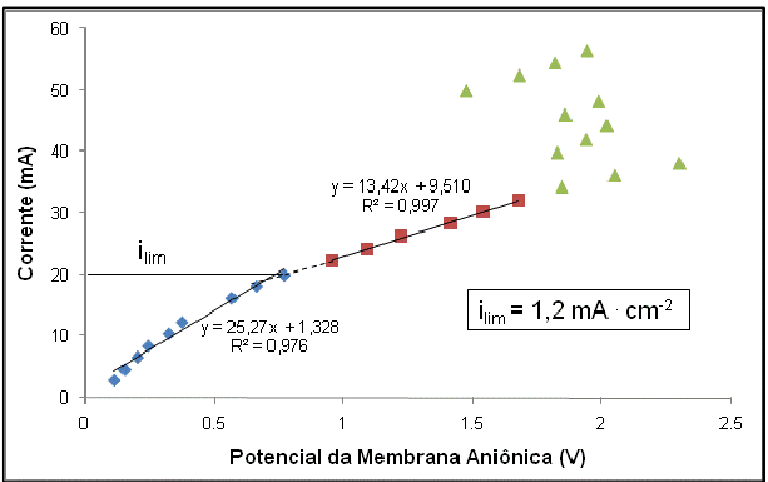

Figura 64 - Curva de polarização da membrana aniônica para a DAM CB.

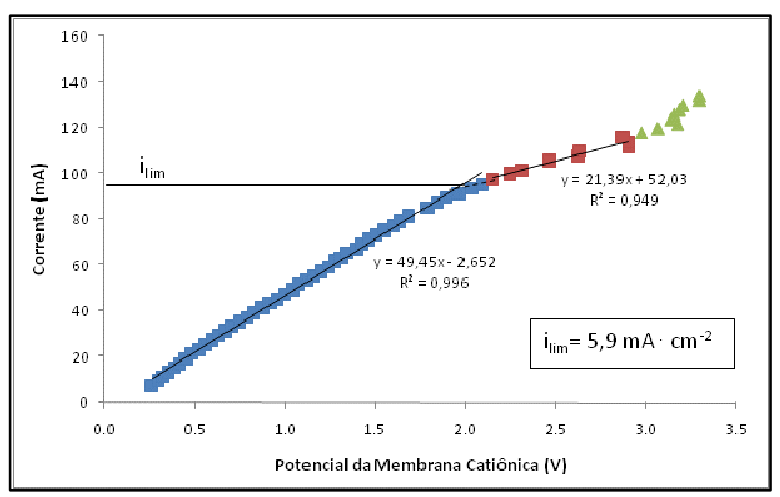

Figura 61 - Curva de polarização da membrana catiônica para a DAM PL.

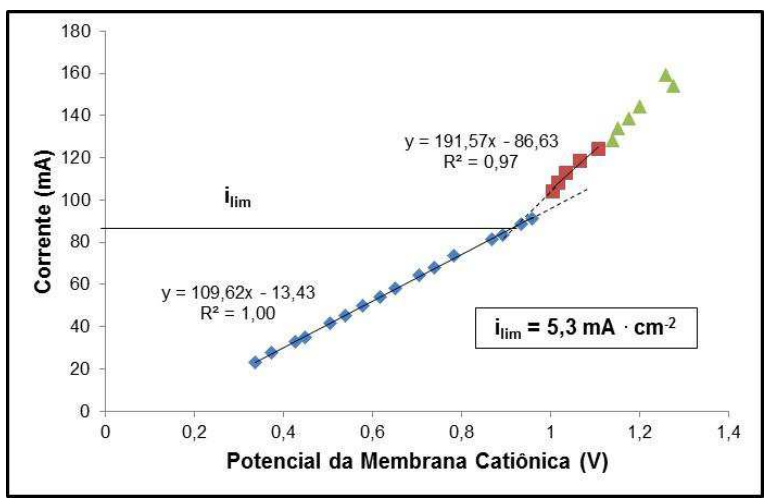

Figura 63 - Curva de polarização da membrana catiônica para a DAM BA.

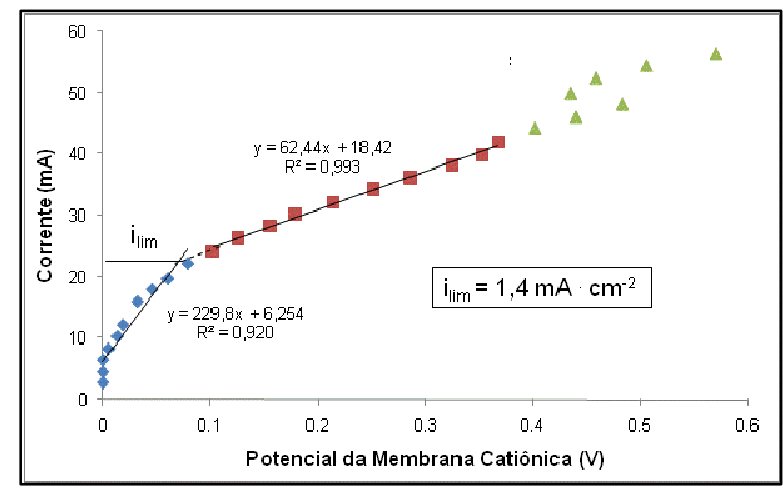

Figura 65 - Curva de polarização da membrana catiônica para a DAM CB. 
Observa-se as três regiões, definidas na literatura, em todas as curvas de polarização. A primeira região linear (I), zona ôhmica, seguida por uma região de platô (II) em que se atinge o valor limite de corrente a ser aplicado, e uma terceira região (III) também linear, na qual a corrente limite já foi ultrapassada ${ }^{69,93,94}$.

$\mathrm{Da}$ análise das curvas de polarização, apresentadas nas figuras 58 a 63, verificou-se que a densidade de corrente limite, para todas as DAMs avaliadas, foi obtida para as membranas aniônicas e catiônicas. Os valores de densidade de corrente limite para cada DAM e respectiva membrana são apresentados na Tabela 17.

Tabela 17 - Densidade de corrente limite para as membranas aniônicas e catiônicas.

\begin{tabular}{|c|c|c|}
\hline \multirow[b]{2}{*}{ DAM } & \multicolumn{2}{|c|}{ Densidade de corrente limite $\left(\mathrm{mA} / \mathrm{cm}^{2}\right)$} \\
\hline & $\begin{array}{c}\text { Membrana Aniônica } \\
\text { (HDX 200) }\end{array}$ & $\begin{array}{c}\text { Membrana Catiônica } \\
\text { (HDX 100) }\end{array}$ \\
\hline PL & 3,3 & 5,9 \\
\hline BA & 4,7 & 5,3 \\
\hline CB & 1,2 & 1,4 \\
\hline
\end{tabular}

Desta forma, as densidades de corrente aplicadas posteriormente nos ensaios de ED foram definidas com base nas curvas de polarização obtidas para as membranas aniônicas, pois estas atingiram a região II a densidades de correntes mais baixas que as membranas catiônicas. A densidade de corrente aplicada considerou $70-80 \%$ do valor limite obtido ${ }^{102,103,104}$, evitando-se assim desperdício de energia e a polarização por concentração nas duas membranas.

\subsection{ELETRODIÁLISE COM DRENAGENS ÁCIDAS DE MINAS EM BANCADA (III)}

De acordo com o item 4.10, foram realizados ensaios de ED em bancada (III) com a DAM BA, DAM CB e DAM PL.

A partir das curvas de polarização obtidas para a DAM BA, determinou-se que a densidade de corrente a ser aplicada seria de $3,8 \mathrm{~mA} \cdot \mathrm{cm}^{-2}$. Considerando que a ED foi realizada no mesmo sistema montado para a obtenção das curvas de 
polarização (Figura 41), com a área superficial das membranas de $16 \mathrm{~cm}^{2}$, a corrente aplicada ao sistema foi de $60,0 \mathrm{~mA}$.

O ensaio de ED foi realizado por 6 horas, e a cada 30 minutos foi monitorado o $\mathrm{pH}$ e a condutividade de todos os compartimentos, conforme resultados apresentados na Figura 66, na Figura 67 e na Tabela 18, na qual apresentam-se os resultados iniciais e finais do monitoramento deste ensaio. Também foram retiradas alíquotas a cada 1 hora para verificação da extração percentual dos íons.

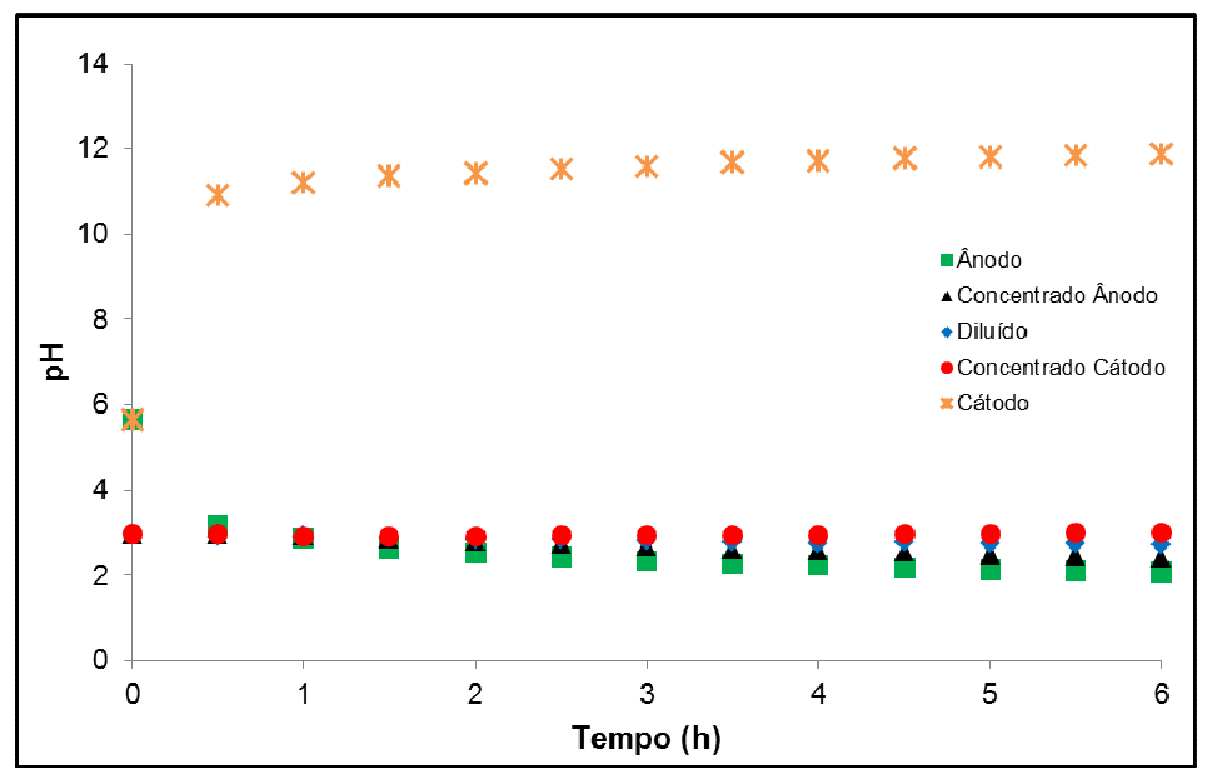

Figura 66 - Monitoramento do $\mathrm{pH}$ da ED para a DAM BA.

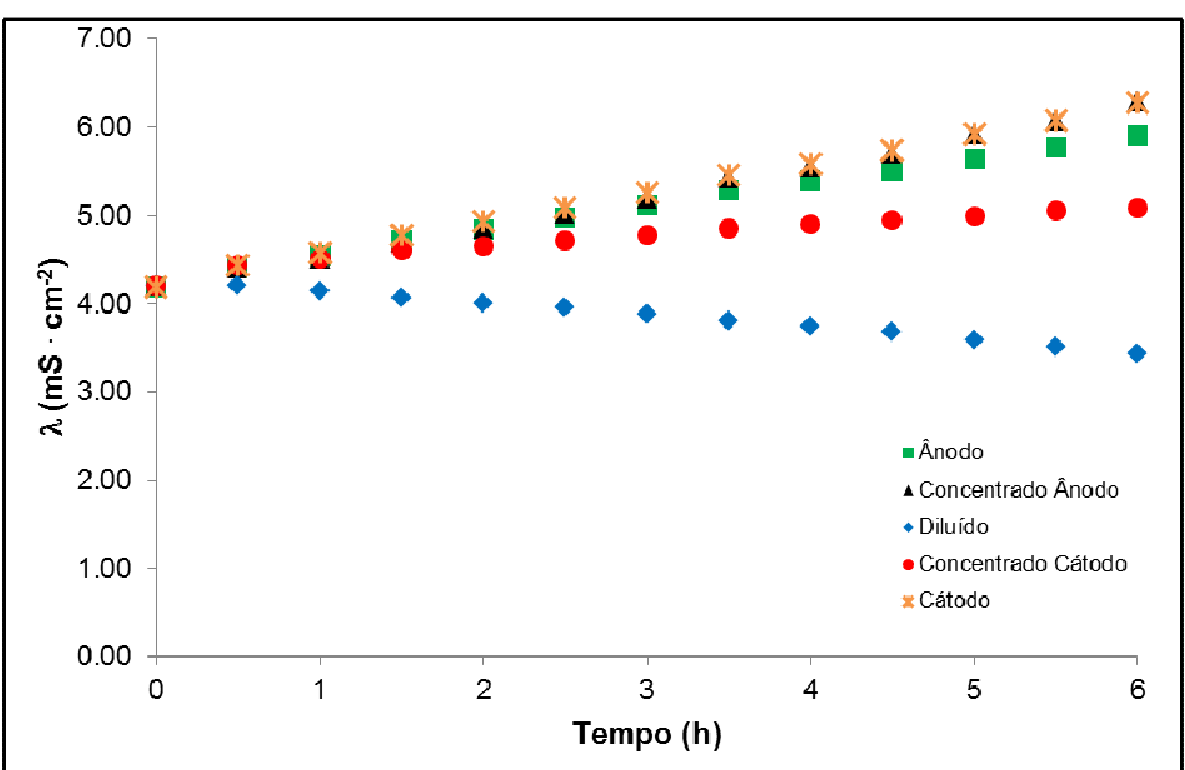

Figura 67 - Monitoramento da condutividade da ED para a DAM BA. 
Tabela 18 - Monitoramento do ensaio de ED para a DAM BA.

\begin{tabular}{ccccccc}
\hline \multirow{2}{*}{ Tempo } & Parâmetro & Ânodo & $\begin{array}{c}\text { Concentrado } \\
\text { Ânodo }\end{array}$ & Diluído & $\begin{array}{c}\text { Concentrado } \\
\text { Cátodo }\end{array}$ & Cátodo \\
\hline \multirow{2}{*}{ Inicial } & $\mathrm{pH}$ & 5,64 & 2,98 & 2,98 & 2,98 & 5,64 \\
& $\lambda\left(\mathrm{mS}^{\prime} \mathrm{cm}^{-2}\right)$ & 4,19 & 4,20 & 4,20 & 4,20 & 4,19 \\
\hline \multirow{2}{*}{$6 \mathrm{~h}$} & $\mathrm{pH}$ & 2,09 & 2,42 & 2,72 & 3,01 & 11,87 \\
& $\lambda\left(\mathrm{mS}^{\cdot} \mathrm{cm}^{-2}\right)$ & 5,90 & 6,29 & 3,43 & 5,09 & 6,27 \\
\hline
\end{tabular}

Observa-se na Figura 67, uma diminuição na condutividade do compartimento diluído e um aumento na condutividade dos demais compartimentos, conforme esperado, uma vez que buscava-se a diluição da DAMBA colocada no compartimento central e a concentração desta nos compartimentos concentrado ânodo e concentrado cátodo.

Já o aumento na condutividade nos compartimentos ânodo e cátodo justifica-se pelas reações nos eletrodos, com consequente liberação de íons $\mathrm{H}^{+}$e $\mathrm{OH}^{-}$, respectivamente, por eles para a solução de cada compartimento, confirmada pelo $\mathrm{pH}$ nestes compartimentos (Figura 66).

As análises de caracterização química, da solução do compartimento diluído, ao longo do ensaio de ED, são apresentadas nas Figura 68, para a análise de extração de ânions e na Figura 69 e Figura 70 para a análise de extração dos cátions.

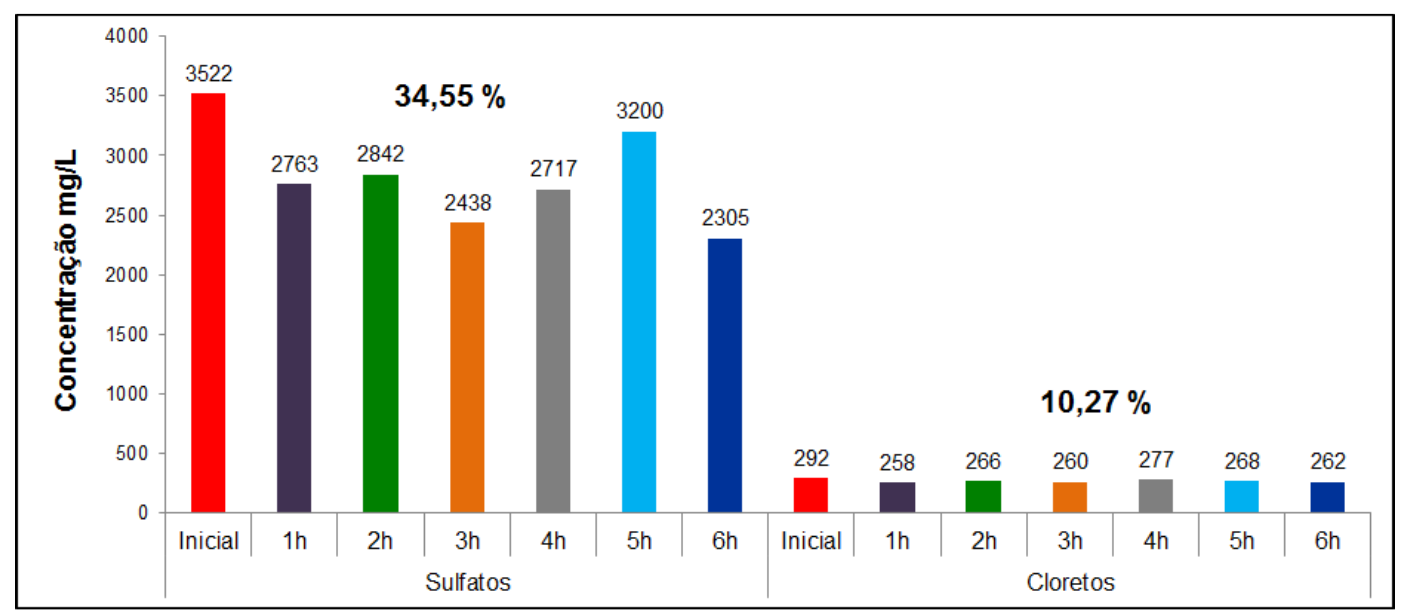

Figura 68 - Extração de ânions durante as 6h de ED da DAM BA. 


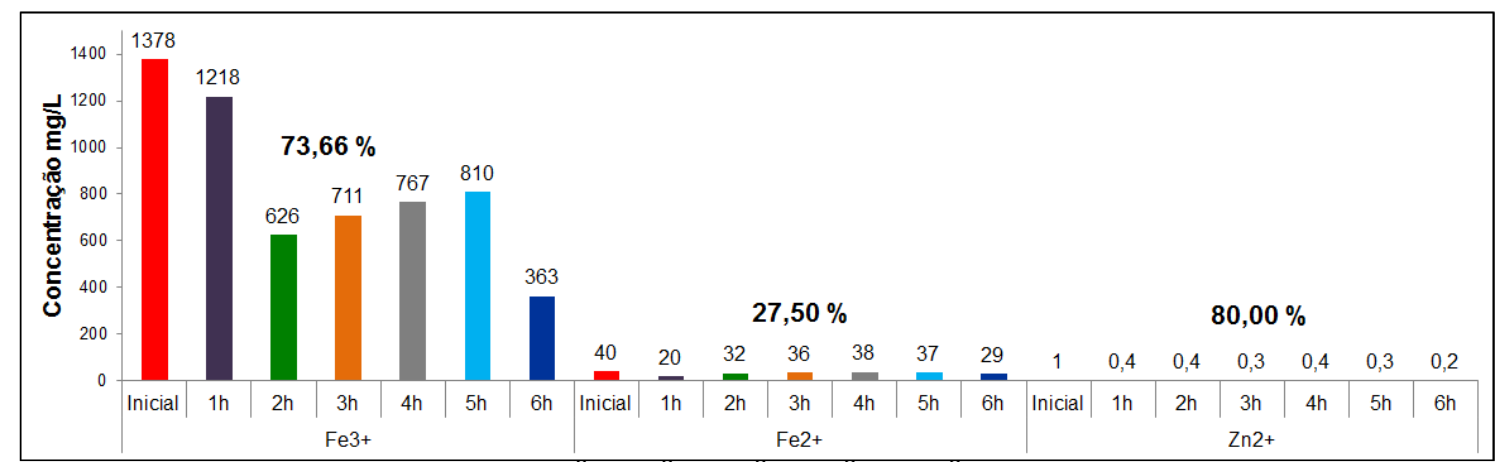

Figura 69 - Extração dos cátions $\mathrm{Fe}^{3+}, \mathrm{Fe}^{2+}, \mathrm{Mn}^{2+}, \mathrm{Co}^{2+}$ e $\mathrm{Zn}^{2+}$ durante as 6h de ED da DAM BA.

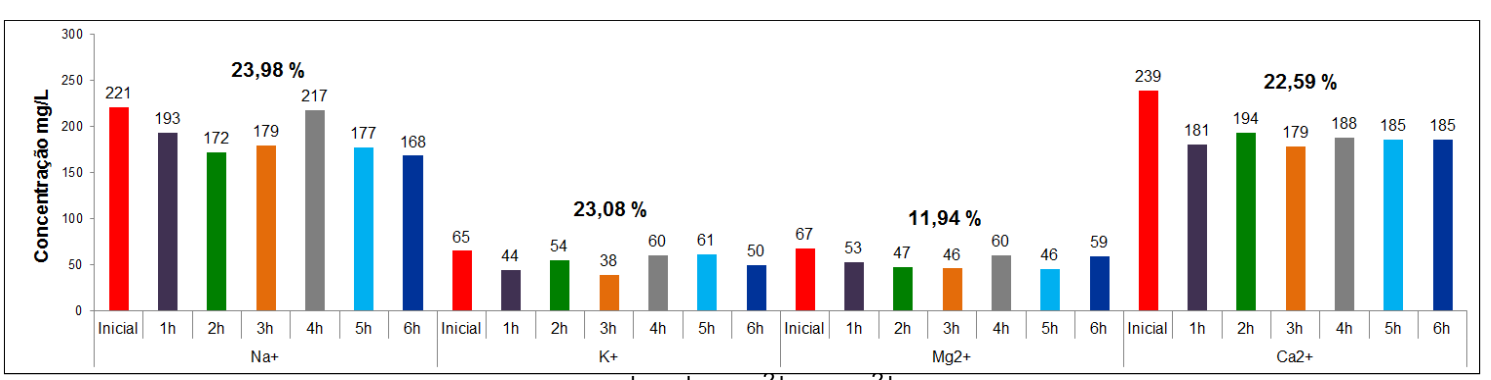

Figura 70 - Extração dos cátions $\mathrm{Na}^{+}, \mathrm{K}^{+}, \mathrm{Mg}^{2+}$ e $\mathrm{Ca}^{2+}$ durante as 6h de ED da DAM BA.

$\mathrm{Na}$ Figura 68, verifica-se os percentuais de remoção dos ânions $\mathrm{SO}_{4}{ }^{2-} \mathrm{e} \mathrm{Cl}^{-}$, durante as 6 horas de ensaio, iguais a 34,55\% e 10,27\%, respectivamente.

Na Figura 69 e na Figura 70 os percentuais de remoção dos cátions, a partir das quais observa-se que as maiores taxas de extração foram obtidas para os cátions $\mathrm{Fe}^{3+}$ e $\mathrm{Zn}^{2+}$, que apresentaram, 73,66\% e 80,00\% de remoção, respectivamente. Para os demais cátions presentes na DAM BA as remoções foram inferiores a $50,00 \%$, sendo igual a $27,50 \%$ para $\circ \mathrm{Fe}^{2+}, 23,98 \%$ para $\circ \mathrm{Na}^{+}$, $23,08 \%$ para o $\mathrm{K}^{+}, 11,94 \%$ para o $\mathrm{Mg}^{2+}$ e $22,59 \%$ para o $\mathrm{Ca}^{2+}$.

No ensaio de ED com a DAM CB, da mesma forma, a partir das curvas de polarização, determinou-se que a corrente a ser aplicada ao sistema seria de $1,0 \mathrm{~mA} \cdot \mathrm{cm}^{-2}$ e considerando a área da membrana a corrente aplicada ao sistema foi de $16 \mathrm{~mA}$.

O ensaio de ED também foi realizado durante 6 horas, e a cada 30 minuto monitorado quanto ao $\mathrm{pH}$ e condutividade de todos os compartimentos. E a cada 1 hora foram retiradas alíquotas para verificação da extração percentual dos íons. $\mathrm{Na}$ Figura 71 e na Figura 72 apresentam-se as curvas de variação do $\mathrm{pH}$ e da condutividade, respectivamente. Na Tabela 19 têm-se os valores iniciais e finais destes mesmos parâmetros monitorados. 


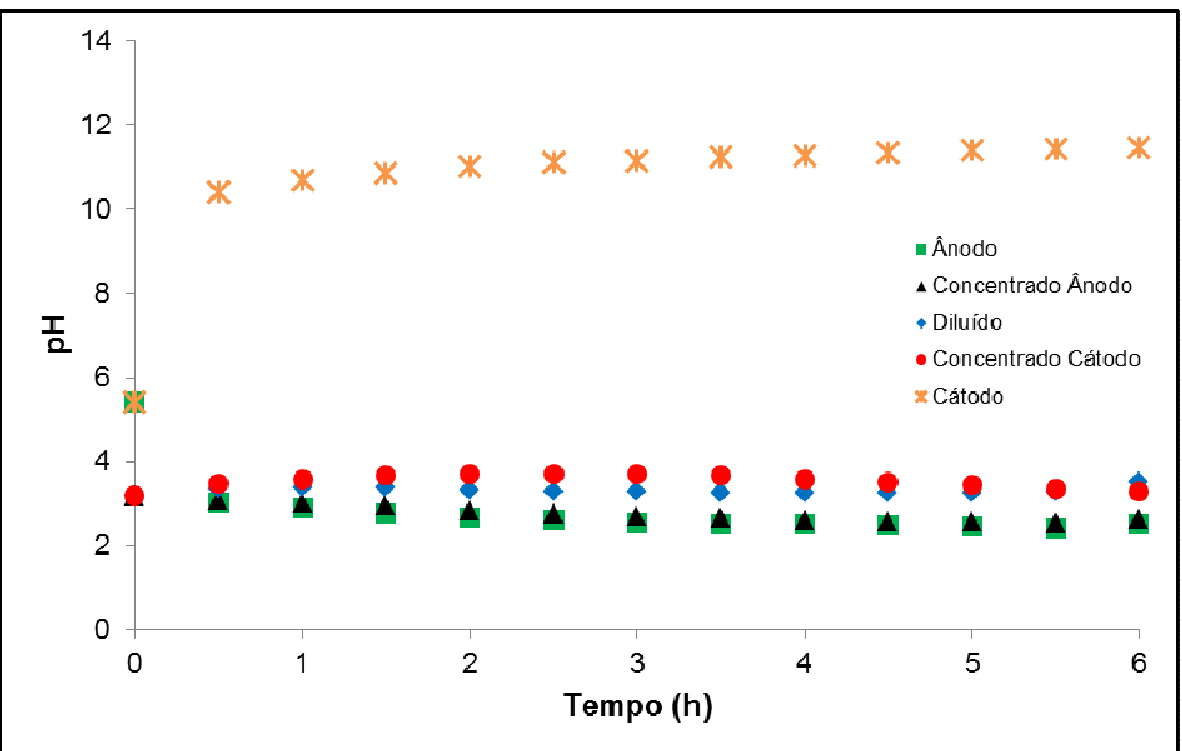

Figura 71 - Monitoramento do $\mathrm{pH}$ da ED para a DAM CB.

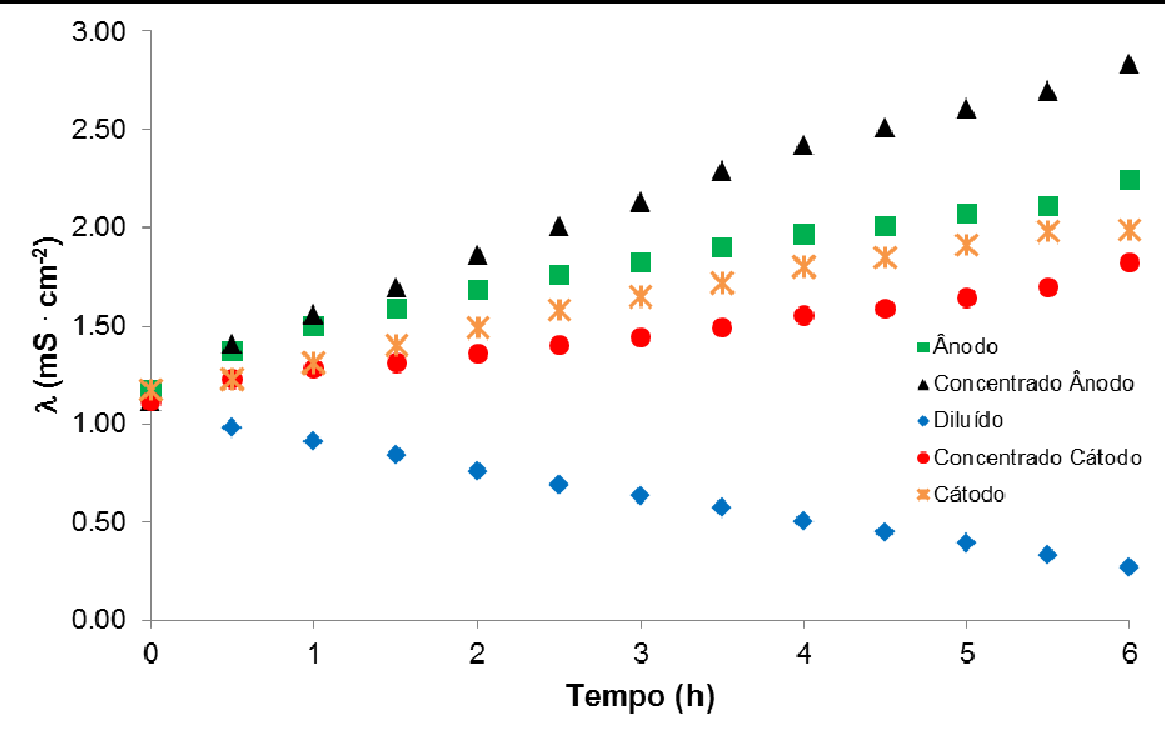

Figura 72 - Monitoramento da condutividade da ED para a DAM CB.

Tabela 19 - Monitoramento do ensaio de ED para a DAM CB.

\begin{tabular}{ccccccc}
\hline Tempo & Parâmetro & Ânodo & $\begin{array}{c}\text { Concentrado } \\
\text { Ânodo }\end{array}$ & Diluído & $\begin{array}{c}\text { Concentrado } \\
\text { Cátodo }\end{array}$ & Cátodo \\
\hline \multirow{2}{*}{ Inicial } & $\mathrm{pH}$ & 5,40 & 3,18 & 3,18 & 3,18 & 5,40 \\
& $\lambda\left(\mathrm{mS} \cdot \mathrm{cm}^{-2}\right)$ & 1,17 & 1,115 & 1,115 & 1,115 & 1,17 \\
\hline \multirow{2}{*}{$6 \mathbf{h}$} & $\mathrm{pH}$ & 2,49 & 2,63 & 3,50 & 3,29 & 11,47 \\
& $\lambda\left(\mathrm{mS} \cdot \mathrm{cm}^{-2}\right)$ & 2,24 & 2,84 & 0,27 & 1,82 & 1,99 \\
\hline
\end{tabular}

O comportamento observado para a DAM BA repete-se para a DAM CB, conforme Figura 75, na qual tem-se uma diminuição na condutividade do compartimento diluído e um aumento na condutividade dos demais compartimentos ao longo do ensaio. Comportamento este esperado, que vai de encontro ao objetivo 
inicial de diluir a DAMCB no compartimento central e concentrá-la nos compartimentos concentrado ânodo e cátodo.

Da mesma forma, observa-se que as reações que se dão nos eletrodos influenciam diretamente no $\mathrm{pH}$ dos compartimentos ânodo e cátodo, apresentando uma diminuição no pH do compartimento ânodo e um aumento no compartimento cátodo, justificados pela liberação de íons $\mathrm{H}^{+}$e $\mathrm{OH}^{-}$, respectivamente. $\mathrm{O}$ que promove o aumento contínuo na condutividade destes dois compartimentos, conforme Figura 72.

As análises de caracterização química, da solução do compartimento diluído, ao longo do ensaio de ED, são apresentadas na Figura 73, para a análise de extração dos ânions e na Figura 74 e Figura 75 para a análise de extração dos cátions.

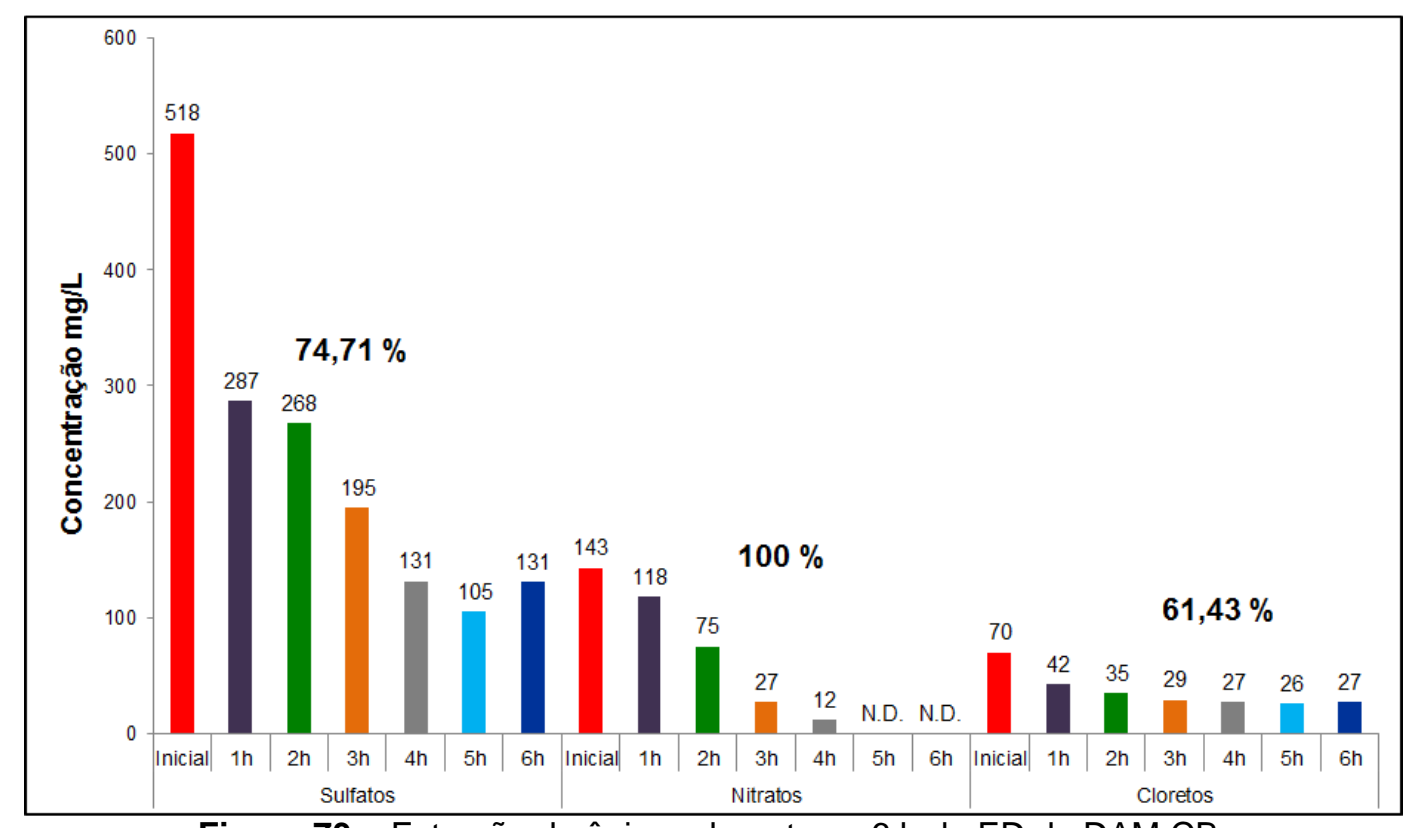

Figura 73 - Extração de ânions durante as $6 \mathrm{~h}$ de ED da DAM CB. 


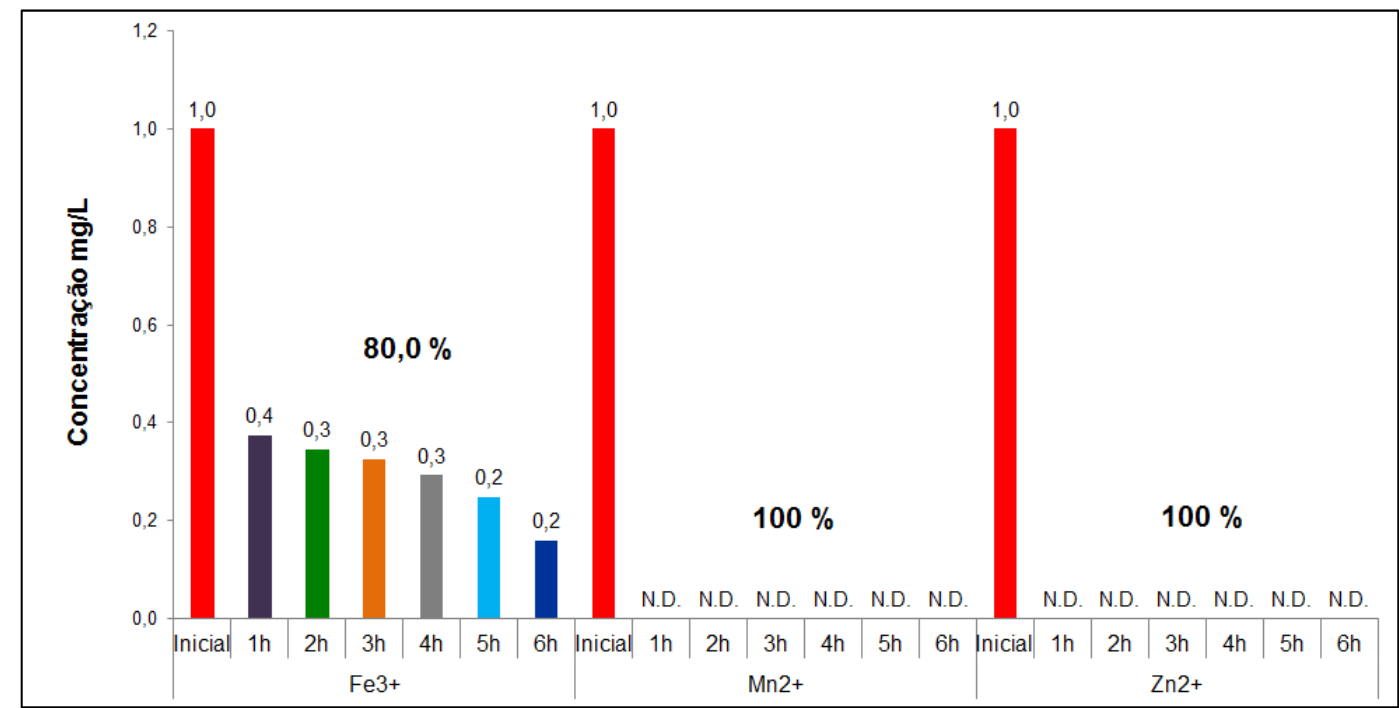

Figura 74 - Extração dos cátions $\mathrm{Fe}^{3+}, \mathrm{Mn}^{2+}$ e $\mathrm{Zn}^{2+}$ durante as $6 \mathrm{~h}$ de ED da DAM CB.

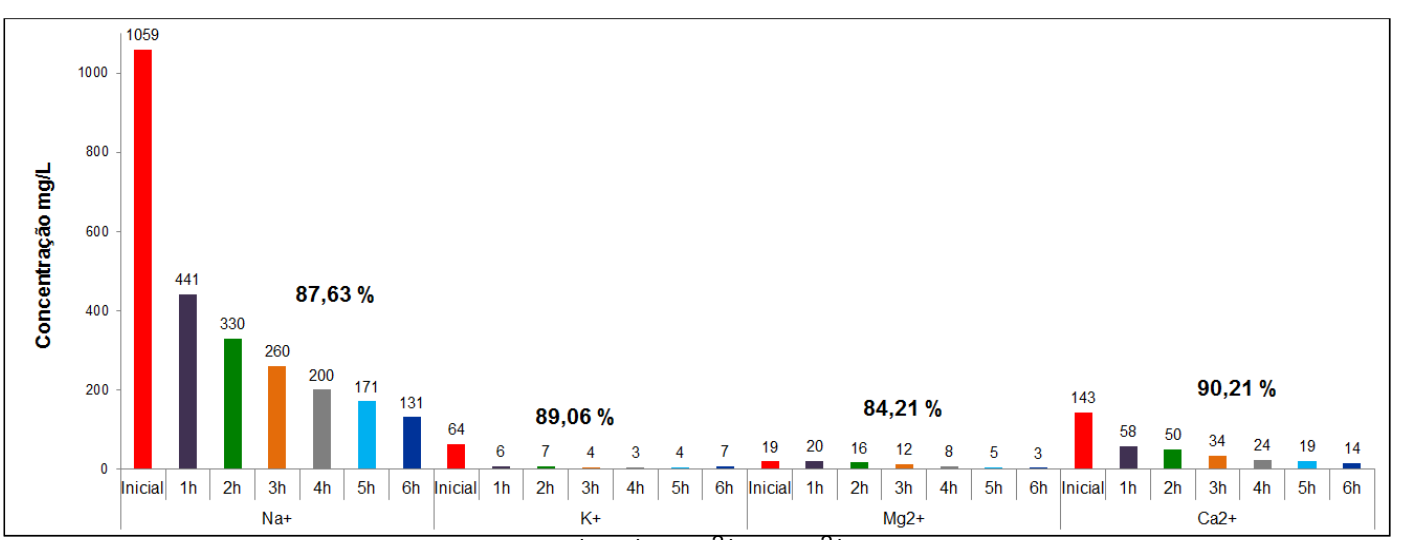

Figura 75 - Extração dos cátions $\mathrm{Na}^{+}, \mathrm{K}^{+}, \mathrm{Mg}^{2+}$ e $\mathrm{Ca}^{2+}$ durante as $6 \mathrm{~h}$ de ED da DAM CB.

Da análise das Figuras 71 a 73, nota-se que a remoção de íons para a DAM CB mostrou-se mais eficaz do que para a DAM BA, apresentando maiores percentuais de remoção tanto para os ânions como para os cátions. O que pode ser justificado pela composição inicial das DAMs, em que a DAM CB apresentava concentrações iniciais menores do que a DAM BA, o que facilitaria o processo de remoção de íons para um mesmo tempo de ensaio, apesar da diferença de densidade de corrente aplicada a cada ensaio.

Verifica-se, na Figura 73, que o processo mostrou-se eficaz para a extração de ânions, removendo do compartimento diluído $61,43 \%$ dos cloretos e $74,71 \%$ dos sulfatos, após as $6 \mathrm{~h}$ de ensaio. 
Analisando-se a Figura 74, observa-se a eficiência do processo de ED para a remoção de cátions, pois houve remoção de $80,00 \%$ de $\mathrm{Fe}^{3+}$, e $100 \%$ do $\mathrm{Mn}$ e do Zn presentes inicialmente na DAM CB.

Por fim, a análise da Figura 75 também apresenta a remoção de $\mathrm{Na}^{+}, \mathrm{K}^{+}, \mathrm{Mg}^{2+}$ e $\mathrm{Ca}^{2+}$, nas proporções 87,63\%, 89,06 \%, 84,21\% e 90,21\%, respectivamente.

Após os ensaios preliminares, foram realizados mais dois ensaios que foram conduzidos até que a redução na condutividade elétrica da solução do compartimento diluído fosse igual ou menor que a condutividade apresentada pela água de abastecimento que é de aproximadamente $300 \mu \mathrm{S} \cdot \mathrm{cm}^{-1}$. Desta forma, o ensaio realizado com a DAM PL teve duração de 55 horas e o novo ensaio realizado com a DAM CB duração de 24 horas.

As densidades de corrente aplicados ao processo também foram definidas com base nas curvas de polarização obtidas para cada DAM, sendo a densidade de corrente aplicada a ED para a DAM PL igual a $2,6 \mathrm{~mA} \cdot \mathrm{cm}^{-2}$ e para a DAM CB $1,0 \mathrm{~mA} \cdot \mathrm{cm}^{-2}$.

$\mathrm{O} \mathrm{pH}$ e a condutividade de todos os compartimentos foram monitorados e os resultados iniciais e finais para cada DAM são apresentados na Tabela 20.

Tabela 20 - Monitoramento dos ensaios de ED para a DAM PL e DAM CB.

\begin{tabular}{cl|cccc} 
& \multirow{2}{*}{ Parâmetros } & \multicolumn{2}{|c}{ DAM PL } & \multicolumn{2}{c}{ DAM CB } \\
& Inicial & $\mathbf{5 5} \mathbf{h}$ & Inicial & $\mathbf{2 4} \mathbf{h}$ \\
\hline \multirow{2}{*}{ Ânodo } & $\mathrm{pH}$ & 3,75 & 1,57 & 5,85 & 2,09 \\
& $\lambda\left(\mathrm{mS} \cdot \mathrm{cm}^{-1}\right)$ & 4,17 & 9,60 & 1,40 & 2,76 \\
\hline Concentrado & $\mathrm{pH}$ & 3,75 & 1,72 & 5,85 & 2,06 \\
Ânodo & $\lambda\left(\mathrm{mS} \cdot \mathrm{cm}^{-1}\right)$ & 4,17 & 12,50 & 1,40 & 3,57 \\
\hline \multirow{2}{*}{ Diluído } & $\mathrm{pH}$ & $\mathbf{2 , 4 1}$ & $\mathbf{2 , 9 2}$ & $\mathbf{2 , 8 4}$ & $\mathbf{4 , 8 3}$ \\
& $\lambda\left(\mathrm{mS} \cdot \mathrm{cm}^{-1}\right)$ & $\mathbf{4 , 4 9}$ & $\mathbf{0 , 3 0}$ & $\mathbf{1 , 1 5}$ & $\mathbf{0 , 0 0 6}$ \\
\hline Concentrado & $\mathrm{pH}$ & 3,75 & 2,50 & 5,85 & 3,87 \\
Cátodo & $\lambda\left(\mathrm{mS} \cdot \mathrm{cm}^{-1}\right)$ & 4,17 & 8,60 & 1,40 & 1,75 \\
\hline \multirow{2}{*}{ Cátodo } & $\mathrm{pH}$ & 3,75 & 12,87 & 5,85 & 11,09 \\
& $\lambda\left(\mathrm{mS} \cdot \mathrm{cm}^{-1}\right)$ & 4,17 & 11,70 & 1,40 & 1,97 \\
\hline
\end{tabular}

Os resultados da Tabela 20 indicam que houve um decréscimo na condutividade do compartimento diluído e um aumento na condutividade nos demais compartimentos, conforme o esperado, uma vez que novamente buscava-se a diluição das duas DAMs colocadas no compartimento diluído.

As reações que ocorrem nos eletrodos justificam a condutividade e as mudanças de $\mathrm{pH}$, observadas nos compartimentos do ânodo e do cátodo, durante 
as ED. Houve um aumento da acidez no compartimento do ânodo, representada por uma diminuição do pH, e uma alcalinização no compartimento do cátodo, ou um aumento do valor de $\mathrm{pH}$. Em ambos os compartimentos, o aumento da condutividade se deu pela presença dos íons $\mathrm{H}^{+}$e $\mathrm{OH}^{-(96)}$. As reações que ocorrem nos eletrodos são apresentadas a seguir:

$$
\begin{gathered}
\text { Cátodo: } 2 \mathrm{H}^{+}+2 \mathrm{e}^{-} \rightarrow \mathrm{H}_{2(\mathrm{~g})} \\
\text { Ânodo: } 2 \mathrm{H}_{2} \mathrm{O} \rightarrow 4 \mathrm{H}^{+}+\mathrm{O}_{2(\mathrm{~g})}+4 \mathrm{e}^{-}
\end{gathered}
$$

O aumento na condutividade dos compartimentos concentrado ânodo e concentrado cátodo, indicam que houve uma concentração dos íons que deixaram o compartimento diluído nestes outros compartimentos.

Para analisar a eficiência da extração dos cátions e ânions, realizou-se a caracterização química da DAM PL e da DAM CB do compartimento diluído após os testes de ED e os resultados são apresentados na Tabela 21.

Tabela 21 - Concentração iônica inicial e final do compartimento diluído e extração percentual para cada DAM.

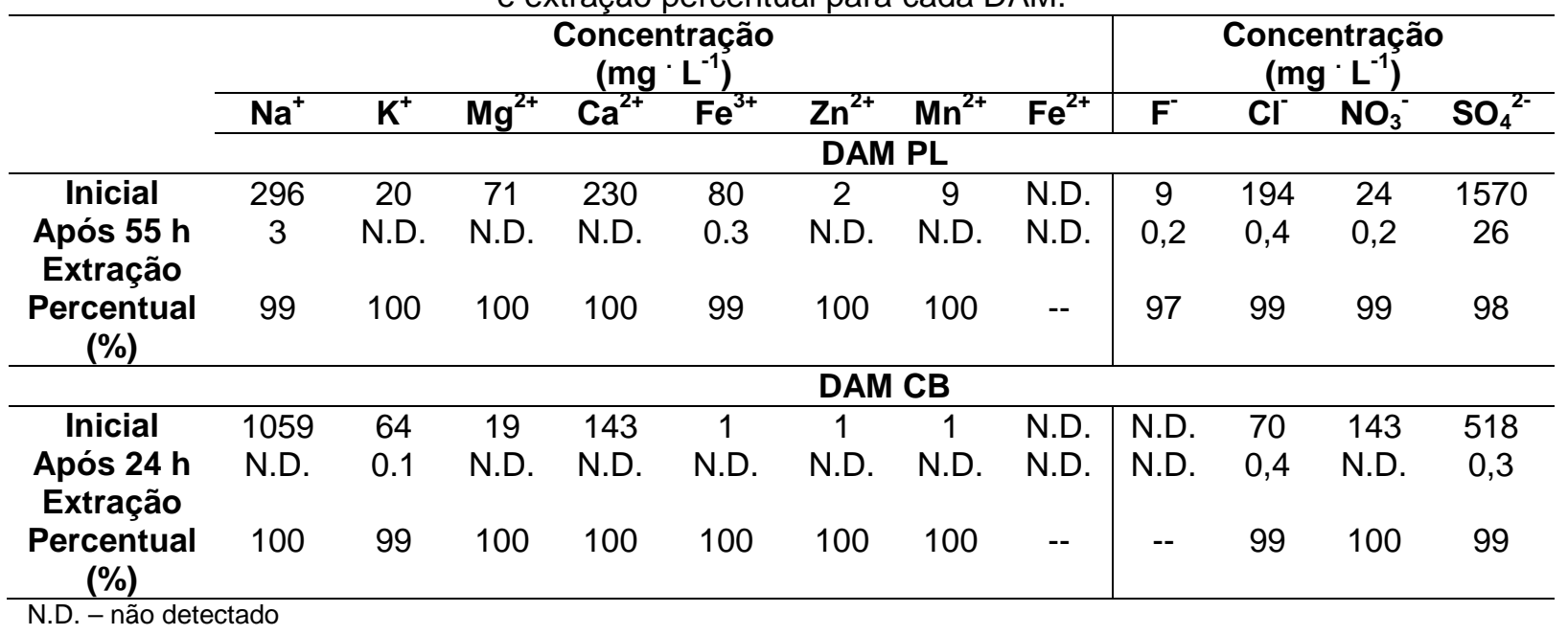

Conforme resultados da Tabela 21, o processo de ED foi eficaz na remoção dos cátions e os ânions a partir das DAMs avaliadas. Apresentando remoções dos contaminantes superiores a $97,00 \%$. Estes resultados indicam que é possível a recuperação de água a partir de amostras da DAMs através do processo de ED.

A influência da presença de ferro nas amostras DAM durante os ensaios ED foi avaliada por uma análise visual das membranas após as ED, comparando as membranas utilizadas para o ensaio com DAM PL ([Fe $\left.\left.{ }^{3+}\right]=80 \mathrm{mg}^{\cdot \mathrm{L}^{-1}}\right)$ e DAM CB 
$\left(\left[\mathrm{Fe}^{3+}\right]=1 \mathrm{mg} \cdot \mathrm{L}^{-1}\right)$ e considerando a diferença na concentração de ferro total nas duas DAMs. Observou-se que após a ED da DAM PL, que continha mais Fe houve formação de um precipitado sobre a superfície da membrana catiônica, enquanto que após a ED da DAM CB não houve formação de qualquer precipitado, o que garante maior vida útil das membranas. Apesar dos bons resultados apresentados para a extração dos íons presentes na DAM PL, o fenômeno de scaling pode ocorrer nas membranas no longo prazo e reduzir a eficiência do processo de ED.

\subsection{ELETRODIÁLISE COM DRENAGEM ÁCIDA DE MINAS VISANDO A RECUPERAÇÃO DE ÁCIDO SULFÚRICO EM BANCADA (IV)}

Os resultados apresentados no item 5.6 demonstraram ser possível recuperar ácido sulfúrico a partir da solução sintética que simulava as características de uma DAM. De modo a comprovar a eficiência desse processo, um novo ensaio foi realizado com uma DAM, a DAM MB.

Para tanto, utilizou-se uma configuração experimental semelhante à empregada nos ensaios com solução sintética (item 5.6), na qual foram mantidos os volumes de $750 \mathrm{~mL}$ no cátodo e ânodo e $3000 \mathrm{~mL}$ no compartimento central. Porém, por questões logísticas, de a DAM não se encontrar no mesmo local da célula de ED de bancada (II), este ensaio foi realizado em outra célula de ED de bancada, com menor área de membrana, neste caso $16 \mathrm{~cm}^{2}$ (célula de ED de bancada (IV)) e não $100 \mathrm{~cm}^{2}$. Também foram utilizados eletrodos de titânio metálico revestidos com óxido de titânio e óxido de rutênio $\left(70 \mathrm{TiO}_{2} / 30 \mathrm{RuO}_{2}\right)$ como cátodo e ânodo. $\mathrm{E}$, como dito anteriormente, neste caso, no lugar da solução sintética de $\mathrm{Fe}_{2}\left(\mathrm{SO}_{4}\right)_{3} 2 \cdot 10^{-2} \mathrm{M}$ $+\mathrm{Na}_{2} \mathrm{SO}_{4} 1 \cdot 10^{-2} \mathrm{M}$ utilizou-se a DAM MB e no ânodo novamente solução de $\mathrm{H}_{2} \mathrm{SO}_{4} 7 \cdot 10^{-2} \mathrm{M}$.

O ensaio foi conduzido por 16 horas com aplicação de densidade de corrente de $5,0 \mathrm{~mA} \cdot \mathrm{cm}^{-2}$.

Este ensaio foi monitorado a cada hora, e a variação na concentração de sulfatos e de ferro, ao longo das 16 horas, é apresentada na Figura 76 e na Figura 77, respectivamente. 


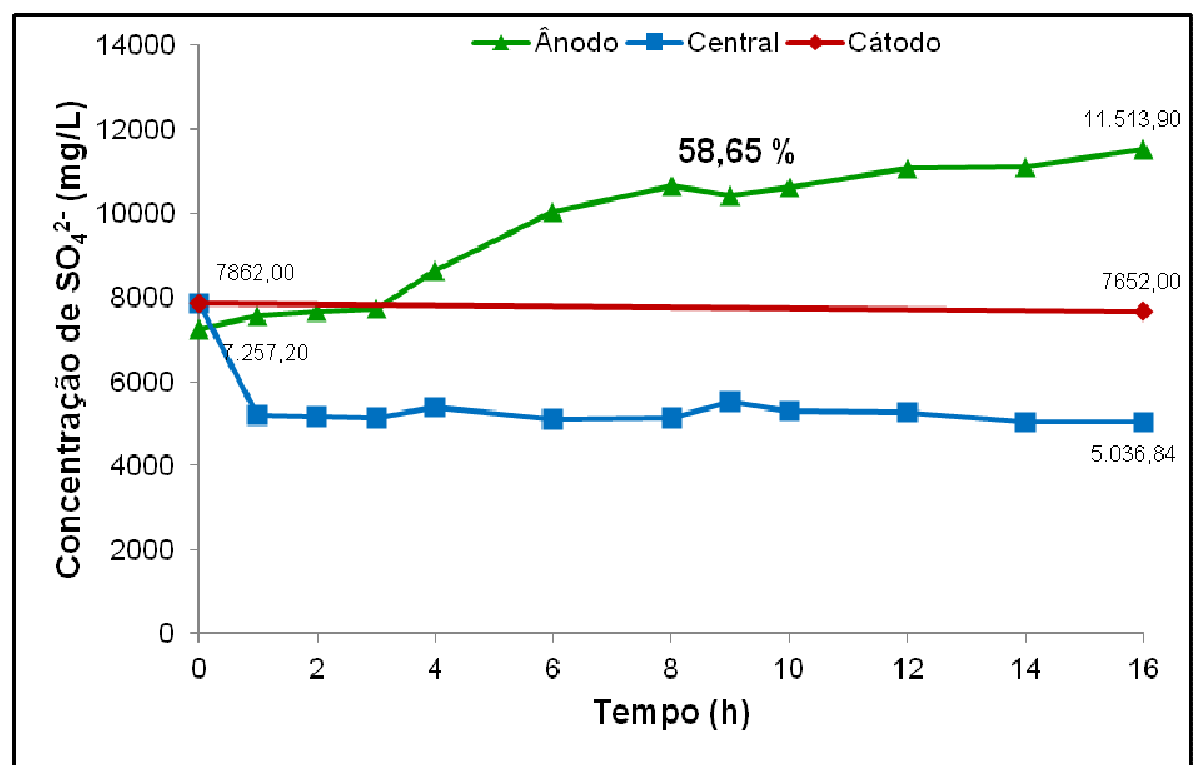

Figura 76 - Concentração de $\mathrm{SO}_{4}{ }^{2-}$ ao longo do ensaio com DAM MB.

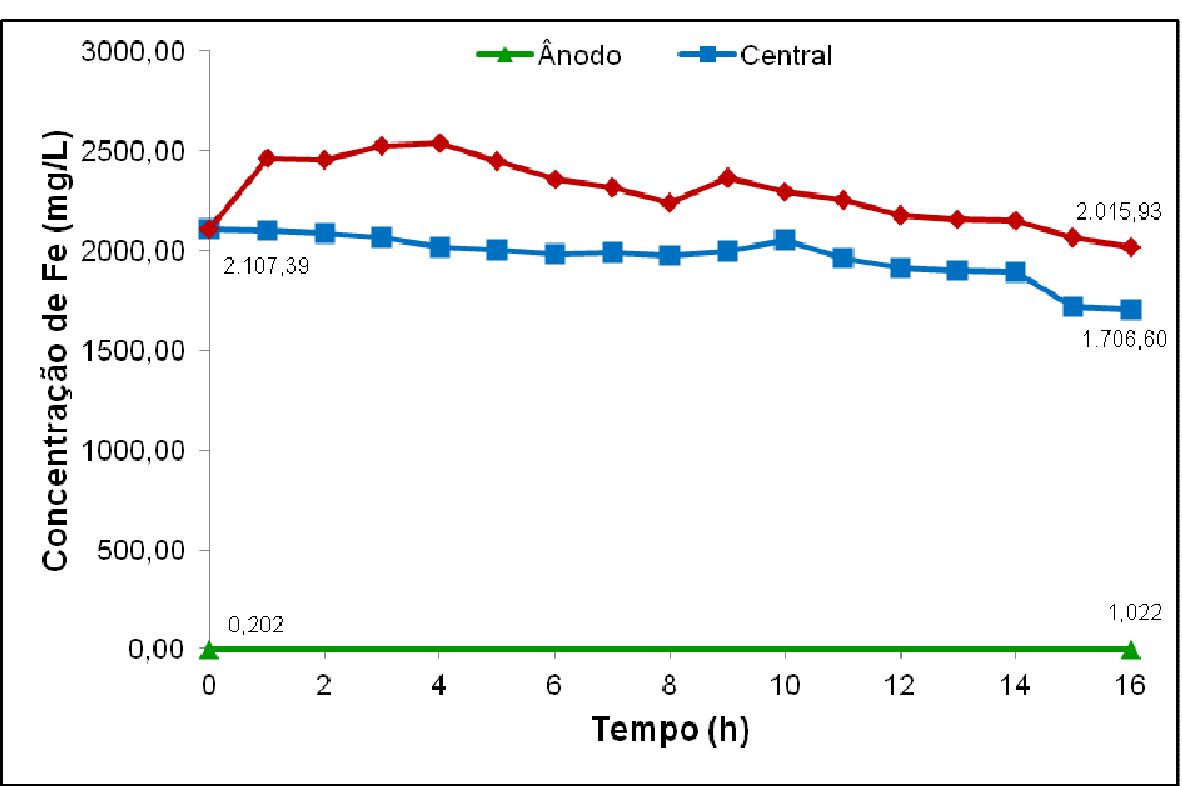

Figura 77 - Concentração de Fe ao longo do ensaio com DAM MB.

$\mathrm{Na}$ Figura 76 tem-se que o aumento na concentração de sulfatos no compartimento do ânodo, nas 16 horas de ensaio, foi de 58,65\%, rendimento inferior quando comparado ao ensaio realizado com solução sintética em bancada (II) com a mesma densidade de corrente aplicada $\left(5,0 \mathrm{~mA} \cdot \mathrm{cm}^{-2}\right)$, que foi de 136,44\%. A partir destes resultados, pode-se inferir que a área da membrana exerce influência no processo, pois o ensaio com solução sintética foi realizado em uma célula de ED de bancada com área de membrana de $100 \mathrm{~cm}^{2}$ e este último com área de membrana de $16 \mathrm{~cm}^{2}$. 
Os resultados da análise de ferro (Figura 77) apresentaram comportamento semelhante aos resultados obtidos com solução sintética, ou seja, redução na concentração de $\mathrm{Fe}$ no compartimento central e aumento no compartimento do cátodo, e também precipitação de Fe neste compartimento em função do aumento de $\mathrm{pH}$ pela presença das hidroxilas geradas no eletrodo.

$\mathrm{O} \mathrm{pH}$ de todos os compartimentos foi monitorado a cada hora de ensaio (Figura 78), bem como a diferença de potencial da célula ao longo das 16 horas. $E$ ao final do ensaio, de modo a comprovar a produção de ácido sulfúrico, quantificou-se a acidez da solução final no compartimento do ânodo, e comparou-se este resultado com a acidez inicial da solução de H2SO4 7 . 10-2 M (Figura 79).

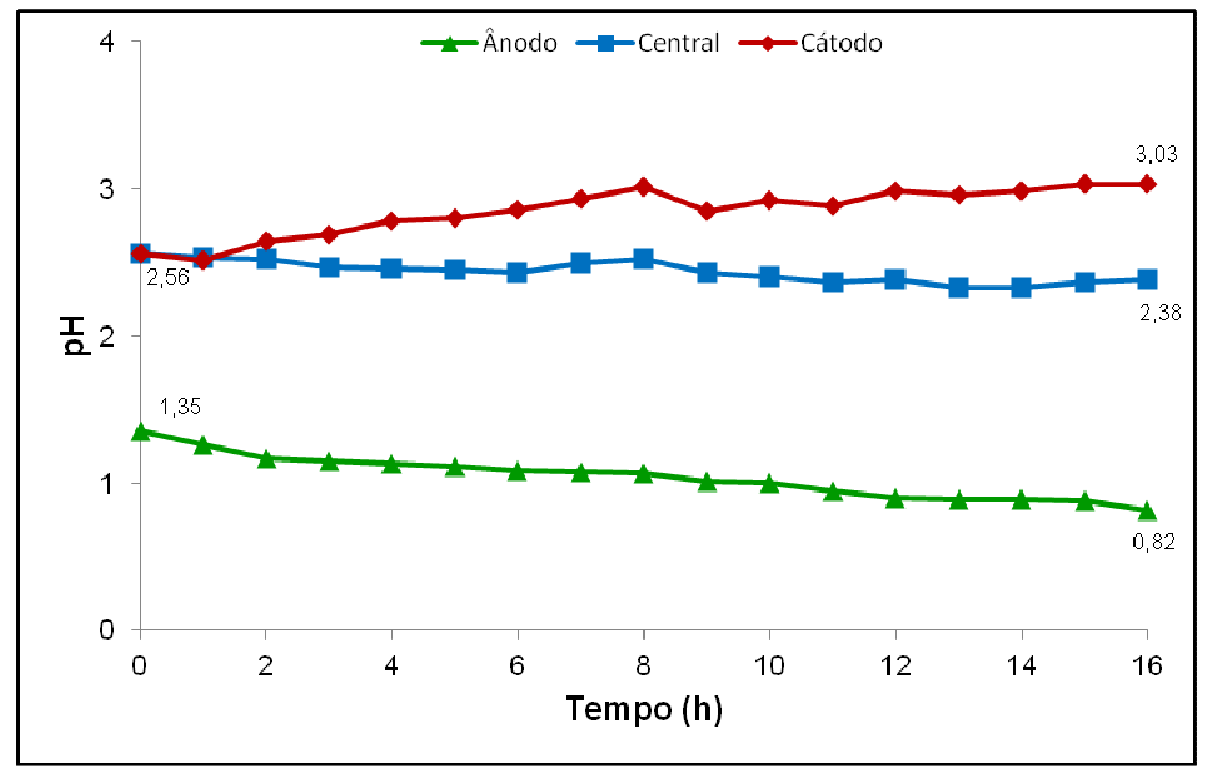

Figura $78-\mathrm{pH}$ ao longo do ensaio com DAM MB. 


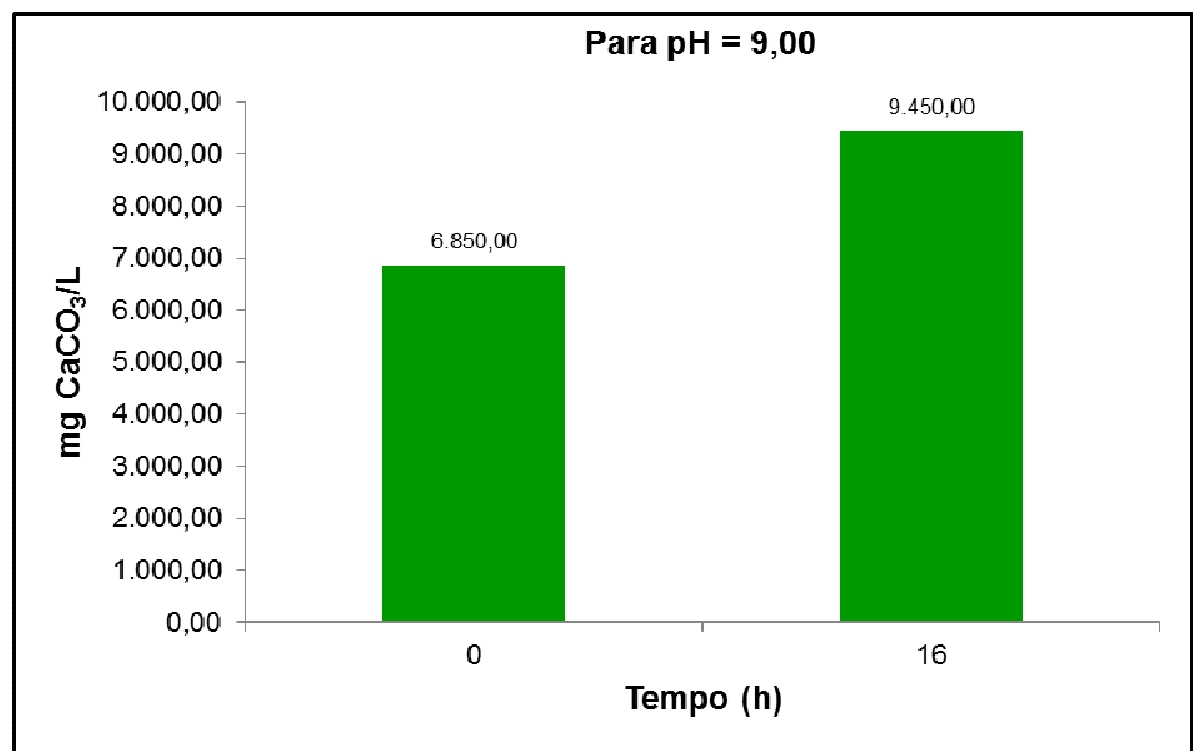

Figura 79 - Acidez inicial e final do compartimento ânodo do ensaio com DAM MB.

O monitoramento do $\mathrm{pH}$ ao longo do ensaio demonstrou que houve redução no $\mathrm{pH}$ durante as 16 horas, passando de 1,35 a 0,82. O aumento na acidez para este ensaio foi de $37,96 \%$, bastante inferior ao obtido no ensaio com solução sintética $(163,12 \%$ de aumento na acidez). Desta forma, confirma-se a influência da área da membrana, e neste caso da área do eletrodo no rendimento da obtenção de ácido sulfúrico.

As soluções dos compartimentos ânodo e cátodo após as 16 horas de ensaio são apresentadas na Figura 80 e Figura 81, respectivamente.

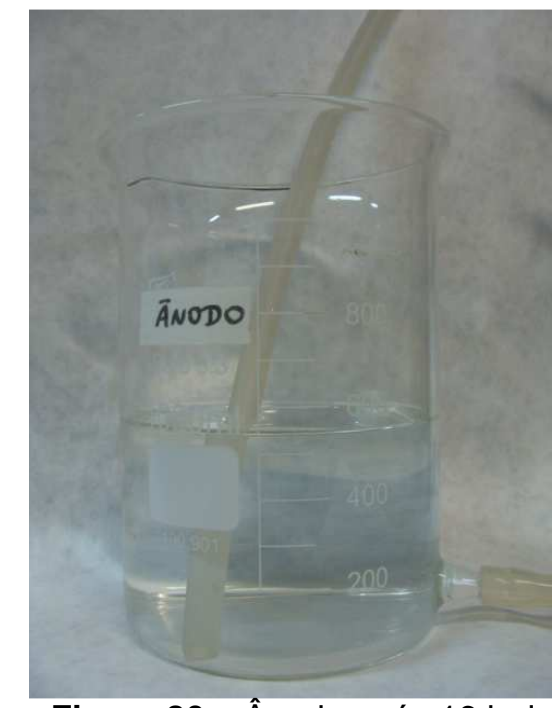

Figura 80 - Ânodo após $16 \mathrm{~h}$ de ED com DAM MB.

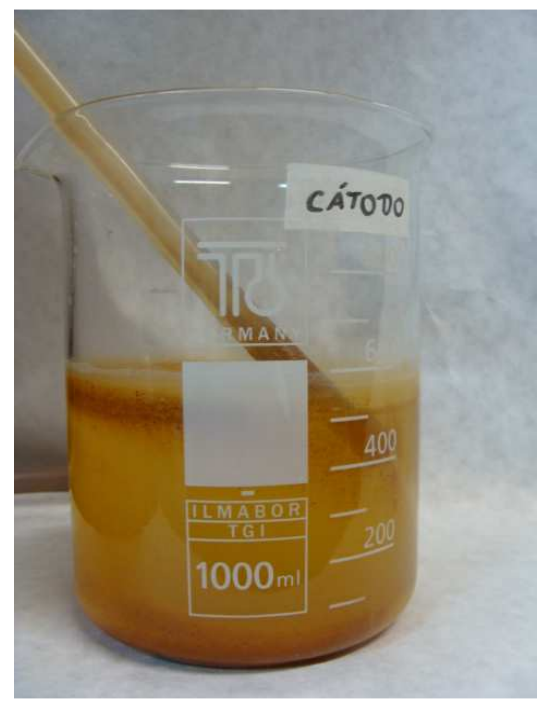

Figura 81 - Cátodo após $16 \mathrm{~h}$ de ED com DAM MB. 
Nas quais se confirmam os resultados supracitados, demonstrando que não houve contaminação com $\mathrm{Fe}$ no compartimento do ânodo, conforme análise química de Fe ao final deste ensaio para este compartimento (Figura 77). E na Figura 81 observa-se, visualmente, o aumento na concentração de Fe no compartimento do cátodo, e a consequente precipitação do mesmo, reflexo do aumento no $\mathrm{pH}$ neste compartimento pela presença da hidroxila, conforme apresentado na Figura 78. 


\section{CONCLUSÕES}




\section{CONCLUSÕES}

Conclui-se que a variabilidade das características químicas de cada DAM é dependente do seu ponto de geração, mas em todas as DAMs, avaliadas neste estudo, observou-se baixos valores de $\mathrm{pH}$, aproximadamente 2,0, ânion sulfato como maior componente, presença de ferro, tanto na forma de $\mathrm{Fe}^{2+}$ como $\mathrm{Fe}^{3+}$, embora o último seja mais comumente encontrado, além de outros cátions e ânions em quantidades variáveis.

A partir dos cronopotenciogramas conclui-se que as densidades de corrente limite são menores para as soluções de $\mathrm{Fe}_{2}\left(\mathrm{SO}_{4}\right)_{3}$ quando comparadas com as soluções de $\mathrm{Na}_{2} \mathrm{SO}_{4}$ em função da presença de íons [ $\left.\mathrm{Fe}\left(\mathrm{SO}_{4}\right)^{2-}\right]$ que diminuem a quantidade de íons $\mathrm{SO}_{4}{ }^{2-}$ livres. Também se pode concluir a partir das CVCs que a densidade de corrente é limitada pela membrana aniônica para as soluções sintéticas.

Da mesma forma, a partir das CVCs obtidas para as DAMs, observou-se que a densidade de corrente também foi limitada pela membrana aniônica.

A recuperação de ácido sulfúrico por ED, tanto para solução sintética como para DAM, mostrou-se eficaz, proporcionando a recuperação do ácido sulfúrico livre de ferro, no compartimento do ânodo e a concentração do ferro e outros cátions no compartimento do cátodo, que pode ser aproveitado em uma nova aplicação.

O rendimento deste processo mostrou-se influenciado diretamente pela densidade de corrente aplicada. Os ensaios na célula de ED de bancada (II) demonstraram que o rendimento do processo também é proporcional à superfície da membrana e a área do eletrodo. Entretanto, em ensaios com maiores densidades de corrente aplicada observou-se a formação de precipitados na superfície da membrana catiônica, considerada um fator limitante, pois reduz a vida útil das membranas e aumenta o consumo de energia para o processo.

Os ensaios de ED provaram que a ED é um processo útil para a recuperação de água a partir da DAM, removendo mais de $97,00 \%$ dos contaminantes presentes durante os testes de laboratório. A formação de precipitados na superfície da membrana catiônica também representou o fator limitante do processo. 
REFERÊNCIAS 


\section{REFERÊNCIAS}

1 FUNGARO, D.A.; IZIDORO, J.C. Remediação de Drenagem Ácida de Mina Usando Zeólitas Sintetizadas a Partir de Cinzas Leves de Carvão. Revista Química Nova. v. 29 (4), p. 735-740, 2006.

2 WEI, X; VIADERO Jr., R.C.; BHOJAPPA, S. Phosporus removal by acid mine drainage sludge from secondary effluents of municipal wastewater treatment plants. Water Research. v. 42, p. 3275-3284, 2008.

3 ASSOCIAÇÃO BRASILEIRA DE NORMAS TÉCNICAS (ABNT). NBR 10004: Resíduos Sólidos - Classificação. Rio de Janeiro, 2004.

4 BOUCHER, M.; TURCOTTE, N.; GUILLEMETTE, V.; LANTAGNE, G.; CHAPOTOT, A.; POURCELLY, G.; SANDEAUX, R.; GAVACH, C. Recovery of spent acid by electrodialysis in the zinc hydrometallurgy industry: performance study of different cation-exchange membranes. Hidrometallurgy. v. 45. p. 137-160, 1997.

5 LUCKS, J.O. Dispose hazardous waste safely. Chem. Eng., v. 97, p. 141-144 1990.

6 BALTAZAR, V.; HARRIS, G.B.; WHITE, C.W. The selective recovery and concentration of sulphuric acid by electrodialysis. Hydrometallurgy. v. 30, p. 463481, 1992.

7 ARSAND, D. Eletrodiálise: uma tecnologia limpa no tratamento de efluentes líquido.Cruz Alta: UNICRUZ, 2005. p. 39-71.

8 BRUN, J.P. Procédés de séparation para membranes, Transport-Techniques membranaires - Applications. Masson, Paris, p. 169-186, 1988.

9 HERRAIZ-CARDONA, I.; ORTEGA, E.; PÉREZ-HERRANZ, V. Evaluation of the $\mathrm{Zn}^{2+}$ transport properties through a cation-exchange membrane by chronopotentiometry. Journal of Colloid and Interface Science, v. 341, p. 380-385, 2010.

10 KRASTING, B. Sulfuric Acid: Leading Economic Indicator? 2009. Disponível em: $<$ http://seekingalpha.com/article/164469-sulfuric-acid-leading-economic-indicator>

Acesso em: 28 ago. 2012.

11 BRASIL. Ministério de Minas e Energia. Plano Nacional de Energia 2030. colaboração Empresa de Pesquisa Energética. v. 6 - Geração termelétrica a partir do carvão mineral. Brasília: MME/EPE, 2007.

12 ANEEL. Atlas da Energia Elétrica do Brasil. $2^{\underline{a}}$ ed. Brasília: Agência Nacional de Energia Elétrica, 2005.

13 SIECESC. Sindicato da Indústria de Extração de Carvão do Estado de Santa Catarina. Relatório Setorial. Criciúma/SC, 2008.

14 NEVES, C.A.R., Silva, L.R., 2007. Universo da Mineração Brasileira. Departamento Nacional de Produção Mineral, Brasília - Brasil. 
15 KOPPE, J.C.; COSTA, J.F.C.L. A lavra de carvão e o meio ambiente em Santa Catarina. In: SOARES, P.S.M.; dos SANTOS, M.D.C.; POSSA, M.V. Carvão Brasileiro: tecnologia e meio ambiente. Rio de Janeiro: CETEM/MCT, p. 25-35, 2008. 16 BORBA, R.F. Carvão Mineral. In: Balanço Mineral Brasileiro, DNPM/RS, 2001.

17 CHAVES, A.P. Flotação de carvão de Santa Catarina (região do alto metalúrgico). 1982. 142 p. Tese (Doutorado) - Escola Politécnica, Universidade de São Paulo, São Paulo, 1982.

18 GOMES, A.J.P. Carvão do Brasil Turfa Agrícola: geologia, meio ambiente e participação estratégica na produção de eletricidade no sul do Brasil. Porto Alegre: EST, 2002. 164 p.

19 SILVAS, F.P.C. Biotecnologia aplicada ao tratamento da drenagem ácida de mina. 2010. 124 p. Dissertação (Mestrado) - Escola Politécnica, Universidade de São Paulo, São Paulo, 2010.

20 AMARAL, J.E.; KREBS, A.S.J.; PAZZETTO, M.B. Bocas de Minas de Carvão abandonadas em Santa Catarina. Anais do XXIII Encontro Nacional de Tratamento de Minérios e Metalurgia Extrativa - Gramado, Rio Grande do Sul, 27 de setembro a $1^{\circ}$ de outubro de 2009. v. 2, p. 397-402.

21 LEFFA, D.D. Avaliação do Potencial Genotóxico do Rejeito de Carvão através do Molusco Helix aspersa (Müller, 1774). Trabalho de Conclusão de Curso. Universidade do Extremo Sul Catarinense - UNESC. Criciúma-SC, 2008.

22 COLLING, A.V.; MENEZES, J.C.S.S.; SCHNEIDER, I.A.H. Bioprocessing of pyrite concentrate from coal tailings for the production of the coagulant ferric sulphate. Minerals Engineering. v. 24 (11), p. 1185-1187, 2011.

23 VIGÂNICO, E.M.; COLLING, A.V.; SILVA, R.A.; SCHNEIDER, I.A. Biohydrometallurgical/UV production of ferrous sulphate heptahydrate crystals from pyrite present in coal tailings. Minerals Engineering. v. 24 (11), p. 1146-1148, 2011.

24 CREPALDI, C. Análise de parâmetros do monitoramento ambiental da Mina do Trevo - Siderópolis, SC. 2003. 201 p. Dissertação (Mestrado) - Escola Politécnica, Universidade de São Paulo, São Paulo, 2003.

25 ZILI, C.B. Considerações sobre o Aproveitamento dos Rejeitos de Produção do Carvão Catarinense. 2002. 99 p. Dissertação (Mestrado) - Escola Politécnica, Universidade de São Paulo, São Paulo, 2002.

26 MENEZES, J.C.S.S. Produção de Coagulantes Férricos na Mineração de Carvão. 2009. 120 p. Tese (Doutorado) - PPGEM, Universidade Federal do Rio Grande do Sul. Porto Alegre, 2009.

27 VAZ, P.A.B. Reparação do dano ambiental - Caso concreto: mineração em Santa Catarina e o meio ambiente. R. CEJ. v. 22, p. 41-48, 2003.

28 MENEZES, J.C.S.S.; SILVA, R.A.; ARCE, I.S.; SCHNEIDER, I.A.H. Production of a poly-ferric sulphate chemical coagulant by selective precipitation of iron from acidic coal mine drainage. Mine Water and the Environment. v. 28 (4), p. 311-314, 2009. 
29 FUNGARO, D.A.; IZIDORO, J.C. Remediação de Drenagem Ácida de Mina Usando Zeólitas Sintetizadas a Partir de Cinzas Leves de Carvão. Revista Química Nova. v. 29 (4), p. 735-740, 2006.

30 EVANGELOU, V.P. Pyrite Oxidation and Its Control: Solution Chemistry, Surface Chemistry, Acid Mine Drainage (AMD), Molecular Oxidation Mechanisms, Microbial Role, Kinetics, Control, Ameliorates and Limitations, Microencapsulation. Editorial Press CRC. New York, 1995.

31 PEPPAS, A.; KOMNITSAS, K.; HALIKIA, I. Use of organic covers for acid mine drainage control. Minerals Engineering. v. 13 (5), p. 563-574, 2000.

32 STUMM, W.; MORGAN, J.J. Aquatic Chemistry: Equilibria and Rates in Natural Waters. (3 ed.). Willey-Interscience. New York - EUA, 1996.

33 ALI, M.S. Remediation of Acid Mine Waters. Rüde, Freund \& Wolkersdorfer. IMWA 2011. Mine Water - Managing the Challenges, p. 253-258, 2011.

34 RITCEY, G.M. 1989. Tailings management: problems and solutions in the mining industry. Process Metallurgy.

35 KONTOPOULOS, A. Acid Mine Drainage Control. In: Effluent Treatment in the Mining Industry. Castro, S. H.; Vergara, F.; Sánchez, M. A.; (Eds.). University of Concepción, 1998.

36 JONHSON, D.B.; HAKKBERG, K.B. Acid mine drainage remediation options: a review. Science of the Total Environment. v. 338, p. 3 - 14, 2005.

37 FARFAN, J.R.J.Z.; BARBOSA FILHO, O.; SOUZA, V.P. Avaliação do potencial de drenagem ácida de rejeitos da indústria mineral. Rio de janeiro: CETEM/MCT, 2004. 58p.

38 HARTINGER, L. Handbook of Effluent Treatment and Recycling for the Metal Finishing Industry. 2ed. UK: Finishing Publications LTD, 1994.

39 FENG, D.; ALDRICH, C.; TAN, H. Treatment of acid mine water by use of heavy metal precipitation and ion exchange. Minerals Engineering. v. 13, p. 623-642, 2000.

40 CAMPANER, V.P.; SILVA, W.L. Processos físico-quimicos em drenagem ácida de minas em mineração de carvão no sul do Brasil. Química Nova. v. 32, p. 146152, 2009.

41 GAZEA, B.; ADAM, K.; KONTOPOULOS, A. A review of passive systems for the treatment of acid mine drainage. Minerals Engineering. v. 9 (1), p. 23-42, 1996.

42 GAIKWAD, R.W.; GUPTA, D.V. Review on removal of heavy metals from acid mine drainage. Applied Ecology and Environmental Research. v. 6, p. 81-98, 2008.

43 RUBIO, J.; SILVA, R.; SILVEIRA, A. Técnicas para tratamento e aproveitamento de águas ácidas residuais da mineração de carvão. III Workshop Gestão e Reúso de Água na Indústria. Florianópolis, SC, 2007.

44 RUBIO, J.; SILVA, R.; SILVEIRA, A. Técnicas para tratamento e alternativas de reúso de águas ácidas de minas de carvão. VI Simpósio Internacional de Qualidade Ambiental - ABES-RS e PUCRS/FENG. Porto Alegre, 2008. 
45 SILVEIRA, A.N.; SILVA, R.; RUBIO, J. Treatment of Acid Mine Drainage (AMD) in South Brazil: Comparative active processes and water reuse. International Journal of Mineral Processing. v. 93 (2), p. 103-109, 2009.

46 SILVA, R.A.; CASTRO, C.D.; VIGÂNICO, E.M.; PETTER, C.O.; SCHNEIDER, I.A.H. Selective precipitation/UV production of magnetite particles obtained from the iron recovered from acid mine drainage. Minerals Engineering. v. 29 (0), p. 22-27, 2012.

47 RIANI, J.C. Utilização de resinas de troca-iônica em efluentes de galvanoplastia. 2008. 121 f. Tese (Doutorado) - Escola Politécnica, Universidade de São Paulo, São Paulo, 2008.

48 BENITO, Y.; RUIZ, M.L. Reverse osmosis applied to metal finishing wastewater. Desalination. v. 142, p. 229-234, 2002.

49 NOBLE, R.D.; STERN, S.A. Membrane Separations Technology Principles and Applications. Amsterdam - Lausanne - New York - Oxford - Shannon - Tokyo: Elsevier, v.2, 1995.

50 LIGHTFOOT, E.N. Membrane separations technology: Principles and applications. Chemical Engineering Science. v. 51 (2), p. 325-326, 1996.

51 MACHADO, M.B. Avaliação do Processo de Eletrodiálise Reversa no Tratamento de Efluentes de Refinaria de Petróleo. 2008. 199 p. Dissertação (Mestrado) - PPGEM, Universidade Federal do Rio Grande do Sul. Porto Alegre, 2008.

52 AUDINOS, R. Improvement of metal recovery by electrodialysis. Jornal of Membrane Science. v. 27, p. 143-154, 1986.

53 AUDINOS, R. Liquid waste concentration by electrodialysis. In: LI, N.N.; CALO, J. M. Separation and purification technology. Marcel Dekker. Cap. 8, p. 229-301, 1992.

54 CHIAPELLO, J.M.; GAL, J.Y. Recovery by electrodialysis of cyanide electroplating rinse waters. J. Membr. Sci. v. 68, p. 283-291, 1992.

55 STRATHMANN, H. Electrodialysis. Encyclopedia of Separation Science, Membrane Separations. Academic Press, 2000.

$56 \mathrm{XU}, \mathrm{T}$. Ion Exchange Membranes: State of their development and perspective. Journal of Membrane Science. v. 263, p. 1-29, 2005.

57 STRÜVER, W. Ion Exchangers. Angewandte Chemie, v. 104 (6), 1991.

58 RAUTENBACH, R.; ALBRECHT, R. Membrane Processes. John Willey e Sons. Cap. 11: Electrodialysis. p. 333-362, 1998.

59 CORNELIS, R.V. Electrodialytic Recovery of Acids and Bases. Multicomponent Mass Transfer Description. 2001. Tese (Doutorado PhD) - The University of Groningen, Groningen. 2001.

60 AMADO, F.D.R. Produção e aplicação de membranas com polímeros convencionais e polianilinas para uso em eletrodiálise no tratamento de efluentes industriais. 2006, 143 p. Tese (Doutorado) - PPGEM, Universidade Federal do Rio Grande do Sul, Porto Alegre, 2006. 
61 GERING, K.L.; SCAMEHORN, J.F. Use of electrodialysis to remove heavy metals from water. Separation Science and Technology. v. 23. p. 2231-2267, 1988.

62 AOUAD, F.; LINDHEIMER, A.; GAVACH, C. Transport properties of electrodilalysis membranes in the presence of $\mathrm{Zn}^{2+}$ complexes with $\mathrm{Cl}^{-}$. Journal of Membrane Science. v. 123. p. 207-223. 1997.

$63 \mathrm{MOON}$, P.J. Competitive anion transport in desalting of mixtures of organic acids by batch electrodialysis. J. Membr. Sci. v. 141, p. 75-89, 1998.

64 BAKER, R.W. Membrane Separation Systems - Recent Developments and Future Directions. William Andrew Publishing/Noyes, 1991.

65 DALLA COSTA, R.F.; KLEIN, C.W.; BERNARDES, A.M.; ZOPPAS FERREIRA, J. Evaluation of the electrodialysis process for the treatment of metal finishing wastewater. Journal of the Brazilian Chemical Society. v. 13, p. 540-547, 2002.

66 KORZENOWSKI, C. Estudo da recuperação de soluções de cromo hexavalente contendo íons $\mathrm{Al}(\mathrm{III})$ e $\mathrm{Fe}$ (III) através da eletrodiálise e efeito na incorporação dos íons na degradação de membranas catiônicas. 2007, 230 p. Tese (Doutorado) - PPGEM, Universidade Federal do Rio Grande do Sul, Porto Alegre, 2007.

67 BERNARDES, A.M.; RODRIGUES, M.A.S.; AMADO, F.D.R.; BISCHOFF, M.R.; FERREIRA, C.A.; ZOPPAS FERREIRA, J. Transport of zinc complexes through an anion exchange membrane. Desalination. v. 227 (1-3), p. 241-252, 2008.

68 IBANEZ, R.; STAMATIALIS, D.F.; WESSLING, M. Role of membrane surface in concentration polarization at cation exchange membranes. Journal of Membrane Science. v. 239, p. 119-128, 2004.

69 BALSTER, J.; YILDIRIM, M.H.; STAMATIALIS, D.F.; IBANEZ, R.; LAMMERTINK, R.G.H.; JORDAN, V.; WESSLING, M. Morphology and Microtopology of CationExchange Polymers and the Origin of the Overlimiting Current. The Journal of Physical Chemistry B. v. 111 (9), p. 2152-2165, 2007.

70 STREIT, K.F. Estudo da aplicação da técnica de eletrodiálise no tratamento de efluentes de curtume. 2006. 100 p. Dissertação (Mestrado) - PPGEM, Universidade Federal do Rio Grande do Sul, Porto Alegre, 2006.

71 SCOTT, K. Handbook of industrial membranes. UK: Elsevier Science Publishers Ltda, 1995. 912p.

72 LEE, H-J. Characterization of anion exchange membranes fouled with humate during electrodialysis. Journal of Membrane Science. v. 203, p. 115-126, 2002.

73 SISTAT, P.; POURCELLY, G. Chronopotentiometric response of an ion-exchange membrane in the underlimiting current-range. Transport phenomena within the diffusion layers. Journal of Membrane Science. v. 123, p. 121-131, 1997.

74 MARTí-CALATAYUD, M.C.; GARCÍA-GABALDÓN, M.; PÉREZ-HERRANZ, V; ORTEGA, E. Determination of transport properties of $\mathrm{Ni}(\mathrm{II})$ through a Nafion cationexchange membrane in chromic acid solutions. Journal of Membrane Science. v. 379, p. 449, 2011. 
$75 \mathrm{CHOI}, \mathrm{J}-\mathrm{H} . ;$ LEE, H-J.; MOON, S-H. Effects of electrolytes on the transport phenomena in a cation-exchange membrane. Journal of Colloids and Interface Science. v. 238, p. 188-195, 2001.

76 KANG, M-S.; CHO, S-H.; KIM, S-H.; CHOI, Y-J.; MOON, S-H. Electrodialytic separation characteristics of large molecular organic acid in highly waterswollen cation-exchange membranes. Journal of Membrane Science. v. 222, p. 149-161, 2003.

77 MARTÍ-CALATAYUD, M.C. Determinación de las propriedades de transporte del $\mathrm{Ni}^{2+}$ a través de una membrana de intercambio catiônico. Influencia de la concentración de ácido crômico y sulfato de níquel presentes en lós baños de lavado de industrias de cromado. 2010. 113 p. Dissertação (Mestrado) - Máster oficial em Seguridad Industrial y Medio Ambiente, Universidad Politécnica de Valencia, Valencia, 2010.

78 PISMENSKAIA, N.; SISTAT, P.; HUGUET, P.; NIKONENKO, V.; POURCELLY, G. Chronopotentiometry applied to the study of ion transfer through anion Exchange membranas. Journal of Membrane Science. v. 228, p. 65-76, 2004.

79 RUBINSTEIN, I.; MALETZKI, F. Electroconvection at an electrically inhomogeneous permselective membrane surface. J. Chem. Soc. Faraday Trans. v. 87, p. 2079-2087, 1991.

80 WILHELM, F.G.; VAN DER VEGT, N.F.A.; WESSLING, M.; STRATHMANN, H. Chronopotentiometry for the advanced current-voltage characterisation of bipolar membranes. Journal of Electroanalytical Chemistry. v. 502, p. 152-166, 2001.

81 BERNARDES, A.M.; RODRIGUES, M.A.S.; AMADO, F.D.R.; XAVIER, J.L.N.; STREIT, K.F.; ZOPPAS FERREIRA, J. Application of photoelectrochemicalelectrodialysis treatment for the recovery and reuse of water from tannery effluents. Journal of Cleaner Production. v. 16 (5), p. 605-611, 2008.

82 AGRAWAL, A.; SAHU, K.K. An overview of the recovery of acid from spent acidic solutions from steel and electroplating industries. Journal of Hazardous Materials. v. 171(1-3), p. 61-75, 2009.

83 BROENS, L.; LIEBRAND, N.; FUTSELAAR, H.; TORRENT, J. C. A.. Effluent reuse at Barranco Seco (Spain): a $1,000 \mathrm{~m}^{3} / \mathrm{h}$ case study. Desalination. v. 167, p. 13-16, 2004.

84 CIFUENTES, L.; GARCÍA, I.; ARRIAGADA, P.; CASAS, J.M. The use of electrodialysis for metal separation and water recovery from $\mathrm{CuSO}_{4}-\mathrm{H}_{2} \mathrm{SO}_{4}-\mathrm{Fe}$ solutions. Separation and Purification Technology. v. 68, p. 105-108, 2009.

85 CIFUENTES, L.; GARCÍA, I.; ORTIZ, R.; CASAS, J. M. The use of electrohydrolysis for the recovery of sulphuric acid from copper-containing solutions. Separation and Purification Technology. v. 50, p. 167-174, 2006.

86 WISNIEWSKI, J.; WISNIEWSKA, G. Water and acid recovery from the rinse after metal etching operations. Hydrometallurgy. v. 53, p. 105-119, 1999.

87 GELUWE, S.V.; BRAEKEN, L.; ROBBERECHT, T.; JANS, M.; CREEMERS, C.; BRUGGEN, B.V. Evaluation of electrodialysis for scaling prevention of nanofiltration 
membranes at high water recoveries. Resources, Conservation and Recycling. v. 56, p. 34-42, 2011.

88 VENKATESAN A.; WANKAT, P.C. Simulation of ion exchange water softening pretreatment for reverse osmosis desalination of brackish water. Desalination. $v$. 271, p. 122-31, 2011.

89 WEI, X.; VIADERO JR., R.C.; BUZBY, K.M. Recovery of Iron and Aluminum from Acid Mine Drainage by Selective Precipitation. Environmental Engineering Science. v. 22 (6), p. 745-755, 2005.

90 FRANCISCO Jr., W.E.; BEVILAQUA, D.; GARCIA Jr., O. Estudo da Dissolução Oxidativa Microbiológica de uma Complexa Amostra Mineral Contendo Pirita $\left(\mathrm{FeS}_{2}\right)$, Pirrotita $\left(\mathrm{Fe}_{1-\mathrm{x}} \mathrm{S}\right)$ e Molibdenita $\left(\mathrm{MoS}_{2}\right)$. Revista Química Nova. v. 30 (5), p. $1095-$ 1099, 2007.

91 DLUGOLECKI, P.; ANET, B.; METZ, S.J.; NIJMEIJER, K.; WESSLING, M. Transport limitations in ion exchange membranes at low salt concentrations. Journal of Membrane Science. v. 346, p. 163-171, 2010.

92 CASAS, J.M.; CRISÓSTOMO, G.; CIFUENTES, L. Speciation of the Fe(II)$\mathrm{Fe}(\mathrm{III})-\mathrm{H}_{2} \mathrm{SO}_{4}-\mathrm{H}_{2} \mathrm{O}$ system at 25 and $50{ }^{\circ} \mathrm{C}$. Hydrometallurgy. v. 80, (4), p. 254-264, 2005.

93 KROL, J.J.; WESSLING, M.; STRATHMANN, H. Concentration polarization with monopolar ion exchange membranes: current-voltage curves and water dissociation. Journal of Membrane Science. v. 162 (1-2), p. 145-154, 1999.

94 VALERDI-PÉREZ, R.; IBÁÑEZ-MENGUAL, J.A. Current-voltage curves for an electrodialysis reversal pilot plant: determination of limiting currents. Desalination. $v$. 141, p. 23-37, 2001.

95 BELASHOVA, E.D.; MELNIK, N.A.; PISMENSKAYA, N.D.; SHEVTSOVA, K.A.; NEBAVSKY, A.V.; LEBEDEV, K.A.; NIKONENKO, V.V. Overlimiting mass transfer through cation-exchange membranes modified by Nafion film and carbon nanotubes. Electrochimica Acta. v. 59, p. 412, 2012.

96 TZANETAKIS, N; TAAMA, W.M; SCOTT, K. Salt splitting in a three-compartment membrane electrolysis cell. Filtration \& Separation. v. 39 (3), p. 30-38, 2002.

97 MENEZES, J.C.S.S.; SILVA, R.A.; ARCE, I.S.; SCHNEIDER, I.A.H. Production of a poly-alumino-iron sulphate coagulant by chemical precipitation of a coal mining acid drainage. Minerals Engineering. v. 23 (3), p. 249-251, 2010.

98 RAO, S.R.; GEHR, R.; RIENDEAU, M.; LU, D.; FINCH, J.A. Acid mine drainage as a coagulant. Minerals Engineering. v. 5 (9), p. 1011-1020, 1992.

99 SILVA, R.A. Recuperação hidrometalúrgica de metais da drenagem ácida de minas por precipitação seletiva. 2010. 130 p. Tese (Doutorado) - PPGEM, Universidade Federal do Rio Grande do Sul, Porto Alegre, 2010.

100 SILVA, R.A.; CASTRO, C.D.; VIGÂNICO, E.M.; PETTER, C.O.; SCHNEIDER, I.A.H. Selective precipitation/UV production of magnetite particles obtained from the iron recovered from acid mine drainage. Minerals Engineering. 29 (0), p. 22-27, 2012. 
101 FLORES, R.G.; ANDERSEN, S.L.F.; MAIA, L.K.K.; JOSÉ, H.J.; MOREIRA, R.F.P.M. Recovery of iron oxides from acid mine drainage and their application as adsorbent or catalyst. Journal of Environmental Management. v. 111, p. 53-60, 2012.

102 CHANDRAMOWLEESWARAN, M.; PALANIVELU, K. Treatability studies on textile effluent for total dissolved solids reduction using electrodialysis. Desalination. v. 201, p. 164-174, 2006.

103 MENG, H.; DENG, D.; CHEN, S.; ZHANG, G. A new Method to Determine the Optimal Operating Current in the Electrodialysis Process. Desalination. v. 181, p. 101-108, 2005.

104 BALSTER, J.; PÜNT, I.; STAMATIALIS, D.F.; WESSLING, M. Multi-layer spacer geometries with improved mass transport. Journal of Membrane Science. v. 282, p. 351-361, 2006. 